\title{
ICTIOFAUNA DE DUAS MICROBACIAS - RIBEIRÃO DOS BUENOS E RIO GUARATINGUETÁ - NA SERRA DA MANTIQUEIRA ORIENTAL
}

\author{
GIULIANNA RODRIGUES RONDINELI
}

Tese apresentada ao Instituto de Biociências do Campus de Rio Claro, Universidade Estadual Paulista, como parte dos requisitos para obtenção do título de Doutor em Ciências Biológicas (Zoologia). 


\section{ICTIOFAUNA DE DUAS MICROBACIAS - RIBEIRÃO DOS BUENOS E RIO GUARATINGUETÁ - NA SERRA DA MANTIQUEIRA ORIENTAL}

\section{GIULIANNA RODRIGUES RONDINELI}

Orientador: Prof. Dr. Francisco Manoel de Souza Braga

Tese apresentada ao Instituto de Biociências do Campus de Rio Claro, Universidade Estadual Paulista, como parte dos requisitos para obtenção do título de Doutor em Ciências Biológicas (Zoologia).

Rio Claro

Estado de São Paulo - Brasil

Abril de 2010 
Aos meus avós, Antonio e Ana Izabel,

Vicente e Noemia (in memorian).

Ao Alberto. 


\section{AGRADECIMENTOS}

Ao meu querido orientador, Prof. Dr. Francisco Manoel de Souza Braga, por esses quase dez anos de convívio e muito aprendizado! Obrigada por todos os ensinamentos, conversas, "puxões-de-orelha”, lições de vida e por me apresentar e me fazer apaixonar pela serra da Mantiqueira. Obrigada também pela dedicação em todas as etapas desse trabalho e pela companhia pra lá de agradável nas coletas!

À FAPESP, pela bolsa de doutorado concedida, ao IBAMA, pela licença para execução das coletas de campo, e à UNESP (Departamento de Zoologia), pela infra-estrutura, que possibilitaram o desenvolvimento desse trabalho.

Ao Alberto e Jeferson pela presença em todas as etapas do trabalho, desde o reconhecimento, escolha dos pontos e coleta em si, sem vocês isso tudo não estaria aqui... Ao Fabio e Henrique pela super-hiper ajuda na última campanha (quase que não chegamos ao ponto mais alto, heim?). A Mari (querida!) pela companhia e ajuda na coleta dos dados ambientais em julho (passamos o maior frio, lembra?).

À Ur e Cris (amigas queridas!) pela amizade, companhia e por estarem sempre ao meu lado durante essa longa caminhada na pós-graduação. Obrigada pelo imenso carinho de vocês! Cris, muito obrigada pela ajuda com o abstract!

Ao Fabio (Morcego) pela nossa amizade (de dez anos!). Obrigada por sempre estar por perto, por todo o carinho e atenção e por sempre estar disposto a ajudar. Obrigada também pela enorme ajuda nas coletas e nas análises de dados.

A coordenadora do Programa de Pós-Graduação, Profa. Dra. Maria José de Oliveira Campos, e ao vice-coordenador, Prof. Dr. Denis Otávio Vieira de Andrade, por toda a atenção dispensada e imenso carinho.

Aos meus queridos e eternos professores: Beto, Cláudio, Denis, Sulene, Zezé, Marquinhos, Roberto, Leila, Miguel, Chaud. Obrigada por todos os ensinamentos, conversas e carinho!

À Dani, pela amizade e ajuda no laboratório. Você é uma estagiária de ouro! 
À Mari, Dani, Cascão, Carlos (Pássaro), Débora, Ju, Xênia, Sílvia, Lê, Vivi, Olguinha, Gabi, Glei, César, Ivan, Ursinha, Cris pela companhia no cafezinho, conversas no corredor, no laboratório, na salinha da pós...

Aos meus queridos amigos da graduação, que ainda continuam em Rio Claro, Silvana e Pablo, pelo e-n-o-r-m-e carinho de sempre.

À Andréia, pela imensa ajuda com os trâmites bancários.

À Pri, pela amizade e confiança.

Ao Prof. Dr. Francisco Langeani Neto, por nos receber tão bem em seu laboratório e pela identificação dos peixes.

Ao Prof. Dr. Miguel Petrere Júnior pelo empréstimo do equipamento de pesca elétrica portátil.

Ao Prof. Dr. Edilberto Gianotti, por todas as brincadeiras descontraídas, companhia no cafezinho e pela valiosa identificação dos insetos dos conteúdos estomacais.

Ao Prof. Dr. Leandro Muller Gomiero pela amizade e por todo o aprendizado sobre biologia de peixes.

Ao Prof. Dr. Maurício Cetra, pela enorme amizade, pelos encontros e conversas divertidas, pela "olhadinha" na tese e dicas valiosas.

Ao pessoal do Núcleo de Educação Ambiental do Ribeirão Grande - NEA, em especial à Sueli, José Roberto, Wagner e Adriana, pela hospedagem e infra-estrutura.

Aos membros do Conselho da Pós Graduação (Zoologia): Chaud, Marcos, Sulene, Beto, Cláudio e Andrigo por todo o aprendizado.

Ao Carlinhos, técnico do departamento de Ecologia (um encanto de pessoa!), pelos empréstimos de última hora dos frasquinhos de Winkler. 
Aos funcionários do departamento de Zoologia, Adriana, Lisa, Cris e Fernando por sempre estarem por perto e dispostos a ajudar.

À todas as funcionárias da Pós Graduação, em especial à Rute e Rose, por todos "os galhos quebrados", atenção e carinho.

Aos meus queridos avós, por acreditarem em mim sempre, por todas as orações e imenso amor oferecido desde o dia em que nasci. Vocês dois são exemplos de vida para mim! Obrigada por tudo!

À toda minha família (as duas!) pela torcida, preocupação, enorme carinho e conversas pra lá de agradáveis.

À Leda, Reinaldo, Maíra e Alberto por tudo o que fizeram e ainda fazem por mim! Obrigada por me deixarem fazer parte dessa família tão linda e especial! Amo muito todos vocês!

Ao meu pai, Duilio, pelo incentivo, imenso amor e por acreditar em mim sempre! Obrigada por tudo o que você fez e faz por mim! Amo demais você!

Aos meus irmãos, Duilio e Marcella, que mesmo distantes de mim, tenho certeza que o amor que sentimos não mudou nem vai mudar nunca!

À Deus por todas as bênçãos, conquistas e alegrias de toda a minha vida. Obrigada por me dar força, paciência, sabedoria, saúde...

Se por acaso me esqueci de aluguém, perdão...

Um agradecimento especial vai para o meu marido, Alberto, por todo o seu amor, dedicação e paciência. Obrigada pela presença em todas as etapas dessa longa caminhada: ajuda e incentivo para escrever o projeto, reconhecimento em campo, coletas dos peixes, processamento do material, laboratório, elaboração do banco de dados, análise dos dados, leitura da tese... Obrigada por me fazer tão bem, por acreditar em mim sempre, me dar toda a força que precisei e por deixar minha vida muito mais feliz! Agradeço a Deus todos os dias por ter colocado você em meu caminho! Amo você mais do que tudo! 


\section{SUMÁRIO}

RESUMO

i

ABSTRACT

iii

INTRODUÇÃO GERAL

\section{CAPÍTULO 1}

Estrutura das comunidades de peixes das microbacias do ribeirão dos Buenos e do rio Guaratinguetá, na serra da Mantiqueira oriental .................................... 4

1. Introdução ..................................................................................................... 4

2. Material e Métodos .................................................................................... 7

2.1. Descrição da área de estudo ......................................................................... 7

2.2. Descrição dos pontos de coleta ..................................................................... 11

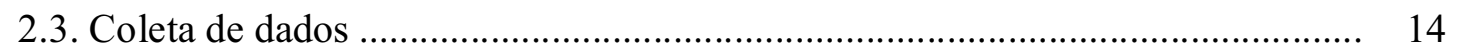

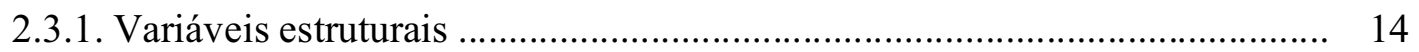

2.3.2. Variáveis físicas e químicas da água …..................................................... 15

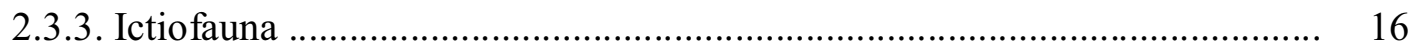

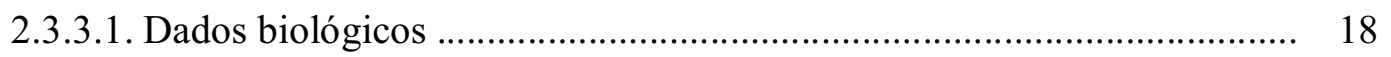

2.4. Análise de dados ............................................................................................ 18

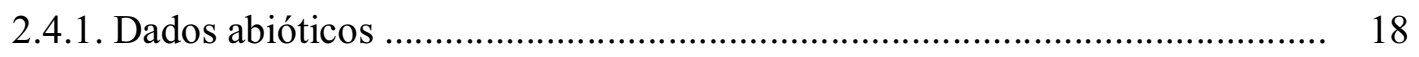

2.4.2. Dados bióticos ....................................................................................... 19

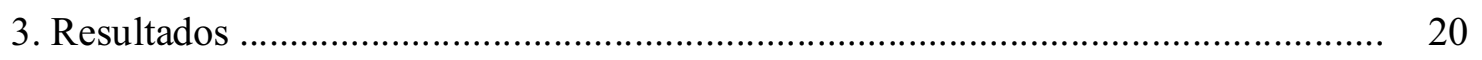

3.1. Variáveis estruturais ............................................................................ 20

3.2. Variáveis físicas e químicas da água .......................................................... 25

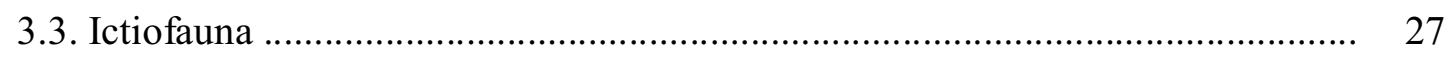

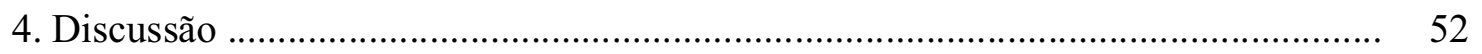

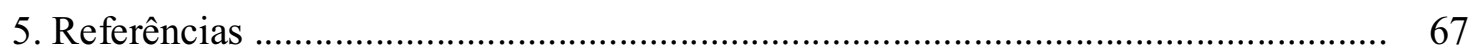




\section{CAPÍTULO 2}

Biologia das populações de peixes nas microbacias do ribeirão dos Buenos e do rio Guaratinguetá, na serra da Mantiqueira oriental .......................................... 78

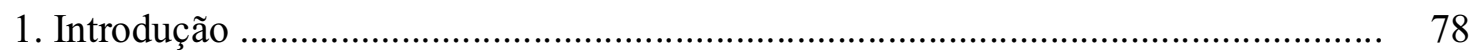

2. Material e Métodos …............................................................................. 80

2.1. Descrição da área de estudo ....................................................................... 80

2.2. Descrição dos pontos de coleta ..................................................................... 80

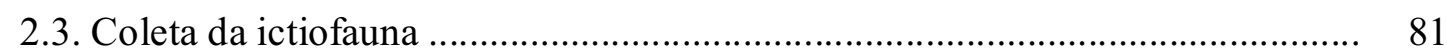

2.3.1. Coleta de dados biológicos ................................................................ 82

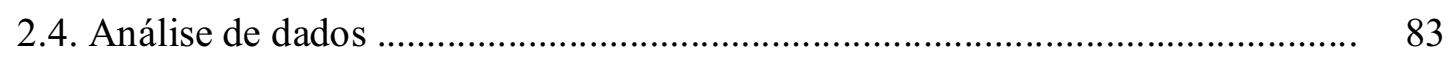

2.4.1. Estrutura das populações ..................................................................... 83

2.4.2. Estudo da dieta .......................................................................................... 83

2.4.3. Estudo da reprodução .......................................................................... 84

2.4.4. Condição corporal ................................................................................... 85

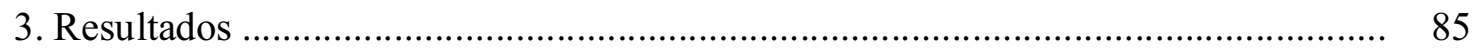

3.1. Estrutura das populações .............................................................................. 87

3.1.1. Estrutura em comprimento .................................................................... 87

3.1.2. Proporção sexual ........................................................................................ 103

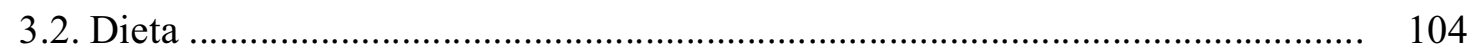

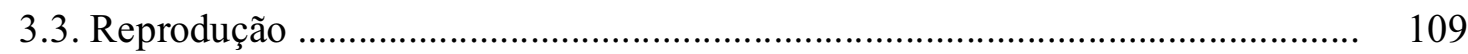

3.3.1. Gordura acumulada na cavidade visceral ................................................. 109

3.3.2. Estádios de maturidade gonadal e relação gonadossomática ...................... 109

3.4. Condição corporal ................................................................................ 118

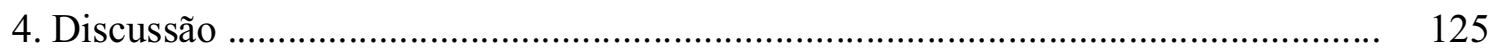

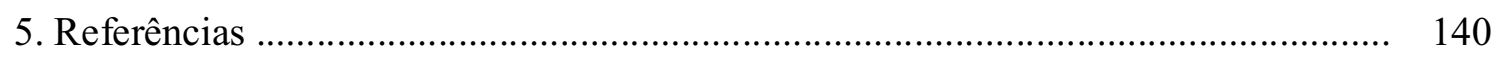

CONSIDERAÇÕES FINAIS _....................................................................... 156

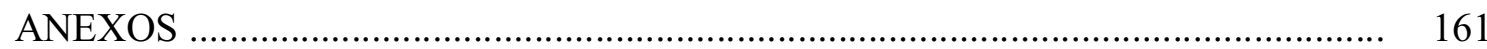




\section{RESUMO}

As microbacias do ribeirão dos Buenos e do rio Guaratinguetá, integrantes da bacia do rio Paraíba do Sul, são sistemas hidrográficos que descem das encostas da serra da Mantiqueira oriental, sendo isoladas de outros sistemas contíguos por formações de relevo. O objetivo deste trabalho foi definir como as comunidades de peixes das microbacias do ribeirão dos Buenos e do rio Guaratinguetá estão estruturadas e como variam suas composições no espaço e no tempo. Estudos sobre a biologia dessas populações foram conduzidos de modo a entender como ocorrem os processos de substituição de espécies. Para contemplar regiões da encosta, do pediplano e do vale foram demarcados 15 pontos de coleta, 8 deles na microbacia do ribeirão dos Buenos e 7 na do rio Guaratinguetá. As coletas aconteceram ao longo de um ano, sendo o aparelho de pesca elétrica, a redinha-de-arrasto e as redes-deespera os apetrechos de pesca utilizados. Variáveis estruturais dos riachos e físicas e químicas da água também foram coletadas. Foram capturados 2805 indivíduos, distribuídos em 34 espécies, 13 famílias e 7 ordens. Na microbacia do ribeirão dos Buenos, ocorreram 27 espécies, das quais 4 foram exclusivas de seus riachos e na microbacia do rio Guaratinguetá 30 espécies foram amostradas, sendo 8 delas também exclusivas de seus riachos. Um gradiente crescente da diversidade, riqueza e equitabilidade foi observado da encosta em direção ao vale. Interações significativas entre ambientes e microbacias para os índices de diversidade e riqueza indicaram que pelo menos um ambiente em uma microbacia diferiu quanto à diversidade e riqueza de espécies. Na dimensão temporal, nenhuma variação significativa nos índices de diversidade, riqueza e equitabilidade foi detectada. Um padrão de adição de espécies, indo da encosta em direção ao pediplano, pode ser observado nas microbacias estudadas, ao passo que, do pediplano ao vale, foi verificado um padrão de substituição de espécies. Dentre as variáveis estruturais e físicas e químicas da água, o tipo de substrato presente no canal e o pH foram importantes na distribuição das espécies nos pontos amostrais. Trichomycterus itatiayae foi a espécie mais freqüente nas duas microbacias e, juntamente com Astyanax bimaculatus, compôs o grupo de espécies mais importantes. No geral, não ocorreu um único item alimentar dominante nas dietas das espécies estudadas, sendo as dietas bastante diversificadas, com pouca ocorrência de itens preferenciais. Foi evidente o maior consumo de itens autóctones na encosta e no pediplano, ao passo que no vale os itens alóctones prevaleceram. No geral, as espécies analisadas 
apresentaram períodos reprodutivos que se estenderam desde o final da estação seca até o final da estação chuvosa. Os aspectos biológicos analisados nessas espécies parecem direcioná-las para uma maior eficiência em explorar o meio em que vivem, proporcionando a manutenção de suas populações. Embora contíguas, as microbacias do ribeirão dos Buenos e do rio Guaratinguetá apresentam composições ictiofaunísticas diferentes, sendo que os papéis desempenhados pelas espécies nessas comunidades parecem diferir, visto que a ocorrência, distribuição, abundância relativa e a biomassa dessas espécies são particulares para cada microbacia.

Palavras-chave: comunidade de peixes; riachos; diversidade; gradiente altitudinal; biologia populacional; dieta; reprodução; condição corporal. 


\begin{abstract}
The watersheds of Buenos and Guaratinguetá streams, integrants of the Paraíba do Sul river basin are systems that comes down the slopes of the serra da Mantiqueira eastern, being isolated from other systems by contiguous relief formations. The aim of this work was to determine how fish communities of the Buenos and Guaratinguetá watersheds are structured and how their composition varies in space and time. Studies on the biology of these populations were conducted in order to understand the processes as species replacement in time and space. In order to include regions of the slope, piedmont and the valley were marked 15 collection points, 8 of them in the Buenos watershed and 7 in the Guaratinguetá watershed. Sampling took place over a year, and the following fishery equipment was used: electric fishing equipment, gill nets and a sieve. Structural variables of streams and physical and chemical properties of water were also collected. We captured 2805 individuals belonging to 34 species, 13 families and 7 orders. In the Buenos watershed, there were 27 species and the Guaratinguetá watershed were captured 30 species. Four species were unique to streams of the Buenos watershed and 8 to streams of the Guaratinguetá watershed. An increasing gradient of diversity, richness and evenness was observed on the slope toward the valley. Significant interactions between environments and watersheds for the contents of richness and diversity indicated that at least one environment in a watershed differed as to the diversity and species richness. In the temporal dimension, no significant variation in diversity, richness and evenness was detected. A standard of species' addition, ranging from the hillside towards the piedmont can be observed in the watersheds studied, whereas from the piedmont to the valley, we noticed a pattern of species replacement. Among the structural variables and physical and chemical properties of water, the type of substrate present in the channel and $\mathrm{pH}$ were important in the distribution of species in the sampling points. Trichomycterus itatiayae was the most frequent species in the two watersheds, and along with Astyanax bimaculatus, composed the group of most important species. Overall, there weren't a single dominant food item in the diets of the species studied, and the diets were quite diverse, with little occurrence of preferential items. It was evident the higher consumption of autochthonous items in the slope and piedmont, while in the valley, allochthonous items prevailed. In general, the
\end{abstract}


species analyzed showed extended reproductive periods since the end of the dry season until the end of the rainy season. The biological aspects analyzed in these species appear to direct them to greater efficiency in exploring the environment which they live, providing the maintenance of their populations. Although contiguous, the ichthyofauna's composition of Buenos and Guaratinguetá watersheds were different, and the roles of the species in these communities seem to differ, since the occurrence, distribution, relative abundance and biomass of these species are particular to each watershed.

Key-words: fish community; streams; species diversity; altitudinal gradient; population biology; diet; reproduction; corporal condition. 


\section{INTRODUÇÃO GERAL}

A serra da Mantiqueira foi formada, conjuntamente com a serra do Mar, pela reativação de um sistema de falhas pré-cambrianas durante o Oligoceno-Mioceno resultando na formação do graben do Vale do Paraíba (PETRI \& FÚLFARO, 1983). Desde então, o relevo tem sido constantemente remodelado sendo que os últimos eventos aconteceram recentemente, no início do Holoceno (MODENESI-GAUTTIERI et al., 2002). O rio Paraíba do Sul foi formado como conseqüência posterior ao falhamento que deu origem ao graben e a formação de um grande lago durante o Oligoceno e Mioceno, e de sua drenagem.

Segundo Ponçano et al. (1981), a serra da Mantiqueira que se estende de sudeste para nordeste no estado de São Paulo, está configurada em duas porções: uma oriental, indo do planalto de Itatiaia (RJ) até a localidade de Monteiro Lobato (SP), com encostas íngremes e festonadas, e outra ocidental, seguindo o rumo de Monteiro Lobato a Poços de Caldas (MG), apresentando relevo menos abrupto. Neste contexto, a serra da Mantiqueira é um divisor de águas entre as bacias do rio Grande (MG) e do rio Paraíba do Sul (SP-RJ).

A cobertura florestal que reveste as encostas da serra da Mantiqueira até o Vale do Paraíba tem sido desde o século XVIII até o presente muito alterada em função dos ciclos cafeeiros e pecuários (DEAN, 1996). Existem, porém, manchas de vegetação ainda nativa nas encostas que apresentam uma certa continuidade na porção oriental da serra da Mantiqueira até o planalto de Itatiaia. Esta cobertura vegetal embora escassa é parte integrante da Mata Atlântica interiorana, que é tida como uma das áreas hot spot e que ocupa o segundo lugar entre as florestas tropicais mais ameaçadas (MYERS et al., 2000).

Sob o ponto de vista geomorfológico, esta área cristalina teve uma ação tectônica no Terciário, seguida de um afeiçoamento no Quaternário, que se fez sentir não só nas grandes serras e bacias hidrográficas, como nas menores, ao nível de pequenos vales e divisores (PETRI \& FÚLFARO, 1983; MODENESI-GAUTTIERI et al., 2002).

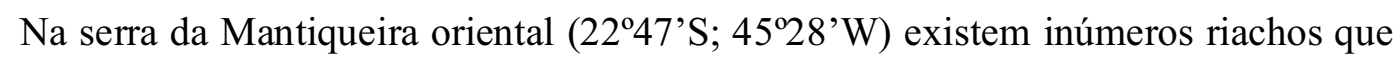
descem a encosta e vão ser tributários do rio Paraíba do Sul. Braga (2004) definiu esses riachos como pertencentes à microbacias, estando estas separadas umas das outras por cristas das encostas. Braga \& Andrade (2005) fizeram a caracterização e a distribuição de 
peixes na microbacia do Ribeirão Grande, verificando a distribuição parapátrica para várias espécies e destacando a importância ecológica do ecótono entre a encosta e o vale para essas populações. Esses ambientes são frágeis e comportam baixas densidades populacionais, sendo inúmeras as espécies $k$-estrategistas, e consequentemente, bem adaptadas a esses ambientes (BRAGA, 2004).

As microbacias do ribeirão dos Buenos (ou dos Moreiras) e do rio Guaratinguetá, integrantes da bacia do rio Paraíba do Sul, são sistemas hidrográficos que descem das encostas da serra da Mantiqueira oriental, sendo isoladas de outros sistemas contíguos por formações de relevo, indo desaguar no rio Paraíba do Sul. O ribeirão dos Buenos tem como principais afluentes o ribeirão dos Guarulhos e o córrego Guamirim. Já o rio Guaratinguetá tem como afluentes o rio do Sino e os ribeirões Pirutinga e Taquaral.

O objetivo deste trabalho foi definir como as comunidades de peixes das microbacias do ribeirão dos Buenos e do rio Guaratinguetá estão estruturadas e como variam suas composições no espaço e no tempo. Estudos sobre a biologia dessas populações foram conduzidos de modo a entender como ocorrem os processos de substituição de espécies no tempo e no espaço.

De modo a atender tais objetivos, a tese está apresentada em dois capítulos: no primeiro são analisados aspectos da estrutura das comunidades de peixes das microbacias do ribeirão dos Buenos e do rio Guaratinguetá e, no segundo, a abordagem é feita sobre a biologia dessas populações.

\section{Literatura citada}

BRAGA, F. M. S. Habitat, distribuição e aspectos adaptativos de peixes da microbacia do ribeirão Grande, Estado de São Paulo, Brasil. Acta Scietiarium, v. 26, n. 1, p. 31-36, 2004.

BRAGA, F. M. S. \& ANDRADE, P. M. Distribuição de peixes na microbacia do Ribeirão Grande, Serra da Mantiqueira Oriental, São Paulo, Brasil. Iheringia, Sér. Zool., v. 95, n. 2, p. 121-126, 2005.

DEAN, W. A ferro e fogo: a história da devastação da Mata Atlântica brasileira. São Paulo, Companhia das Letras, 484p., 1996. 
MODENESI-GAUTTIERI, M. C.; HIRUMA, S. T. \& RICCOMINI, C. Morphotectonics of a high plateu on the northwestern flank of the Continental Rift of southeastern Brazil. Geomorphlogy, v. 43, p. 257-271, 2002.

MYERS, N.; MITTERMEIER, R. A.; MITTERMEIER, C. G.; FONSECA, G. A. B. \& KENT, J. Biodiversity hotspots for conservation priorities. Nature, v. 403, p. 853-858, 2000.

PETRI, S. \& FÚLFARO, V. S. Geologia do Brasil (Fanerozóico). São Paulo, Edusp, 631p., 1983.

PONÇANO, W. L.; CARNEIRO, C. D. R.; BISTRICHI, C. A.; ALMEIDA, F. F. \& PRANDINI, F. L. Mapa geomorfológico do Estado de São Paulo. São Paulo, Instituto de Pesquisas Tecnológicas, v. 1, p. 38-41 (Monografias 5), 1981. 


\section{CAPÍTULO 1}

\section{Estrutura das comunidades de peixes das microbacias do ribeirão dos Buenos e do rio Guaratinguetá, na serra da Mantiqueira oriental}

\section{Introdução}

Os modelos conceituais que procuram explicar as mudanças longitudinais que ocorrem na composição das assembléias de peixes no sentido cabeceira-foz são baseados principalmente em pesquisas realizadas em riachos de regiões temperadas (MATTHEWS, 1998). Esses modelos geralmente assumem que mudanças no hábitat dos trechos mais altos em direção à foz influenciam na distribuição das espécies de peixes.

Durante os últimos 50 anos, dois conceitos têm dominado a discussão sobre as mudanças longitudinais na composição das assembléias de peixes: o conceito europeu de "biozonação" e o conceito norte-americano de "adição de espécies". Ambas as idéias têm em comum que as assembléias de peixes refletem as alterações estruturais, físicas e químicas que ocorrem das cabeceiras em direção à foz.

O conceito europeu de biozonação sugere que os rios temperados podem ser divididos longitudinalmente em quatro zonas, cada uma sendo caracterizada pela ocorrência de uma espécie principal indicadora. Dependendo da ocorrência das famílias dominantes, tem-se a região dos salmonídeos, que corresponde às seções de cabeceira, e a região dos ciprinídeos, que corresponde às seções mais baixas do rio (JENS, 1980 apud PETRY \& SCHULZ, 2006). A idéia geral desse conceito é que as espécies de uma dada zona ou região são substituídas por outras espécies na seguinte zona ou região.

Já a escola norte-americana defende o conceito de adição de espécies, onde mudanças nas assembléias de peixes refletem o contínuo aumento da complexidade de hábitat no sentido cabeceira-foz, devido a adição de espécies (SHELDON, 1968; EVANS \& NOBLE, 1979).

Nos anos 80, Vannote et al. (1980) elaboraram o conceito do rio contínuo (RCC), que entende o sistema fluvial como um contínuo de séries integrantes de gradientes físicos e ajustes biológicos. Inicialmente formulado para explicar alterações na composição de 
macroinvertebrados em riachos temperados, o RCC foi estendido para outros grupos, como os peixes (ROPER \& SCARNECCHIA, 2001). Entre as inúmeras doutrinas desse conceito, estão a substituição de espécies ao longo do gradiente e a maximização da diversidade biótica nos trechos médios, como resultado da maior variabilidade ambiental nessas áreas e mudanças espaciais na abundância dos grupos alimentares funcionais.

Os principais conceitos em ecologia fluvial (zonação e RCC) vêm sendo questionados, pois alguns autores acreditam que os conceitos de substituição e adição de espécies podem ser complementares, visto que eles podem agir sob diferentes escalas espaciais (RAHEL \& HUBERT, 1991).

Jackson et al. (2001) comentam que a adição de espécies geralmente está relacionada a gradientes ambientais que apresentam alterações menos severas dos fatores abióticos ao longo do gradiente, enquanto que a substituição de espécies corresponde à alterações abruptas no riacho com relação à geomorfologia e às condições abióticas.

A geomorfologia é um dos importantes fatores que afeta a estrutura das comunidades de peixes em ambientes lóticos (ALLAN, 1997), visto que esta se altera de modo gradual ao longo do canal, ocasionando mudanças nas características limnológicas do ambiente, desde as cabeceiras até a foz.

A influência dos fatores abióticos e bióticos sobre as comunidades varia em magnitude de uma população para outra. Se as condições locais forem altamente previsíveis, a estrutura das comunidades será determinada por ações estocásticas do ambiente e, se essas flutuações forem menores, dando origem a sistemas previsíveis, as interações biológicas podem ser mais importantes na organização (PERES-NETO et al., 1995).

Peres-Neto et al. (1995) mostraram que os fatores-chave na estruturação de comunidades estão relacionados às características de hábitat, e que características biológicas, como reprodução e interações tróficas podem também ser importantes, sendo, no entanto, mais difíceis de serem medidas do que variáveis físicas e químicas.

Dentre os fenômenos físicos que agem sobre as comunidades, Matthews (1998) mostrou que a profundidade e a largura do riacho estão entre os principais, Barreto \& Uieda (1998) relataram as alterações na descarga e velocidade da corrente e Mazzoni \& IglesiasRios (2002) a disponibilidade de alimento e abrigo. Gerhard et al. (2004) chamaram a 
atenção para as características locais do ambiente como grau de sombreamento, vegetação marginal e turbidez da água, e as regionais como a latitude, a posição na área de drenagem e a ordem do rio, como fatores controladores da composição das comunidades.

O destaque da importância das interações inter-específicas na estruturação da distribuição geográfica e abundância de espécies foi apresentado por Gilliam et al. (1993).

A riqueza de espécies normalmente aumenta em direção à foz e a razão para esse fenômeno está geralmente relacionada ao aumento gradual na diversidade de hábitat (GORMAN \& KARR, 1978; REYES-GAVILÁN et al., 1996). Além disso, as condições físicas e químicas nas regiões de cabeceira são muito mais estressantes que nos demais trechos e poucas são as espécies de peixes que apresentam adaptações para sobreviver nesses ambientes (MATTHEWS \& STYRON, 1981).

Osborne \& Wiley (1992) e Castro et al. (2003) analisaram a influência da posição do canal na rede de drenagem sobre a estrutura da comunidade de peixes e verificaram adição de espécies à medida que o trecho se aproximava da desembocadura do curso de água. Pavanelli \& Caramaschi (2003) e Casatti (2005) verificaram aumento na diversidade de espécies da cabeceira para a foz e aumento da diversidade temporal na estação de cheia.

De acordo com Schlosser (1982) dois gradientes primários de hábitat que influenciam a estrutura de comunidades podem ser destacados: os gradientes cabeceira-foz e corredeira-poço. Angermeier \& Schlosser (1989) definiram a complexidade estrutural em riachos como um mosaico de manchas de meso-habitat como poços e corredeiras, que são claramente delimitados por diferentes combinações de correnteza, profundidade e composição. Taylor (2000), Lemes \& Garutti (2002) e Langeani et al. (2005) desenvolveram estudos utilizando-se destes gradientes e constataram diferenças nos padrões de distribuição e abundância das comunidades.

Dentro de cada hábitat, existe uma enorme variedade de nichos ecológicos que diferem em detalhes, e ocorrem mudanças contínuas com o decorrer do tempo, particularmente com as variações sazonais no nível da água, disponibilidade de alimento e número de espécies presentes. Tal ambiente instável é dinâmico e resiliente, e a diversidade de nichos em um trecho de água relativamente pequeno permite a coexistência de numerosas espécies intimamente relacionadas, com requerimentos ecológicos aparentemente idênticos (LOWE-McCONNELL, 1999). 
No presente capítulo são apresentadas a estrutura das comunidades de peixes das microbacias do ribeirão dos Buenos e do rio Guaratinguetá e as variações de suas composições no espaço e no tempo.

Argumentos foram levantados para responder as seguintes questões:

i) Como as espécies estão distribuídas nas microbacias?

ii) Existe diferença nas distribuições de espécies entre as microbacias?

iii) Essa distribuição está relacionada com os diferentes ambientes (encosta, pediplano e vale)?

\section{Material e Métodos}

\section{1. Descrição da área de estudo}

As microbacias do ribeirão dos Buenos e do rio Guaratinguetá são redes hidrográficas que descem das encostas da serra da Mantiqueira oriental (22\%43'28' S; $45^{\circ} 26^{\prime} 14$ '’W) e vão desembocar na margem esquerda do rio Paraíba do Sul (2250'42'’s; 45 $\left.16^{\circ} 31^{\prime \prime} \mathrm{W}\right)$, estando situadas entre os municípios de Pindamonhangaba e Guaratinguetá, no estado de São Paulo (Figura 1). 


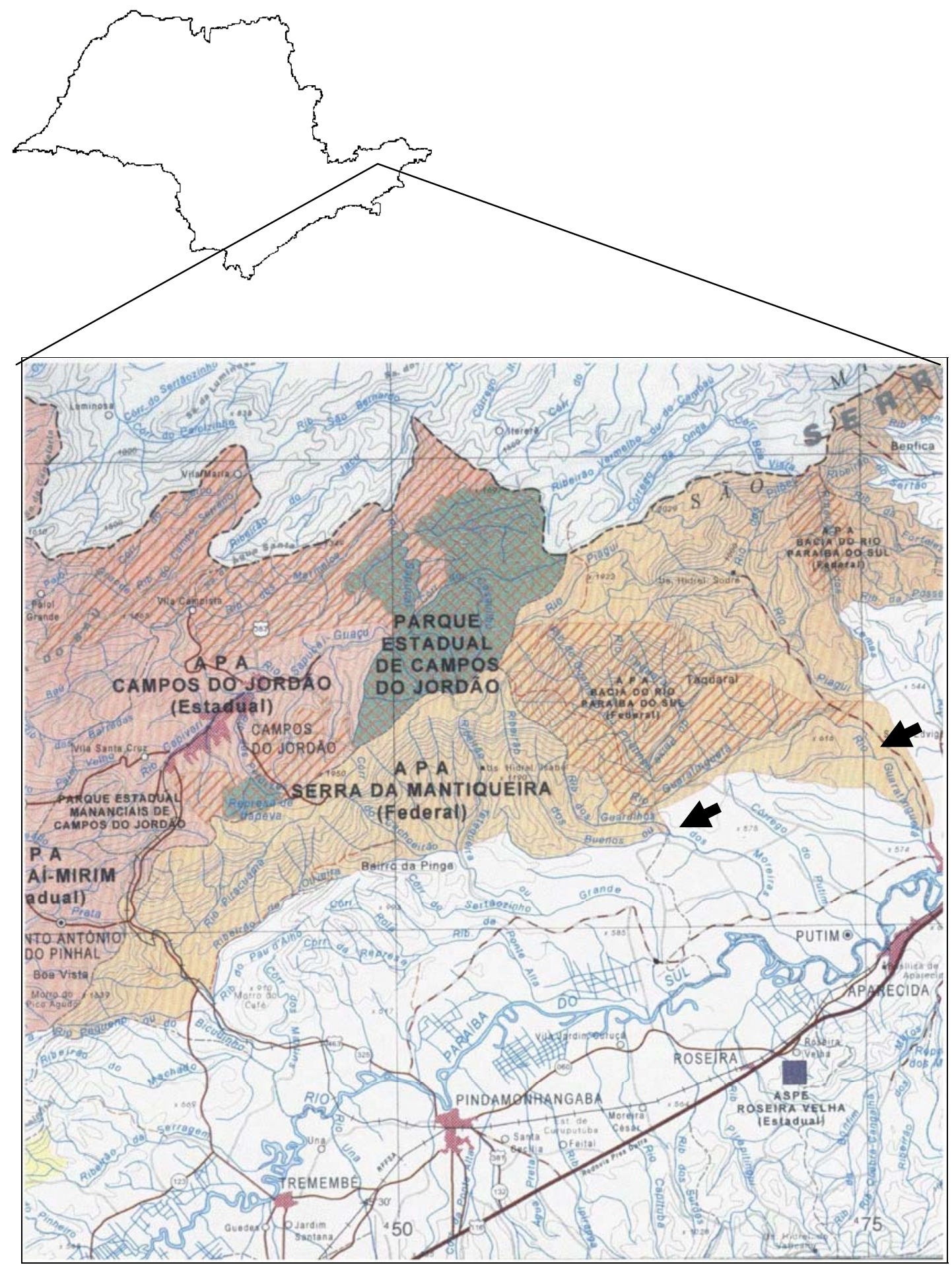

Figura 1: Mapa da área de estudo com destaque (setas) para as microbacias do ribeirão dos Buenos e do rio Guaratinguetá. 
O ribeirão dos Buenos nasce a cerca de 1950 metros de altitude, desce a escarpa da serra da Mantiqueira de forma abrupta, indo desaguar no rio Paraíba do Sul, na cota de 550 metros. Nesse trajeto percorre cerca de 20 quilômetros. Seus principais afluentes são o ribeirão dos Guarulhos e o córrego Guamirim.

A nascente do rio Guaratinguetá encontra-se a cerca de 850 metros de altitude, no pediplano da serra da Mantiqueira. Hoje em dia, está totalmente assoreada e tomada pelo gado, tendo seu fluxo de água interrompido. São seus principais afluentes, o rio do Sino e os ribeirões Pirutinga e Taquaral, que nascem a cerca de 1900 metros de altitude, que formam o seu curso principal, que percorre um trajeto de cerca de 25 quilômetros até sua foz, no rio Paraíba do Sul.

Conforme a classificação de Köppen, o tipo climático da região é mesotérmico, com verões quentes e chuvosos e com uma estação seca bem acentuada coincidindo com o inverno.

A região montanhosa apresenta as temperaturas mais baixas, possuindo verão brando, sendo que, durante os meses de inverno, é comum observar a formação de geadas. Por outro lado, a região do médio Vale do Paraíba apresenta temperaturas médias anuais mais elevadas. $\mathrm{O}$ mês mais quente do ano é fevereiro com temperatura média de $24,2^{\circ} \mathrm{C}$, e o mês mais frio é julho, com $17,2^{\circ} \mathrm{C}$ (PLANO DIRETOR, 2000).

Quanto à formação geológica, Benites et al. (2003) destacam o predomínio de granitos e gnaisses e rochas de grau metamórfico intermediário, ocorrendo também algumas áreas de quartzito e figurando ainda como elementos da paisagem extensões variáveis de rocha aflorada.

A cobertura florestal apresenta remanescentes de Mata Atlântica interiorana na encosta intercalados com áreas abertas de pastagens. O desmatamento, a pequena espessura do solo e a forte declividade da encosta tem provocado em diversas áreas o deslizamento do regolito, expondo a rocha nua (talus).

No Pleistoceno terminal (15.000 anos atrás) o clima passou de seco e árido para úmido, acarretando mudanças na paisagem do sudeste do Brasil. As florestas, até então localizadas nas partes mais altas e úmidas das encostas tiveram um avanço para altitudes menores, substituindo a vegetação xeromórfica existente nas partes mais baixas (AB'SABER, 1969). Evidências desses acontecimentos encontram-se nas linhas de pedra 
presentes em barrancos situados no pediplano (Figura 2), que registram a existência de um clima mais seco do Pleistoceno terminal.
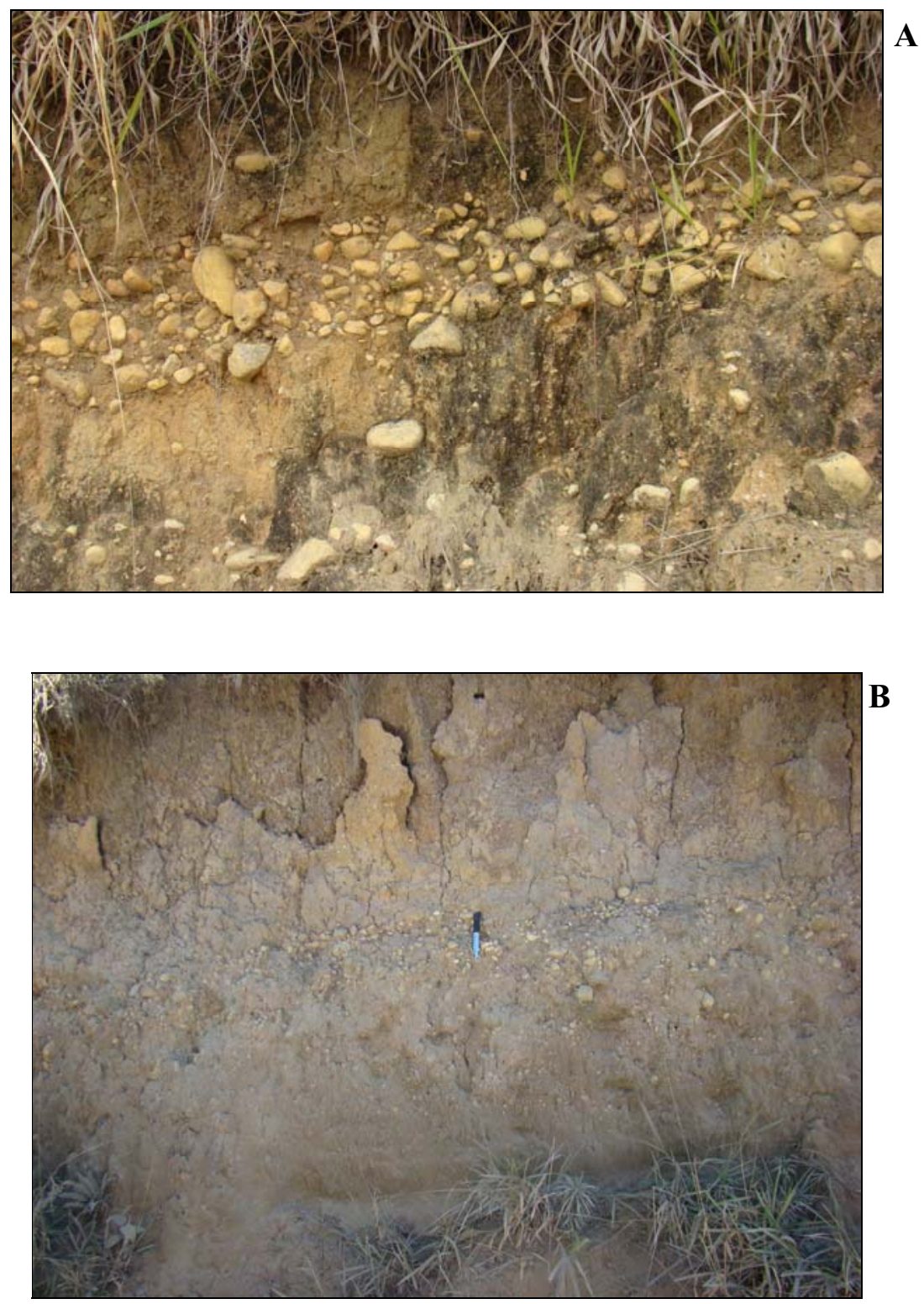

Figura 2: Linhas de pedra encontradas no pediplano das microbacias estudadas. Em (A) linha de pedra localizada na confluência do ribeirão dos Buenos com o ribeirão dos Guarulhos e em (B) linha de pedra localizada na estrada municipal "Taquaral”, no município de Guaratinguetá. 


\subsection{Descrição dos pontos de coleta}

De modo a contemplar regiões da encosta, do pediplano e do vale foram demarcados 15 pontos de coleta, 8 deles na microbacia do ribeirão dos Buenos e 7 na do rio Guaratinguetá (Figura 3).

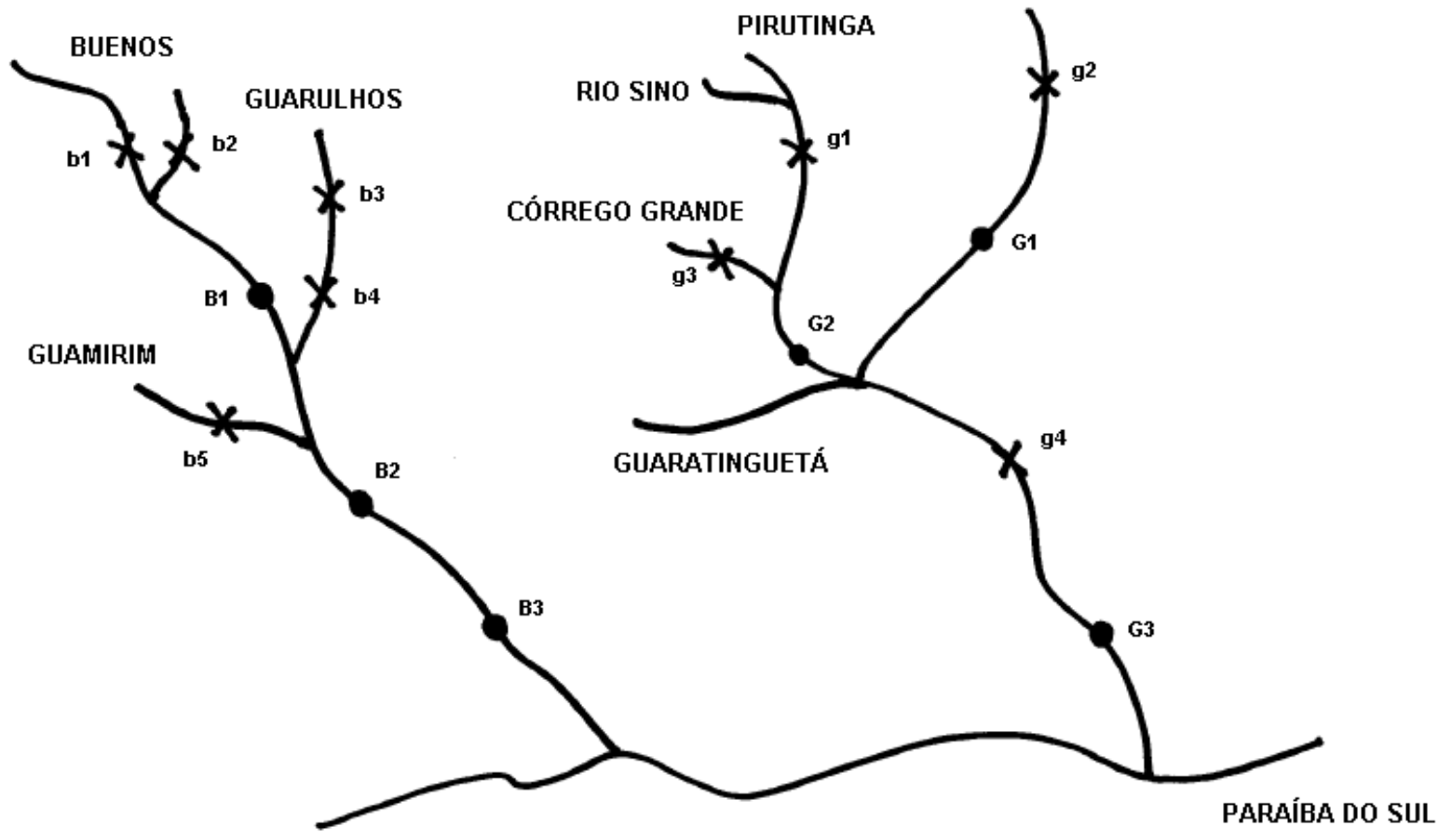

Figura 3: Mapa esquemático com os pontos de coleta distribuídos nas microbacias do ribeirão dos Buenos (à esquerda) e rio Guaratinguetá (à direita) (os círculos correspondem aos pontos temporais e os "X" aos pontos espaciais). 
Dentre os pontos selecionados, seis foram determinados como pontos temporais, sendo amostrados quatro vezes ao longo de um ano (maio, agosto e novembro de 2008 e fevereiro de 2009) possibilitando, assim, o desenvolvimento de estudos sazonais sobre a biologia das espécies. Três pontos estiveram localizados no próprio ribeirão dos Buenos, sendo denominados de B1, B2 e B3. Os outros três pontos localizaram-se nos ribeirões Taquaral (G1) e Pirutinga (G2) e no rio Guaratinguetá (G3) (Figura 4).

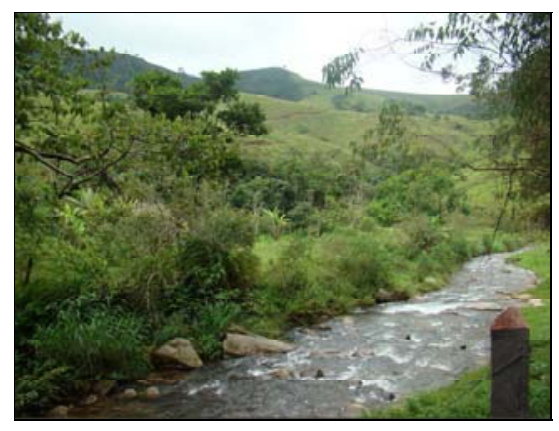

B1 (encosta)

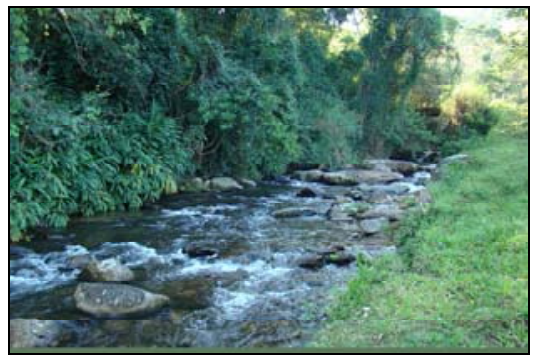

G1 (encosta)

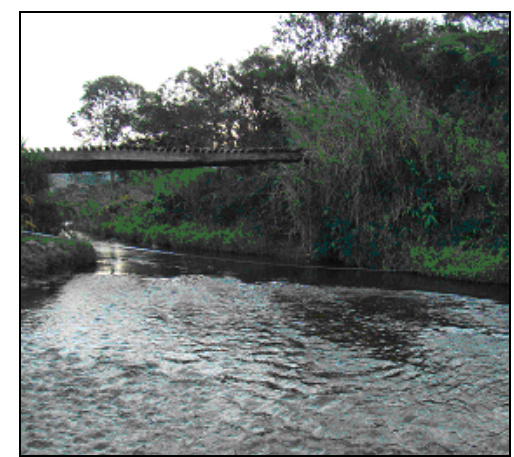

B2 (pediplano)

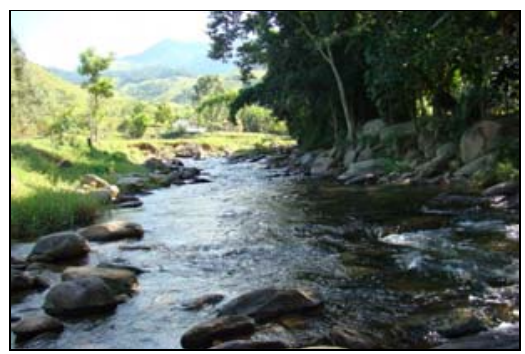

G2 (pediplano)

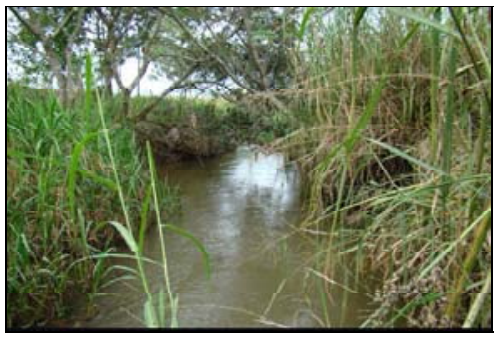

B3 (vale)

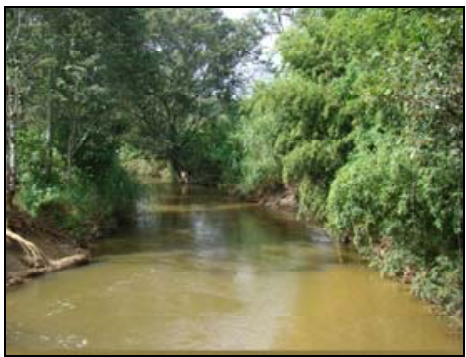

G3 (vale)

Figura 4: Vista dos pontos temporais localizados nas microbacias do ribeirão dos Buenos (B1, B2, B3) e do rio Guaratinguetá (G1, G2, G3) amostrados temporalmente nos meses de maio, agosto e novembro de 2008 e fevereiro de 2009 (entre parêntesis encontra-se o ambiente no qual o ponto se encontra - encosta, pediplano ou vale).

Os nove pontos restantes foram determinados como pontos espaciais e amostrados uma única vez ao longo do período de estudo, o que possibilitou, juntamente com os seis pontos mencionados anteriormente, o conhecimento da distribuição das espécies nas duas microbacias estudadas (Figura 5). 


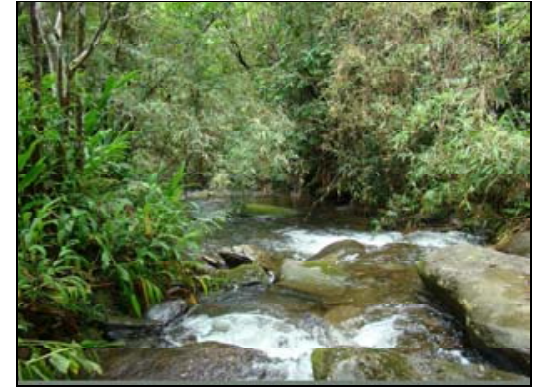

b1 (encosta)

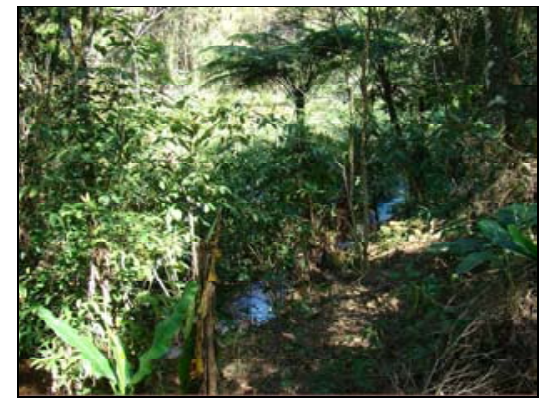

b4 (pediplano)

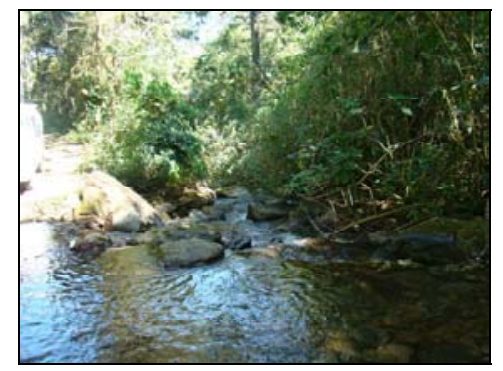

g2 (encosta)

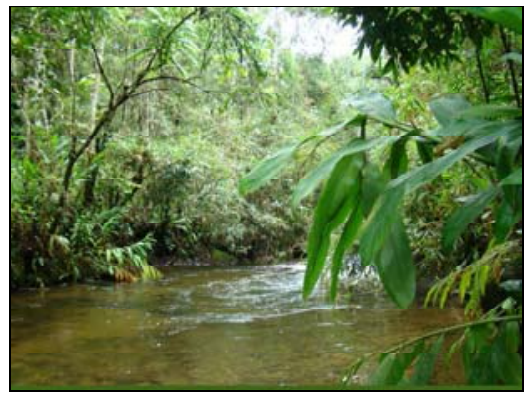

b2 (encosta)

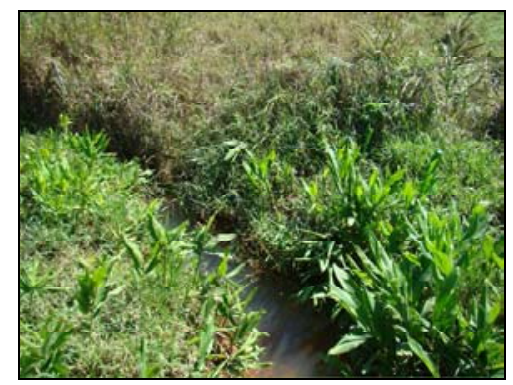

b5 (pediplano)

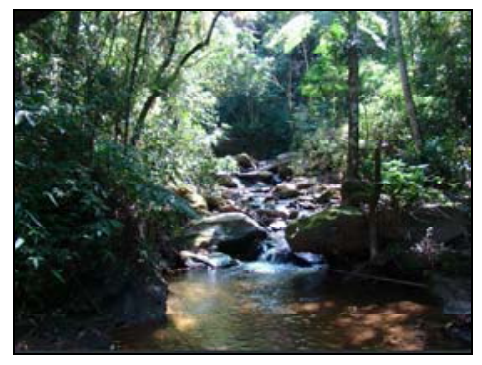

g3 (encosta)

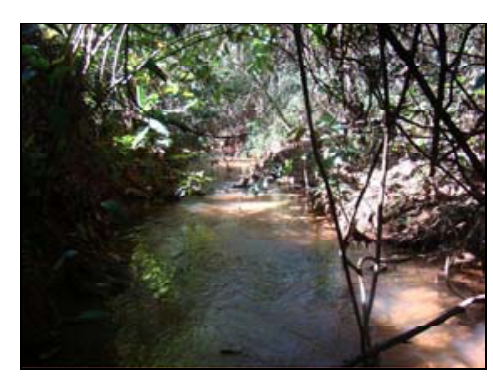

b3 (pediplano)

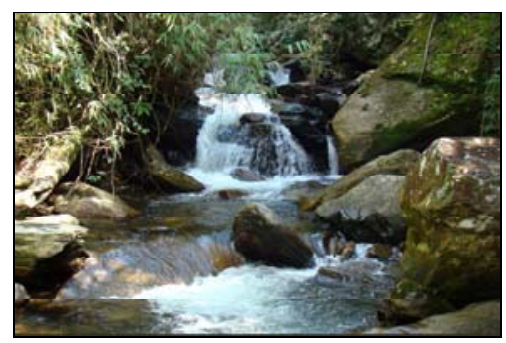

g1 (encosta)

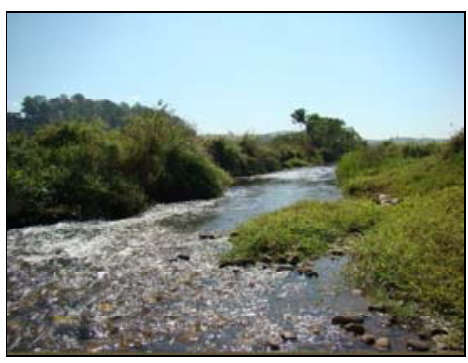

g4 (vale)

Figura 5: Vista dos pontos espaciais localizados nas microbacias do ribeirão dos Buenos (b1 e b2 no ribeirão dos Buenos, b3 e b4 no ribeirão dos Guarulhos e b5 no córrego Guamirim) e do rio Guaratinguetá (g1 no ribeirão Pirutinga, g2 no ribeirão Taquaral, g3 no ribeirão Córrego Grande, afluente do ribeirão Pirutinga, e g4 no rio Guaratinguetá) (entre parêntesis encontra-se o ambiente no qual o ponto se encontra - encosta, pediplano ou vale).

Além disso, 3 pontos na região da cimeira da serra (Figura 6) foram vistoriados, dois localizados na área de nascente do ribeirão dos Buenos e um no ribeirão dos Sinos, afluente do ribeirão Pirutinga (Figura 7). Como nesses pontos não se encontrou nenhuma espécie de peixe, eles não foram inseridos nas análises. 

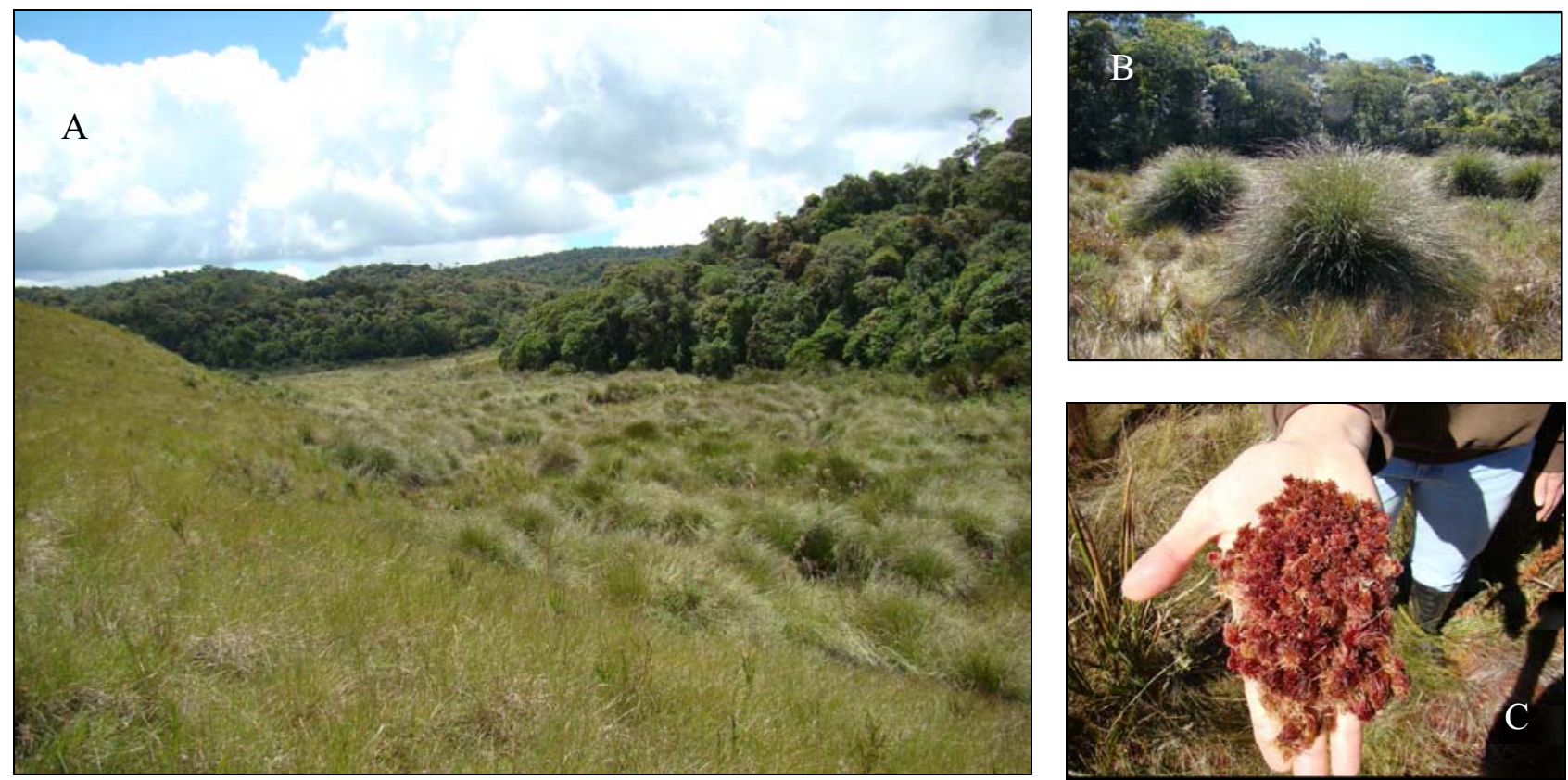

Figura 6: Vista da região da cimeira da serra da Mantiqueira (A), com destaque para a vegetação presente: Cortaderia sp. (B) e Sphagnum sp. (C).
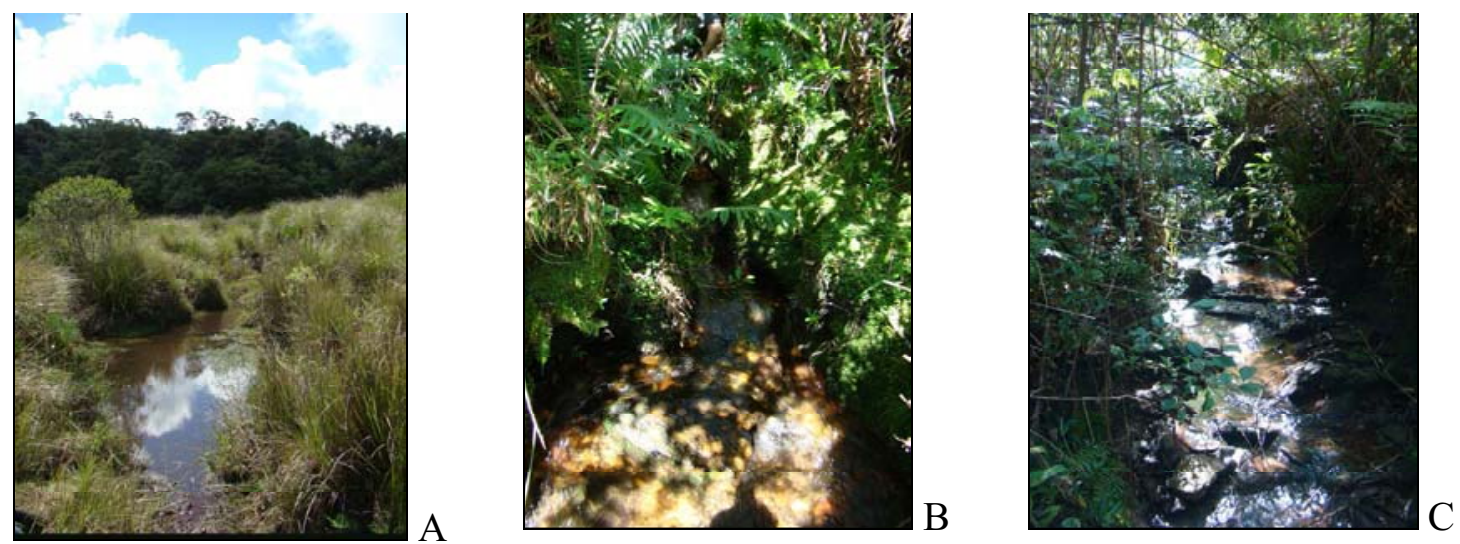

Figura 7: Vista dos pontos localizados na região da cimeira da serra da Mantiqueira (nascentes do ribeirão dos Buenos: A = brejo e B = córrego; $\mathrm{C}$ : nascente rio dos Sinos).

\subsection{Coleta de dados}

\subsubsection{Variáveis estruturais}

As variáveis denominadas estruturais foram: largura, profundidade, velocidade da corrente e tipo de substrato. Em julho de 2008, os pontos B1, B2 e B3 (pertencentes à 
microbacia do ribeirão dos Buenos) e G1, G2 e G3 (da microbacia do rio Guaratinguetá) foram visitados e trechos de $50 \mathrm{~m}$ foram delimitados. A cada $5 \mathrm{~m}$, da margem esquerda para a direita, em intervalos de $1 \mathrm{em} 1 \mathrm{~m}$, foi tomada a largura do segmento em metros (com o auxílio de uma trena), a profundidade em centímetros (com o auxílio de uma régua), a categoria de substrato predominante (de forma visual) e a velocidade de corrente (com um fluxômetro mecânico da marca General Oceanics). As categorias utilizadas para a classificação de profundidade, velocidade de corrente e tipo de substrato encontram-se nas Tabelas 1,2 e 3.

Tabela 1: Categorias utilizadas para classificar as medidas de profundidade.

\begin{tabular}{lc}
\hline Categoria & Profundidade (cm) \\
\hline Raso & entre 0 e 30 \\
Moderado & entre 30 e 100 \\
Fundo & $>100$ \\
\hline
\end{tabular}

Tabela 2: Categorias utilizadas para classificar as medidas de velocidade de corrente.

\begin{tabular}{lc}
\hline Categoria & Velocidade de corrente $(\mathbf{m} / \mathbf{s})$ \\
\hline Muito lento & $<0,05$ \\
Lento & entre 0,5 e 0,2 \\
Moderado & entre 0,2 e 0,4 \\
Rápido & entre 0,4 e 1,0 \\
Torrente & $>1,0$ \\
\hline
\end{tabular}

Tabela 3: Categorias utilizadas para classificar as medidas do tipo de substrato predominante.

\begin{tabular}{lc}
\hline Categoria & Tamanho $(\mathbf{m m})$ \\
\hline Argila & $<0,05$ \\
Areia & entre 0,05 e 2 \\
Cascalho & entre 2 e 10 \\
Seixo & entre 10 e 100 \\
Pedra & entre 100 e 300 \\
Matacão & $>300$ \\
Leito de rocha & - \\
Vegetação & - \\
Lodo & - \\
\hline
\end{tabular}

\subsubsection{Variáveis físicas e químicas da água}

As variáveis físicas e químicas da água foram coletadas em todas as amostragens (maio, agosto e novembro de 2008 e fevereiro de 2009). O oxigênio dissolvido foi 
determinado através do método de Winkler (MORAES, 2001) e as demais variáveis medidas com analisadores de água eletrônicos.

\subsubsection{Ictiofauna}

Os pontos temporais foram visitados nos meses de maio, agosto e novembro de 2008 e fevereiro de 2009, sendo amostrados, portanto, quatro vezes. Como os pontos espaciais foram amostrados uma única vez, suas amostragens estiveram distribuídas ao longo dos períodos de coleta nos pontos temporais.

As amostras foram realizadas com aparelho de pesca elétrica, redinha-de-arrasto, redes-de-espera e puçá de acordo com as características físicas de cada ponto. A distribuição dos apetrechos de pesca utilizados em cada ponto amostral encontra-se na Tabela 4.

Tabela 4: Apetrechos de pesca utilizados em cada ponto amostral, com indicação da coordenada geográfica, riacho e microbacia.

\begin{tabular}{|c|c|c|c|c|}
\hline & Coordenada & & & Apetrecho de pesca \\
\hline Ponto & Geográfica & Riacho & Microbacia & utilizado \\
\hline $\mathrm{B} 1 *$ & $\mathrm{~S} 22^{\circ} 46^{\prime} 30,9^{\prime \prime} \mathrm{W} 45^{\circ} 24^{\prime} 44,5^{\prime}$, & Buenos & Buenos & Pesca elétrica \\
\hline $\mathrm{B} 2 *$ & $\mathrm{~S} 22^{\circ} 47^{\prime} 42,7^{\prime \prime} \mathrm{W} 45^{\circ} 17^{\prime} 52,8^{\prime}$, & Buenos & Buenos & Pesca elétrica \\
\hline B3* & $\mathrm{S} 22^{\circ} 47^{\prime} 53,3^{\prime \prime} \mathrm{W} 45^{\circ} 18^{\prime} 33,8^{\prime}$, & Buenos & Buenos & Rede-de-espera/Redinha \\
\hline $\mathrm{G} 1 *$ & $\mathrm{~S} 22^{\circ} 43^{\prime} 29,1^{\prime \prime} \mathrm{W} 45^{\circ} 20^{\prime} 36,8^{\prime \prime}$ & Taquaral & Guaratinguetá & Pesca elétrica \\
\hline $\mathrm{G} 2 *$ & $\mathrm{~S} 22^{\circ} 44^{\prime} 25,3^{\prime \prime} \mathrm{W} 45^{\circ} 22^{\prime} 23,8^{\prime \prime}$ & Pirutinga & Guaratinguetá & Pesca elétrica \\
\hline G3* & S $22^{\circ} 45^{\prime} 19,6^{\prime \prime}$ W $45^{\circ} 13^{\prime} 39,2^{\prime \prime}$ & Guaratinguetá & Guaratinguetá & Rede-de-espera/Redinha \\
\hline $\mathrm{b} 1 * *$ & $\mathrm{~S} 22^{\circ} 45^{\prime} 07,3^{\prime \prime} \mathrm{W} 45^{\circ} 25^{\prime} 39,7^{\prime}$ & Buenos & Buenos & Pesca elétrica portátil \\
\hline $\mathrm{b} 2 * *$ & $\mathrm{~S} 22^{\circ} 43^{\prime} 48,0^{\prime \prime} \mathrm{W} 45^{\circ} 28^{\prime} 24,0^{\prime}$ & Buenos & Buenos & Pesca elétrica portátil \\
\hline $\mathrm{b} 3 * *$ & S $22^{\circ} 46^{\prime} 92,7^{\prime \prime}$ W 45²3’29,2'’' & Guarulhos & Buenos & Pesca elétrica \\
\hline $\mathrm{b} 4 * *$ & S $22^{\circ} 46^{\prime} 61,9^{\prime \prime} \mathrm{W} 45^{\circ} 21^{\prime} 77,0^{\prime \prime}$ & Guarulhos & Buenos & Pesca elétrica \\
\hline $\mathrm{b} 5 * *$ & S $22^{\circ} 47^{\prime} 24,4^{\prime \prime}$ W $45^{\circ} 25^{\prime} 45,2^{\prime \prime}$ & Guamirim & Buenos & Pesca elétrica \\
\hline $\mathrm{g} 1 * *$ & $\mathrm{~S} 22^{\circ} 42^{\prime} 39,2^{\prime \prime} \mathrm{W} 45^{\circ} 23^{\prime} 40,3^{\prime \prime}$ & Pirutinga & Guaratinguetá & Pesca elétrica \\
\hline $\mathrm{g} 2 * *$ & S $22^{\circ} 42^{\prime} 49,3^{\prime \prime}$ W 4521'19,2'”, & Taquaral & Guaratinguetá & Pesca elétrica \\
\hline $\mathrm{g} 3 * *$ & S $22^{\circ} 43^{\prime} 26,8^{\prime \prime}$ W $45^{\circ} 24^{\prime} 05,2^{\prime \prime}$ & Ribeirão Córrego Grande & Guaratinguetá & Pesca elétrica \\
\hline $\mathrm{g} 4 * *$ & S $22^{\circ} 44^{\prime} 22,7^{\prime \prime}$ W $45^{\circ} 17^{\prime} 11,7^{\prime \prime}$ & Guaratinguetá & Guaratinguetá & Pesca elétrica \\
\hline Nascente Buenos Brejo*** & $\mathrm{S} 22^{\circ} 42^{\prime} 51,1^{\prime \prime} \mathrm{W} 45^{\circ} 25^{\prime} 51,1^{\prime}$ & Buenos & Buenos & Pesca elétrica portátil \\
\hline Nascente Buenos Córrego*** & S $22^{\circ} 42^{\prime} 51,9^{\prime}{ }^{\prime} \mathrm{W} 45^{\circ} 26^{\prime} 04,2^{\prime}$, & Buenos & Buenos & Puçá \\
\hline Sinos*** & $\mathrm{S} 22^{\circ} 42^{\prime} 56,7^{\prime \prime} \mathrm{W} 45^{\circ} 25^{\prime} 18,3^{\prime \prime}$ & Rio dos Sinos & Guaratinguetá & Pesca elétrica portátil \\
\hline
\end{tabular}

* Pontos temporais, **Pontos espaciais, ***Pontos não inseridos nas análises. 
Nos pontos amostrais em que se utilizou o equipamento de pesca elétrica foram selecionados trechos de $50 \mathrm{~m}$, onde o aparelho foi passado por duas vezes sem o uso de rede de contenção. $\mathrm{O}$ aparelho consiste em um gerador que fornece energia a um retificador de corrente que se conecta a dois puçás, que foram manuseados por duas pessoas, que caminharam no riacho em sentido contrário à corrente, usando botas isolantes. À medida que os coletores avançavam, os peixes, sujeitos ao campo elétrico, eram atraídos por galvanotaxia anódica e capturados através dos puçás. A voltagem utilizada foi $500 \mathrm{~V}$ com corrente direta.

O equipamento de pesca elétrica portátil (Figura 8) foi utilizado nos pontos amostrais de difícil acesso (região da encosta e cimeira da serra). Duas pessoas manusearam os puçás e percorreram trechos variáveis do riacho, procurando amostrar os diferentes ambientes.

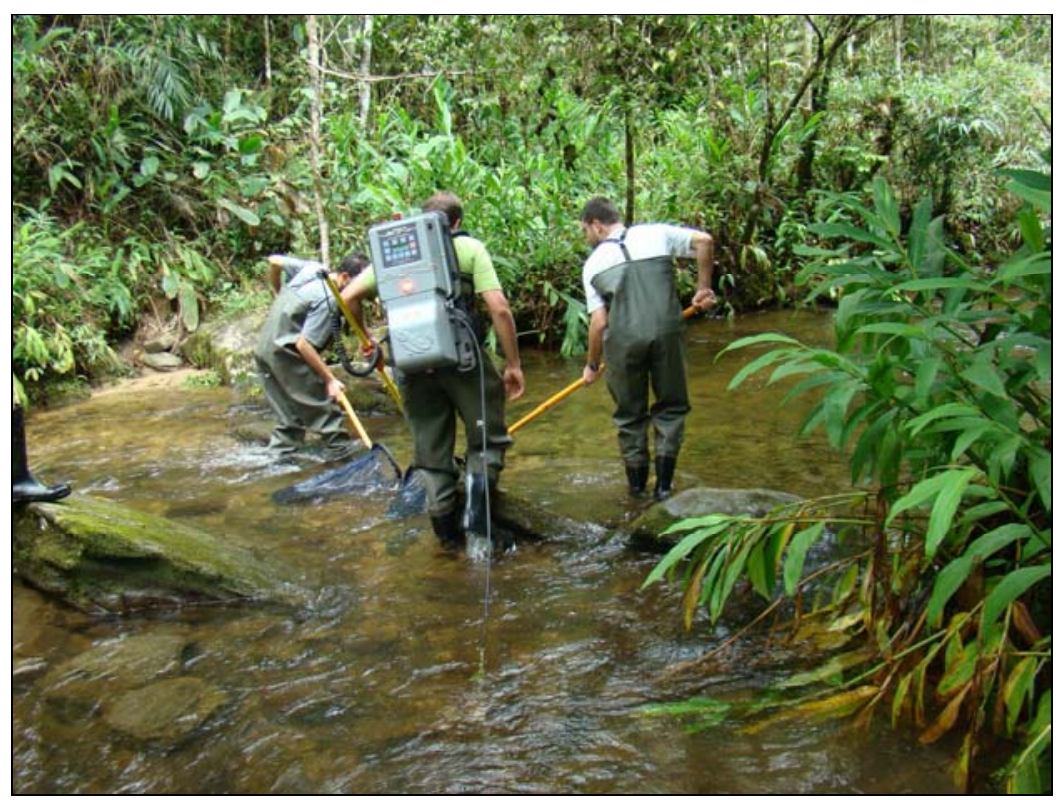

Figura 8: Equipamento de pesca elétrica portátil.

As redes-de-espera (de 1,5, 2,0, 2,5 e 3,0 cm entre nós adjacentes) foram utilizadas em apenas dois pontos amostrais. A seqüência de redes foi determinada ao acaso sendo colocadas no período da tarde permanecendo até a manhã do dia seguinte.

A redinha-de-arrasto foi passada na vegetação marginal por dez vezes nos pontos em que se utilizou redes-de-espera. 
O puçá foi utilizado em um ponto da região de cimeira em que os demais apetrechos não podiam ser utilizados devido às condições locais (pequeno volume de água e mata de galeria bastante fechada).

Após cada uma das coletas, os peixes foram colocados em sacos plásticos separados por ponto amostral e, então, fixados em formalina $10 \%$ durante 2 dias e posteriormente transferidos para álcool $70 \%$ até a realização das análises.

\subsubsection{Coleta de dados biológicos}

No laboratório, os peixes foram identificados até o nível de espécie e tomados os seguintes dados: comprimento total e padrão em centímetros e peso total em gramas.

\subsection{Análise de Dados}

\subsubsection{Dados abióticos}

As variáveis estruturais (largura do riacho, profundidade, velocidade da corrente e tipo de substrato) foram colocadas em gráfico para visualização da heterogeneidade ambiental por ponto amostral, para cada microbacia. Os índices de diversidade de Shannon, riqueza de Margalef e equitabilidade de Pielou foram estimados, bem como os respectivos intervalos de confiança através do programa PAST (QUINN \& KEPUGH, 2002).

O teste de Friedman (CAMPOS, 1983) foi aplicado aos dados de freqüência das variáveis estruturais por ponto amostral para cada microbacia, de modo a verificar possíveis diferenças entre pontos amostrais, adotando-se 0,05 como o nível de significância.

O teste de Spearman (SIEGEL, 1975) foi aplicado aos dados de freqüência das variáveis estruturais de cada microbacia, para verificar a existência ou não de correlação entre as mesmas, sendo 0,05 o nível de significância adotado.

As variáveis físicas e químicas da água $(\mathrm{pH}$, condutividade elétrica, oxigênio dissolvido e temperatura) também foram graficadas. O teste de Mann-Whitney (SIEGEL, 1975) foi aplicado para verificar possíveis diferenças dessas variáveis entre as microbacias, sendo 0,05 o nível de significância. 


\subsubsection{Dados bióticos}

\section{Riqueza}

O estimador bootstrap para a riqueza das microbacias foi calculado através do programa PAST (QUINN \& KEPUGH, 2002). Também foi aplicada uma curva de rarefação, que estima a riqueza dado um número de indivíduos conhecido, para cada microbacia. Para a estimativa de riqueza foram considerados os dados dos pontos temporais e para a curva de rarefação os dados dos pontos temporais e espaciais.

\section{Similaridade}

A similaridade da ictiofauna foi avaliada em termos qualitativos utilizando-se o índice de similaridade de Jaccard (J), que faz uso de dados de presença e ausência das espécies. Para essa análise foram considerados os dados das primeiras coletas realizadas nos pontos temporais - B1, B2, B3, G1, G2 e G3 - e os dados dos pontos espaciais.

\section{Diversidade}

O índice de diversidade de Shannon, equitabilidade de Pielou e riqueza de Margalef foram estimados para cada ponto amostral. Os pontos temporais tiveram os respectivos desvios padrão calculados para cada índice e para os pontos espaciais foram calculados intervalos de confiança. Uma ANOVA 3-way foi aplicada com o objetivo de verificar diferenças nos índices de diversidade, equitabilidade e riqueza entre microbacias (Buenos e Guaratinguetá), períodos (seco e chuvoso) e ambientes (encosta, pediplano e vale).

\section{Constância}

Para identificar qualitativamente as espécies residentes, foi aplicado o método de constância de ocorrência (DAJOZ, 1978): $c=\left(c_{i} / C\right) * 100$. Sendo: $c$ o valor de constância da espécie, $c_{i}$ o número de coletas em que ocorreu a espécie $i$ e $C$ o número total de coletas. As espécies com $c \geq 50$ foram consideradas constantes, com $25 \leq c<50$ acessórias e com $c<$ 25 ocasionais. A constância das espécies foi calculada considerando-se os pontos temporais, para as microbacias e para os ambientes de encosta, pediplano e vale, bem como a freqüência de ocorrência das espécies constantes, acessórias e ocasionais. 


\section{Curvas de abundância e biomassa}

A abundância cumulativa das espécies (como proporção ou porcentagem) foi plotada contra o rank do ln do número de indivíduos. Duas curvas foram construídas para cada ponto temporal de cada microbacia: uma baseada no número de indivíduos e a outra nos dados de biomassa.

\section{Raridade}

A representatividade das espécies nas microbacias foi resumida pelos seus valores de freqüência de ocorrência $\left(F_{o}\right)$ e suas medidas de abundância $\left(\bar{N}=N / F_{o}\right)$ e pesos médios $\left(\bar{P}=P / F_{o}\right)$. Desta forma, $F_{o}$ mede a importância regional enquanto $\bar{N}$ e $\bar{P}$ medem a importância local de cada espécie nas microbacias. Foram destacadas as espécies mais e menos importantes local e regionalmente (FERREIRA, 2007a). Para essa análise foram considerados os dados dos indivíduos capturados nas primeiras coletas realizadas nos pontos temporais (B1, B2, B3, G1, G2 e G3) e todos os indivíduos capturados nos pontos espaciais.

\section{Análise de correspondência}

Uma análise de correspondência (CA) foi realizada com os dados de abundância das espécies nos pontos amostrados temporalmente (B1, B2, B3, G1, G2 e G3). Para testar a hipótese de que a distribuição das espécies nos pontos amostrais é influenciada pelas variáveis físicas e químicas da água e pelas variáveis estruturais (largura do riacho, profundidade, velocidade da corrente e tipo de substrato) um teste de significância foi conduzido através do pacote "Envfit" do software R - versão 2.8.1 (R DEVELOPMENT CORE TEAM, 2009).

\section{Resultados}

\subsection{Variáveis estruturais}

As freqüências numéricas das categorias de profundidade, velocidade da corrente e tipo de fundo encontradas nos pontos temporalmente amostrados nas microbacias do ribeirão dos Buenos e rio Guaratinguetá encontram-se nas Figuras 9 e 10. 

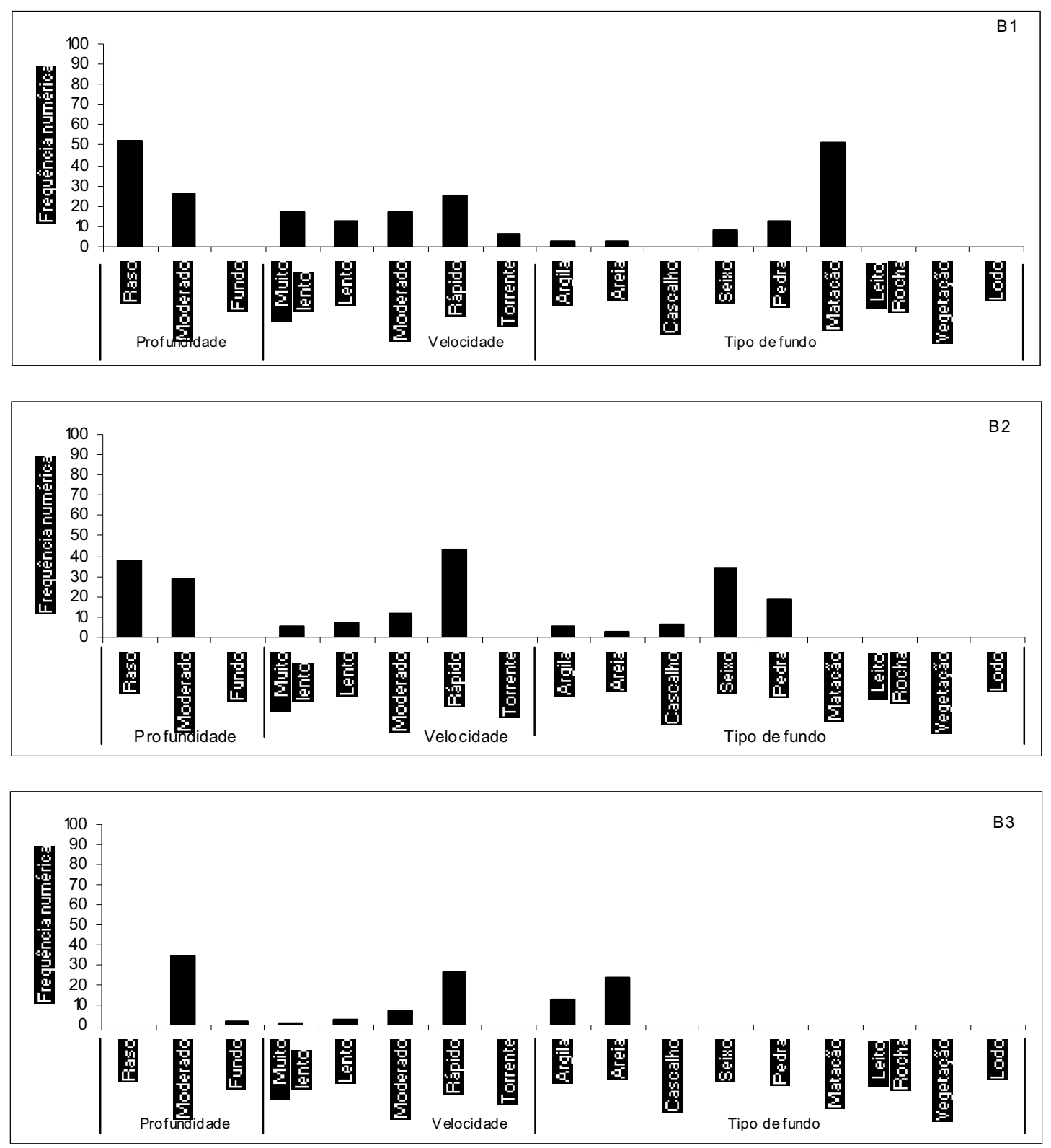

Figura 9: Freqüência numérica das categorias de profundidade, velocidade da corrente e tipo de fundo encontradas nos pontos temporalmente amostrados na microbacia do ribeirão dos Buenos (B1, B2 e B3). 

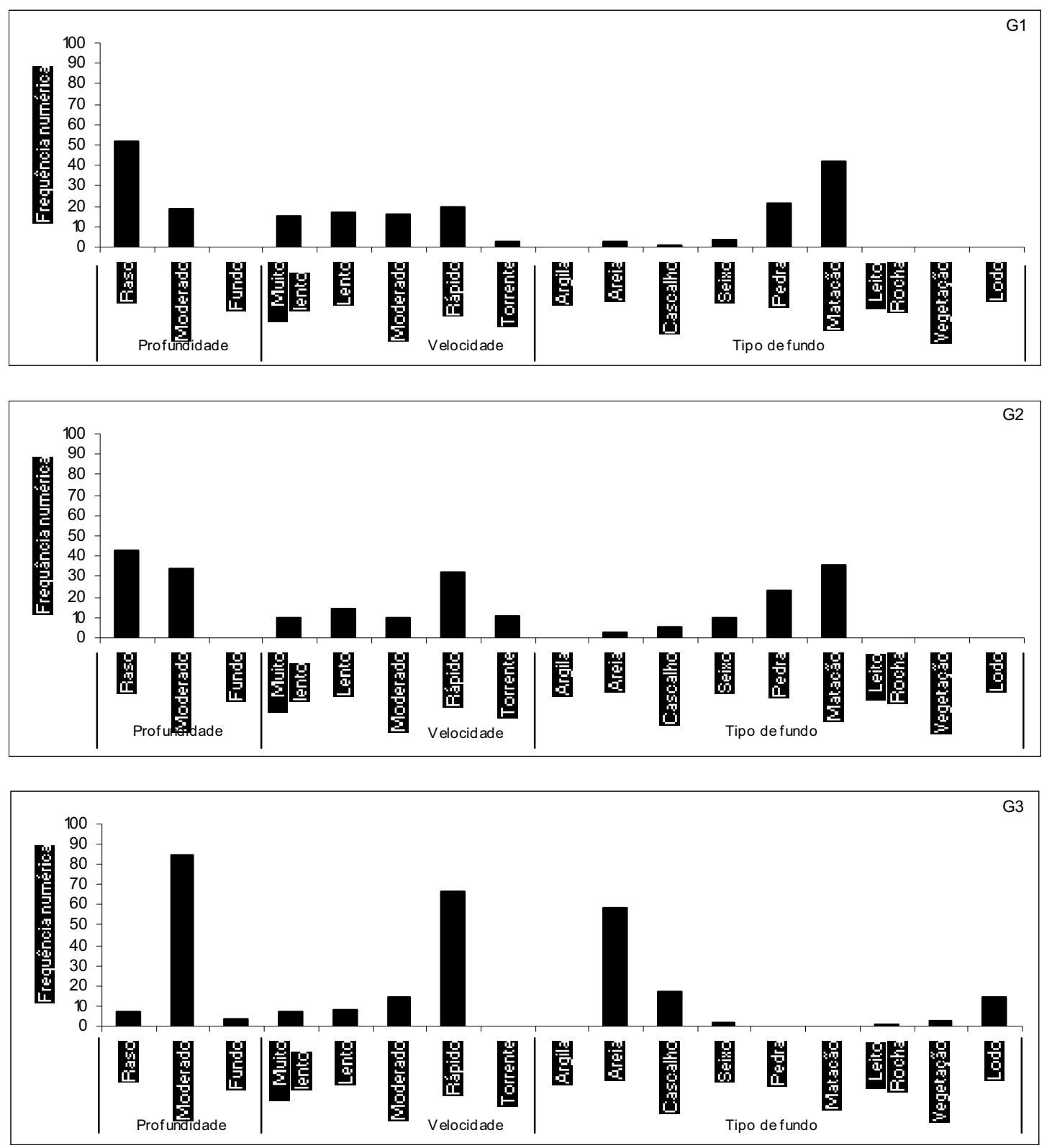

Figura 10: Freqüência numérica das categorias de profundidade, velocidade da corrente e tipo de fundo encontradas nos pontos temporalmente amostrados na microbacia do rio Guaratinguetá (G1, G2 e G3).

As categorias predominantes de profundidade foram "raso" e "moderado" para ambas as microbacias, sendo a categoria "raso" mais freqüente nos pontos mais à montante (B1 e G1) sendo substituída por “moderado” nos pontos mais à jusante (B3 e G3). 
Com relação às categorias de velocidade de corrente, "rápido" foi a mais freqüente em todos os pontos amostrados, embora as demais categorias também tenham ocorrido, só que de forma menos pronunciada.

A categoria mais freqüente de tipo de substrato encontrada nos pontos localizados mais próximos à encosta da serra (B1 e G1) foi "matacão". Como na região do pediplano a granulometria tende a ser menor, seixo/pedra predominaram no ponto B2 e matacão/pedra no G2. Na região do vale o tipo de substrato mais freqüente foi areia/argila (pontos B3 e G3).

Os valores dos índices de diversidade de Shannon (H'), riqueza de Margalef (MG) e equitabilidade de Pielou ( $\mathrm{J}$ ) com seus respectivos intervalos de confiança para os dados de estrutura de hábitat (profundidade, velocidade de corrente e tipo de substrato) para os pontos amostrados temporalmente nas microbacias do ribeirão dos Buenos (B1, B2 e B3) e rio Guaratinguetá (G1, G2 e G3) estão apresentados na Tabela 5 e Figura 11.

Os valores mais altos para o índice de diversidade foram obtidos nos pontos mais à montante de ambas as microbacias (B1 e B2 da microbacia do ribeirão dos Buenos, e G1 e G2 da microbacia do rio Guaratinguetá), acontecendo o mesmo com os valores do índice de riqueza.

Tabela 5: Valores dos índices de diversidade de Shannon (H'), riqueza de Margalef (MG) e equitabilidade de Pielou $(\mathrm{J})$ com seus respectivos intervalos de confiança para os dados de estrutura de hábitat (profundidade, velocidade de corrente e tipo de substrato) para os pontos amostrados temporalmente nas microbacias do ribeirão dos Buenos (B1, B2 e B3) e rio Guaratinguetá (G1, G2 e G3).

\begin{tabular}{ccccccccc}
\hline Pontos & H' & Mín & Máx & MG & Mín & J & Mín & Máx \\
\hline B1 & 2,173 & 0,12 & 0,063 & 2,016 & 0,183 & 0,8743 & 0,0451 & 0,03 \\
B2 & 2,084 & 0,126 & 0,063 & 1,886 & 0,189 & 0,8692 & 0,0499 & 0,0325 \\
B3 & 1,673 & 0,161 & 0,09 & 1,486 & 0,424 & 0,8045 & 0,0552 & 0,0835 \\
G1 & 2,133 & 0,129 & 0,062 & 2,052 & 0,373 & 0,8586 & 0,0339 & 0,0462 \\
G2 & 2,25 & 0,114 & 0,05 & 2,021 & 0,184 & 0,9056 & 0,0414 & 0,0218 \\
G3 & 1,927 & 0,133 & 0,091 & 2,119 & 0,353 & 0,7511 & 0,0393 & 0,0512 \\
\hline
\end{tabular}

Não foram detectadas diferenças significativas $(\mathrm{p}>0,05)$ entre as variáveis estruturais encontradas nos pontos amostrais das microbacias do ribeirão dos Buenos $\left(\chi_{\mathrm{r}}^{2}=1,08 ; \mathrm{p}=0,580\right)$ e do rio Guaratinguetá $\left(\chi_{\mathrm{r}}^{2}=0,08 ; \mathrm{p}=0,957\right)$.

Houve correlação entre as microbacias $(r=0,866 ; p=0,606)$, indicando que não existe diferença entre elas com relação às variáveis estruturais. 

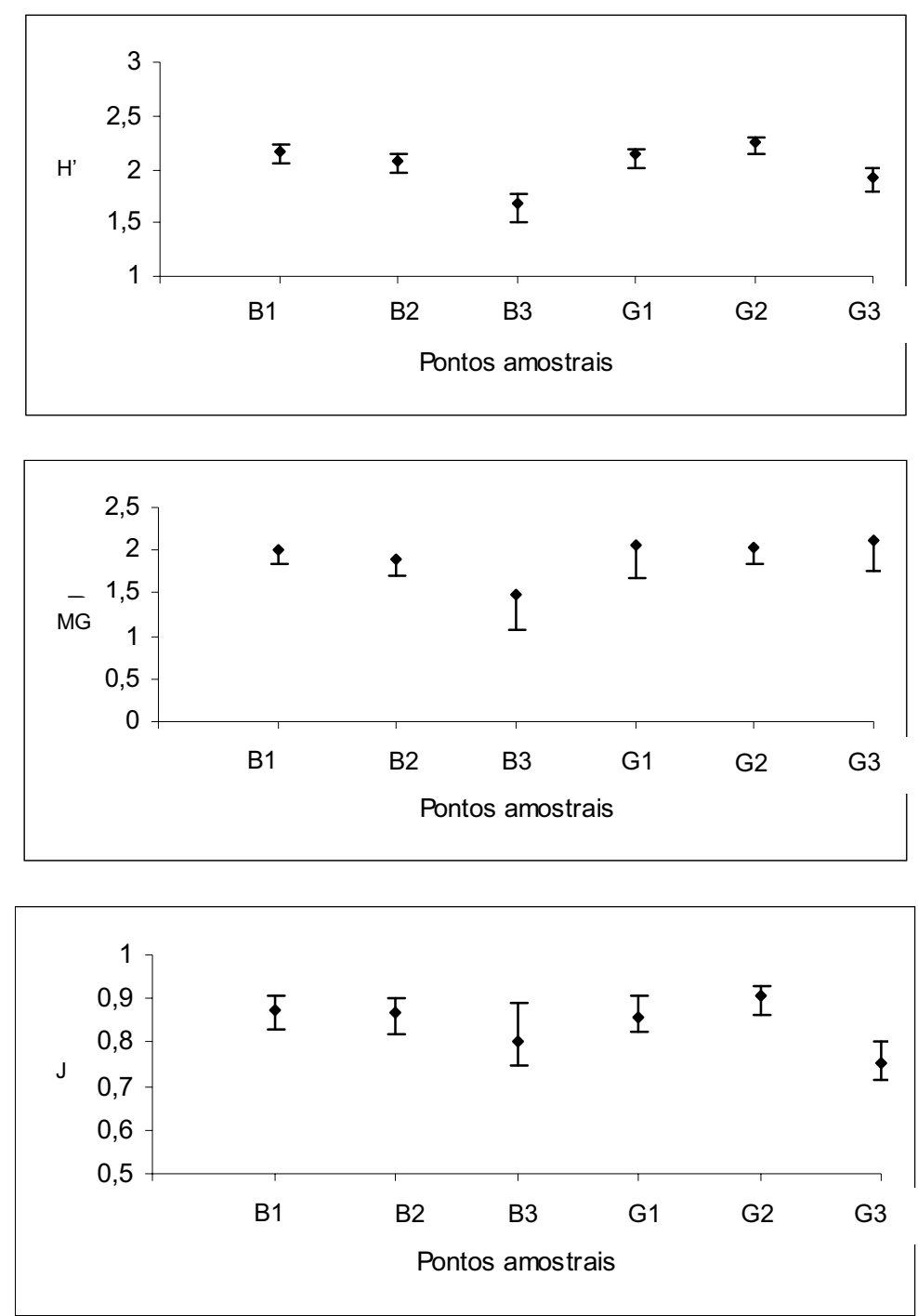

Figura 11: Valores dos índices de diversidade de Shannon (H'), riqueza de Margalef (MG) e equitabilidade de Pielou (J) com seus respectivos intervalos de confiança para os dados de estrutura de hábitat (profundidade, velocidade de corrente e tipo de substrato) para os pontos amostrados temporalmente nas microbacias do ribeirão dos Buenos (B1, B2 e B3) e rio Guaratinguetá (G1, G2 e G3). 


\subsection{Variáveis físicas e químicas da água}

Os valores medianos de $\mathrm{pH}$, condutividade elétrica, oxigênio dissolvido e temperatura da água para os pontos temporalmente amostrados nas microbacias estudadas estão apresentados na Figura 11.

Os valores de $\mathrm{pH}$ encontrados variaram de 5,3 a 6,9, sendo os valores mais baixos encontrados no ponto B2, na microbacia do ribeirão dos Buenos. A condutividade elétrica variou de 13 a 37,6 $\mu \mathrm{S} / \mathrm{cm}$, com uma tendência de aumento da condutividade no sentido montante-jusante para as microbacias do ribeirão dos Buenos e do rio Guaratinguetá. O oxigênio dissolvido foi abundante em todos os pontos amostrados. E, assim como a condutividade, a temperatura da água também aumentou no sentido montante-jusante para ambas as microbacias.

Dentre as variáveis físicas e químicas da água, apenas o $\mathrm{pH}$ diferiu entre as microbacias $(\mathrm{p}<0,05)($ Tabela 6$)$.

Tabela 6: Resultados do teste de Mann-Whitney para as variáveis físicas e químicas da água $U$ = valor do teste.

\begin{tabular}{ccc}
\hline Variáveis & $\mathbf{U}$ & $\mathbf{p}$ \\
\hline $\mathrm{pH}$ & 0,00 & $\mathrm{p}=0,04$ \\
Condutividade elétrica & 1,00 & $\mathrm{p}=0,12$ \\
Oxigênio dissolvido & 5,00 & $\mathrm{p}=0,82$ \\
Temperatura da água & 8,00 & $\mathrm{p}=0,12$ \\
\hline
\end{tabular}



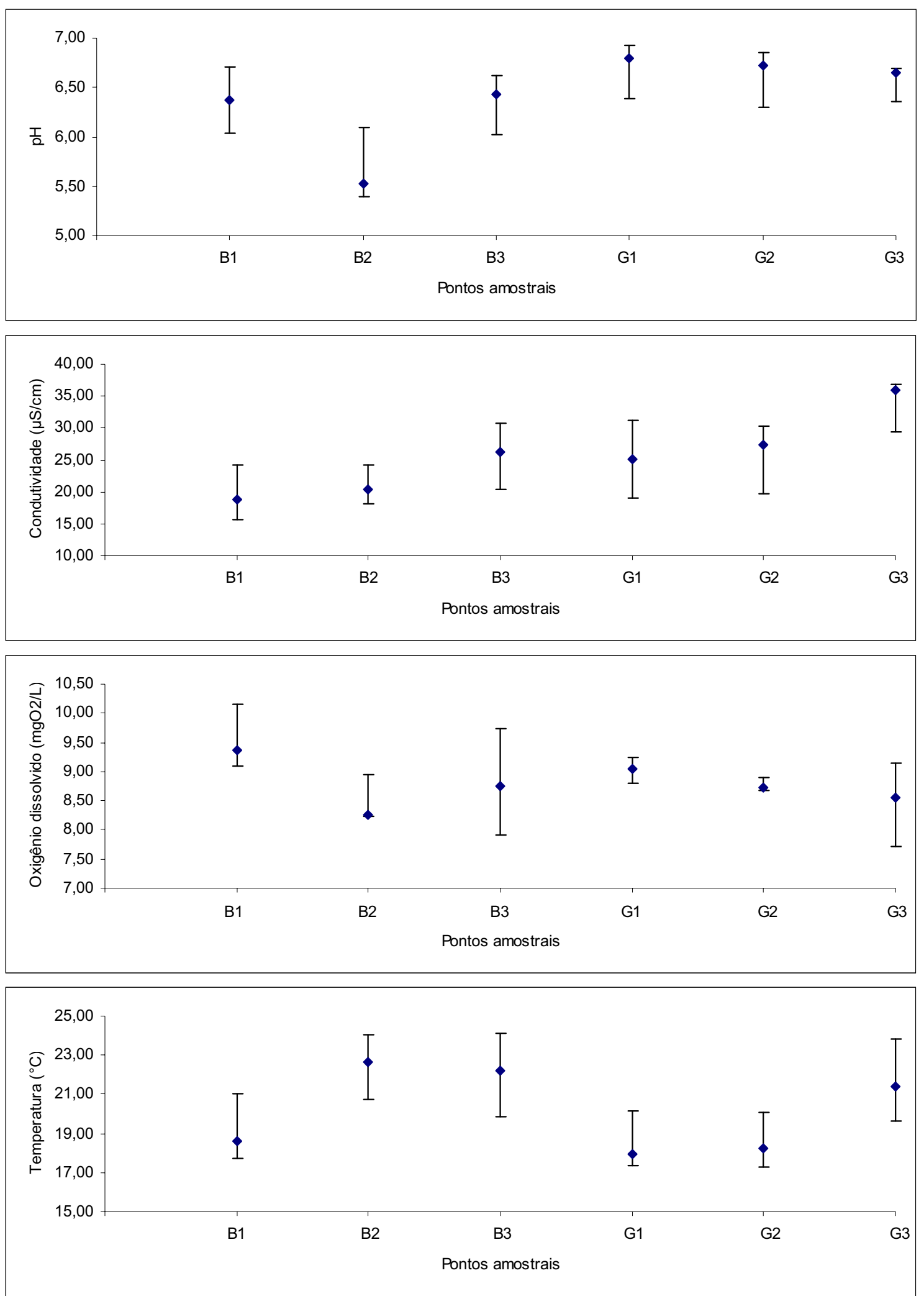

Figura 11: Valores medianos de $\mathrm{pH}$, condutividade elétrica, oxigênio dissolvido e temperatura da água para os pontos amostrais nas microbacias do ribeirão dos Buenos (B1, B2 e B3) e do rio Guaratinguetá (G1, G2 e G3). 


\subsection{Ictiofauna}

Foram capturados 2805 indivíduos, pertencentes à 34 espécies, 13 famílias e 7 ordens (Tabela 7 e Quadro 1). Na microbacia do ribeirão dos Buenos, ocorreram 27 espécies, das quais 4 foram exclusivas e na microbacia do rio Guaratinguetá, 30 espécies foram amostradas, sendo 7 delas exclusivas de seus riachos.

Tabela 7: Distribuição numérica das espécies de peixes nas microbacias do ribeirão dos Buenos (B1, B2 e B3 $=$ pontos temporais; $\mathrm{b} 1, \mathrm{~b} 2, \mathrm{~b} 3, \mathrm{~b} 4$ e b5 = pontos espaciais) e do rio Guaratinguetá (G1, G2 e G3 = pontos temporais; g1, g2, g3 e g4 = pontos espaciais).

\begin{tabular}{|c|c|c|c|c|c|c|c|c|c|c|c|c|c|c|c|c|}
\hline Espécie/Ponto amostral & B1 & B2 & B3 & b1 & b2 & b3 & b4 & b5 & G1 & G2 & G3 & g1 & g2 & g3 & g4 & Total \\
\hline Trichomycterus itatiayae & 256 & 0 & 0 & 18 & 21 & 15 & 0 & 1 & 407 & 482 & 0 & 46 & 63 & 19 & 1 & 1329 \\
\hline Phalloceros caudimaculatus & 18 & 0 & 0 & 0 & 0 & 10 & 0 & 252 & 3 & 0 & 0 & 0 & 0 & 0 & 0 & 283 \\
\hline Characidium lauroi & 143 & 0 & 0 & 3 & 8 & 0 & 0 & 3 & 5 & 55 & 0 & 0 & 0 & 0 & 0 & 217 \\
\hline Neoplecostomus microps & 59 & 0 & 0 & 3 & 7 & 9 & 13 & 15 & 45 & 15 & 0 & 0 & 8 & 0 & 2 & 176 \\
\hline Characidium alipioi & 101 & 32 & 1 & 0 & 0 & 1 & 10 & 0 & 4 & 2 & 0 & 0 & 0 & 0 & 6 & 157 \\
\hline Astyanax bimaculatus & 0 & 19 & 29 & 0 & 0 & 0 & 2 & 29 & 0 & 0 & 54 & 0 & 0 & 0 & 11 & 144 \\
\hline Trichomycterus iheringi & 1 & 13 & 0 & 0 & 0 & 11 & 16 & 0 & 0 & 18 & 0 & 0 & 0 & 0 & 24 & 83 \\
\hline Harttia carvalhoi & 13 & 0 & 0 & 0 & 0 & 0 & 0 & 0 & 20 & 49 & 0 & 0 & 0 & 0 & 0 & 82 \\
\hline Pareiorhina rudolphi & 1 & 0 & 0 & 0 & 0 & 1 & 0 & 0 & 31 & 6 & 0 & 0 & 23 & 0 & 0 & 62 \\
\hline Pareiorhina brachyrhyncha & 6 & 0 & 0 & 0 & 0 & 4 & 0 & 0 & 33 & 11 & 0 & 0 & 6 & 0 & 0 & 60 \\
\hline Rineloricaria kronei & 0 & 13 & 0 & 0 & 0 & 0 & 2 & 0 & 0 & 0 & 5 & 0 & 0 & 0 & 17 & 37 \\
\hline Ancistrus stigmaticus & 0 & 2 & 0 & 0 & 0 & 0 & 0 & 0 & 0 & 0 & 1 & 0 & 0 & 0 & 31 & 34 \\
\hline Astyanax fasciatus & 0 & 2 & 17 & 0 & 0 & 0 & 0 & 0 & 0 & 0 & 11 & 0 & 0 & 0 & 1 & 31 \\
\hline Astyanax intermedius & 0 & 0 & 0 & 0 & 0 & 0 & 5 & 0 & 14 & 1 & 0 & 0 & 0 & 0 & 0 & 20 \\
\hline Oligosarcus hepsetus & 0 & 2 & 8 & 0 & 0 & 0 & 0 & 0 & 0 & 0 & 3 & 0 & 0 & 0 & 2 & 15 \\
\hline Hypostomus luetkeni & 0 & 0 & 1 & 0 & 0 & 0 & 0 & 0 & 0 & 0 & 11 & 0 & 0 & 0 & 0 & 12 \\
\hline Gymnotus pantherinus & 3 & 4 & 0 & 0 & 0 & 0 & 3 & 0 & 0 & 0 & 0 & 0 & 0 & 0 & 0 & 10 \\
\hline Rhamdia sp. & 0 & 0 & 2 & 0 & 0 & 0 & 0 & 0 & 0 & 0 & 3 & 0 & 0 & 0 & 2 & 7 \\
\hline Pimelodella sp. & 0 & 3 & 0 & 0 & 0 & 0 & 0 & 0 & 0 & 0 & 2 & 0 & 0 & 0 & 0 & 5 \\
\hline Geophagus brasiliensis & 0 & 0 & 0 & 0 & 0 & 0 & 0 & 1 & 0 & 0 & 2 & 0 & 0 & 0 & 2 & 5 \\
\hline Gymnotus carapo & 0 & 1 & 0 & 0 & 0 & 0 & 0 & 0 & 0 & 0 & 1 & 0 & 0 & 0 & 3 & 5 \\
\hline Crenicichla lacustris & 0 & 0 & 0 & 0 & 0 & 0 & 0 & 0 & 0 & 0 & 6 & 0 & 0 & 0 & 0 & 6 \\
\hline Hypostomus sp.1 & 0 & 0 & 0 & 0 & 0 & 0 & 0 & 0 & 0 & 0 & 0 & 0 & 0 & 0 & 4 & 4 \\
\hline Hypostomus sp.2 & 0 & 0 & 3 & 0 & 0 & 0 & 0 & 0 & 0 & 0 & 1 & 0 & 0 & 0 & 0 & 4 \\
\hline Synbranchus marmoratus & 0 & 2 & 0 & 0 & 0 & 0 & 0 & 0 & 0 & 0 & 0 & 0 & 0 & 0 & 1 & 3 \\
\hline Hoplerythrinus unitaeniatus & 0 & 0 & 1 & 0 & 0 & 0 & 0 & 0 & 0 & 0 & 1 & 0 & 0 & 0 & 0 & 2 \\
\hline Hisonotus notatus & 0 & 0 & 2 & 0 & 0 & 0 & 0 & 0 & 0 & 0 & 0 & 0 & 0 & 0 & 0 & 2 \\
\hline Hoplosternun littorale & 0 & 0 & 0 & 0 & 0 & 0 & 0 & 0 & 0 & 0 & 1 & 0 & 0 & 0 & 1 & 2 \\
\hline Taunayia bifasciata & 0 & 0 & 0 & 0 & 0 & 0 & 0 & 0 & 0 & 2 & 0 & 0 & 0 & 0 & 0 & 2 \\
\hline Pimelodus maculatus & 0 & 0 & 0 & 0 & 0 & 0 & 0 & 0 & 0 & 0 & 2 & 0 & 0 & 0 & 0 & 2 \\
\hline Pseudotocinclus parahybae & 0 & 1 & 0 & 0 & 0 & 0 & 0 & 0 & 0 & 0 & 0 & 0 & 0 & 0 & 0 & 1 \\
\hline Trichomycterus sp. & 0 & 0 & 0 & 0 & 0 & 1 & 0 & 0 & 0 & 0 & 0 & 0 & 0 & 0 & 0 & 1 \\
\hline Oncorhynchus mykiss & 0 & 0 & 0 & 0 & 0 & 0 & 0 & 0 & 0 & 1 & 0 & 0 & 0 & 0 & 0 & 1 \\
\hline Hypostomus sp.3 & 0 & 0 & 0 & 0 & 0 & 0 & 0 & 0 & 0 & 0 & 1 & 0 & 0 & 0 & 0 & 1 \\
\hline Total & 01 & 94 & 64 & 24 & 36 & 52 & 51 & 301 & 562 & 642 & 105 & 46 & 100 & 19 & 108 & 2805 \\
\hline
\end{tabular}


Quadro 1: Lista taxonômica das espécies capturadas nas microbacias do ribeirão dos Buenos e rio Guaratinguetá na serra da Mantiqueira oriental, baseado em Reis et al. (2003) modificado.

Superordem Ostariophisy

Ordem Characiformes

Família Crenuchidae

Characidium alipioi Travassos, 1955

Characidium lauroi Travassos, 1949

Genera Incertae Sedis

Astyanax bimaculatus (Linnaeus, 1758)

Astyanax fasciatus (Cuvier, 1819)

Astyanax intermedius Eigenmann, 1908

Oligosarcus hepsetus (Cuvier, 1829)

Família Erythrinidae

Hoplerythrinus unitaeniatus (Agassiz, 1829)

Ordem Siluriformes

Família Trichomycteridae

Trichomycterus iheringi (Eigenmann, 1917)

Trichomycterus itatiayae Miranda Ribeiro, 1906

Trichomycterus sp.

Família Callichthyidae

Hoplosternun littorale (Hancock, 1828)

Família Loricariidae

Subfamília Neoplecostominae

Neoplecostomus microps (Steindachner, 1877)

Subfamília Hypoptopomatinae

Hisonotus notatus Eigenmann \& Eigenmann, 1889

Pseudotocinclus parahybae Takako, Oliveira \& Oyakawa, 2005

Subfamília Loricariinae

Harttia carvalhoi Miranda Ribeiro, 1939

Rineloricaria kronei (Miranda-Ribeiro, 1911)

Subfamília Hypostominae

Hypostomus luetkeni (Steindachner, 1877)

Hypostomus sp.1

Hypostomus $\mathrm{sp} .2$

Hypostomus sp.3

Pareiohina rudolphi (Miranda Ribeiro, 1911)

Pareiohina brachyrhyncha Chamon, Aranda \& Buckup, 2005

Subfamília Ancistrinae

Ancistrus stigmaticus Eigenmann \& Eigenmann, 1889

Família Heptapteridae

Pimelodella $\mathrm{sp}$.

Rhamdia sp.

Taunayia bifasciata (Eigenmann \& Norris, 1900)

Família Pimelodidae

Pimelodus maculatus Lacepède, 1803
Ordem Gymnotiformes

Família Gymnotidae

Gymnotus carapo Linnaeus, 1758

Gymnotus pantherinus (Steindachner, 1908)

Ordem Cyprinodontoformes

Família Poeciliidae

Phalloceros caudimaculatus (Hensel, 1868)

Ordem Synbranchiformes

Família Synbranchidae

Synbranchus marmoratus Bloch, 1795

Ordem Perciformes

Família Cichlidae

Crenicichla lacustris (Castelnau, 1855)

Geophagus brasiliensis (Quoy \& Gaimard, 1824)

Ordem Salmoniformes

Família Salmonidae

Oncorhynchus mykiss (Walbaum, 1792) 


\section{Riqueza}

O estimador bootstrap de riqueza para a microbacia do ribeirão dos Buenos foi de 28,6 e para o rio Guaratinguetá 33,6. Esses valores foram bem próximos ao número de espécies coletado em cada microbacia.

A Figura 12 apresenta as curvas de rarefação para cada microbacia estudada. As duas curvas encontram-se bem próximas à assíntota, indicando que o ambiente foi bem amostrado.

A
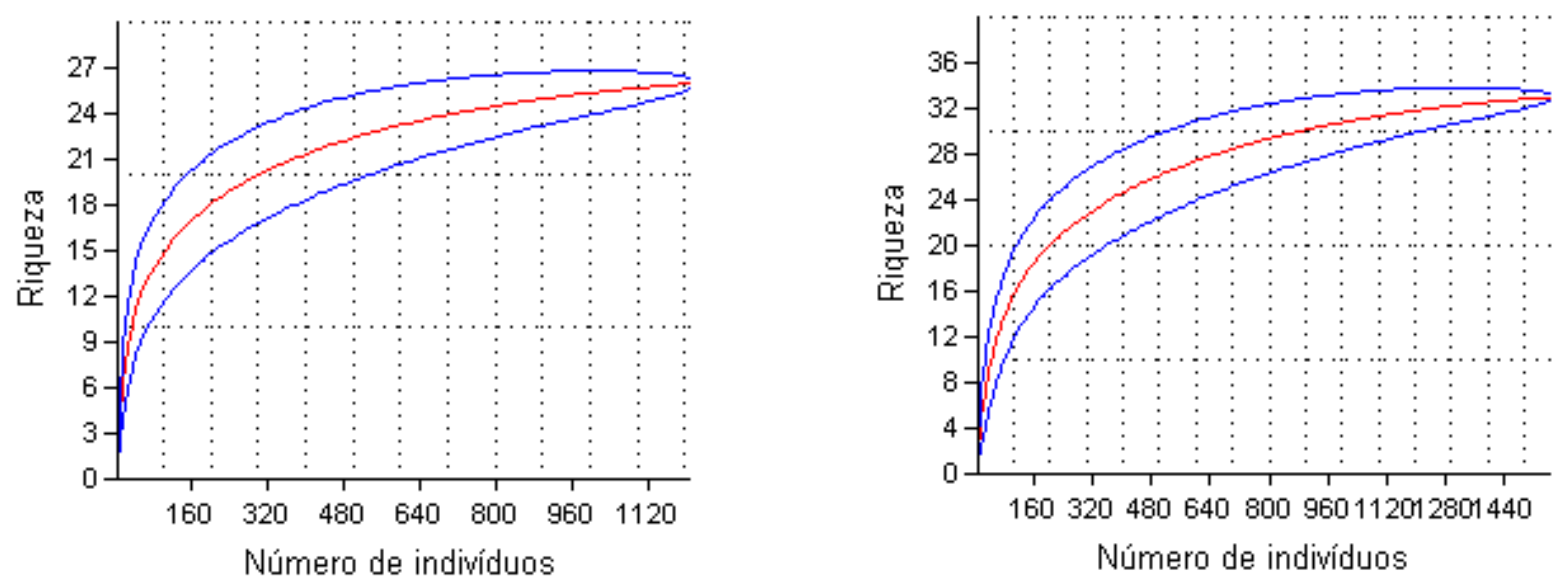

Figura 12: Curvas de rarefação (em vermelho) e os respectivos intervalos de confiança (em azul) para as microbacias do ribeirão dos Buenos (A) e do rio Guaratinguetá (B). 


\section{Similaridade}

Pelo dendrograma observou-se a formação de dois grandes grupos: o primeiro com os pontos localizados mais próximos à encosta e no pediplano (g1, g3, b3, G1, B1, G2, g2, b1, b2 e b5) e o outro com os pontos mais baixos, localizados no pediplano e no vale (b4, B2, g4, B3 e G3) (Figura 13).

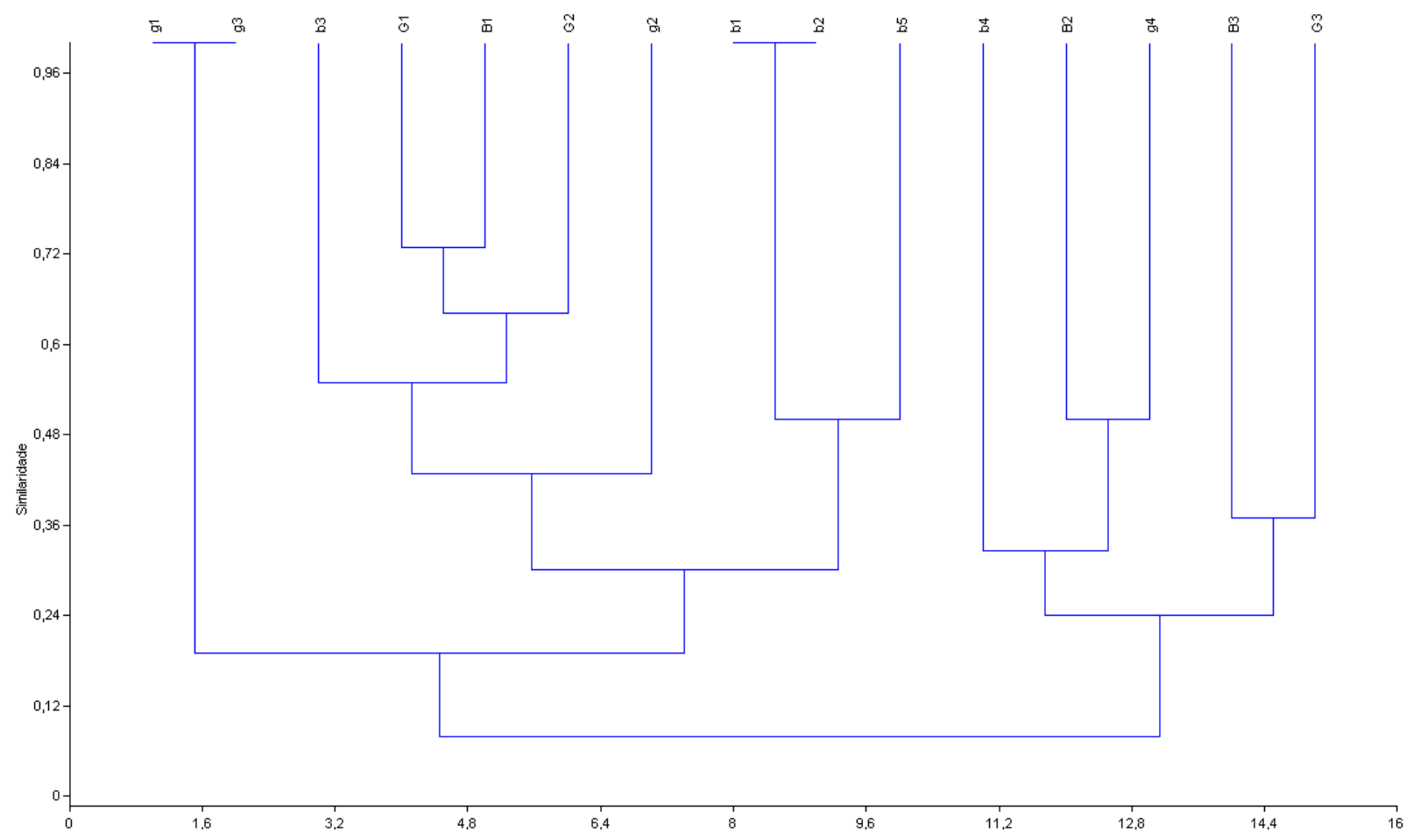

Figura 13: Dendrograma com as relações de similaridade entre os pontos amostrais das microbacias do ribeirão dos Buenos (B1, B2, B3, b1, b2, b3, b4 e b5) e do rio Guaratinguetá (G1, G2, G3, g1, g2, g3 e g4). 


\section{Diversidade}

Os valores dos índices de diversidade de Shannon (H'), riqueza de Margalef (MG) e equabilidade de Pielou (J) para cada um dos pontos amostrais encontram-se nas Tabelas 8 e 9.

Considerando apenas os pontos amostrados temporalmente, na microbacia do ribeirão dos Buenos, B1 foi o ponto que apresentou o maior valor para o índice de diversidade de Shannon, B2 para o índice de riqueza de Margalef e B3 para o índice de equitabilidade de Pielou. Na microbacia do rio Guaratinguetá, o ponto G3 foi aquele que apresentou os maiores valores para os três índices calculados.

Com relação aos pontos amostrados espacialmente, b3 na microbacia do ribeirão dos Buenos e g4 na microbacia do rio Guaratinguetá foram os pontos com os maiores valores dos índices de diversidade de Shannon, riqueza de Margalef e equitabilidade de Pielou.

Tabela 8: Valores do índice de diversidade de Shannon (H'), índice de riqueza de Margalef (MG), índice de equabilidade de Pielou (J) e os respectivos desvios padrão ( ) para cada um dos pontos temporais.

\begin{tabular}{cccc}
\hline Pontos & H' & MG & J \\
\hline B1 & $1,413(0,185)$ & $1,292(0,320)$ & $0,709(0,017)$ \\
B2 & $1,358(0,360)$ & $1,506(0,280)$ & $0,836(0,145)$ \\
B3 & $1,067(0,306)$ & $1,035(0,599)$ & $0,883(0,092)$ \\
G1 & $1,029(0,135)$ & $1,272(0,086)$ & $0,519(0,059)$ \\
G2 & $0,875(0,173)$ & $1,290(0,240)$ & $0,437(0,085)$ \\
G3 & $1,518(0,502)$ & $2,095(0,987)$ & $0,801(0,191)$ \\
\hline
\end{tabular}

Tabela 9: Valores do índice de diversidade de Shannon (H'), índice de riqueza de Margalef (MG), índice de equabilidade de Pielou (J) e os respectivos intervalos de confiança a 95\% (IC) para cada um dos pontos espaciais (os pontos g1 e g3 não aparecem devido a ocorrência de uma única espécie).

\begin{tabular}{ccccccc}
\hline Pontos & H' & IC & MG & IC & J & IC \\
\hline b1 & 0,736 & $(0,345-0,960)$ & 0,629 & $(0,315-0,629)$ & 0,670 & $(0,414-0,881)$ \\
b2 & 0,967 & $(0,734-1,078)$ & 0,558 & $(0,588-0,588)$ & 0,880 & $(0,666-0,976)$ \\
b3 & 1,733 & $(1,475-1,840)$ & 1,109 & $(0,693-1,109)$ & 1,772 & $(1,012-1,772)$ \\
b4 & 1,680 & $(1,413-1,786)$ & 0,980 & $(0,840-0,980)$ & 1,526 & $(1,272-1,526)$ \\
b5 & 0,608 & $(0,483-0,711)$ & 0,346 & $(0,231-0,346)$ & 0,876 & $(0,526-0,876)$ \\
g2 & 1,000 & $(0,808-1,130)$ & 0,400 & $(0,400-0,400)$ & 0,651 & $(0,651-0,651)$ \\
g4 & 2,067 & $(1,782-2,173)$ & 1,443 & $(1,058-1,443)$ & 2,990 & $(2,136-2,990)$ \\
\hline
\end{tabular}


Interações significativas entre ambientes e microbacias foram encontradas para os índices de diversidade de Shannon e riqueza de Margalef (Tabelas 10 e 11). Com isso, temse que pelo menos um ambiente dentro de uma microbacia apresentou diferença quanto aos índices de diversidade e riqueza. Os maiores valores desses dois índices foram encontrados para o ambiente de vale. Em relação à microbacia, os valores do índice de diversidade foram bem semelhantes, já o índice de riqueza apresentou maior valor para a microbacia do rio Guaratinguetá (Figuras 14 e 15). O índice de equitabilidade apresentou diferenças significativas entre ambientes e entre microbacias (Tabela 12). Os maiores valores do índice foram encontrados no ambiente de vale e na micorbacia do ribeirão dos Buenos (Figura 16). Para os três índices considerados, um gradiente crescente desses valores foi observado da encosta em direção ao vale.

Tabela 10: Análise de variância para o índice de diversidade de Shannon (H'), considerando ambiente (encosta, pediplano e vale), microbacia (Buenos e Guaratinguetá) e época (seca e cheia) $(\mathrm{FV}=$ fonte de variação; $\mathrm{SQ}=$ soma de quadrados; $\mathrm{gl}=$ graus de liberdade; $\mathrm{QM}=$ quadrado médio; $\mathrm{F}=$ teste $\mathrm{F})(\mathrm{n}=31$; $\left.\mathrm{R}^{2}=0,457\right)$.

\begin{tabular}{rcccrr}
\hline FV & SQ & gl & QM & F & P \\
\hline Ambiente & 0,398 & 2 & 0,199 & 1,425 & 0,265 \\
Microbacia & 0,006 & 1 & 0,006 & 0,046 & 0,833 \\
Época & 0,171 & 1 & 0,171 & 1,224 & 0,282 \\
Ambiente*Microbacia & 1,269 & 2 & 0,634 & 4,544 & $\mathbf{0 , 0 2 4}$ \\
Ambiente*Época & 0,082 & 2 & 0,041 & 0,295 & 0,748 \\
Microbacia*Época & 0,186 & 1 & 0,186 & 1,329 & 0,263 \\
Ambiente*Microbacia*Época & 0,019 & 2 & 0,009 & 0,067 & 0,935 \\
Resíduo & 2,652 & 19 & 0,140 & & \\
\hline
\end{tabular}


Tabela 11: Análise de variância para o índice de riqueza de Margalef (MG), considerando ambiente (encosta, pediplano e vale), microbacia (Buenos e Guaratinguetá) e época (seca e cheia) (FV = fonte de variação; $S Q=$ soma de quadrados; $\mathrm{gl}=$ graus de liberdade; $\mathrm{QM}=$ quadrado médio; $\mathrm{F}=$ teste $\mathrm{F})\left(\mathrm{n}=31 ; \mathrm{R}^{2}=0,561\right)$.

\begin{tabular}{rrccrr}
\hline FV & SQ & gl & QM & F & P \\
\hline Ambiente & 1,412 & 2 & 0,706 & 2,500 & 0,109 \\
Microbacia & 1,127 & 1 & 1,127 & 3,991 & 0,060 \\
Época & 0,033 & 1 & 0,033 & 0,117 & 0,737 \\
Ambiente*Microbacia & 2,908 & 2 & 1,454 & 5,149 & $\mathbf{0 , 0 1 6}$ \\
Ambiente*Época & 0,276 & 2 & 0,138 & 0,489 & 0,621 \\
Microbacia*Época & 0,961 & 1 & 0,961 & 3,403 & 0,081 \\
Ambiente*Microbacia*Época & 0,129 & 2 & 0,064 & 0,228 & 0,798 \\
Resíduo & 5,365 & 19 & 0,282 & & \\
\hline
\end{tabular}

Tabela 12: Análise de variância para o índice de equitabilidade de Pielou (J), considerando ambiente (encosta, pediplano e vale), microbacia (Buenos e Guaratinguetá) e época (seca e cheia) (FV = fonte de variação; $S Q=$ soma de quadrados; $\mathrm{gl}=$ graus de liberdade; $\mathrm{QM}=$ quadrado médio; $\mathrm{F}=$ teste $\mathrm{F})\left(\mathrm{n}=31 ; \mathrm{R}^{2}=0,581\right)$.

\begin{tabular}{rrrrrr}
\hline FV & SQ & gl & QM & F & $\mathbf{P}$ \\
\hline Ambiente & 0,282 & 2 & 0,141 & 5,833 & $\mathbf{0 , 0 1 1}$ \\
Microbacia & 0,291 & 1 & 0,291 & 12,032 & $\mathbf{0 , 0 0 3}$ \\
Época & 0,002 & 1 & 0,002 & 0,096 & 0,760 \\
Ambiente*Microbacia & 0,066 & 2 & 0,033 & 1,356 & 0,281 \\
Ambiente*Época & 0,010 & 2 & 0,005 & 0,199 & 0,822 \\
Microbacia*Época & 0,033 & 1 & 0,033 & 1,355 & 0,259 \\
Ambiente*Microbacia*Época & 0,006 & 2 & 0,003 & 0,123 & 0,885 \\
Resíduo & 0,460 & 19 & 0,024 & & \\
\hline
\end{tabular}



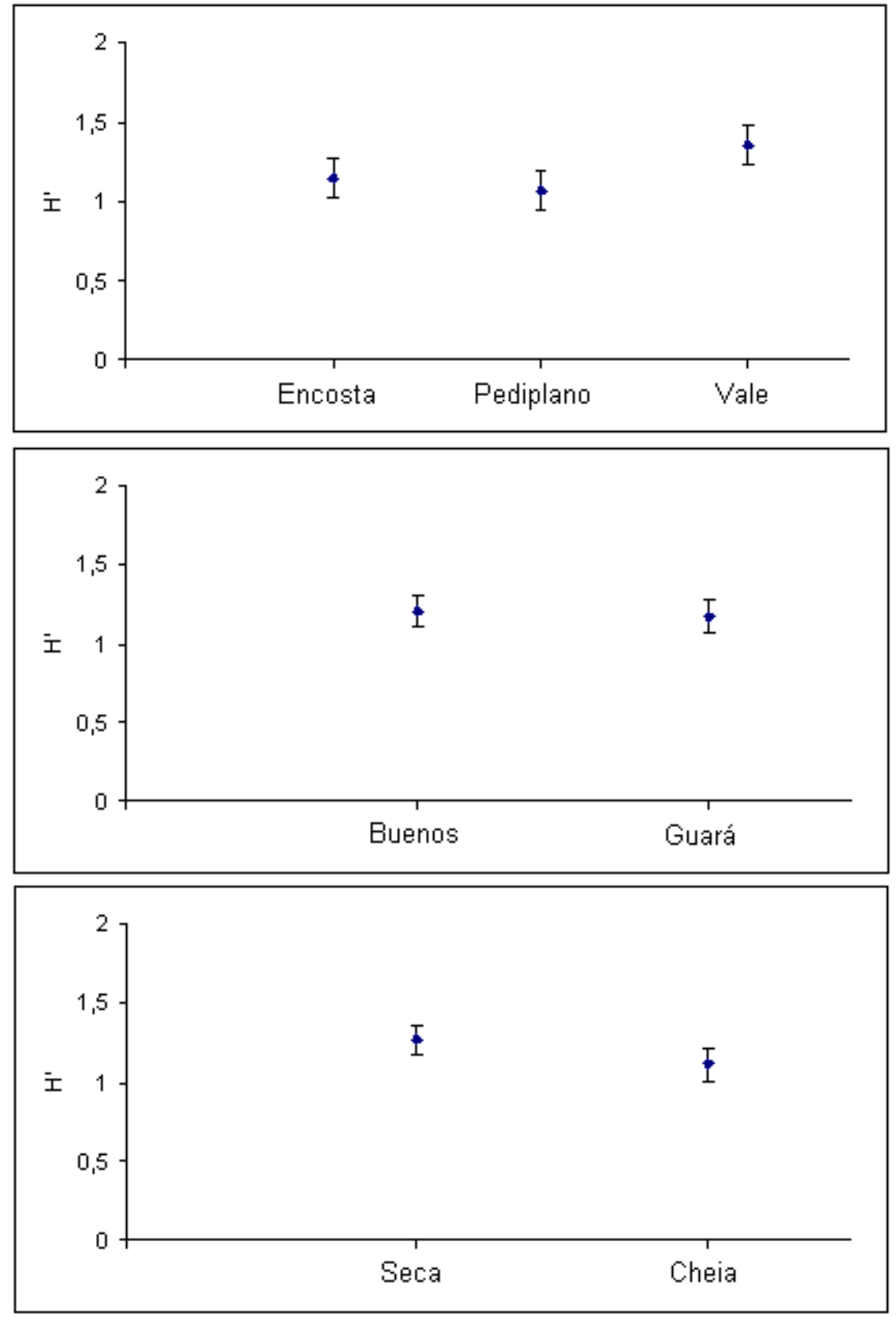

Figura 14: Valores médios e desvios padrão para o índice de diversidade de Shannon (H') por ambiente (Encosta, Pediplano e Vale), por microbacia (Buenos e Guaratinguetá) e época (Seca e Cheia). 

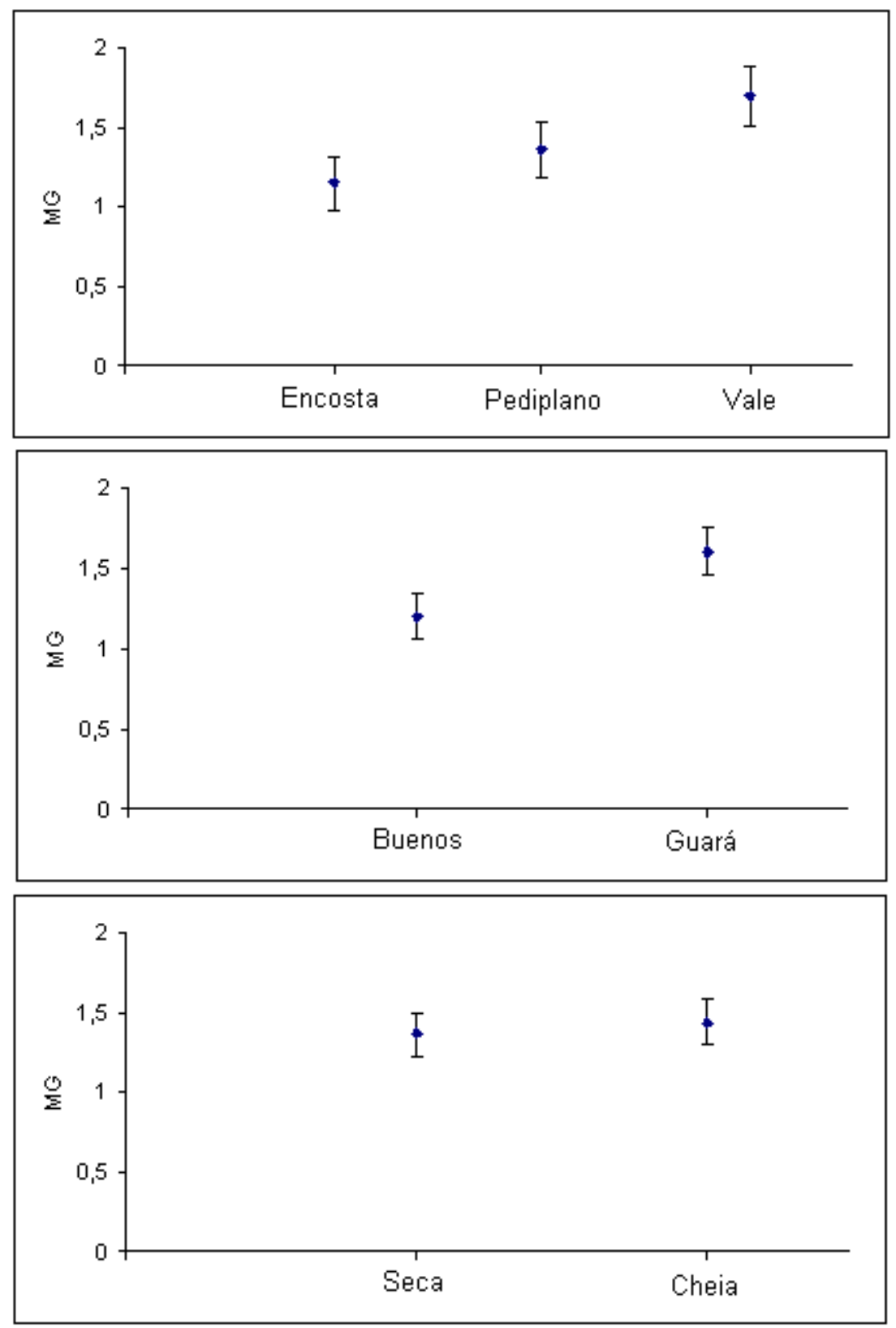

Figura 15: Valores médios e desvios padrão para o índice de riqueza de Margalef (MG) por ambiente (Encosta, Pediplano e Vale), por microbacia (Buenos e Guaratinguetá) e época (Seca e Cheia). 

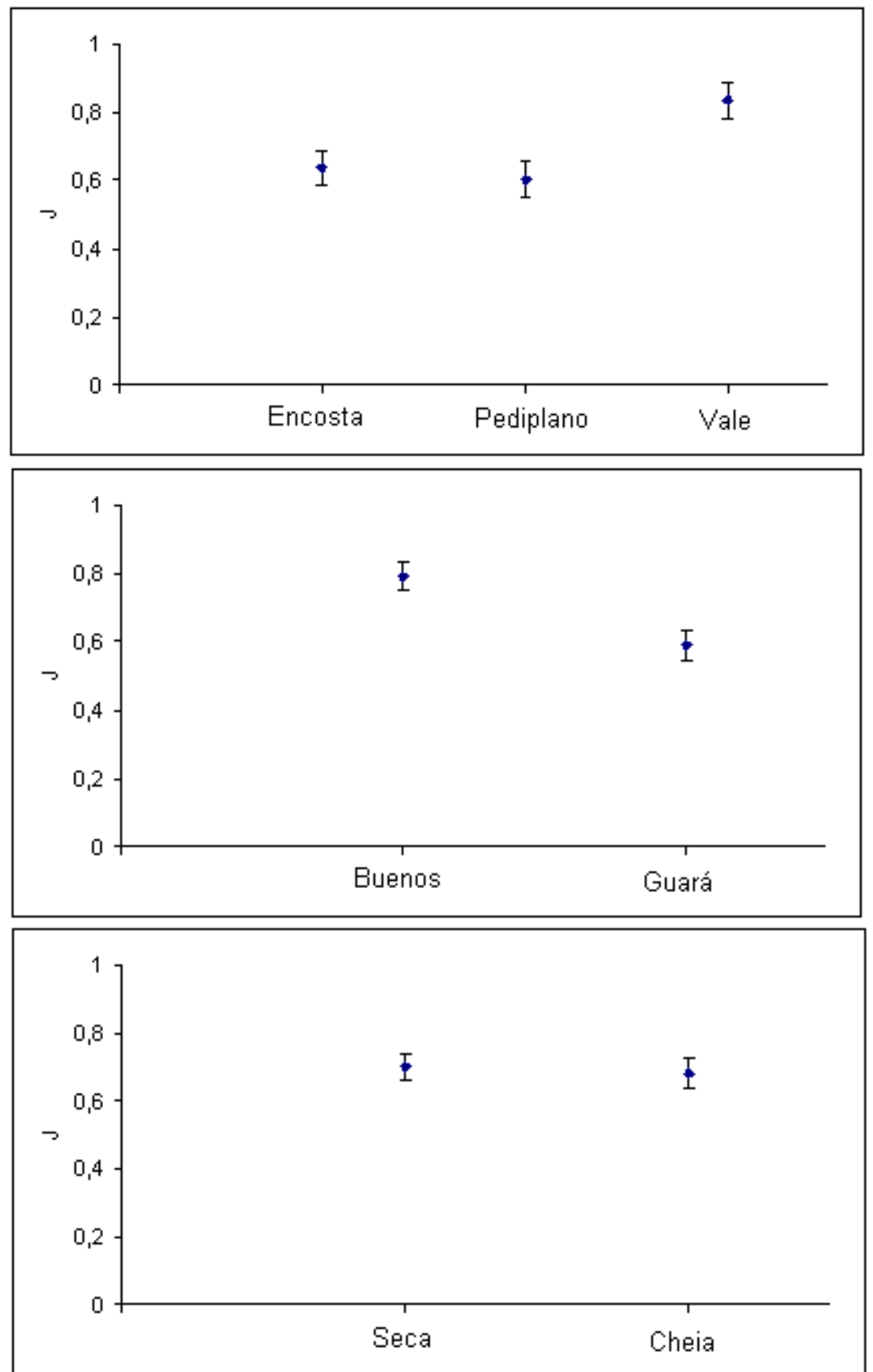

Figura 16: Valores médios e desvios padrão para o índice de equitabilidade de Pielou (J) por ambiente (Encosta, Pediplano e Vale), por microbacia (Buenos e Guaratinguetá) e época (Seca e Cheia). 


\section{Constância}

A Tabela 13 apresenta a relação das espécies capturadas nos pontos amostrados temporalmente (B1, B2, B3, G1, G2 e G3), nas microbacias (ribeirão dos Buenos e rio Guaratinguetá) e nos ambientes de encosta, pediplano e vale e sua classificação baseada na persistência das espécies nas coletas: constante (C), acessória (A) e ocasional (O).

$\mathrm{Na}$ microbacia do ribeirão dos Buenos, dez espécies foram constantes em pelo menos um dos pontos amostrados temporalmente: Trichomycterus itatiayae, Phalloceros caudimaculatus, Characidium lauroi, Neoplecostomus microps, Characidium alipioi, Astyanax bimaculatus, Trichomycterus iheringi, Pareiorhina brachyrhyncha, Astyanax fasciatus e Gymnotus pantherinus. Characidium alipioi foi a única espécie presente nos três pontos, sendo constante em B1 e B2 e ocasional em B3.

Na microbacia do rio Guaratinguetá, treze espécies foram constantes em pelo menos um dos pontos amostrados temporalmente: Trichomycterus itatiayae, Characidium lauroi, Neoplecostomus microps, Astyanax bimaculatus, Trichomycterus iheringi, Harttia carvalhoi, Pareiorhina rudolphi, Pareiorhina brachyrhyncha, Rineloricaria kronei, Astyanax fasciatus, Astyanax intermedius, Hypostomus luetkeni e Crenicichla lacustris. Nenhuma espécie ocorreu simultaneamente nos três pontos considerados.

Considerando as microbacias, Neoplecostomus microps, Characidium alipioi e Astyanax bimaculatus foram as espécies constantes na microbacia do ribeirão dos Buenos, e Trichomycterus itatiayae e Neoplecostomus microps as espécies constantes na microbacia do rio Guaratinguetá.

Em relação aos ambientes, Trichomycterus itatiayae e Neoplecostomus microps foram constantes na encosta e no pediplano, Characidium lauroi e Pareiorhina brachyrhyncha foram constantes na encosta, Characidium alipioi e Trichomycterus iheringi foram constantes no pediplano, e Astyanax fasciatus e Oligosarcus hepsetus foram constantes no vale. 
Tabela 13: Relação das espécies capturadas nos pontos amostrados temporalmente (B1, B2, B3, G1, G2 e G3), nas microbacias (ribeirão dos Buenos e rio Guaratinguetá) e nos ambientes de encosta, pediplano e vale e sua classificação baseada na persistência das espécies nas coletas: constante (C), acessória (A) e ocasional $(\mathrm{O})$.

\begin{tabular}{|c|c|c|c|c|c|c|c|c|c|c|c|}
\hline & B1 & B2 & B3 & G1 & G2 & G3 & Buenos & Guará & Encosta & Pediplano & Vale \\
\hline Trichomycterus itatiayae & $\mathrm{C}$ & & & $\mathrm{C}$ & $\mathrm{C}$ & & $\mathrm{A}$ & $\mathrm{C}$ & $\mathrm{C}$ & $\mathrm{C}$ & $\mathrm{O}$ \\
\hline Phalloceros caudimaculatus & $\mathrm{C}$ & & & A & & & A & $\mathrm{O}$ & A & $\mathrm{O}$ & \\
\hline Characidium lauroi & $\mathrm{C}$ & & & $\mathrm{C}$ & $\mathrm{C}$ & & A & A & $\mathrm{C}$ & A & \\
\hline Neoplecostomus microps & $\mathrm{C}$ & & & $\mathrm{C}$ & $\mathrm{C}$ & & $\mathrm{C}$ & $\mathrm{C}$ & $\mathrm{C}$ & $\mathrm{C}$ & $\mathrm{O}$ \\
\hline Characidium alipioi & $\mathrm{C}$ & $\mathrm{C}$ & $\mathrm{O}$ & $\mathrm{O}$ & A & & $\mathrm{C}$ & $\mathrm{O}$ & A & $\mathrm{C}$ & $\mathrm{O}$ \\
\hline Astyanax bimaculatus & & $\mathrm{C}$ & & & & $\mathrm{C}$ & $\mathrm{C}$ & A & & A & \\
\hline Trichomycterus iheringi & $\mathrm{O}$ & $\mathrm{C}$ & & & $\mathrm{C}$ & & A & A & $\mathrm{O}$ & $\mathrm{C}$ & $\mathrm{O}$ \\
\hline Harttia carvalhoi & A & & & $\mathrm{C}$ & $\mathrm{C}$ & & $\mathrm{O}$ & A & A & $\mathrm{A}$ & \\
\hline Pareiohina rudolphi & $\mathrm{O}$ & & & $\mathrm{C}$ & A & & $\mathrm{O}$ & A & A & A & \\
\hline Pareiohina brachyrhyncha & $\mathrm{C}$ & & & $\mathrm{C}$ & $\mathrm{C}$ & & $\mathrm{O}$ & A & $\mathrm{C}$ & A & \\
\hline Rineloricaria kronei & & A & & & & $\mathrm{C}$ & $\mathrm{O}$ & $\mathrm{O}$ & & A & A \\
\hline Ancistrus stigmaticus & & $\mathrm{O}$ & & & & $\mathrm{O}$ & $\mathrm{O}$ & $\mathrm{O}$ & & $\mathrm{O}$ & $\mathrm{O}$ \\
\hline Astyanax fasciatus & & $\mathrm{O}$ & $\mathrm{C}$ & & & $\mathrm{C}$ & $\mathrm{O}$ & $\mathrm{O}$ & & $\mathrm{O}$ & $\mathrm{C}$ \\
\hline Astyanax intermedius & & & & $\mathrm{C}$ & $\mathrm{O}$ & & $\mathrm{O}$ & $\mathrm{O}$ & A & $\mathrm{O}$ & \\
\hline Oligosarcus hepsetus & & $\mathrm{O}$ & A & & & A & $\mathrm{O}$ & $\mathrm{O}$ & & $\mathrm{O}$ & $\mathrm{C}$ \\
\hline Hypostomus luetkeni & & & $\mathrm{O}$ & & & $\mathrm{C}$ & $\mathrm{O}$ & $\mathrm{O}$ & & & A \\
\hline Gymnotus pantherinus & $\mathrm{C}$ & A & & & & & A & & A & A & \\
\hline Rhamdia sp. & & & $\mathrm{O}$ & & & $\mathrm{O}$ & $\mathrm{O}$ & $\mathrm{O}$ & & & A \\
\hline Pimelodella sp. & & $\mathrm{O}$ & & & & $\mathrm{O}$ & $\mathrm{O}$ & $\mathrm{O}$ & & $\mathrm{O}$ & $\mathrm{O}$ \\
\hline Geophagus brasiliensis & & & & & & A & $\mathrm{O}$ & $\mathrm{O}$ & & $\mathrm{O}$ & A \\
\hline Gymnotus carapo & & $\mathrm{O}$ & & & & $\mathrm{O}$ & $\mathrm{O}$ & $\mathrm{O}$ & & $\mathrm{O}$ & $\mathrm{O}$ \\
\hline Crenicichla lacustris & & & & & & $\mathrm{C}$ & & $\mathrm{O}$ & & & A \\
\hline Hypostomus sp.1 & & & & & & & & $\mathrm{O}$ & & & $\mathrm{O}$ \\
\hline Hypostomus sp.2 & & & $\mathrm{O}$ & & & $\mathrm{O}$ & $\mathrm{O}$ & $\mathrm{O}$ & & & $\mathrm{O}$ \\
\hline Synbranchus marmoratus & & $\mathrm{O}$ & & & & & $\mathrm{O}$ & $\mathrm{O}$ & & $\mathrm{O}$ & $\mathrm{O}$ \\
\hline Hoplerythrinus unitaeniatus & & & $\mathrm{O}$ & & & $\mathrm{O}$ & $\mathrm{O}$ & $\mathrm{O}$ & & & $\mathrm{O}$ \\
\hline Hisonotus notatus & & & $\mathrm{O}$ & & & & $\mathrm{O}$ & & & & $\mathrm{O}$ \\
\hline Hoplosternun littorale & & & & & & $\mathrm{O}$ & & $\mathrm{O}$ & & & $\mathrm{O}$ \\
\hline Taunayia bifasciata & & & & & A & & & $\mathrm{O}$ & & $\mathrm{O}$ & \\
\hline Pimelodus maculatus & & & & & & $\mathrm{O}$ & & $\mathrm{O}$ & & & $\mathrm{O}$ \\
\hline Pseudotocinclus parahybae & & $\mathrm{O}$ & & & & & $\mathrm{O}$ & & & $\mathrm{O}$ & \\
\hline Trichomycterus sp. & & & & & & & $\mathrm{O}$ & & & $\mathrm{O}$ & \\
\hline Oncorhynchus mykiss & & & & & $\mathrm{O}$ & & & $\mathrm{O}$ & & $\mathrm{O}$ & \\
\hline Hypostomus sp.3 & & & & & & $\mathrm{O}$ & & $\mathrm{O}$ & & & $\mathrm{O}$ \\
\hline
\end{tabular}

As freqüências de ocorrência das espécies constantes, acessórias e ocasionais para os pontos temporais amostrados nas microbacias do ribeirão dos Buenos e do rio Guaratinguetá, para as microbacias e para os ambientes de encosta, pediplano e vale estão apresentadas na Tabela 14. Para os pontos amostrais, B1, G1 e G2 apresentaram maiores freqüências de espécies constantes, e B2, B3 e G3 de espécies ocasionais. Para as microbacias, as maiores freqüências de ocorrência foram de espécies ocasionais. Considerando os diferentes ambientes, na encosta as maiores freqüências foram de espécies acessórias, seguidas das constantes, e no pediplano e no vale, de espécies ocasionais. 
Tabela 14: Freqüência de ocorrência das espécies constantes (C), acessórias (A) e ocasionais (O) para os pontos temporais amostrados nas microbacias do ribeirão dos Buenos e do rio Guaratinguetá, para as microbacias e para os ambientes de encosta, pediplano e vale.

\begin{tabular}{cccccccccccc} 
& B1 & B2 & B3 & G1 & G2 & G3 & Buenos & Guará & Encosta & Pediplano & Vale \\
\hline O & 0,20 & 0,58 & 0,75 & 0,11 & 0,18 & 0,53 & 0,70 & 0,74 & 0,09 & 0,54 & 0,70 \\
A & 0,10 & 0,17 & 0,13 & 0,11 & 0,27 & 0,18 & 0,19 & 0,19 & 0,55 & 0,29 & 0,22 \\
C & 0,70 & 0,25 & 0,13 & 0,78 & 0,55 & 0,29 & 0,11 & 0,06 & 0,36 & 0,17 & 0,09 \\
\hline
\end{tabular}

\section{Curvas ABC}

Na microbacia do ribeirão dos Buenos, a abundância foi superior à biomassa para os pontos B1 e B2, sendo que no ponto B1 uma pequena inversão dessa relação aconteceu para as espécies intermediárias e no ponto B2 essa relação ocorreu para um maior número de espécies. No ponto B3, a biomassa foi superior à abundância para as primeiras espécies, essa relação foi invertida para as espécies intermediárias, retornando à situação inicial para o restante das espécies (Figura 17).

Na microbacia do rio Guaratinguetá, a abundância foi superior à biomassa em todos os pontos: no ponto G1, essa relação aconteceu apenas para as primeiras espécies mais importantes, no ponto G2 essa relação se estendeu para um maior número de espécies e no ponto G3 essa relação aconteceu para todas as espécies consideradas (Figura 18). 

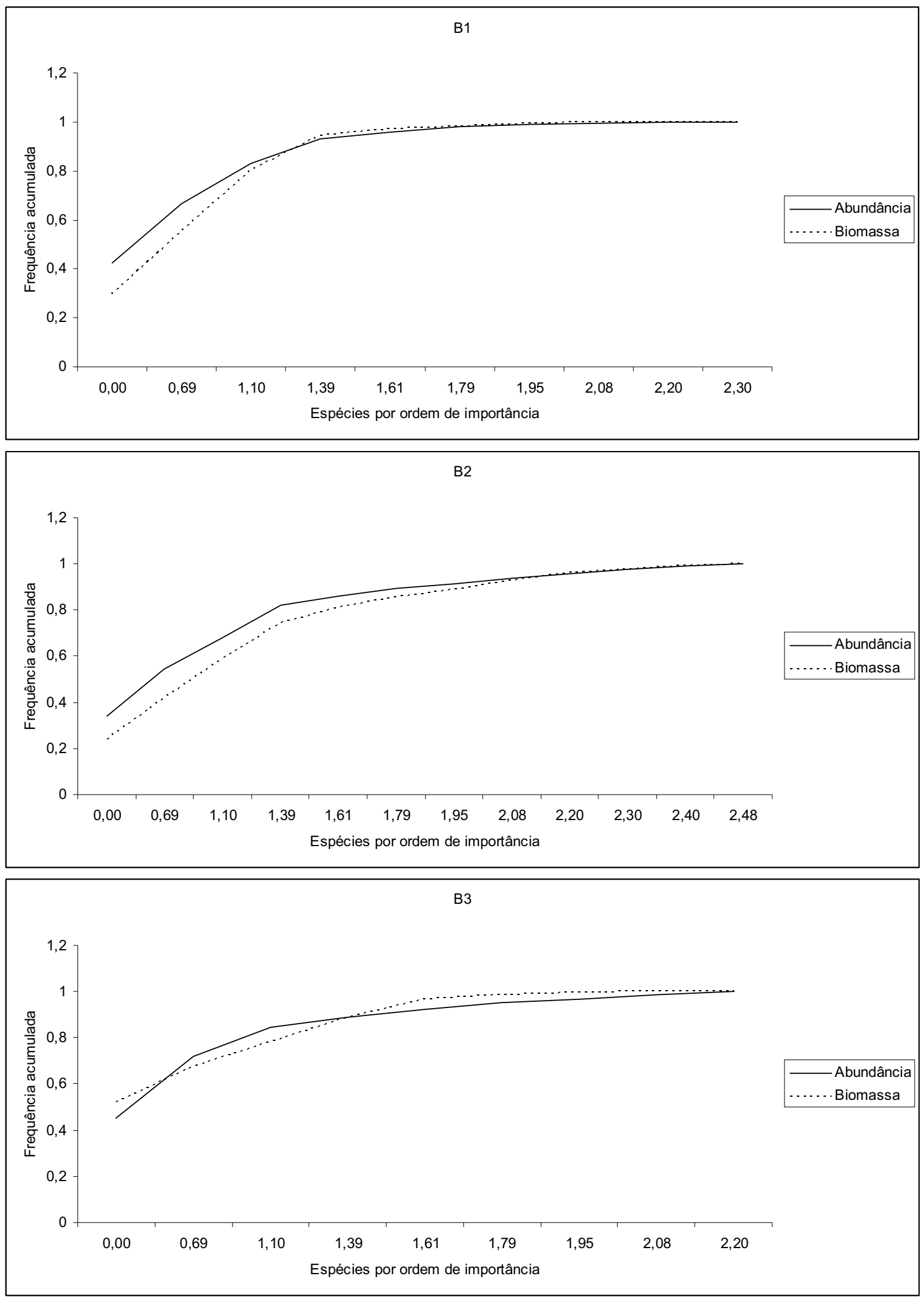

Figura 17: Representação das relações de abundância e biomassa das espécies capturadas nos pontos B1, B2 e B3 da microbacia do ribeirão dos Buenos. 
G1

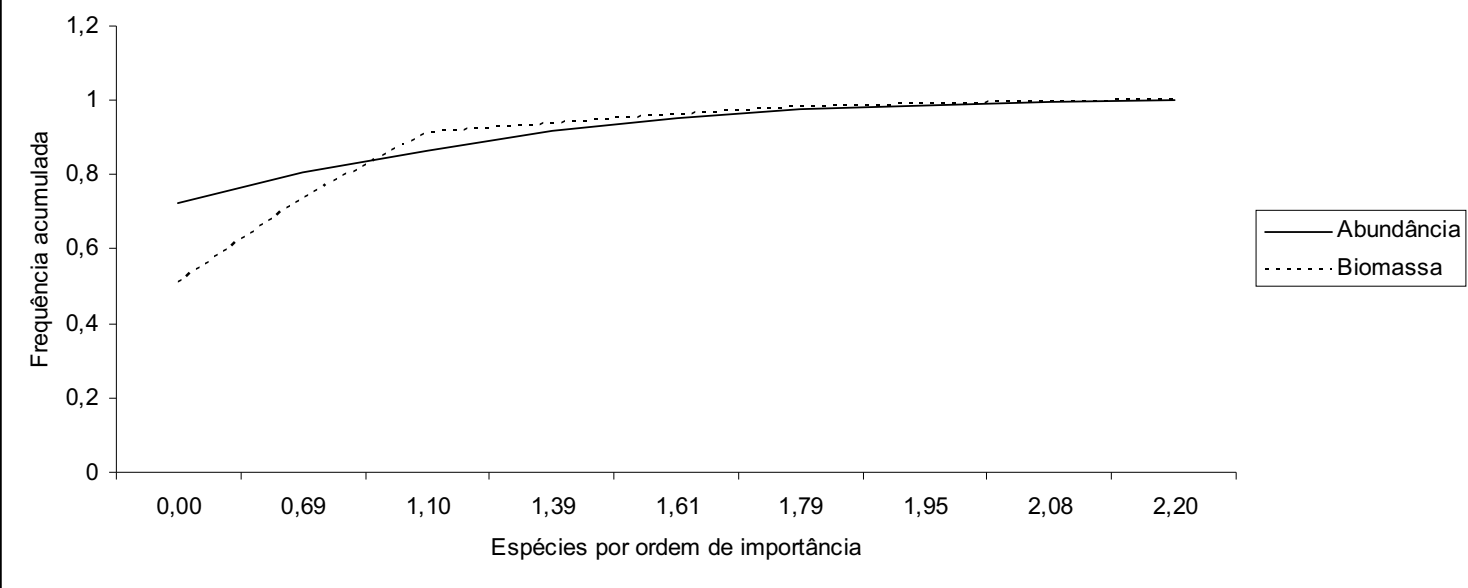

G2

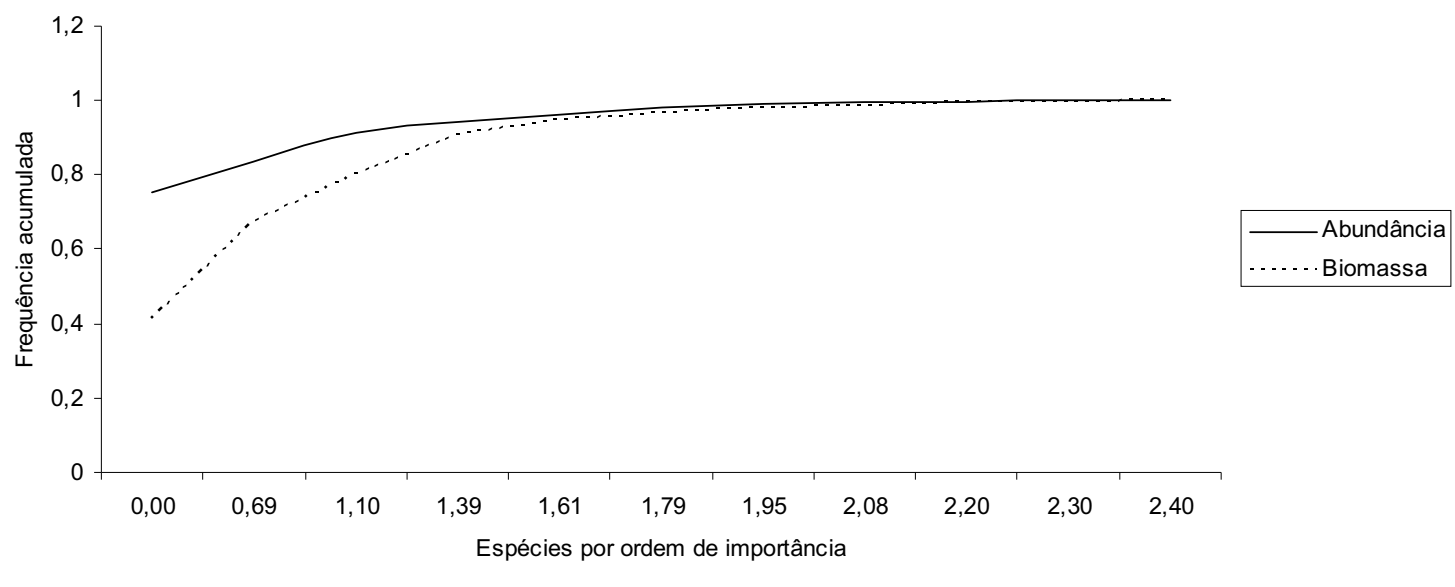

G3

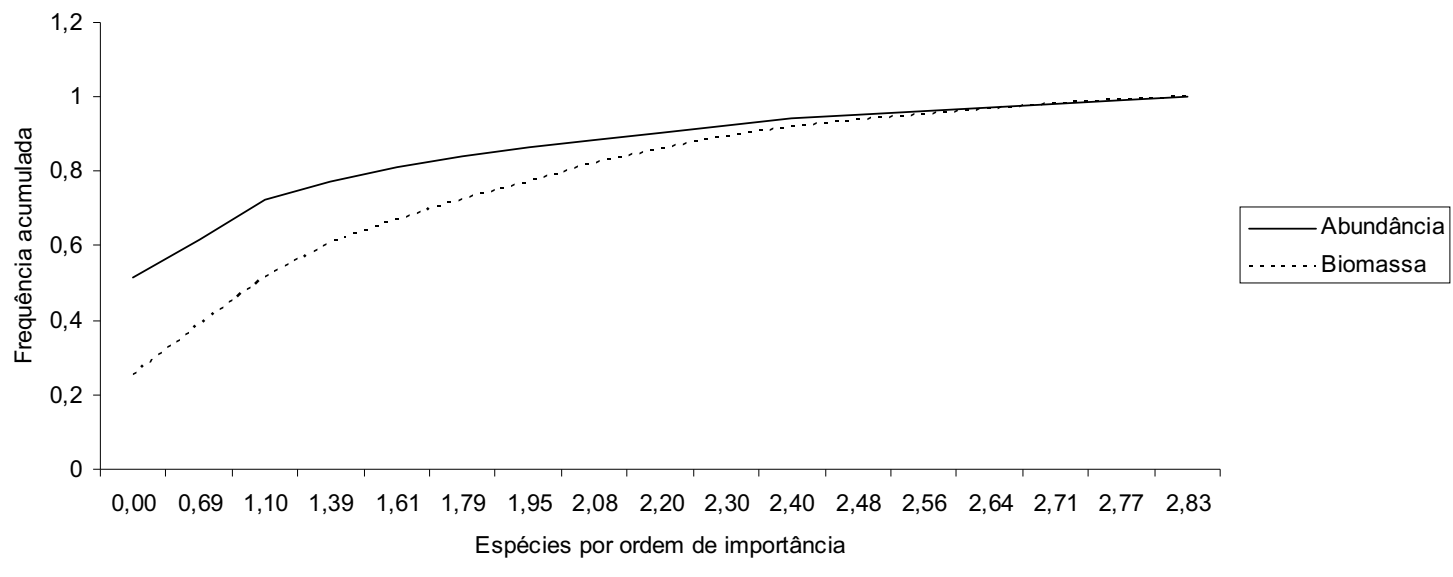

Figura 18: Representação das relações de abundância e biomassa das espécies capturadas nos pontos G1, G2 e G3 da microbacia do rio Guaratinguetá. 


\section{Raridade}

Trichomycterus itatiayae foi uma espécie importante quanto à freqüência nas duas microbacias, estando presente em cinco dos oito pontos amostrados na microbacia dos Buenos e em seis dos sete amostrados na microbacia do Guaratinguetá. Neoplecostomus microps e Characidium alipioi também foram importantes quanto à freqüência na microbacia dos Buenos, ocorrendo em seis e em cinco dos pontos amostrados, respectivamente (Tabela 15).

Tabela 15: Ocorrência e número de pontos em que as espécies de peixes foram capturadas nas microbacias do ribeirão dos Buenos (Buenos) e do rio Guaratinguetá (Guará).

\begin{tabular}{|c|c|c|c|}
\hline Espécie & Código & Buenos & Guará \\
\hline Trichomycterus itatiayae & Tita & 5 & 6 \\
\hline Phalloceros caudimaculatus & Pcau & 3 & 1 \\
\hline Characidium lauroi & Clau & 4 & 2 \\
\hline Neoplecostomus microps & Nmic & 6 & 4 \\
\hline Characidium alipioi & Cali & 5 & 3 \\
\hline Astyanax bimaculatus & Abim & 4 & 2 \\
\hline Trichomycterus iheringi & Tihe & 4 & 2 \\
\hline Harttia carvalhoi & Hcar & 1 & 2 \\
\hline Pareiohina rudolphi & Prud & 2 & 3 \\
\hline Pareiohina brachyrhyncha & Pbra & 2 & 3 \\
\hline Rineloricaria kronei & Rkro & 2 & 2 \\
\hline Ancistrus stigmaticus & Asti & 1 & 2 \\
\hline Astyanax fasciatus & Afas & 2 & 2 \\
\hline Astyanax intermedius & Aint & 1 & 2 \\
\hline Oligosarcus hepsetus & Ohep & 2 & 2 \\
\hline Hypostomus luetkeni & Hlue & 1 & 1 \\
\hline Gymnotus pantherinus & Gpan & 3 & 0 \\
\hline Rhamdia sp. & Rham & 1 & 2 \\
\hline Pimelodella sp. & Pimsp & 1 & 1 \\
\hline Geophagus brasiliensis & Gbra & 1 & 2 \\
\hline Gymnotus carapo & Gcar & 1 & 2 \\
\hline Crenicichla lacustris & Clac & 0 & 1 \\
\hline Hypostomus sp.1 & Hypsp1 & 0 & 1 \\
\hline Hypostomus sp.2 & Hypsp2 & 1 & 1 \\
\hline Synbranchus marmoratus & Smar & 1 & 1 \\
\hline Hoplerythrinus unitaeniatus & Huni & 1 & 1 \\
\hline Hoplosternun littorale & Hlit & 0 & 2 \\
\hline Pseudotocinclus parahybae & Ppar & 1 & 0 \\
\hline Trichomycterus sp. & Trisp & 1 & 0 \\
\hline Hypostomus sp.3 & Hypsp3 & 0 & 1 \\
\hline
\end{tabular}


Nas Figuras 19 e 20 estão apresentadas as relações entre o número médio e o peso médio de indivíduos capturados nas microbacias do ribeirão dos Buenos e do rio Guaratinguetá. Para algumas espécies (por exemplo, Rhamdia sp. e Oligosarcus hepsetus na microbacia dos Buenos e Rhamdia sp. e Synbranchus marmoratus na do rio Guaratinguetá), apesar dos poucos indivíduos coletados, a contribuição em biomassa dessas espécies foi alta. Com relação à contribuição em número de indivíduos, Trichomycterus itatiayae e Astyanax bimaculatus foram espécies importantes para as duas microbacias. Neoplecostomus microps e Phalloceros caudimaculatus também tiveram alta contribuição em número na microbacia dos Buenos e Ancistrus stigmaticus na microbacia do rio Guaratinguetá.

Quando a freqüência de ocorrência, o número de indivíduos e a biomassa foram analisados em conjunto, Trichomycterus itatiayae e Astyanax bimaculatus apareceram como as espécies mais importantes nas duas microbacias: essas espécies ocorreram em um grande número de pontos, tiveram muitos indivíduos coletados e suas contribuições em peso foram significantes. Os cascudos presentes nas microbacias também merecem destaque, já que Neoplecostomus microps foi importante apenas na microbacia do ribeirão dos Buenos e Ancistrus stigmaticus na do rio Guaratinguetá (Figuras 21 a 24).

Um conjunto de espécies raras (que foram pouco freqüentes, tiveram poucos indivíduos coletados e baixa contribuição em biomassa) foi encontrado para cada microbacia. Pareiorhina brachyrhyncha, Hoplerythrinus unitaeniatus, Geophagus brasiliensis, Astyanax fasciatus, Pseudotocinclus parahybae, Trichomycterus sp. e Pareiorhina rudolphi para a microbacia do ribeirão dos Buenos; e Synbranchus marmoratus, Crenicichla lacustris, Hoplosternum littorale, Hoplerythrinus unitaeniatus, Hypostomus luetkeni, Hypostomus sp.2 e Hypostomus sp.3 para a microbacia do rio Guaratiguetá. Apenas Hoplerythrinus unitaeniatus foi a espécie em comum para os conjuntos das duas microbacias. 


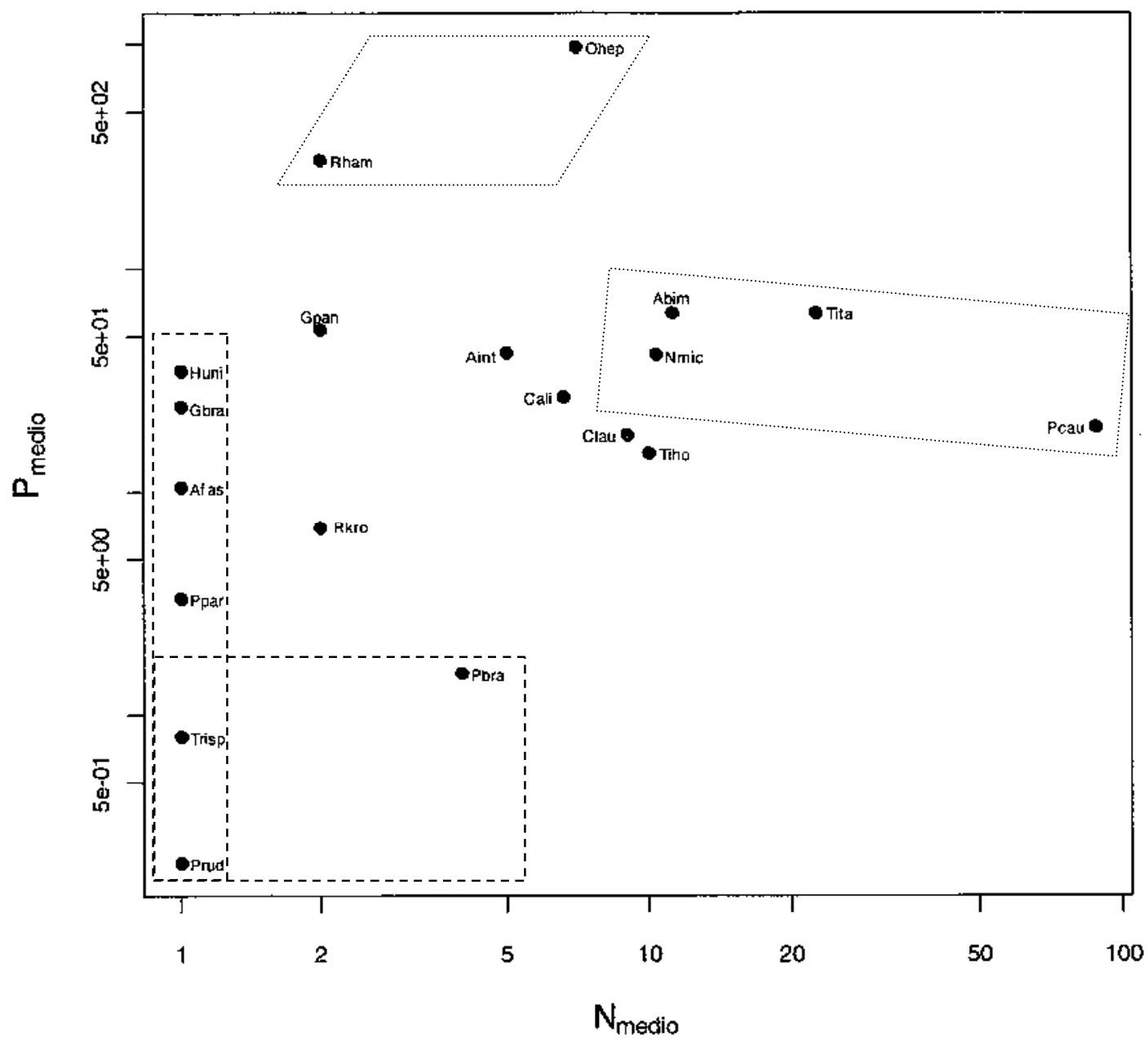

Figura 19: Relação entre o número médio e o peso médio de indivíduos capturados na microbacia do ribeirão dos Buenos (ver Tabela 15 para os códigos). São destacadas as espécies mais abundantes (linhas pontilhadas) e menos abundantes (linhas tracejadas) em número e peso. 


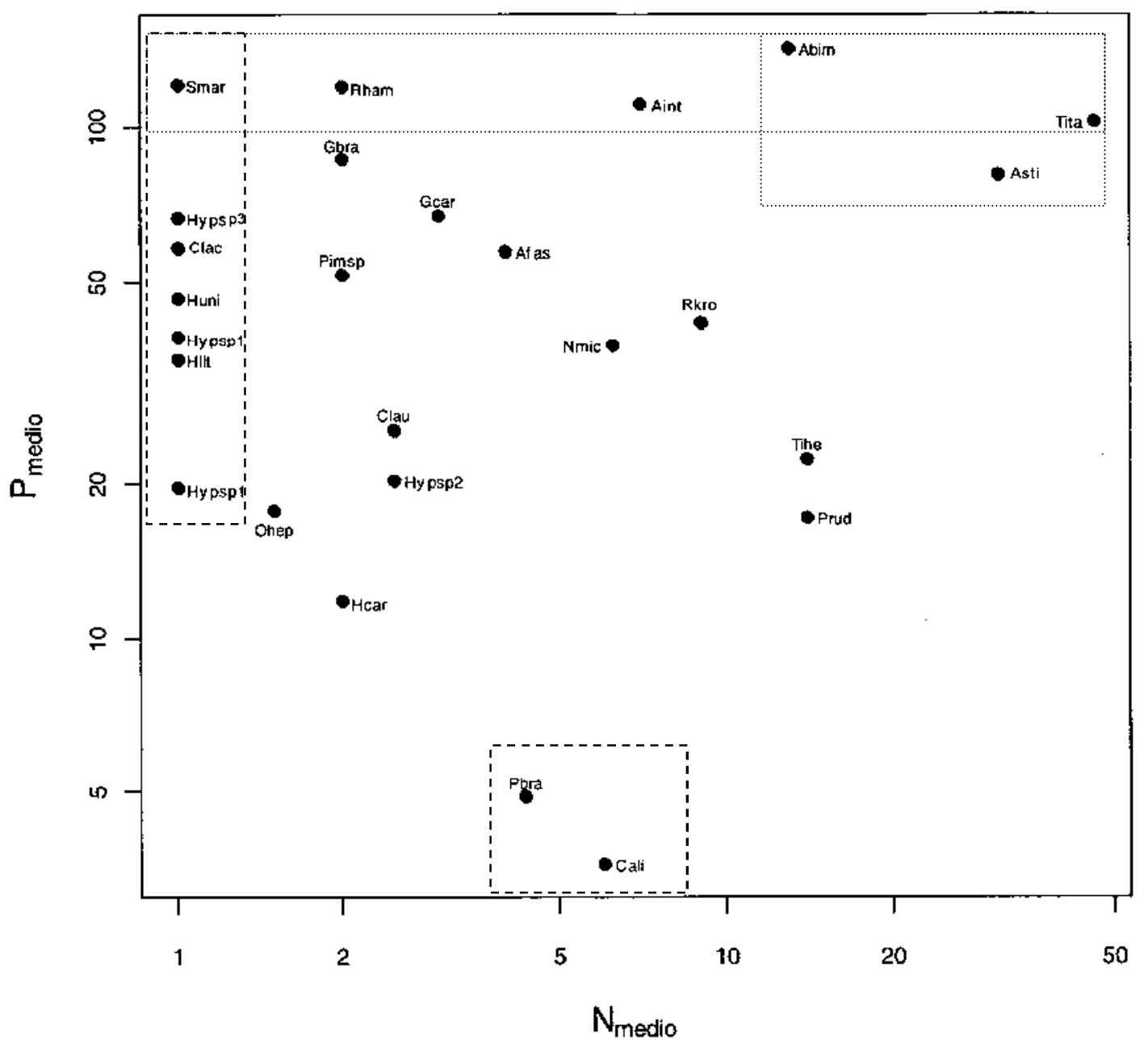

Figura 20: Relação entre o número médio e o peso médio de indivíduos capturados na microbacia do rio Guaratinguetá (ver Tabela 15 para os códigos). São destacadas as espécies mais abundantes (linhas pontilhadas) e menos abundantes (linhas tracejadas) em número e peso. 


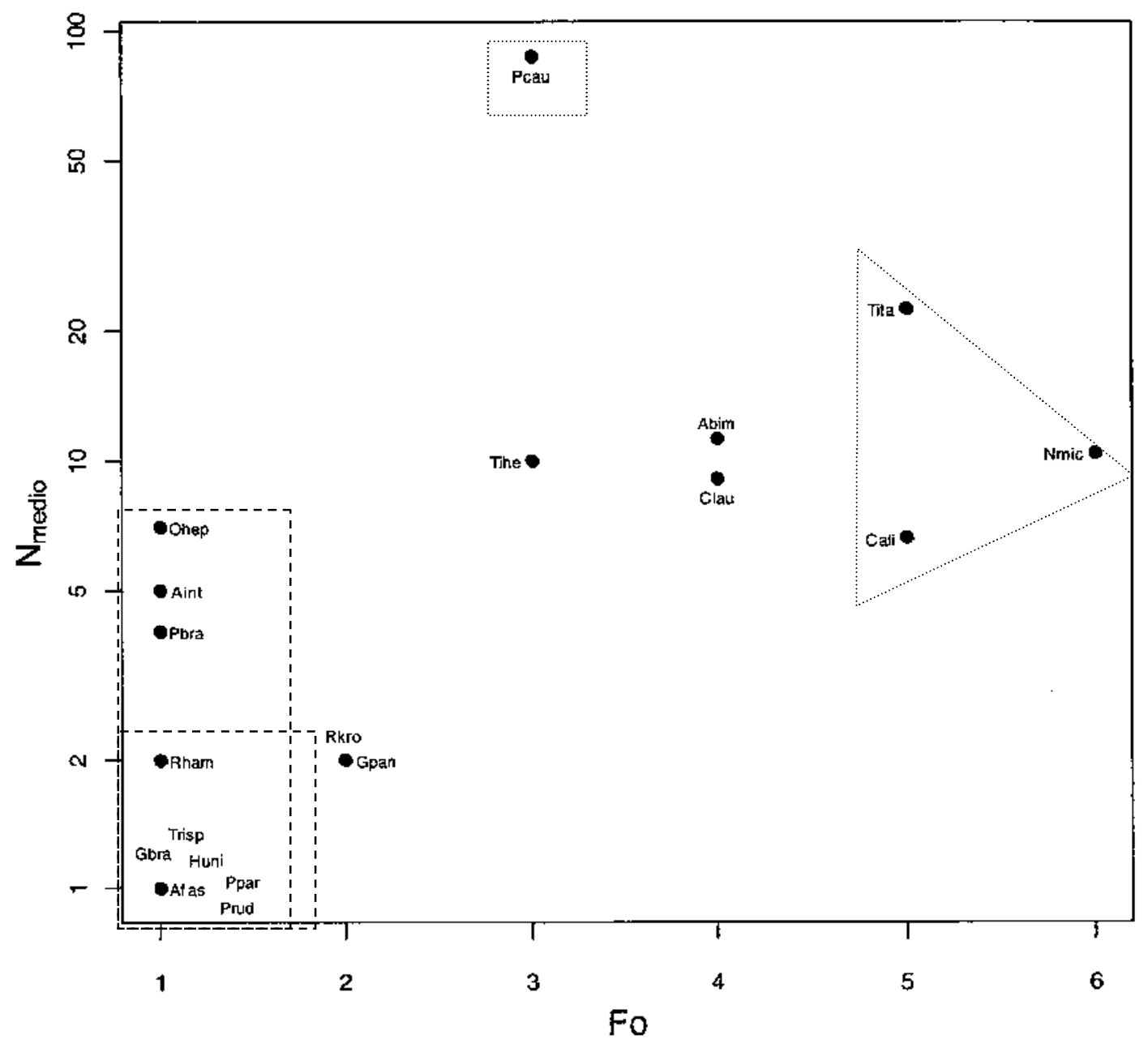

Figura 21: Relação entre o número médio e a freqüência de indivíduos capturados na microbacia do ribeirão dos Buenos (ver Tabela 15 para os códigos). São destacadas as espécies mais abundantes (linhas pontilhadas) e menos abundantes (linhas tracejadas) em número e peso. 


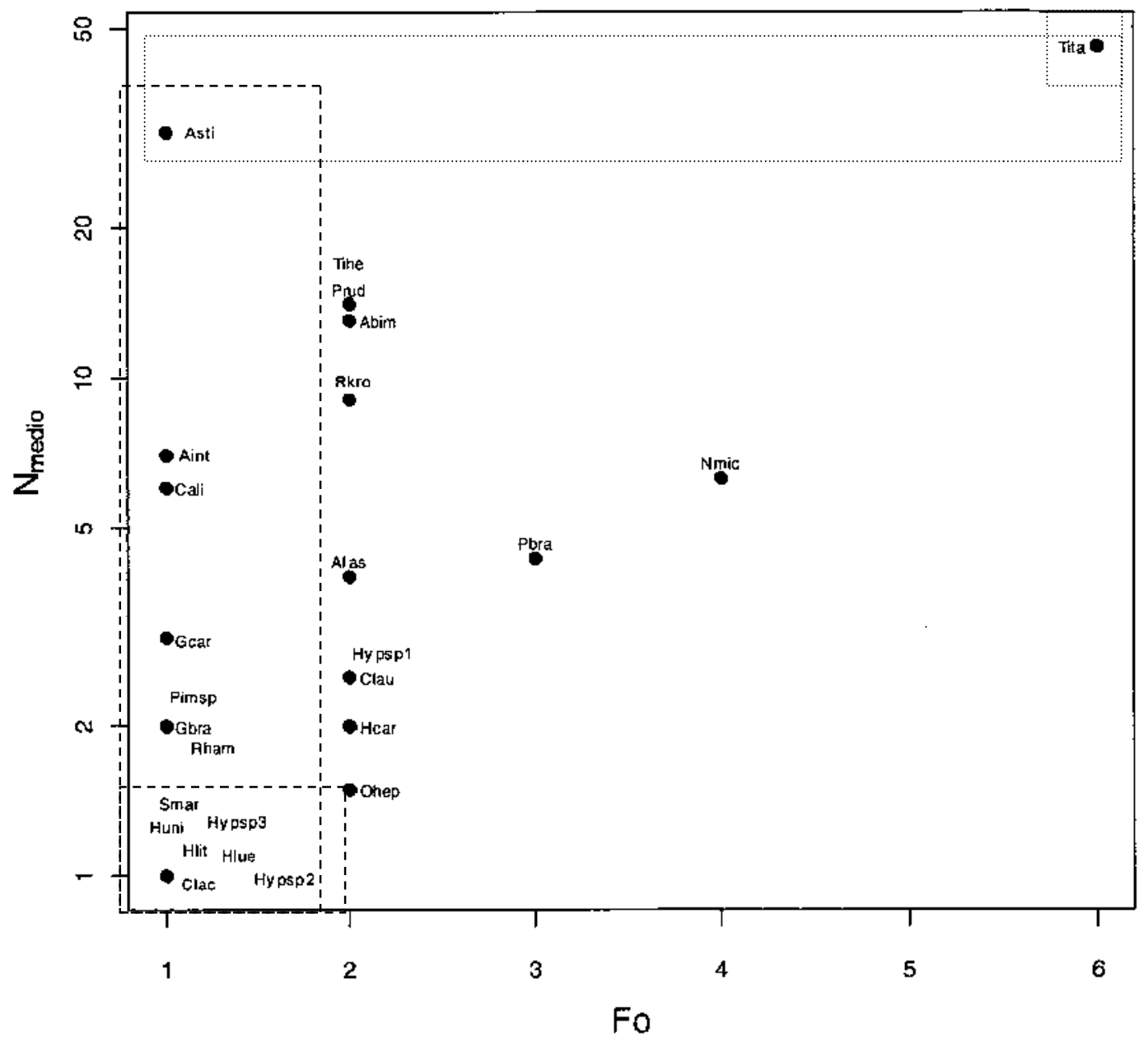

Figura 22: Relação entre o número médio e a freqüência de indivíduos capturados na microbacia do rio Guaratinguetá (ver Tabela 15 para os códigos). São destacadas as espécies mais abundantes (linhas pontilhadas) e menos abundantes (linhas tracejadas) em número e peso. 


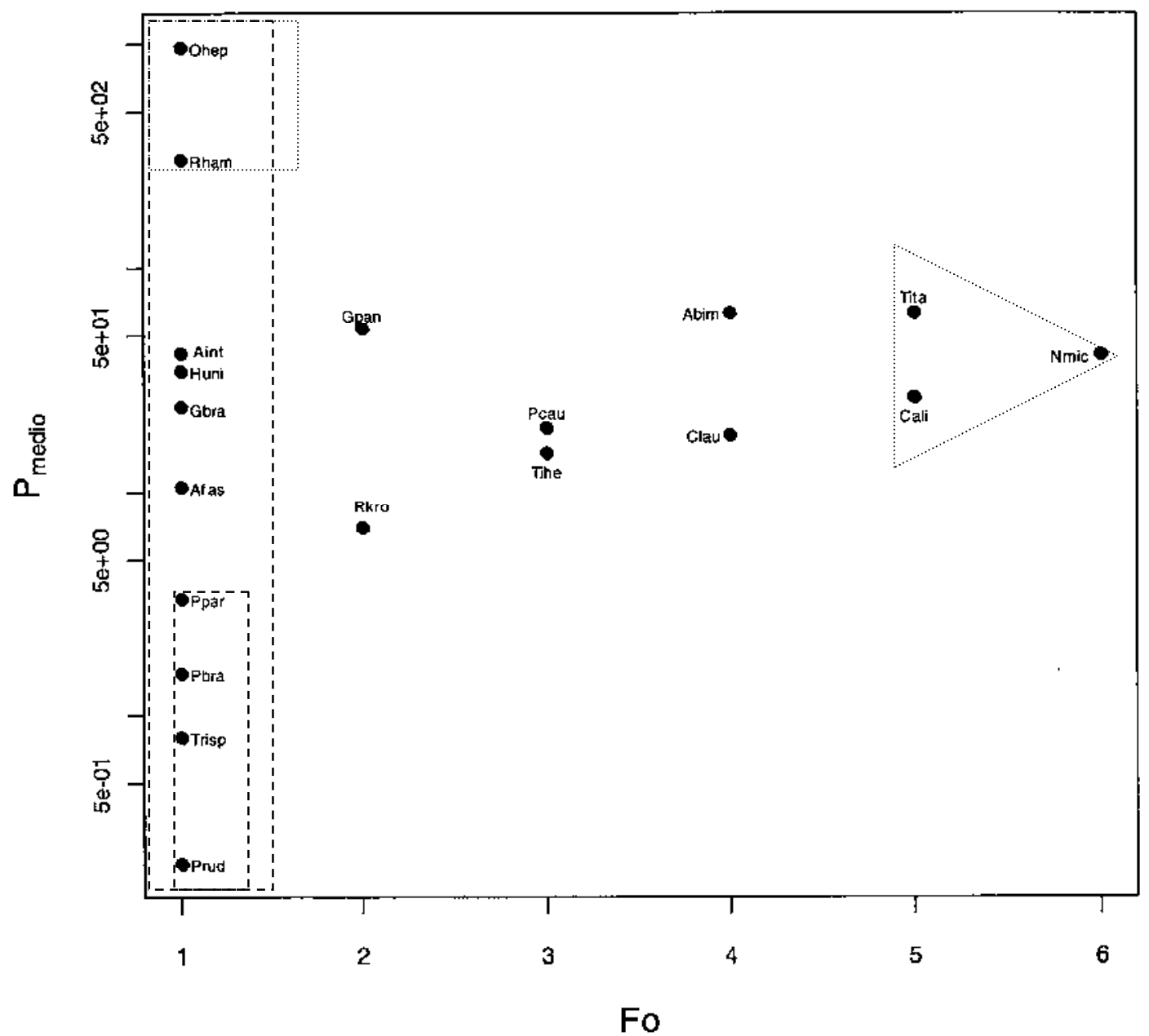

Figura 23: Relação entre o peso médio e a freqüência de indivíduos capturados na microbacia do ribeirão dos Buenos (ver Tabela 15 para os códigos). São destacadas as espécies mais abundantes (linhas pontilhadas) e menos abundantes (linhas tracejadas) em número e peso. 


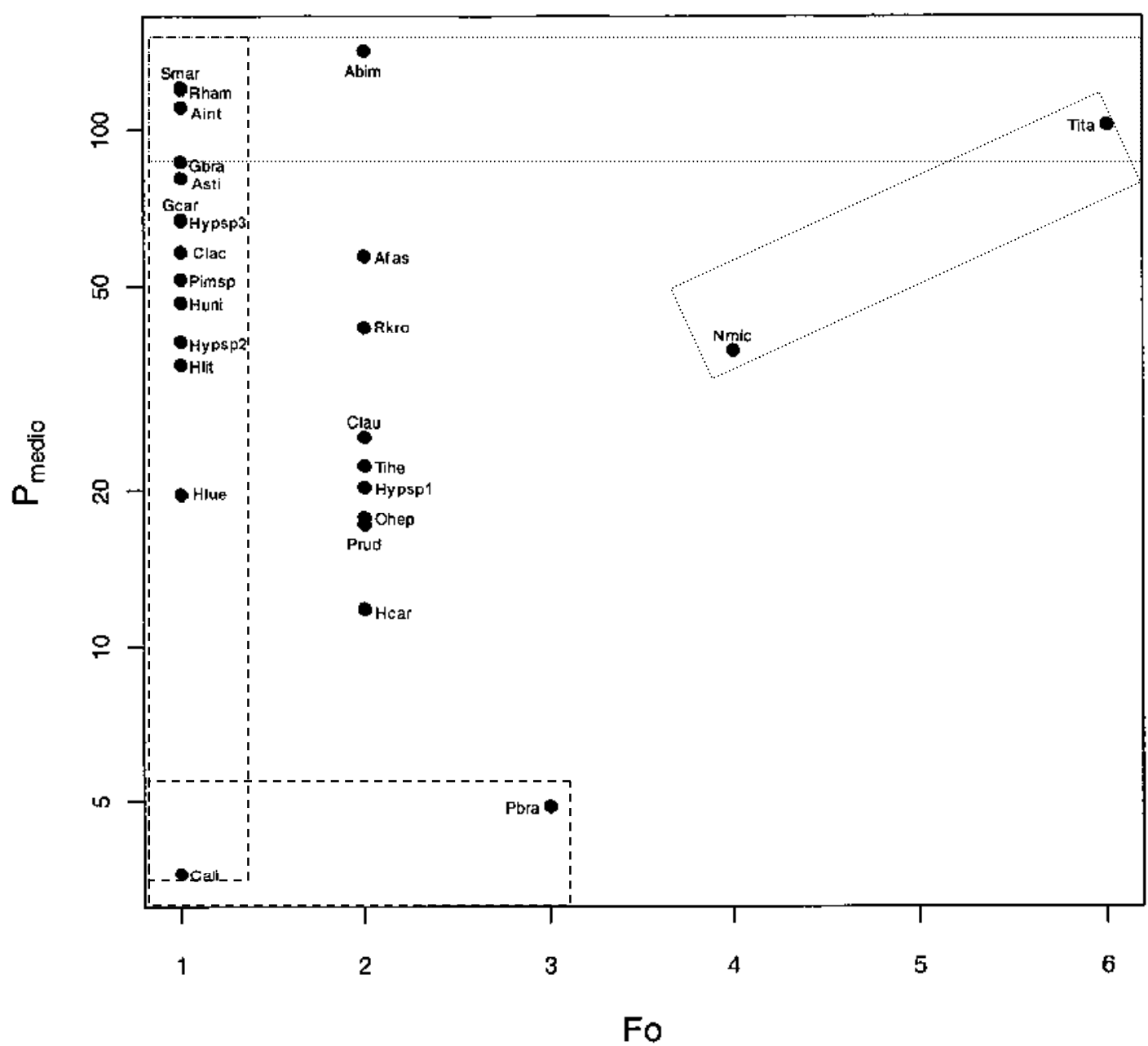

Figura 24: Relação entre o peso médio e a freqüência de indivíduos capturados na microbacia do rio Guaratinguetá (ver Tabela 15 para os códigos). São destacadas as espécies mais abundantes (linhas pontilhadas) e menos abundantes (linhas tracejadas) em número e peso. 


\section{Análise de correspondência}

A análise de correspondência (Figura 25) mostra um gradiente ambiental, indo dos pontos mais próximos à encosta (B1, G1 e G2), passando pelo pediplano (B2) e chegando ao vale (B3 e G3).

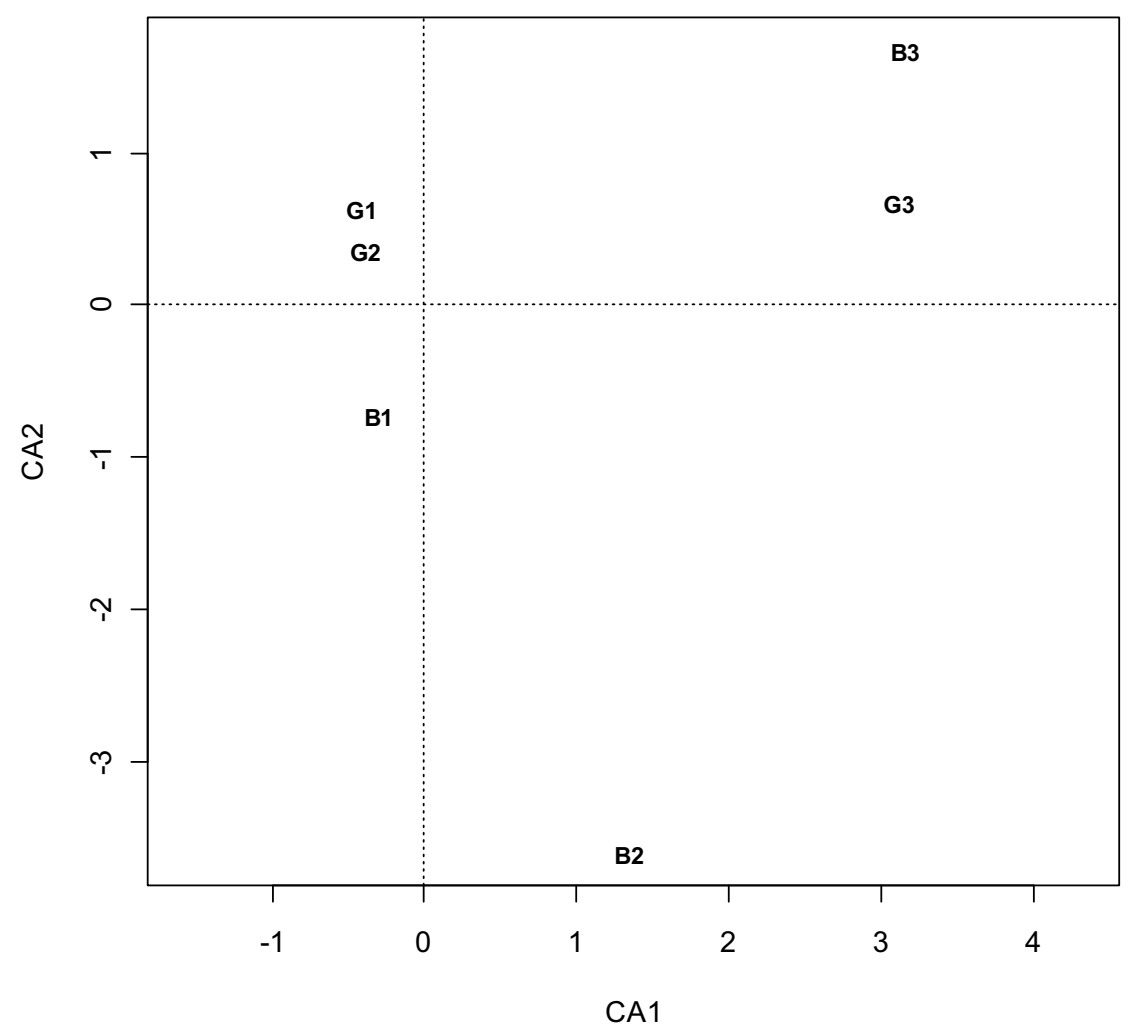

Figura 25: Resultados na análise de correspondência para a abundância das espécies nos pontos amostrais (B1, B2, B3 = pontos amostrados temporalmente na microbacia do ribeirão dos Buenos; G1, G2, G3 = pontos amostrados temporalmente na microbacia do rio Guaratinguetá). 
Para o eixo 1 da CA, três variáveis estruturais relativas ao tipo de substrato foram significativas $(\mathrm{P}<0,05)$ : areia/argila, pedra/matacão e leito de rocha/vegetação/lodo. Para o eixo 2 da CA apenas o $\mathrm{pH}$ foi significativo (Tabela 16). Com isso, verifica-se que dentre as variáveis estruturais e físicas e químicas da água, o tipo de substrato presente no canal e o pH são importantes na distribuição das espécies nos pontos amostrais.

Tabela 16: Valores do teste de significância aplicado aos dois eixos da CA variáveis físicas e químicas da água e variáveis estruturais $\left(\mathrm{r}^{2}=\right.$ valor do coeficiente de determinação).

\begin{tabular}{ccccc} 
& \multicolumn{3}{c}{ Eixo 1 da CA } & \multicolumn{3}{c}{ Eixo 2 da CA } \\
\hline Variáveis ambientais & r2 & P & r2 & P \\
\hline Largura & 0,008 & 0,815 & 0,001 & 0,876 \\
Profundidade & 0,146 & 0,192 & 0,198 & 0,318 \\
Velocidade & 0,477 & 0,057 & 0,167 & 0,386 \\
Temperatura da água & 0,754 & 0,066 & 0,209 & 0,361 \\
pH & 0,108 & 0,35 & 0,799 & 0,025 \\
Condutividade & 0,226 & 0,163 & 0,421 & 0,114 \\
Oxigênio dissolvido & 0,083 & 0,477 & 0,134 & 0,454 \\
Areia/Argila & 0,847 & $<0,0001$ & 0,041 & 0,794 \\
Cascalho/Seixo & 0,069 & 0,469 & 0,397 & 0,086 \\
Pedra/Matacão & 0,957 & 0,008 & 0,002 & 0,897 \\
Leito de rocha/Vegetação/Lodo & 0,504 & $<0,0001$ & 0,031 & 0,845 \\
\hline & & & &
\end{tabular}




\section{Discussão}

\section{Dados abióticos}

A serra da Mantiqueira constitui um dos conjuntos montanhosos mais importantes da região Sudeste, abrigando remanescentes significativos do bioma Mata Atlântica. Localizada na interface entre os estados de Minas Gerais, São Paulo e Rio de Janeiro, representa o grande divisor de águas das bacias do Paraíba do Sul e Paraná. A bacia do rio Paraíba do Sul, integrante da bacia do Leste, situa-se no Vale do Paraíba, onde a noroeste encontra-se a serra da Mantiqueira oriental. Pelas encostas da serra descem inúmeros riachos que formam microbacias distintas, isoladas por cristas de relevo íngrime, que vão desaguar no rio Paraíba do Sul (BRAGA, 2004). Apesar de as microbacias do ribeirão dos Buenos e do rio Guaratinguetá estarem separadas pelas cristas das encostas, suas nascentes estão bem próximas, distantes por cerca de $8 \mathrm{~m}$, na região de cimeira da serra (observação pessoal; MODENESI-GAUTTIERI et al. 2002).

Nas porções mais elevadas da serra, ocupando o topo da paisagem, ocorrem os Complexos Rupestres de Altitude que são ecossistemas de características singulares e que se diferem dos ecossistemas regionais predominantes pelas características dos solos, da flora e da fauna (BENITES et al., 2003). A região de cimeira da serra é caracterizada pelo baixo relevo $(40-50 \mathrm{~m})$, profundo intemperismo, generalizado declive nas colinas, depressões rasas, e planícies aluviais relativamente amplas e cheias de sedimentos turfosos (MODENESI-GAUTTIERI et al. 2002). A paisagem dessa região está constituída por extensos brejos que se formam nas planícies aluviais, onde a vegetação predominante é composta pela Poacea Cortaderia modesta e pela Bryophita Sphagnum sp., que formam bancos associados. Essas planícies aluviais são consideradas paleovales (MODENESIGAUTTIERI et al. 2002), que aparentemente secam no inverno, no entanto, a água fica retida por capilaridade nas células mortas de Sphagnum que formam um substrato esponjoso (obs. pess.). Desta maneira, o terreno fica permanentemente úmido inclusive na seca. Nesta paisagem de campos de altitude formam-se pequenos corpos de água que vão constituir as microbacias que descem as encostas da serra da Mantiqueira. 
Os solos da serra da Mantiqueira, em geral, são arenosos, com alta saturação de alumínio e teores variados de matéria orgânica, o que lhes confere pHs ácidos (BENITES et al., 2007). Os valores de $\mathrm{pH}$ encontrados nos pontos amostrais estiveram ao redor de 6,0, ou seja, levemente ácidos. Braga \& Andrade (2005) encontraram valores baixos para o pH da água no riacho Cachoeirão, localizado na cimeira da serra. $\mathrm{O} \mathrm{pH}$ da água dos brejos localizados na região da cimeira das microbacias do Ribeirão dos Buenos e do rio Guaratinguetá foi igualmente baixo, sendo de 5,60. O ponto B2, localizado no pediplano na microbacia do ribeirão dos Buenos, foi o que apresentou os valores mais baixos de $\mathrm{pH}$, ao redor de 5,0. Esse ponto é contíguo a uma vasta plantação de arroz que é irrigada pelo próprio ribeirão dos Buenos, que sofre um desvio para tal. Segundo a Agência Nacional de Águas (2001), os agricultores de arroz fazem uso intensivo de agrotóxicos e fertilizantes, que durante a drenagem das plantações de arroz retornam ao ribeirão, o que pode contribuir para uma acentuada queda no $\mathrm{pH}$.

A condutividade elétrica é um preditor da quantidade total de íons dissolvidos na água e diferenças na condutividade resultam, principalmente, da concentração de íons carregados em solução e, em menor grau, de composição iônica e temperatura (ALLAN, 1997). Os valores de condutividade elétrica encontrados foram mais elevados do que aqueles apresentados por Braga \& Andrade (2005) em riachos da microbacia do Ribeirão Grande, contígua à microbacia do ribeirão dos Buenos, sendo todos os valores inferiores à $50 \mu \mathrm{S} / \mathrm{cm}$, reportados por Mazzoni (1998) como típicos de riachos neotropicais, salvo àqueles que sofrem certa influência das marés. Um crescente no sentido montante-jusante foi observado: valores mais baixos de condutividade foram encontrados nos pontos mais altos e, à medida que se aproximaram do vale, os valores de condutividade foram maiores, o que reflete um acúmulo de íons ao longo do sistema. Padrão semelhante foi encontrado por Braga \& Andrade (2005) em riachos da microbacia do Ribeirão Grande.

O oxigênio dissolvido é o mais importante gás na dinâmica e na caracterização dos ecossistemas aquáticos (ESTEVES, 1988), sua concentração varia ao longo de um curso de água, sendo influenciada pelo vento, velocidade da água, efeitos térmicos e decomposição da matéria orgânica ao longo do ciclo hidrológico (BAYLEY, 1995). Quanto maior a temperatura, maior a taxa de desprendimento desse gás para a atmosfera e maior os metabolismos dos organismos aquáticos. Em pequenos riachos a concentração de oxigênio 
encontra-se bem próxima à saturação (ALLAN, 1997). A concentração de oxigênio nos pontos amostrados nos riachos das microbacias do ribeirão dos Buenos e do rio Guaratinguetá foi bastante elevada, assim como o encontrado por Braga \& Andrade (2005) em riachos da microbacia do Ribeirão Grande.

A temperatura da água em riachos varia usualmente de modo sazonal e diário, devido ao clima, altitude e extensão da cobertura vegetal (ALLAN, 1997). Os pontos mais altos, localizados mais próximos às encostas da serra e providos de vegetação marginal apresentaram as temperaturas mais baixas da água. À medida que os corpos d'água aproximam-se do vale, ganham maior volume de água e permanecem mais tempo em contato com o ar, visto que a cobertura vegetal torna-se cada vez mais escassa, o que thes confere maiores valores de temperatura.

A profundidade, a velocidade da corrente e a composição do substrato estão dentre as variáveis mais relevantes na estrutura de hábitat (RINCÓN, 1999), estando estas relacionadas com a declividade (LOWE-McCONNELL, 1999). A profundidade apresentou um gradiente crescente longitudinal, ao passo que a velocidade e a composição do substrato tenderam a apresentar comportamento contrário: velocidades maiores e substratos de maior tamanho foram encontrados mais à montante nos riachos. Com base nessas variáveis, unidades fisionômicas de meso-hábitat podem ser descritas (riffles, runs e pools) (GORMAN, 1988), que vêem a interferir na distribuição de peixes de riachos (RINCÓN, 1999). Os riffles são áreas de gradiente elevado, com correnteza rápida e turbulenta, substrato composto por matacões gastos e arrendondados, podendo existir também sobre leito rochoso. Os runs possuem correnteza relativamente rápida e águas não turbulentas, geralmente são mais profundos do que os riffles e com gradiente menor. Os pools são áreas profundas, com correnteza lenta, sendo comum a presença de sedimento no substrato. Essas unidades tendem a ocorrer ao longo do sistema e a identificação destas pode trazer informações acerca da profundidade, velocidade e substrato, bem como da posição longitudinal dos diversos ambientes. Forman \& Godron (1986) apud Fialho et al. (2007) afirmam que nas várias escalas espaciais consideradas, os hábitats devem ser analisados como paisagens que pertencem a um mosaico de manchas interligadas. As sucessões desses meso-hábitats em um sistema de riachos neotropicais de montanha, associado com o input de matéria orgânica e sedimento transportado da floresta para os riachos, mantém a 
dinâmica da biota aquática nesses ambientes aparentemente oligotróficos. Por outro lado, espelham também a fragilidade desses ambientes frentes às alterações estruturais no hábitat.

Os valores do índice de diversidade calculados para os hábitats apresentaram alta correspondência com os valores de equitabilidade e riqueza, com exceção do ponto G3, na microbacia do rio Guaratinguetá, que apesar do alto valor do índice de riqueza, apresentou um valor mais baixo do índice de diversidade devido ao baixo valor do índice de equitabilidade encontrado. Isso porque, apesar da grande variedade de ambientes encontrada, houve predomínio das seguintes categorias: profundidade moderada, fluxo rápido e fundo de areia. Os trechos superiores apresentam uma diversidade de hábitats menor do que os trechos inferiores (UIEDA \& BARRETO, 1999), o que leva a uma tendência de aumento de diversidade das cabeceiras à foz em decorrência de uma maior disponibilidade de hábitats (GARUTTI, 1988). De acordo com o conceito do rio contínuo (RCC) (VANNOTE et al., 1980), um gradiente de condições físicas, no sentido montantejusante, acontece nos sistemas lóticos, o que implica em ajustes biológicos das comunidades ali viventes.

\section{Ictiofauna}

Diversos levantamentos da ictiofauna do rio Paraíba do Sul têm sido realizados, quer seja nos distintos trechos do canal principal (superior, médio-superior, médio-inferior e inferior) e/ou em seus principais tributários (ARAÚJO, 1996; BIZERRIL, 1999; ARAÚJO, 1998; ARAÚJO et al., 2001; TEIXEIRA et al., 2005; ESTILIANO, 2006; PINTO et al., 2006; PINTO, 2008; ARAÚJO et al., 2009). Cerca de 130 espécies de peixes de água doce ocorrem no rio Paraíba do Sul, de acordo com estimativa de Bizerril (1999), incluindo o levantamento da ictiofauna de pequenos riachos.

No entanto, o conhecimento da composição das comunidades de peixes dos pequenos riachos que formam as microbacias tributárias do rio Paraíba do Sul ainda é escasso, restringindo-se aos trabalhos de Andrade (2004) e Braga \& Andrade (2005) nos riachos da microbacia do ribeirão Grande e Ingenito \& Buckup (2007) em amostragens pontuais no ribeirão Grande, rio Piracuama e ribeirão dos Buenos. Bizerril (1999) caracteriza a região do Alto rio Paraíba e sistemas tributários associados como uma zona de 
endemismo, onde importantes grupos de espécies podem ser encontrados, remontando um período de conexão dos sistemas Tietê/Paraíba. Na microbacia do ribeirão Grande, Braga \& Andrade (2005) amostraram 37 espécies, sendo as mais abundantes dois pequenos crenucídeos, Characidium lauroi e C. alipioi. Ingenito \& Buckup (2007) compilaram 25 espécies para o ribeirão Grande, 18 para o rio Piracuama e 6 para o ribeirão dos Buenos. A captura de espécies no presente estudo foi de 27 para a microbacia do ribeirão dos Buenos e 30 para a microbacia do rio Guaratinguetá. Indicativos de que as riquezas encontradas nas duas microbacias correspondem às espécies que de fato existem nesses ambientes firmamse nos estimadores de riqueza calculados, que se encontraram bem próximos ao número de espécies coletadas, bem como a proximidade às assíntotas das curvas de rarefação aplicadas.

O maior desafio nos estudos de ecologia de rios é a identificação de gradientes ambientais que estruturem as comunidades lóticas (WALTER et al., 2003). Modificações nas comunidades de peixes são esperadas conforme os trechos do rio, como resultado dos processos evolutivos e históricos de adaptações peculiares de cada espécie, modulados por influências ambientais, condições de hábitats e alteradas por influências de origem antrópica (MARTIN-SMITH, 1998; MEADOR \& GOLDESTEIN, 2003). Locais escarpados e com alta declividade, em geral possuem um grupo de espécies particular à áreas de cabeceira, enquanto em rios de relevo suave, esta divisão não é tão pronunciada (BALON \& STEWART, 1983).

Trichomycterus itatiayae, a espécie mais abundante nas microbacias estudadas, teve sua distribuição limitada aos ambientes de encosta e pediplano, como o encontrado por Braga \& Andrade (2005), estando presente em trechos de corredeiras com substratos de maior diâmetro. Na microbacia do rio Guaratinguetá, T. itatiayae representou $64 \%$ de todos os indivíduos capturados. Phalloceros caudimaculatus foi a segunda espécie mais abundante na microbacia do ribeirão dos Buenos, sendo que a maior captura ocorreu no córrego Guamirim (ponto b5), um riacho bastante antropizado, no pediplano. Poecilidae são peixes amplamente conhecidos por sua capacidade de tolerar ambientes alterados, ocorrendo em locais onde um grande número de espécies tem sua distribuição limitada (ARAÚJO et al., 2003). Characidium lauroi e C. alipioi também foram espécies abundantes na microbacia do ribeirão dos Buenos, sendo que a primeira ocorreu 
preferencialmente em ambientes de encosta e a segunda tanto na encosta como no pediplano, padrão esse verificado também para essas duas espécies na microbacia do Ribeirão Grande (BRAGA, 2005). Comportamento de distribuição semelhante ocorreu com Neoplecostomus microps, outra espécie com abundância destacada para a microbacia do ribeirão dos Buenos. A presença de odontodes nos opérculos de T. itatiayae e nas placas que recobrem o corpo de $N$. microps, bem como as nadadeiras peitorais expandidas em Characidium, características adaptativas dessas espécies, permitem a melhor exploração dos ambientes encontrados em riachos de fluxo rápido, facilitando sua permanência entre cascalhos e seixos do fundo (BRAGA, 2004).

Braga \& Andrade (2005) verificaram um padrão de distribuição parapátrico para várias espécies na microbacia do Ribeirão Grande, onde espécies muito próximas não sobrepõem suas áreas de distribuição. Segundo Angermeier \& Karr (1983) a distribuição de peixes pequenos, como os que ocorrem em regiões de cabeceira, está mais relacionada com a abundância do recurso alimentar.

Uma única espécie exótica ocorreu durante as amostragens: uma truta arco-íris (Oncorrynchus mykiss) capturada na região do pediplano da microbacia do rio Guaratinguetá. Na região do alto da serra e com inúmeras nascentes, é comum o cultivo de trutas em tanques de "pesque-pague". Provavelmente, esse indivíduo escapou de um dos tanques, sendo capturado mais à jusante no riacho. Espécies não nativas (e.g. Tilapia spp., Oreochromis spp., Poecilia spp., Cichla spp., Aequidens sp.) têm sido reportadas em diversos estudos no rio Paraíba do Sul (ARAÚJO, 1996; ARAÚJO, 1998; ARAÚJO et al., 2001; TEIXEIRA et al., 2005; ESTILIANO, 2006; PINTO et al., 2006; PINTO, 2008; ARAÚJO et al., 2009). No entanto, nos riachos das microbacias tributárias do rio Paraíba do Sul, nenhum registro foi observado (BRAGA \& ANDRADE, 2005; INGENITO \& BUCKUP, 2007).

\section{Similaridade}

O dendrograma de similaridade distinguiu dois grandes grupos: um formado por pontos típicos de encosta e pediplano e o outro com pontos mais baixos, localizados tanto no pediplano como no vale. As maiores similaridades ocorreram entre os pontos g1 e g3, 
onde capturou-se apenas Trichomycterus itatiayae, e entre b1 e b2, cuja ictiofauna foi composta exclusivamente por T. itatiayae, Characidium lauroi e Neoplecostomus microps. $\mathrm{O}$ ponto b5, além de apresentar essas três espécies, apresentou também Phalloceros caudimaculatus e Astyanax bimaculatus. Dentre as dez espécies capturadas no ponto B1, oito em G1 e onze em G2, oito delas ocorreram nesses três pontos simultaneamente. A presença de Pareiorhina brachyrhyncha e P. rudolphi no ponto b3, pode ter contribuído pela junção desse ponto ao grupo formado pelos pontos G1-B1-G2. Algo semelhante pode ter acontecido no ponto g2, devido ao fato da presença de P. rudolphi. Ancistrus stigmaticus ocorreu apenas nos pontos g4 e G3 da microbacia do rio Guaratinguetá e em B2 da microbacia do ribeirão dos Buenos. O agrupamento dos pontos $\mathrm{g} 4$ e B2 deve ter ocorrido principalmente pela ocorrência dessa espécie, além de outras oito espécies que ocorreram de modo simultâneo nos pontos g4 e B2, sendo Characidium alipioi, Astyanax bimaculatus, Trichomycterus iheringi e Rineloricaria kronei também comum ao ponto b4. Os pontos B3 e G3, situados em típicos ambientes de vale, apresentaram como espécies comuns Astyanax bimaculatus, A. fasciatus, Hypostomus luetkeni, Oligosarcus hepsetus, Rhamdia sp., Hypostomus sp.2 e Hoplerythrinus unitaeniatus.

Nas microbacias do ribeirão dos Buenos e do rio Guaratinguetá pode ser observado um padrão de adição de espécies indo dos pontos de encosta em direção aos pontos do pediplano, ao passo que dos pontos do pediplano aos pontos do vale foi verificado um padrão de substituição de espécies. Padrão semelhante foi encontrado por Andrade (2004) nos riachos da microbacia do Ribeirão Grande, sendo a provável fonte de variação as características fisiográficas desses ambientes (SÚAREZ \& PETRERE, 2006). Na microbacia do ribeirão dos Buenos, Trichomycterus itatiayae, Characidium lauroi e Neoplecostomus microps ocorreram nos pontos mais altos (b1 e b2). Ainda na encosta, no ponto B1, novas espécies ocorreram, acontecendo o mesmo para os pontos localizados no pediplano. No ponto B3, constatou-se uma comunidade um pouco diferenciada, destacando-se a presença de Astyanax fasciatus, Hypostomus spp., Rhamdia sp. e Hoplerithrytnus unitaeniatus. Na microbacia do rio Guaratinguetá, a tendência foi a mesma, nos pontos localizados mais no alto da encosta (g1, g2, g3), capturou-se Trichomycterus itatiayae (espécie única em g1 e g3), Neoplecostomus microps, Pareiorhina rudolphi e P. brachyrhyncha. Ainda na encosta, e passando pelo pediplano 
(G1 e G2) novas espécies foram adicionadas à lista. Já nos pontos G3 e g4 um novo conjunto de espécies pode ser observado, sendo Astyanax bimaculatus a espécie mais abundante, seguida por Ancistrus stigmaticus e Rineloricaria kronei. Destacam-se, ainda, Astyanax fasciatus, Hypostomus luetkeni, Crenicichla lacustris, Oligosarcus hepsetus, Geophagus brasiliensis e Gymnotus carapo como espécies de ambiente de planície.

É esperado que áreas geograficamente mais próximas, numa mesma região, tenham ictiofauna mais similar do que áreas mais distantes (MATTHEWS, 1998), sendo que diferenças na riqueza de espécies em nível regional está claramente relacionada ao grau de conectividade ou isolamento das regiões (LUIZ et al., 2003). Súarez \& Lima-Júnior (2009) amostrando riachos da bacia do rio Guiraí (Alto rio Paraná) também encontraram baixa similaridade entre pontos na região de cabeceira e em porções intermediárias da bacia com os trechos finais da bacia. Os processos locais (características limnológicas e estruturais do hábitat bem como interações intra e interespecíficas) têm sido apontados como os principais responsáveis pela estruturação das comunidades de peixes presentes nos diferentes tipos de ambientes de um mesmo ecossistema ou região biogeográfica (AGOSTINHO et al., 1997). Porém, a determinação de qual variável é importante no processo de estruturação é dificultado devido a alta correlação entre as variáveis (MATTHEWS et al., 1992).

\section{Diversidade de espécies}

$\mathrm{Na}$ microbacia do ribeirão dos Buenos, os valores de diversidade e riqueza de espécies encontrados corresponderam aos de diversidade e riqueza de hábitat: os pontos B1 e B2 foram os que apresentaram os maiores valores desses índices, que foram calculados a partir das variáveis estruturais. Forte influência da estrutura física do hábitat sobre a estrutura das comunidades foi constatada por Ferreira \& Casatti (2006), sendo que as maiores diversidades específicas foram registradas nos trechos de maior complexidade estrutural. $\mathrm{O}$ índice de equitabilidade para espécies apresentou um gradiente crescente no sentido encosta-vale, sendo a maior equitabilidade encontrada no vale. Isso não correspondeu com o encontrado para o hábitat, visto que o ponto B3, no vale, apresentou o menor valor desse índice. Uma menor equitabilidade significa maior dominância: no vale, um menor volume de hábitats foi encontrado, com predomínio de profundidade moderada, 
velocidade rápida e fundo de areia, assim, uma menor número de espécies acaba ocupando os nichos disponíveis.

Na microbacia do rio Guaratinguetá, os maiores valores de diversidade, riqueza e equitabilidade de espécies ocorreram no ponto G3, localizado na planície do vale. Nessa microbacia não foi observada correspondência desses valores com os encontrados para o hábitat, visto que o ponto G3 apresentou baixos valores de diversidade e equitabilidade de hábitat, sendo a riqueza bastante semelhante aos outros dois pontos. $\mathrm{O}$ aumento da diversidade de espécies com o aumento do volume de água é esperado, sendo o número de espécies menos numerosas diretamente proporcional ao volume da água, enquanto que a dominância das espécies é inversamente proporcional a este mesmo volume (GARUTTI, 1988). A correlação entre a riqueza de espécies e o volume dos riachos tendo sido demonstrada (GORMAN \& KARR, 1978; ANGERMEIER \& SCHLOSSER, 1989), sendo que o maior volume dos riachos levaria à uma maior diversificação de nichos e permitiria a coexistência de maior número de espécies.

Quando os índices de diversidade, riqueza e equitabilidade foram verificados na dimensão espacial, interações significativas foram encontradas entre ambientes e microbacias para os dois primeiros índices, indicando que pelo menos um ambiente em uma microbacia difere quanto aos índices de diversidade e riqueza. Os valores do índice de diversidade foram bem semelhantes entre as microbacias, sendo o índice de riqueza maior para a microbacia do rio Guaratinguetá. Em relação ao ambiente, os maiores valores dos índices de diversidade e riqueza foram encontrados para o vale. $\mathrm{O}$ índice de equitabilidade variou significativamente entre microbacias e entre ambientes, apresentando os maiores valores na microbacia do ribeirão dos Buenos e no ambiente de vale. Um gradiente crescente da diversidade, riqueza e equitabilidade foi observado da encosta em direção ao vale o que não vai de encontro com o proposto por Vannote et al. (1980), que afirmam que é a região do curso médio dos rios que apresenta maior diversidade, e o encontrado por Braga (2004), na microbacia do Ribeirão Grande, onde maior riqueza de espécies ocorreu no ponto de transição entre o pediplano e a planície, que corresponde a um ecótono entre encosta e vale, onde o Ribeirão Grande já recebeu todos os seus afluentes que descem as encostas e seguem pelo vale até desaguar no Paraíba do Sul. Ferreira (2007b), estudando três trechos de um riacho tributário do rio Mogi Guaçu, também encontrou maior 
diversidade de espécies no trecho mais baixo, onde a descarga foi três vezes maior do que a registrada nos outros dois trechos. De acordo com Lowe-McConnell (1999), o aumento do nível da água é um fator responsável pela expansão do microhábitat, aumentando a disponibilidade de alimentos, gerando lugares, e as áreas que servirão de abrigo.

Não houve variação significativa nos índices de diversidade, riqueza e equitabilidade entre as épocas de seca e cheia. Uma maior riqueza de espécies durante o período chuvoso foi detectada em diversos estudos (GARUTTI, 1988; MAZZONI \& LOBÓN-CERVIÁ, 2000; CASATTI, 2005; FERREIRA \& CASATTI, 2006; CARMASSI, 2008; PINTO, 2008; ARAÚJO et al., 2009; SÚAREZ \& LIMA-JÚNIOR, 2009). Silvano et al. (2000) encontraram maior riqueza de espécies para a comunidade do alto rio Juruá (Amazônia) na estação seca e atribuíram isso ao fato de os peixes ficarem mais concentrados devido ao baixo nível da água, sendo capturados mais facilmente. Taylor \& Warren (2001) sugerem que nos trechos mais inferiores das bacias hidrográficas, as comunidades de peixes são mais influenciadas pela dinâmica da migração. Pavanelli \& Caramaschi (2003) verificaram maior importância da migração planície/riacho no trecho final de microbacias do alto rio Paraná e Súarez (2008) amostrando trechos relativamente distantes da calha do rio Ivinhema e da maior parte de sua planície de inundação, verificou pouca variação temporal na diversidade e composição de espécies de peixes.

Essa pouca variação temporal constatada por Súarez (2008) pode ser verificada na microbacia do rio Guaratinguetá com o aparecimento de Pimelodus maculatus (dois indivíduos, um macho e uma fềmea, ambos em estádio de maturação gonadal avançado) na amostragem do período chuvoso no ponto localizado no vale (G3). Com isso, sugere-se que este local possa ser utilizado como rota na migração reprodutiva dessa espécie.

Como apresentado em diversos outros trabalhos (e.g. LANGEANI et al., 2005. CETRA \& PETRERE, 2006; VALÉRIO et al., 2007; SANTOS \& CARAMASCHI, 2007; SÚAREZ \& PETRERE, 2007; SÚAREZ \& LIMA-JÚNIRO, 2009) parece que as características espaciais tenham maior importância do que as temporais sobre a organização das comunidades de peixes nas microbacias do ribeirão dos Buenos e do rio Guaratinguetá na serra da Mantiqueira oriental.

\section{Constância}


A constância de ocorrência das espécies, como preconizada por Dajoz (1978), além de possibilitar uma visão geral da distribuição longitudinal dos peixes, torna-se importante na caracterização ictiofaunística de qualquer ponto de um curso de água. Lemes \& Garutti (2002) acrescentam que a constância pode refletir a habilidade biológica que a espécie tem nas diferentes fases ontogenéticas, em explorar os recursos ambientais disponíveis num determinado momento do biótopo. Os pontos B1, G1 e G2 apresentaram maiores freqüências de espécies constantes. Os dois primeiros pontos localizam-se na encosta e G2, apesar de localizar-se no pediplano, possui muitas características estruturais de hábitat semelhantes ao ambiente de encosta como fluxo turbulento de água e substrato composto por material de grande diâmetro. As condições físicas e químicas nas cabeceiras são bem mais estressantes do que nos demais trechos, sendo poucas as espécies de peixes que apresentam adaptações para sobreviverem nessas condições (MATTEWS \& STYRON, 1981). Por outro lado, os pontos B3 e G3, localizados no vale, e B2, no pediplano, que representam ambientes mais estáveis, apresentaram maiores freqüências de espécies ocasionais. Quando os ambientes foram considerados na análise da constância, um padrão semelhante foi encontrado: a maioria das espécies do ambiente de encosta foi acessória/constante, ao passo que, nos ambientes de pediplano e vale, a maioria foi ocasional.

Uieda (1984) apresentou três explicações para justificar a ocorrência de espécies acessórias e ocasionais: i) que estas espécies provavelmente são migratórias e juntam-se à comunidade local em certos períodos do ano; ii) que estas espécies apresentam baixa densidade populacional; ou iii) que estas espécies se abrigam nos lugares em que a amostragem é difícil, resultando em baixas freqüências nas amostragens. Para as microbacias estudadas, as duas últimas situações podem ter ocorrido. Braga (2004) verificou, na microbacia do Ribeirão Grande, que muitas espécies de diferentes famílias apresentam baixa fecundidade, o que leva a uma diminuição no tamanho das populações e, apesar do grande esforço amostral empregado nesse estudo, nos pontos mais baixos, os apetrechos de pesca utilizados foram as redes-de-espera e a redinha-de-arrasto, que são bastante seletivos, o que pode ter deixado de amostrar espécies que se abrigam em locais de difícil acesso. 


\section{Curvas de Abundância e Biomassa (ABC)}

O método de comparação de abundância e biomassa ( $\mathrm{ABC}$ ), proposto por Warwick (1986), foi inicialmente aplicado para estimar o impacto da poluição sobre comunidades de macroinvertebrados bentônicos de ambientes marinhos. Atualmente esse método está bem difundido na literatura especializada e utilizado para comunidades de peixes (COECK et al., 1993; PENCZAK \& AGOSTINHO, 1997; PENCKZAK \& KRUK, 1999; YEMANE et al., 2005; CARMASSI, 2008; GONÇALVES \& BRAGA, 2008). O modelo é fundamentado nas bases teóricas da seleção $r$ e $k$ (PIANKA, 1994), onde espécies $r$ estrategistas investem na rápida colonização dos ambientes enquanto que as $k$-estrategistas buscam uma maior eficiência na utilização desses ambientes. Em locais onde distúrbios estão ausentes (físicos e biológicos naturais ou poluição e perturbação induzidas), as comunidades são supostamente dominadas por espécies $k$-estrategistas, estando a curva de biomassa acima da curva de abundância; ao passo que, com o aumento dos distúrbios, espécies $k$-estrategistas são substituídas por espécies $r$-estrategistas, que passam a dominar o sistema, estando a curva de biomassa abaixo da curva de abundância (YEMANE et al., 2005). Meire \& Dereu (1990) acrescentam ainda que, sob condições intermediárias de estresse, as curvas de abundância e biomassa aparecem juntas, chegando a cruzarem-se uma ou várias vezes.

A colonização dos riachos pelas comunidades de peixes se faz pela interação entre fatores bióticos e abióticos (JACKSON et al., 2001) e, como resultados, surgem respostas fisiológicas e morfológicas para acomodar essas comunidades ao ambiente (BRAGA, 2004). As condições variáveis e severas das regiões de cabeceiras exigem adaptações e, consequentemente, maior gasto energético dos organismos aquáticos que ali vivem para se moverem contra a corrente e para diminuírem a probabilidade de serem arrastados rio abaixo, ao passo que trechos onde a água é mais lenta ou mesmo parada ao longo do canal, representam um ambiente mais estável, onde a ausência de um fluxo mais forte exige menor gasto de energia dos organismos para sua permanência no local (ALLAN, 1997). Como é menos custoso investir na quantidade do que na qualidade ao tratar-se de reprodução, espera-se que nos trechos mais altos ocorra uma superior abundância em relação à biomassa. Carmassi (2008) encontrou tal padrão para a comunidade de peixes do rio Passa Cinco, um riacho pertencente à sub-bacia do rio Corumbataí, integrante da bacia 
do rio Piracicaba. Nesse mesmo riacho, Rondineli (2007) encontrou fềmeas de Characidium zebra maiores e mais fecundas nos trechos mais à montante. Nos ambientes amostrados, em geral, a abundância foi superior à biomassa, com exceção do ponto mais baixo da microbacia do ribeirão dos Buenos (B3) que, apesar de abundância ser superior para as espécies intermediárias, o que prevaleceu foi a biomassa superior à abundância, $\mathrm{o}$ que pode ser explicado pela presença de uma guilda de predadores (CLARKE \& WARWICK, 1994 apud CASATTI et al., 2006). No entanto, as curvas de abundância e biomassa apresentaram-se bem próximas para todos os pontos analisados, cruzando-se ao menos uma vez. Assim, pode-se dizer que as comunidades das microbacias do ribeirão dos Buenos e do rio Guaratinguetá encontram-se sob condições intermediárias de estresse (ou moderadamente perturbadas), havendo, portanto, um equilíbrio entre as estratégias de vida adotadas pelas espécies.

\section{Raridade}

Além da ocorrência e do número de indivíduos, a abundância também pode ser definida em peso, sendo essas três medidas complementares e com diferentes informações acerca da assembléia (FERREIRA, 2007a). Algumas espécies de médio-grande porte foram abundantes em peso (Rhamdia sp., Oligosarcus hepsetus e Synbranchus marmoratus), mas numericamente pouco representativas. Como o tamanho do animal está relacionado com o peso, e é razoável supor que peixes maiores são mais pesados, a alta contribuição em biomassa dessas espécies pode ser explicada. Por outro lado, a pequena contribuição em peso para outras espécies pode ser atribuída ao pequeno porte e/ou aos poucos indivíduos coletados (por exemplo, Pareiorhina spp.). Trichomycterus itatiayae foi a espécie mais freqüente nas duas microbacias e, juntamente com Astyanax bimaculatus, compôs o grupo de espécies mais importantes, ou seja, que ocorreram em um grande número de pontos, tiveram muitos indivíduos capturados e contribuições significantes em peso. As espécies de Trichomycterus apresentam distribuição particular aos trechos de corredeiras dos riachos, onde adotam hábitos criptobióticos em ambientes de pequena profundidade, correnteza forte e fundo composto por seixos e cascalhos, protegendo-se de predadores ao mesmo tempo que alimentam-se de insetos aquáticos e algas, recursos abundantes em trechos de 
corredeira (CASATTI \& CASTRO 1998; CASTRO 1999). Já Astyanax bimaculatus está mais relacionado à coluna da água, sendo uma importante espécie forrageira para diversos predadores (ESTEVES, 1996), alimentando-se principalmente de insetos, tanto aquáticos como terrestres (ARCIFA \& MESCHIATTI, 1991).

Gaston (1994) utiliza a proporção de espécies raras para definir locais menos impactados, no entanto, Ferreira (2007a) chama à atenção para o fato dessa variável estar associada à riqueza e, com isso, não trazer informações adicionais e/ou não ser eficiente. $\mathrm{O}$ conjunto de espécies raras aqui apresentado baseou-se na baixa freqüência, nos poucos indivíduos coletados e na baixa contribuição em biomassa. Andrade (2004), utilizando o termo espécie rara no sentido de uma amostragem não representativa da espécie, classificou o jeju (Hoplerythrinus unitaeniatus) e o mussum (Synbranchus marmoratus) como espécies raras na microbacia do Ribeirão Grande.

$\mathrm{Na}$ microbacia do ribeirão dos Buenos três espécies do conjunto das raras merecem destaque. Pseudotocinclus paraybae, recentemente descrita por Takako et al. (2005) na bacia do rio Paraíba do Sul, apresentou apenas um indivíduo no ponto B2. A espécie apresenta cerca de $6 \mathrm{~cm}$ de comprimento padrão e, assim como os demais Hypoptopomatinae, é essencialmente herbívora, mais comumente encontrada próxima ou na parte superior da coluna de água, associada a galhos submersos e macrófitas aquáticas (SHAEFER, 1998 apud TAKAKO et al., 2005). Pareiorhina brachyrhyncha e P. rudolphi ocorreram em apenas dois pontos da microbacia do ribeirão dos Buenos (B1 e b3), sendo o total de indivíduos capturados 10 e 2, respectivamente. Pareiorhina brachyrhyncha também foi recentemente descrita por Chamon et al. (2005) para o Ribeirão Grande e bacias adjacentes. Essas duas espécies, também de pequeno porte, têm suas distribuições restritas aos riachos tributários do rio Paraíba do Sul, na serra da Mantiqueira oriental (REIS et al., 2003; BRAGA \& ANDRADE, 2005; CHAMON et al., 2005). Na microbacia do rio Guaratinguetá, as espécies incluídas no conjunto das raras se deu principalmente pela ocorrência de poucos indivíduos em um único ponto amostral. 


\section{Análise de correspondência}

A análise de correspondência evidenciou o gradiente ambiental, indo dos pontos de encosta em direção ao vale. Para o eixo 1 da CA, foram significativas as variáveis relativas ao tipo de substrato, que evidenciaram a formação de três grupos: o primeiro formado pelos pontos mais altos B1 e G1 e também por G2, que apesar de estar no pediplano compartilha muitas características de hábitat, principalmente tipo de substrato, com os ambientes de encosta, como encontrados em B1 e G1; o segundo formado pelo ponto do pediplano da microbacia do ribeirão dos Buenos (B2); e por fim, os pontos do vale (B3 e G3) formando o terceiro agrupamento. $\mathrm{O}$ eixo 2 da CA separou o ponto $\mathrm{B} 2$, sendo o $\mathrm{pH}$ significativo. Esse ponto é aquele localizado à jusante de uma plantação de arroz, em que o ribeirão dos Buenos sofre um desvio para a irrigação, possuindo $\mathrm{pH}$ mais ácido como já discutido anteriormente. Nas microbacias estudadas, dentre as variáveis estruturais e físicas e químicas da água analisadas, o tipo de substrato presente no canal e o $\mathrm{pH}$ foram importantes na distribuição das espécies de peixe. Gerhard et al. (2004) distinguiram três grupos de riachos no Parque Estadual Intervales, de acordo com a composição e diversidade de peixes, sendo as principais diferenças encontradas entre os grupos atribuídas a fatores de grande escala, como altitude, inclinação e posição na rede de drenagem. Por outro lado, os autores verificaram que diferenças existentes dentro de cada grupo estiveram relacionadas a fatores específicos de cada local, como complexidade de hábitat, variáveis físicas e químicas da água, bem como impactos antrópicos, o que é bastante plausível para as comunidades estudadas no presente trabalho. Assim, a estrutura de uma comunidade parece refletir as respostas das populações às condições ambientais bem como a dinâmica das populações de todas as suas espécies constituintes. 


\section{Referências}

AB'SABER, A. N. Ocorrência de "linhas de pedra" na região de São Paulo. Geomorfologia, v. 10, p. 9-10, 1969.

AGÊNCIA NACIONAL DE ÁGUA (ANA). Projeto Gestão dos Recursos Hídricos da Bacia Hidrográfica do Rio Paraíba do Sul. Laboratório de Hidrologia e Estudos de Meio Ambiente da COPPE/UFRJ, 2001.

AGOSTINHO A. A.; BINI, L. M.; GOMES, L. C. Ecologia de comunidades de peixes da área de influência do reservatório de Segredo. In: AGOSTINHO A. A.; GOMES, L. C. (Eds.) Reservatório de Segredo: bases ecológicas para o manejo. EDUEM, Maringá - PR, Cap.6, p. 97-111, 1997.

ALLAN, J.D. Stream Ecology: structure and function of running water. New York: Chapman \& Hall, 338p., 1997.

ANDRADE, P. M. Distribuição, dieta e ecomorfologia das espécies de peixes no sistema do ribeirão Grande, no município de Pindamonhangaba, SP. 2004. Tese (Doutorado em Ciências Biológicas - Zoologia) - Instituto de Biociências - Unesp, Rio Claro, 2004.

ANGERMEIER, P. L. \& KARR, J. R. Fish communities along environmental gradients in a system of tropical streams. Environmental Biology of Fishes, v. 9, n. 2, p.135, 1983.

ANGERMEIER, P. L. \& SCHLOSSER, I. J. Species-area relationships for stream fishes. Ecology, v. 70, n. 5, p. 1450-1462, 1989.

ARAÚJO, F. G. Composição e estrutura da comunidade de peixes do médio e baixo rio Paraíba do Sul, RJ. Revista Brasileira de Biologia, v. 56, n. 1, p. 111-126, 1996.

ARAÚJO, F. G. Adaptação do índice de integridade biótica usando a comunidade de peixes para o rio Paraíba do Sul. Revista Brasileira de Biologia, v. 58, n. 4, p. 547-558, 1998. 
ARAÚJO, F. G.; FICHBERG, I.; PINTO, B. C. T. \& PEIXOTO, M. G. Variações espaciais na assembléia de peixes no rio Paraíba do Sul (Barra Mansa, Barra do Piraí), Rio de Janeiro, Brasil. Revista Brasileira de Zoologia, v. 18, n. 2, p. 483-492, 2001.

ARAÚJO, F. G.; FICHBERG, I.; PINTO, B. C. T. \& PEIXOTO, M. G. A preliminary Index of Biotic Integrity for monitoring the condition of the rio Paraíba do Sul, sothesat Brazil. Environmental Management, v. 32, n. 4, p. 516-526, 2003.

ARAÚJO, F. G.; PINTO, B. C. T. \& TEIXIERA, T. P. Longitudinal patterns of fish assemblages in a large tropical river in southeastern Brazil: evaluating environmental influences and some concepts in river ecology. Hydrobiologia, v. 618, p. 89-107, 2009.

ARCIFA, M. S. \& MESCHIATTI, A. J. Distribuição e ecologia alimentar de peixes em um reservatório do estado de São Paulo (SP). In: Encontro Brasileiro de Ictiologia, Maringá, PR, 1991, Resumos, p. 81, 1991.

BALON, E. K. \& STEWART, D. J. Fish assemblage in a river with unusual gradient (Luongo, Africa - Zire system), reflections on river zonation, and description of another new species. Environmental Biology of Fishes, v. 9, p. 225-252, 1983.

BARRETTO, M. G. \& UIEDA, V. S. Influence of the abiotic factors on the ichthyofauna composition in different orders stretches of Capivara river, SP, Brazil. Verh. Internat. Verein. Limnol., v. 26, p. 2180-2183, 1998.

BAYLEY, P. B. Understanding larger river-floodplain ecossystems: significant economic advantage and increased biodiversity and stability would result from restoration of impaired systems. Bioscience, v. 45, n. 3, p. 153-158, 1995.

BENITES, V. M.; CAIAFA, A. N.; MENDONÇA, E. S.; SHAEFER, C. E. \& KER, J. C. Solos e vegetação nos complexos rupestres de altitude da Mantiqueira e Espinhaço. Floresta e Ambiente, v. 10, n. 1, p. 76-85, 2003.

BENITES, V. M.; SCHAEFER, C. E, G. R.; SIMAS, F. N. B. \& SANTOS, H. G. Soils associated with rock outcrops in the Brazilian mountain ranges Mantiqueira and Espinhaço. Revista Brasileira de Botânica, V.30, n.4, p.569-577, 2007. 
BIZERRIL, C. R. S. F. A ictiofauna da bacia do rio Paraíba do Sul. Biodiversidade e padrões biogeográficos. Brazilian Archives Biology and Technology, Curitiba, v. 42, n. 2, p. 233-250, 1999.

BRAGA, F. M. S. \& ANDRADE, P. M. Distribuição de peixes na microbacia do Ribeirão Grande, Serra da Mantiqueira Oriental, São Paulo, Brasil. Iheringia, Sér. Zool., v. 95, n. 2, p. 121-126, 2005.

BRAGA, F. M. S. Habitat, distribuição e aspectos adaptativos de peixes da microbacia do ribeirão Grande, Estado de São Paulo, Brasil. Acta Scietiarium, v. 26, n. 1, p. 31-36, 2004.

CAMPOS, H. Estatística experimental não paramétrica. 4 ed. São Paulo: ESALQ/USP, 1983.

CARMASSI, A. L. Variação espaço-temporal na composição da comunidade de peixes do rio Passa Cinco (SP). 2008. Dissertação (Mestrado em Zoologia) - Universidade Estadual Paulista, Rio Claro, 2008.

CASATTI, L. Fish assemblage structure in a first order stream, southeastern Brazil: longitudinal distribution, seasonality, and microhabitat diversity. Biota Neotropica, v. 5, n. 1, p. 1-9, 2005.

CASATTI, L., LANGEANI, F. \& FERREIRA, C.P. Effects of physical habitat degradation on the stream fish assemblage structure in a pasture region. Environmental Management, v. 38, n. 6, p. 974-982, 2006.

CASATTI, L. \& CASTRO, R. M. C. A fish community of the São Francisco Rivers headwaters riffles, southeastern Brazil. Ichthyol. Explor. Freshwaters, v. 9, n. 3, p. 229$242,1998$.

CASTRO, R. M. C.; CASATTI, L.; SANTOS, H. F.; FERREIRA, K. M.; RIBEIRO, A. C.; BENINE, R. C.; DARDIS, G. Z. P.; MELO, A. L. A.; STOPIGLIA, R.; ABREU, R. X.; BOCKMANN, F. A.; CARVALHO, M.; GIBRAN, F. Z. \& LIMA, F. C. T. Estrutura e composição da ictiofauna de riachos do rio Paranapanema, sudeste do Brasil. Biota Neotropica, v. 3, n. 1, p. 1-31, 2003. 
CASTRO, R. M. Evolução da ictiofauna de riachos sul-americanos: padrões gerais e possíveis processos causais. In: Oecologia Brasiliensis: Ecologia de peixes de riachos, (E.P. Caramaschi; R. Mazzoni; P.R. Peres-Neto. eds.). Programa de Pós-Graduação em Ecologia, UFRJ. Rio de Janeiro. p. 139-155, 1999.

CETRA, M. \& PETRERE-JÚNIOR, M. Fish assemblage structure of the Corumbataí River Basin, São Paulo State, Brazil: characterization and anthropogenic disturbances. Braz. J. Biol. = Rev. Bras. Biol., v. 66, n. 2A,p. 431-439, 2006.

CHAMON, C. C.; ARANDA, A. T. \& BUCKUP, P. A. Pareiorhina brachyrhyncha (Loricariidae: Siluriformes): a New Species of Fish from the Para1'ba do Sul Slope of Serra da Mantiqueira, Southeastern Brazil. Copeia, n. 3, p. 550-558, 2005.

COEK, J.; VANDELANNOOTE, A.; YSEBOODT, R. \& VERHETEN, R. F. Use of the abundance/biomass method for comparison of fish communities in regulated and unregulated lowland rivers in Belgium. Regul. Rivers, v. 8, n. 1/2, p. 73-82, 1993.

DAJOZ, R. Ecologia Geral. São Paulo, Vozes. 472p., 1978.

ESTEVES, F. A. Fundamentos de Limnologia. Rio de Janeiro, Interciência, 575p., 1988.

ESTEVES, K. E. Feeding ecology of three Astyanax species (Characidae, Tetragonopterinae) from a foodplain lake of Mogi-Guaçú River, Paraná River basin, Brazil. Environmental Biology of Fishes, v. 46, p. 83-101, 1996.

ESTILIANO, E. O. Influências da geomorfologia fluvial na distribuição espacial das assembléias de peixes do rio Paraíba do Sul. 2006. Dissertação (Mestrado em Ciências Ambientais e Florestais), Universidade Federal do Rio de Janeiro, 2006.

EVANS, J.W. \& NOBLE, R.L. The longitudinal distribution of fishes in an east Texas stream. American Naturalist, v. 101, p. 333-342, 1979.

FERREIRA, C.P. \& CASATTI, L. Influência da estrutura do habitat sobre a ictiofauna de um riacho em uma micro-bacia de pastagem, São Paulo, Brasil. Rev. Bras. Zool., v. 23, n. 3, p. 642-651, 2006. 
FERREIRA, F. C. Ictiofauna de riachos na planície costeira da bacia do rio Itanhaém, litoral sul de São Paulo. 2007. Dissertação (Mestrado em Zoologia) - Universidade Estadual Paulista, Rio Claro, 2007a.

FERREIRA, K. Biology and ecomorphology of stream fishes from the rio Mogi-Guaçu basin, Southeastern Brazil. Neotropical Ichthyology, v. 5, n. 3, p. 311-326, 2007 b.

FIALHO, A. P.; OLIVEIRA, L. G.; TEJERINA-GARRO, F. L. \& GOMES, L. C. Fish assemblage structure in tributaries of the Meia Ponte River, Goiás, Brazil. Neotropical Ichthyology, v. 5, n. 1, p. 53-60, 2007.

GARUTTI, V. Distribuição longitudinal da ictiofauna em um córrego da região noroeste do Estado de São Paulo, bacia do rio Paraná. Revista Brasileira de Biologia, v. 48, n. 4, p. $747-759,1988$.

GASTON, K. J. Rarity. London: Chapman \& Hall, 205p.,1994.

GERHARD, P.; MORAES, R. \& MOLANDER, S. Stream fish communities and their associations to habitat variables in a rain forest reserve in southeastern Brazil. Environmental Biology of Fishes, v. 71, p. 321-340, 2004.

GILLIAM, J.F., FRASER, D.F. \& ALKINS-KOO, M. Structure of a tropical stream fish community: a role for biotic interactions. Ecology, v.74, p. 1856-1870, 1993.

GONÇALVES, C. S. \& BRAGA, F. M. S. Diversidade e ocorrência de peixes na área de influência da UHE Mogi Guaçu e lagoas marginais, bacia do alto rio Paraná, São Paulo, Brasil. Biota Neotropica, v.8, n. 2, p. 103-114, 2008.

GORMAN, O. T. The dynamics of habitat use in a guild of Ozark minnows. Ecological Monographs, v. 58, p. 1-18, 1988.

GORMAN, O.T. \& KARR, J. R. Habitat structure and stream fish communities. Ecology, v. 59, n. 3 , p. 507-515, 1978. 
INGENITO, L F. S. \& BUCKUP, P. A. The Serra da Mantiqueira, south-eastern Brazil, as a biogeographical barrier for fishes. Journal of Biogeography, v. 34, p. 1173-1182. 2007.

JACKSON, D.A., PERES-NETO, P.R. \& OLDEN, J.D. What controls who is where in freshwater fish communities - the rules of biotic, abiotic, and spatial factors. Can. J. Fish. Aquat. Sci., v. 58, p. 157-170, 2001.

LANGEANI, F.; CASATTI, L.; GAMEIRO, H. S.; CARMO, A. B. \& ROSSA-FERES, D. C. Riffle and pool fish communities in a large stream of southeastern Brazil. Neotropical Ichthyology, v. 3, n. 2, p. 305-311, 2005.

LEMES, E. M. \& GARUTTI, V. Ecologia da ictiofauna de um córrego de cabeceira da bacia do Alto rio Paraná, Brasil. Iheringia, Sér. Zool., v. 92, n. 3, p. 69-78, 2002.

LOWE-MCCONNELL, R. H. Estudos ecológicos de comunidades de peixes tropicais. São Paulo, Edusp. 535p., 1999.

LuiZ, E. A.; GOMES, L. C.; AGOstinhO, A. A. \& BUlla, C. K. Influência de processos locais e regionais nas assembléias de peixes em reservatórios do Estado do Paraná, Brasil. Acta Scientiarum, v. 25, n. 1, p. 107-114, 2003.

MARTIN-SMITH, K. M. Relationships between fishes and habitat in rainforest streams in Sabah, Malaysia. Journal of Fish Biology, v. 52, p. 458-482, 1998.

MATTHEWS, W.J. Patterns in freshwater fish ecology. Chapman \& Hall, New York, 1998.

MATTHEWS, W. J. \& STYRON, J. T. Tolerance of headwater vs. mainstream fishes for abrupt physicochemical changes. American Midland Naturalist, v. 105, p. 149-158, 1981.

MATTHEWS, W.J.; HOUGH, D. J. \& ROBISON, H. W. Similarities in fish distribution and water quality patterns in streams of Arkansas: congruence of multivariate analyses. Copeia, v. 2, p. 296-303, 1992. 
MAZZONI, R. Estrutura das comunidades e produção de peixes de um sistema fluvial costeiro de Mata Atlântica, Rio de Janeiro. 1998. Tese (Doutorado em Ecologia e Recursos Naturais) - Universidade Federal de São Carlos, 100p., 1998.

MAZZONI, R. \& IGLESIAS-RIOS, R. Distribution pattern of two fish species in a costal stream in southeast Brazil. Braz. J. Biol., v. 62, n. 1, p. 171-178, 2002.

MAZZONI, R. \& LOBÓN-CERVIÁ, J. Longitudinal structure, density and production rates of a neotropical stream fish assemblage: the river Ubatiba in the Serra do Mar, southeast Brazil. Ecography, v.23, p. 588-602, 2000.

MEADOR, M. R. \& GOLDSTEIN, R. M. Assessing water quality at large geographic scales: relations among land use, water physicochemistry, riparian condition, and fish community structure. Environmental Management, v.31, p. 504-517, 2003.

MEIRE, P. M. \& DEREU, J. Use of the abundance/biomass comparison method for detecting environmental stress: some considerations base don intertidal macrozoobenthos and bird communities. Journal Applied Ecology, v. 27, p. 210-223, 1990.

MODENESI-GAUTTIERI, M. C.; HIRUMA, S. T. \& RICCOMINI, C. Morphotectonics of a high plateu on the northwestern flank of the Continental Rift of southeastern Brazil. Geomorphlogy, v. 43, p. 257-271, 2002.

MORAES, A. J. Manual para avaliação da qualidade da água. São Carlos: RIMA, 2001.

OSBORNE, L. L. \& WILEY, M. J. 1992. Influence of tributary spatial position on the structure of warmwater fish communities. Can. J. Fish. Aquat. Sci., v. 49, p. 671-681, 2000.

PAVANELLI, C. S. \& CARAMASCHI, E. P. Temporal and spatial distribution of the ichthyofauna in two streams of upper rio Paraná basin. Braz. Arch. Biol. Tech., v. 46, n. 2, p. 271-280, 2003.

PENCKZAK, T. \& AGOSTINHO, A. A. Aplicação do método de comparação de abundância/biomassa $(\mathrm{ABC})$ na comunidade de peixes do reservatório de Segredo. In: In: 
A. A. Agostinho; L. C. Gomes, L.C. (Eds.) Reservatório de Segredo: bases ecológicas para o manejo. EDUEM, Maringá - PR, Cap.6, p. 97-111, 1997.

PENCKZAK, T. \& KRUK, A. Applicability of the abundance/biomass comparison method for detecting human impacts on fish popualtions in teh Pilica river, poland. Fisheries Research, v. 39, p. 229-240, 1999.

PERES-NETO, P. R.; BIZERRIL, C. R. S. F. \& IGLESIAS, R. An overview of some aspects of river ecology: a case study on fish assemblages distribution in na eastern brazilian coastal river. Oecolgia Brasiliensis, v. 1, p. 317-334, 1995.

PETRY, A. C. \& SCHULZ, U. H. Longitudinal changes and indicator species of the fish fauna in the subtropical Sinos River, Brazil. Journal of Fish Biology, v. 69, p. 272-290, 2006.

PIANKA, E. R. Evolutionary ecology. New York: Harper Collins College, 1994.

PINTO, B. C. T. Condicionantes ambientais estruturadores das assembléias de peixes da bacia do rio Paraíba do Sul: condição do uso da terra, do hábitat físico e qualidade físico-química da água. 2008. Tese de Doutorado (Biologia Animal). Universidade Federal do Rio de Janeiro, 2008.

PINTO, B. C. T.; PEIXOTO, M. G. \& ARAÚJO, F. G. Effects of the proximity from na industrial plant on fish assemblages in the rio Paraíba do Sul, southeastern Brazil. Neotropical Ichthyology, v. 4, n. 2, p. 269-278, 2006.

PLANO DIRETOR DE ECODESENVOLVIMENTO DA APA DA MANTIQUEIRA, PERÍMETRO RESENDE. Conhecimentos, diagnósticos e Proposições. Caderno 1, Prefeitura Municipal de Resende - Secretaria Municipal de Meio Ambiente. Escritório contratado: B\&PG Arquitetura e Uso do Solo, Rio de Janeiro, junho, 2000.

QUINN, G.P. \& KEPUGH, M.J. Experimental design and data analysis for biologists. Cambridge: Cambridge University Press, 2002. 
R DEVELOPMENT CORE TEAM. R: a language and environment for statistical computing. versão 2.8.1. Vienna, Austria, R Foundation for statistical computing. Disponível em: http://www.r-project.org/, 2009.

RAHEL, F. J. \& HUBERT, W. A. Fish assemblages and habitat gradients in a rocky mountain - great plains stream: biotic zonation and additive patterns of community change. Transactions of the American Fishesries Society, v. 120, p. 319-332, 1991.

REIS, R.E., KULLANDER, S.O. \& FERRARIS, Jr., C.J. Check list of the freshwater fishes of South and Central America. EDIPUCRS, Porto Alegre, 2003.

REYES-GAVILÁN, F. G.; GARRIDO, R.; NICIEZA, A. G.; TOLEDO, M. M. \& BRAÑA, F. Fish community variation along physical gradients in short streams of northern Spain and the disruptive effect of dams. Hydrobiologia, v. 321, p. 155-163, 1996.

RINCÓN, P. A. Uso do micro-habitat em peixes de riachos: métodos e perspectivas. In: CARAMASCHI, E. P.; MAZZONI, R. \& PERES-NETO, P. R. (eds). Ecologia de peixes de riachos. Série Oecologia Brasiliensis, v. 6, PPGE-UFRJ, Rio de Janeiro, p. 23-90, 1999.

RONDINELI, G. R. Biologia alimentar e reprodutiva na comunidade de peixes do rio Passa Cinco (SP). 2007. Dissertação (Mestrado em Zoologia) - Universidade Estadual Paulista, Rio Claro, 2007.

ROPER, B. B. \& SCARNECCHIA, D. L. Patterns of diversity, density and biomass of ectothrmic vertebrates in ten small streams along a North America river continuum. Northwest Science, v. 75, p. 168-175, 2001.

SANTOS, A. C. A. \& CARAMASCHI, E. P. Coposition abd seasonal variation of the ichthyofauna from upper rio Paraguaçu (Chapada Diamantina, Bahia, Brazil). Brazilian Archives of Biology and Technology, v. 50, n. 4, p. 663-672, 2007.

SCHLOSSER, I.J. Fish community structure and function along two habitat gradients in a headwater stream. Ecological Monographs, v. 52, n. 4, p. 395-414, 1982. 
SHELDON, A. L. Species diversity and longitudinal succession in stream fishes. Ecology, v. 49, p. 193-198, 1968.

SIEGEL, S. Estatística não-paramétrica para as ciências do comportamento. Rio de Janeiro: McGraw-Hill do Brasil, 350p., 1975.

SILVANO, R. A. M.; AMARAL, B. D. \&OYAKAWA, O. T. Spatial and temporal patterns of diversity and distribution of the Upper Juru'a River fish community (Brazilian Amazon). Environmental Biology of Fishes, v. 57, p. 25-35, 2000.

SÚARÉZ, Y. R. Variação espacial e temporal na diversidade e composição de espécies de peixes em riachos da bacia do Rio Ivinhema, Alto Rio Paraná. Biota Neotrop., v. 8, n. 3,198-204, 2008.

SÚAREZ, Y. R. \& LIMA-JR, S. E. Variação espacial e temporal nas assembléias de peixes de riachos na bacia do rio Guiraí, Alto Rio Paraná. Biota Neotrop., v. 9, n. 1, p. 101-111, 2009.

SÚAREZ, Y.R. \& PETRERE Jr., M. Gradientes de diversidade nas comunidades de peixes da bacia do rio Iguatemi, Mato Grosso do Sul, Brasil. Iheringia, Sér. Zool., v. 96, n. 2, p. 197-204, 2006.

SÚAREZ, Y.R. \& PETRERE Jr., M. Environmental factors predicting fish communities structure of two neotropical rivers in Brazil. Neotrop. Ichthyol., v. 5, n. 1, p. 61-68, 2007.

TAKAKO, A. K.; OLIVEIRA, C. \& OYAKAWA, O. T. Revision of the genus Pseudotocinclus (Siluriformes: Loricariidae: Hypoptopomatinae), with descriptions of two new species. Neotropical Ichthyology, v. 3, n. 4, p. 499-508, 2005.

TAYLOR, C. M. A large-scale comparative analysis of riffle and pool fish communities in a upland stream system. Environmental Biology of Fishes, v. 58, p. 89-95, 2000.

TAYLOR, C.M. \& WARREN Jr, M.L. Dynamics in species composition of stream fish assemblages: environmental variability and nested subsets. Ecology, v. 82, n. 8, p. 23202330, 2001. 
TEIXEIRA, T. P.; PINTO, B. C. T.; TERRA, B. F.; ESTILIANO, E. O. ; GARCIA, D. \& ARAÚJO, F. G. Diversidade das assembléias de peixes nas quatro unidades geográficas do rio Paraíba do Sul. Iheringia, Sér. Zoologia, v. 95, n. 4, p. 347-357, 2005.

UIEDA, V. S. Ocorrência e distribuição dos peixes em um riacho de água doce. Revista Brasileira de Biologia, v. 44, n. 2, p. 203-213, 1984.

UIEDA, V.S. \& BARRETO, M.G. Composição da ictiofauna de quatro trechos de diferentes ordens do rio capivara, Bacia do Tietê, Botucatu, São Paulo. Rev. Bras. Zoociências, v. 1, n. 1, p. 55-67, 1999.

VALÉRIO, S. B.; SÚAREZ, Y. R.; FELIPE, T. R. A.; TONDATO, K. K. \& XIMENES, L. Q. L. Organization patterns of headwater-stream fish communities in the Upper ParaguayParaná basins. Hydrobiologia, v. 583, n.1, p. 241-250, 2007.

VANNOTE, R.L., MINSHALL, G.W., CUMMINS, K.W., SEDELL, J.R. \& CUSHING, C.E. The river continuum concept. Can. J. Fish. Aquat. Sci., v. 37, p. 130-137, 1980.

WALTER, D. M.; LEIGH, D. S.; FREEMAN, M. C.; FREEMAN, B. J. \& PRINGLE, C. M. Geomorphology and fish assemblages in a Piedmont river basin, USA. Freshwater Biology, v. 48, p. 1950-1970, 2003.

WARWICK, R. M. A new method for detecting pollution effects on marine macrobenthic communities. Marine Biology, v. 92, 0. 557-562, 1986.

YEMANE, D.; FIELD, J. G. \& LESLIE, R. W. Exploring the effects of fishing on fish assemblages using Abundance Biomass Comparison (ABC) curves. ICES Journal of Marine Science, v. 62, p. 374-379, 2005. 


\section{CAPÍTULO 2}

\section{Biologia das populações de peixes nas microbacias do ribeirão dos Buenos e do rio Guaratinguetá, na serra da Mantiqueira oriental}

\section{Introdução}

O completo entendimento dos fatores que regem uma comunidade depende do conhecimento da estrutura das populações componentes, particularmente das espécies dominantes, com isso, muitas respostas sobre a ecologia das espécies podem ser obtidas através de estudos sobre a estrutura das populações de peixes.

A análise da estrutura em comprimento de uma população fornece indicativos qualitativos do desenvolvimento da espécie, visto que o crescimento de um indivíduo reflete as condições ambientais (bióticas e abióticas) vigentes (BENEDITO-CECÍLIO \& AGOSTINHO, 1997). Além disso, o conhecimento da estrutura populacional em comprimento fornece indicativos de como a população se distribui longitudinalmente em um segmento de riacho ou em distintos pontos de uma bacia em termos etários, pois o comprimento se relaciona com a idade (SANTOS, 2005; GOMIERO \& BRAGA, 2005).

Através do conhecimento da dieta das espécies é possível compreender as relações entre a ictiofauna e os demais componentes do sistema aquático, servindo de base para o entendimento do papel ecológico desempenhado pelos peixes e fornecendo subsídios para a conservação dos ambientes aquáticos. A insetivoria parece ser comum para a maioria dos peixes de riachos, tanto para aqueles de hábitos diurnos quanto para os noturnos e também para aqueles bentônicos ou nectônicos. Porém, a plasticidade trófica das espécies oportunistas pode garantir a sobrevivência em condições adversas encontradas nesses tipos de ambientes (TEIXEIRA et al., 2005). Outro fator importante é a maneira como o item alimentar se apresenta no ambiente (fixo, enterrado ou vágil) e a capacidade dos peixes para capturar e ingerir esses itens possibilitando a partilha do alimento e a redução da competição (BRAGA et al., 2009), tendo a paisagem do entorno grande influência tanto na qualidade quanto na quantidade de itens alimentares disponíveis para os peixes dessas comunidades (GOMIERO et al., 2008). 
O sucesso alcançado pelos peixes, em ambientes distintos, deve-se à enorme gama de estratégias reprodutivas desenvolvidas pelo grupo, que englobam táticas extremas e, embora estas possam variar em função do ambiente, algumas são conservativas (WOOTTON, 1984). Winemiller (1989), procurando vincular aspectos da história de vida ao hábitat, sugeriu que as características reprodutivas dicotômicas $r-k$, originalmente propostas por Pianka (1970), não contemplavam algumas importantes variações na reprodução de peixes, e reconheceu três padrões reprodutivos para as espécies de água doce da América do Sul: estratégia de equilíbrio (caracterizada pela presença de cuidado parental e reprodução não-sazonal), estratégia oportunista (caracterizada pela capacidade de colonização rápida, maturação precoce e reprodução contínua) e estratégia sazonal (caracterizada pela reprodução sincronizada com a estação chuvosa, alta fecundidade, ausência de cuidado parental e deslocamentos reprodutivos). Winemiller \& Rose (1992), estudando 16 características da história de vida de 216 espécies de peixes da América do Norte, aprimoraram a proposta anterior, discutindo a existência de um contínuo entre os extremos desse sistema triangular de estratégias.

A determinação da época de reprodução de uma espécie fornece importante informação para análises populacionais e sua duração constitui um dado importante para a estratégia de manutenção da espécie (BARBIERI \& BARBIERI, 1988). A maioria das espécies mostra uma periodicidade em seu processo reprodutivo, iniciando o desenvolvimento gonadal em uma época anterior à da reprodução, e completando sua maturação no momento em que as condições ambientais forem adequadas à fecundação e ao desenvolvimento da prole (VAZZOLER, 1996), podendo, entretanto variar de um ano para outro de acordo com as variações abióticas (VAZZOLER et al., 1997).

A estreita correlação entre o peso e o comprimento descreve características bionômicas dos indivíduos de uma população, fornecendo informações importantes sobre a população de uma determinada espécie. Entre as mais freqüentes utilizações da relação entre o peso e o comprimento destacam-se a possibilidade da determinação indireta do peso através do comprimento ou vice-versa, a indicação da condição do peixe em relação ao armazenamento de gordura ou desenvolvimento gonadal, ou mesmo a análise indireta do ritmo do crescimento (LE CREN, 1951). 
Assim, as espécies tendem a manter-se sob condições continuamente dinâmicas e tanto a estrutura como outras características das espécies são alteradas dentro de certos limites, sendo que essa variabilidade representa adaptações às mudanças dentro das condições de sobrevivência (NIKOLSKII, 1969).

No presente capítulo são apresentadas informações biológicas das principais espécies de peixes das microbacias do ribeirão dos Buenos e do rio Guaratinguetá. A estrutura das populações em relação às distribuições de comprimento e proporção sexual, a dieta, a dinâmica reprodutiva e a condição corporal das espécies foram verificadas em relação ao ambiente (microbacias) e ao período (épocas de seca e cheia).

\section{Material e Métodos}

\section{1. Descrição da área de estudo}

Situadas entre os municípios de Pindamonhangaba e Guaratinguetá, no estado de São Paulo, encontram-se as microbacias do ribeirão dos Buenos e do rio Guaratinguetá. Essas redes hidrográficas descem as encostas da serra da Mantiqueira oriental e vão desembocar na margem esquerda do rio Paraíba do Sul.

\subsection{Descrição dos pontos de coleta}

Foram amostrados quinze pontos de coleta (oito deles na microbacia do ribeirão dos Buenos e sete na do rio Guaratinguetá), localizados em regiões da encosta, do pediplano e do vale (Figura 1), nos meses de maio, agosto (representando a estação seca) e novembro de 2008 e fevereiro de 2009 (representando a estação chuvosa). Seis pontos foram amostrados quatro vezes ao longo do período de estudo (B1, B2 e B3 na microbacia do ribeirão dos Buenos e G1, G2 e G3 na microbacia do rio Guaratinguetá), denominados pontos temporais, o que possibilitou o acompanhamento de um ciclo anual completo das espécies. Os demais pontos foram amostrados uma única vez (b1, b2, b3, b4 e b5 na microbacia do ribeirão dos Buenos e g1, g2, g3 e g4 na microbacia do rio Guaratinguetá), 
denominados pontos espaciais e, quando possível, complementaram as informações acerca da biologia das espécies dentro de cada estação.

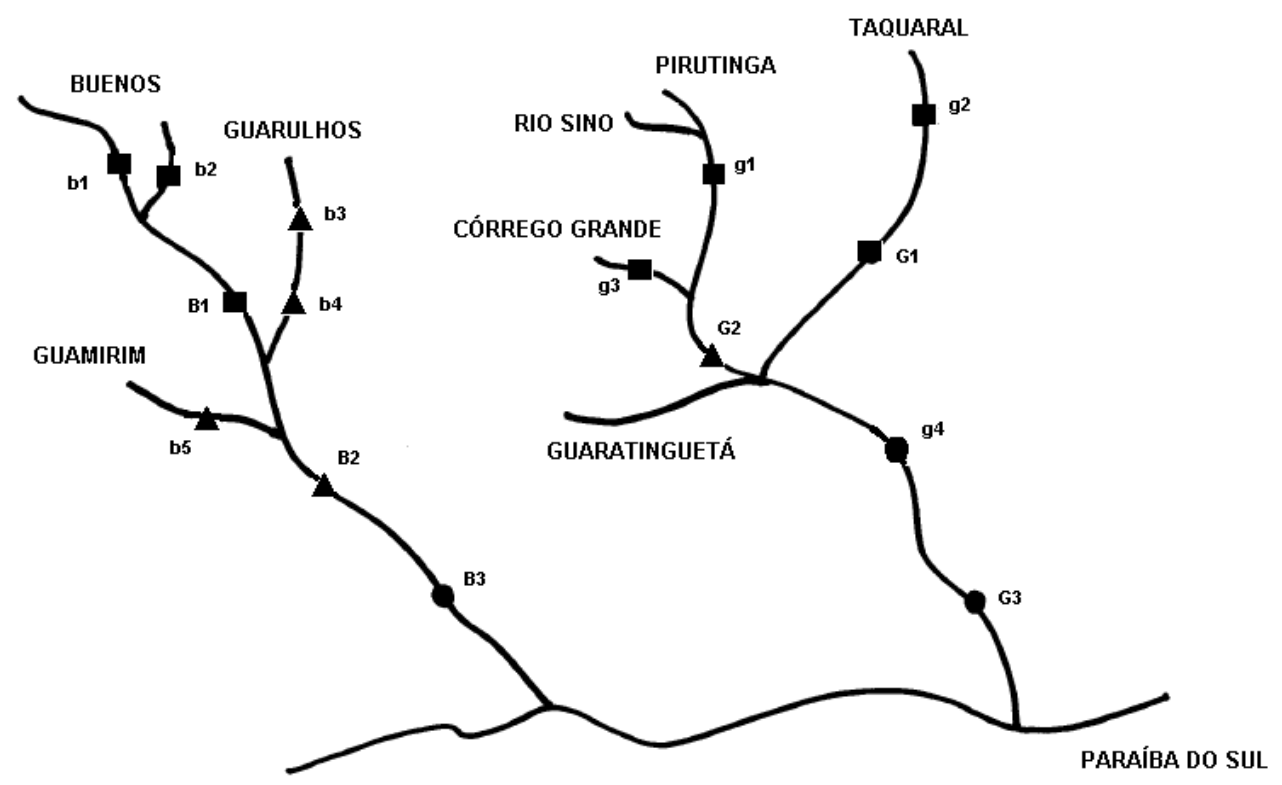

Figura 1: Mapa esquemático com os pontos de coleta distribuídos nas microbacias do ribeirão dos Buenos e rio Guaratinguetá ( $\boldsymbol{\square}$ = pontos na encosta, $\boldsymbol{\Delta}$ =pontos no pediplano, $\boldsymbol{O}$ = pontos no vale).

\subsection{Coleta da ictiofauna}

As amostras foram realizadas com aparelho de pesca elétrica, redinha-de-arrasto e redes-de-espera de acordo com as características físicas de cada ponto. $\mathrm{O}$ equipamento de pesca elétrica foi passado por duas vezes em trechos de $50 \mathrm{~m}$ sem o uso de rede de contenção. $\mathrm{O}$ aparelho, que consiste em um gerador que fornece energia a um retificador de corrente que se conecta a dois puçás, foi manuseado por duas pessoas, que caminharam no riacho em sentido contrário à corrente, usando botas isolantes. À medida que os coletores avançavam, os peixes, sujeitos ao campo elétrico, eram atraídos por galvanotaxia anódica e capturados pelos puçás. A voltagem utilizada foi $500 \mathrm{~V}$ com corrente direta. Em pontos de difícil acesso (região de encosta) foi utilizado o equipamento portátil de pesca elétrica. Redes-de-espera com malhagem de 1,5, 2,0,2,5 e 3,0 cm entre nós adjacentes foram utilizadas em apenas dois pontos amostrais (B3 e G3); a seqüência de redes foi determinada 
ao acaso sendo colocadas no período da tarde e permanecendo até a manhã do dia seguinte. A redinha-de-arrasto foi passada na vegetação marginal por dez vezes nos pontos em que se utilizou redes-de-espera.

Após cada uma das coletas, os peixes foram colocados em sacos plásticos separados por ponto amostral e, então, fixados em formalina $10 \%$ durante 2 dias e posteriormente transferidos para álcool $70 \%$ até a realização das análises.

\subsubsection{Coleta de dados biológicos}

No laboratório, os peixes foram identificados até o nível de espécie e tomados os seguintes dados: comprimento total (CT) e padrão (CP) em centímetros, peso total (PT) em gramas, grau de repleção do estômago (GR), grau de gordura acumulada na cavidade visceral (GA), sexo e estádio de maturação gonadal (BRAGA, 1990).

Ao grau de repleção estomacal (estado de enchimento do estômago) foram atribuídos os seguintes valores: 1 para estômagos considerados vazios, 2 para estômagos parcialmente cheios e 3 para estômagos completamente cheios. Os estômagos com grau de repleção igual a 3 foram retirados da cavidade visceral e mantidos em álcool a 70\% (ZAVALA-CAMIN, 1996), para posterior estudo da dieta.

Para o grau de gordura acumulada na cavidade visceral foram atribuídas três categorias: 1 para a cavidade visceral que não apresenta gordura, 2 para a cavidade visceral parcialmente preenchida com gordura e 3 para a cavidade visceral repleta de gordura.

O estádio de maturação gonadal de cada exemplar foi determinado macroscopicamente, quando possível, ou sob estereomicroscópio, considerando-se os seguintes aspectos: cor, transparência, vascularização superficial e, no caso de ovários, a visualização e aparência dos ovócitos. Ao estádio de maturação gonadal foram atribuídas quatro categorias (conforme escala previamente estabelecida): A para gônadas consideradas imaturas, B para gônadas em maturação ou em repouso, C para gônadas maduras e D para aquelas consideradas esgotadas. 


\subsection{Análise de Dados}

\subsubsection{Estrutura das populações}

A estrutura em comprimento das espécies foi verificada por meio de análises das distribuições de comprimento por microbacia. O comprimento médio dos indivíduos foi comparado por uma ANOVA 2-way, onde os fatores categóricos foram sexo e microbacia. No caso das espécies abundantes em apenas uma microbacia, os comprimentos médios de machos e fềmeas foram comparados por um teste $t$.

Para verificar se a proporção entre machos e fêmeas diferia do esperado (1:1), foi utilizado o teste de $\chi^{2}$ (SIEGEL, 1975), sendo 0,05 o nível de significância considerado.

\subsubsection{Estudo da Dieta}

O método do grau de preferência alimentar - GPA (BRAGA, 1999) foi aplicado para as espécies que tiveram mais que 5 estômagos examinados. Este método consiste em atribuir valores aos itens alimentares de uma dada espécie de acordo com a participação relativa de cada item no estômago analisado. O valor 4 é atribuído quando existe apenas um item alimentar no estômago, quando aparece mais de um item por estômago, os valores adotados são 3, 2 ou 1 de acordo com sua participação relativa no conteúdo estomacal analisado. O valor de GPA é dado pela divisão da somatória dos valores atribuídos a cada item pelo número de estômagos analisados. Assim, os itens alimentares podem ser classificados como preferencial absoluto (GPA igual a 4), preferencial em alto grau (GPA entre 3 e 4), preferencial (GPA entre 2 e 3), secundário (GPA entre 1 e 2) e ocasional (GPA entre 0 e 1$)$.

O método do GPA também foi aplicado aos itens alimentares, possibilitando diagnosticar os principais itens ingeridos pelas espécies durante as estações de seca e cheia.

A freqüência de ocorrência percentual de itens alimentares autóctones e alóctones foi verificada para os ambientes de encosta, pediplano e vale. 


\subsubsection{Estudo da Reprodução}

Foram verificadas as variações dos estádios de maturação gonadal (EM) e dos graus de gordura acumulada na cavidade visceral (GA) por coleta. Para testar a hipótese de que o grau de gordura acumulada na cavidade visceral depende da época do ano não levando em consideração o sexo, foi aplicado um teste de $\chi^{2}$ para testar a hipótese de que duas variáveis categorizadas são independentes (VIEIRA, 2004), sendo 0,05 o nível de significância considerado.

Para que a delimitação do período reprodutivo de uma espécie ou população seja feita, é necessário encontrar um ponto de equilíbrio entre a redução da subjetividade das classificações baseadas em escalas macroscópicas e a impossibilidade de se realizar análises microscópicas para um elevado número de indivíduos, de várias espécies. Daí a necessidade da utilização de mais de um método, por exemplo, a associação entre a variação temporal da freqüência de ovários nos diferentes estádios de maturidade, classificados macroscopicamente, e o uso de indicadores quantitativos da fase em que a gônada se encontra dentro do processo de maturação.

Em função da estreita relação entre o avanço do processo de maturação ovocitária e o aumento do volume e, conseqüentemente, do peso dos ovários, a relação gonadossomática (RGS), que expressa a porcentagem que as gônadas representam do peso total dos indivíduos, é um indicador eficiente do estado funcional dos ovários (VAZZOLER, 1996), sendo que a variação temporal da RGS fornece indicações sobre o período reprodutivo de uma espécie ou população.

Assim, foram ser feitas inferências sobre o período reprodutivo das espécies através das freqüências de indivíduos com gônadas nos diferentes estádios de maturidade e a variação temporal na RGS. Para isso, as espécies mais abundantes ( $\mathrm{n}>30$ ) de cada microbacia tiveram as freqüências dos diferentes estádios de maturação determinadas, assim como a variação do grau máximo de gordura na cavidade visceral (de modo a acompanhar o desenvolvimento das gônadas durante o período de estudo) e a RGS calculada por amostra. 


\subsubsection{Condição corporal}

As relações peso e comprimento foram estimadas para as espécies mais abundantes por sexo, por época de amostragem (seca e cheia) e por microbacia, considerando a expressão $P=a \times C^{b}$, onde $P=$ peso, $C=$ comprimento padrão, $a=$ valor numérico do intercepto e $b=$ valor do coeficiente angular (LE CREN, 1951).

A partir dessas relações, análises de covariância foram utilizadas para avaliar o comportamento do peso (variável dependente) entre os sexos, épocas e microbacias (fatores), considerando o comprimento padrão como covariável (CETRA, 2005).

\section{Resultados}

Dentre as 34 espécies de peixes capturadas nas microbacias do ribeirão dos Buenos e do rio Guaratinguetá, 11 delas apresentaram mais de trinta indivíduos capturados. Considerando todos os pontos amostrais, Trichomycterus itatiayae, Characidium lauroi, Neoplecostomus microps, Astyanax bimaculatus e T. iheringi foram espécies abundantes nas duas microbacias; C. alipioi e Phalloceros caudimaculatus foram abundantes apenas na microbacia do ribeirão dos Buenos e Harttia carvalhoi, Pareiohina rudolphi, $P$. brachyrhyncha e Ancistrus stigmaticus abundantes na microbacia do rio Guaratinguetá (Tabelas1e2). 


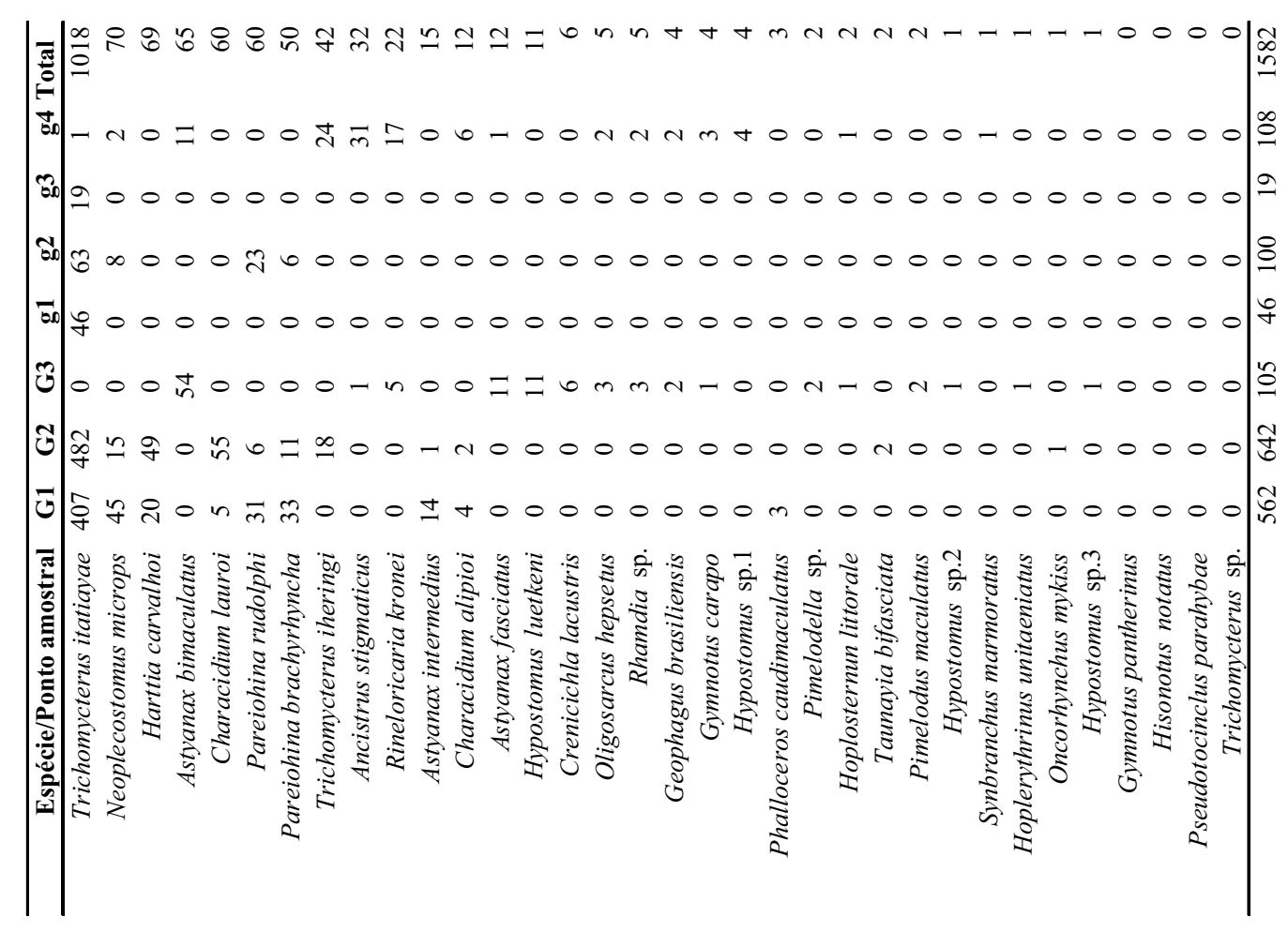

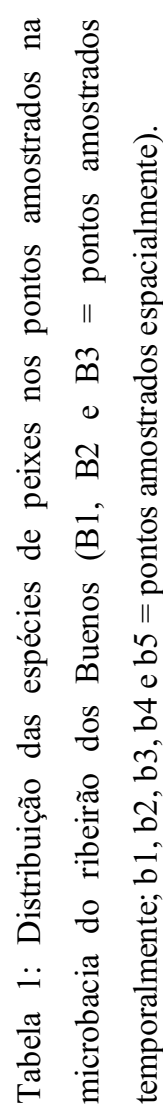

$\bar{\Xi} \mid \bar{m}$

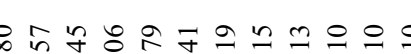

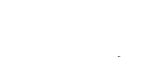

$444 h-7-7-0,400000$ 


\subsection{Estrutura das populações}

\subsubsection{Estrutura em comprimento}

A amplitude de variação de comprimento padrão para os indivíduos de Trychomycterus itatiayae capturados na microbacia do ribeirão dos Buenos foi de 31 a 89 mm e na microbacia do rio Guaratinguetá de 30 a 93 mm (Figura 2).
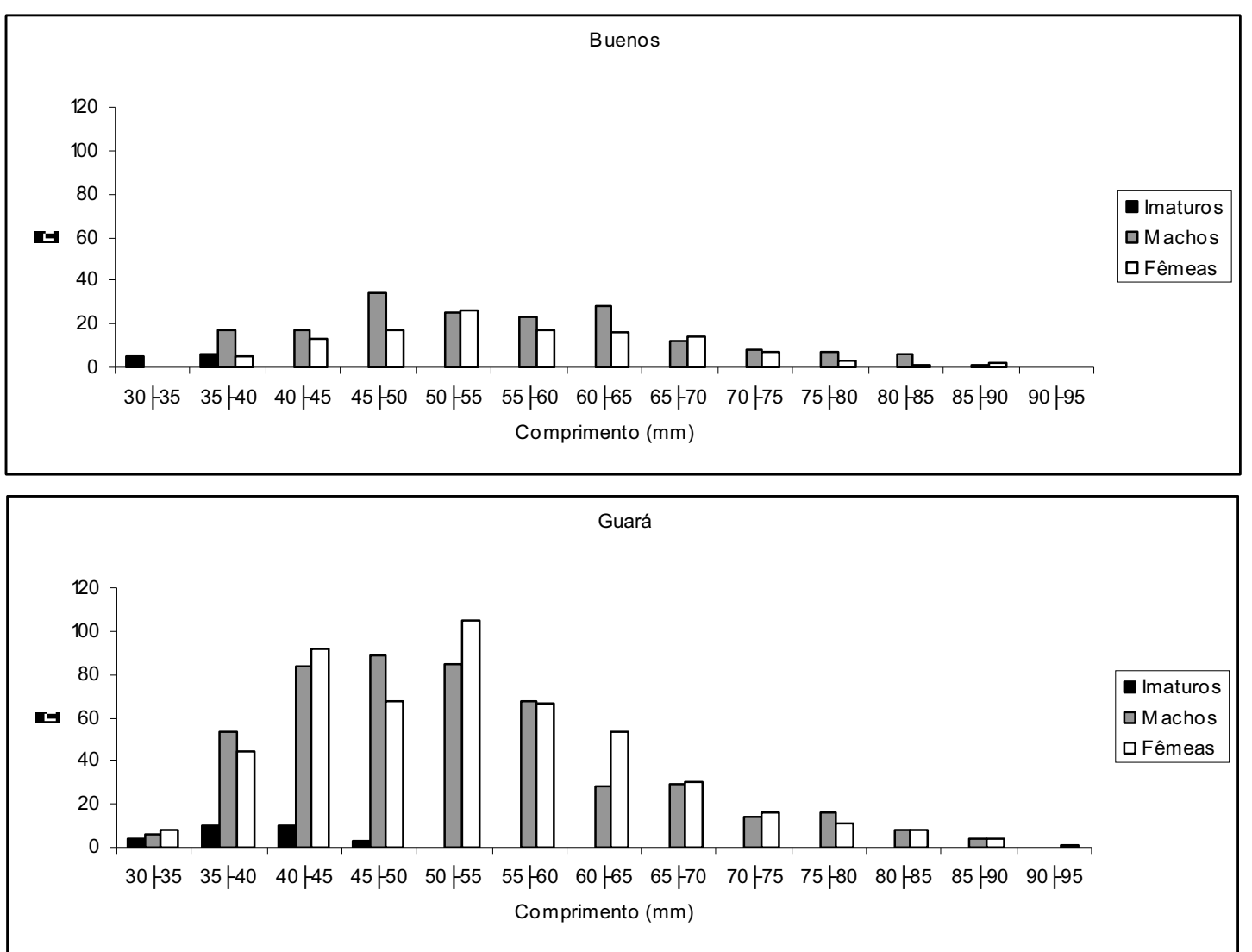

Figura 2: Freqüência numérica (n) de imaturos, machos e fềmeas de Trychomycterus itatiayae amostrados em cada classe de comprimento padrão (mm) nas microbacias do ribeirão dos Buenos e do rio Guaratinguetá. 


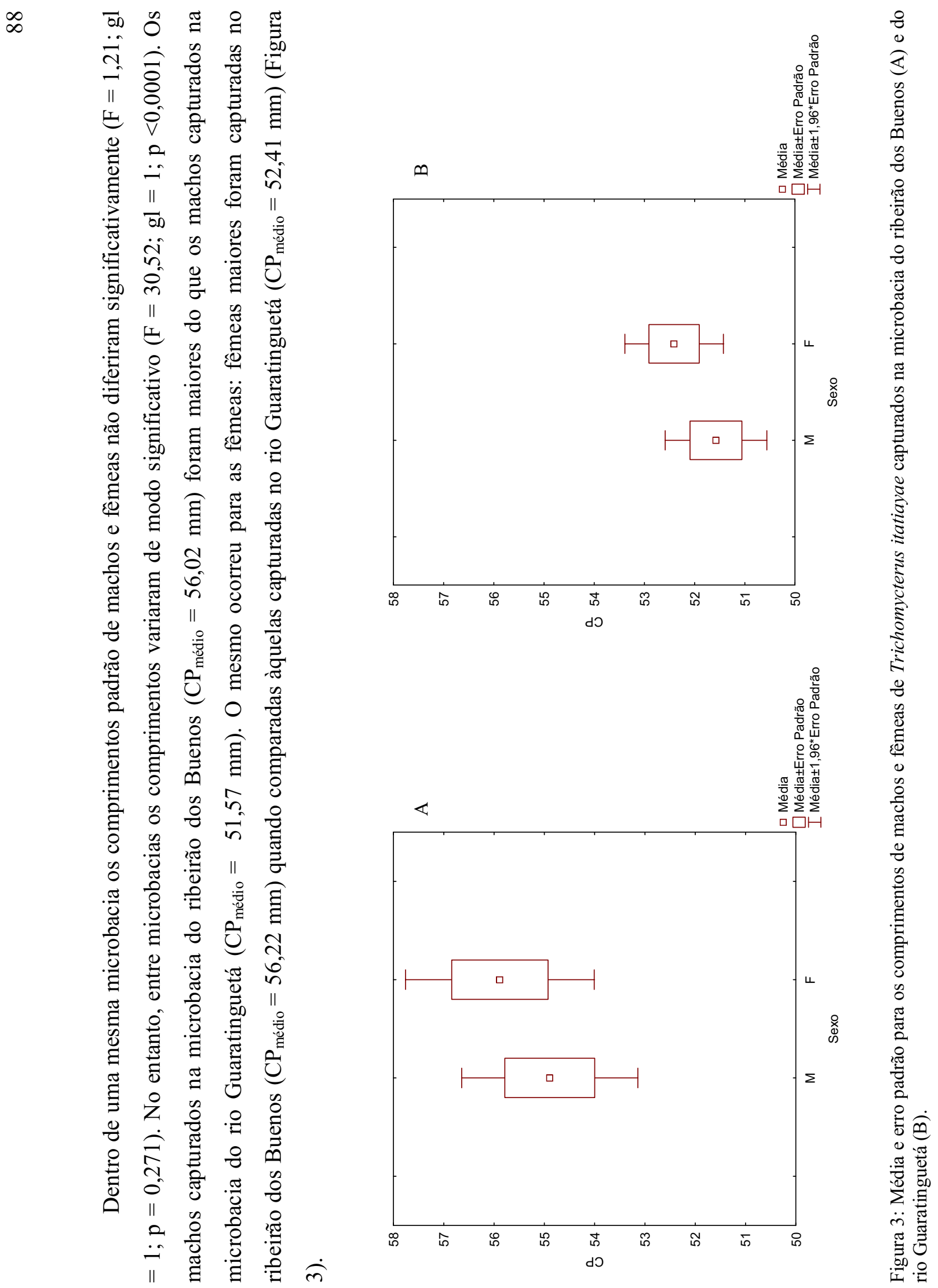


A amplitude de variação de comprimento padrão para os indivíduos de Characidium lauroi capturados na microbacia do ribeirão dos Buenos foi de 24 a $65 \mathrm{~mm}$ e na microbacia do rio Guaratinguetá de 35 a 66 mm (Figura 4).
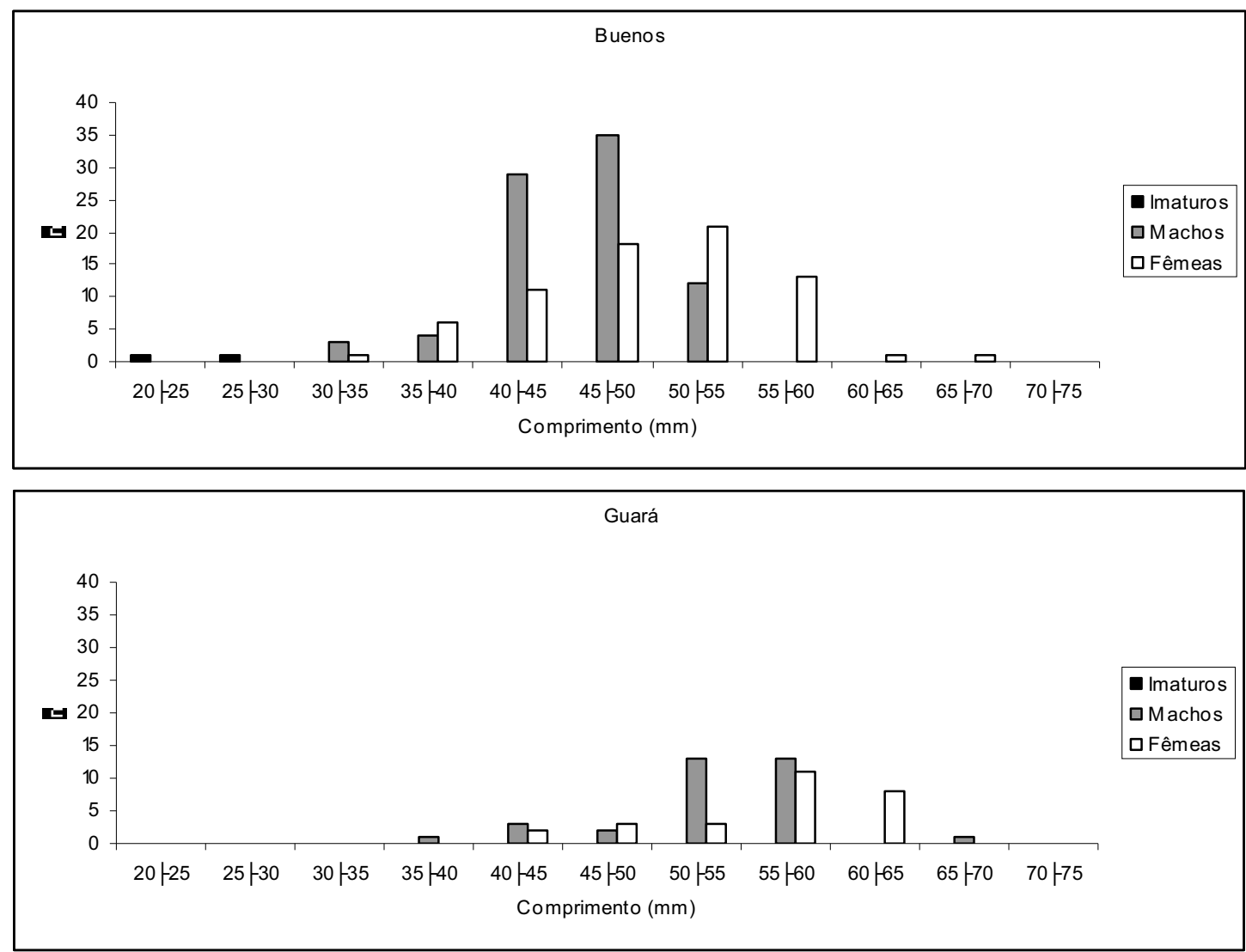

Figura 4: Freqüência numérica (n) de imaturos, machos e fềmeas de Characidium lauroi amostrados em cada classe de comprimento padrão (mm) nas microbacias do ribeirão dos Buenos e do rio Guaratinguetá. 


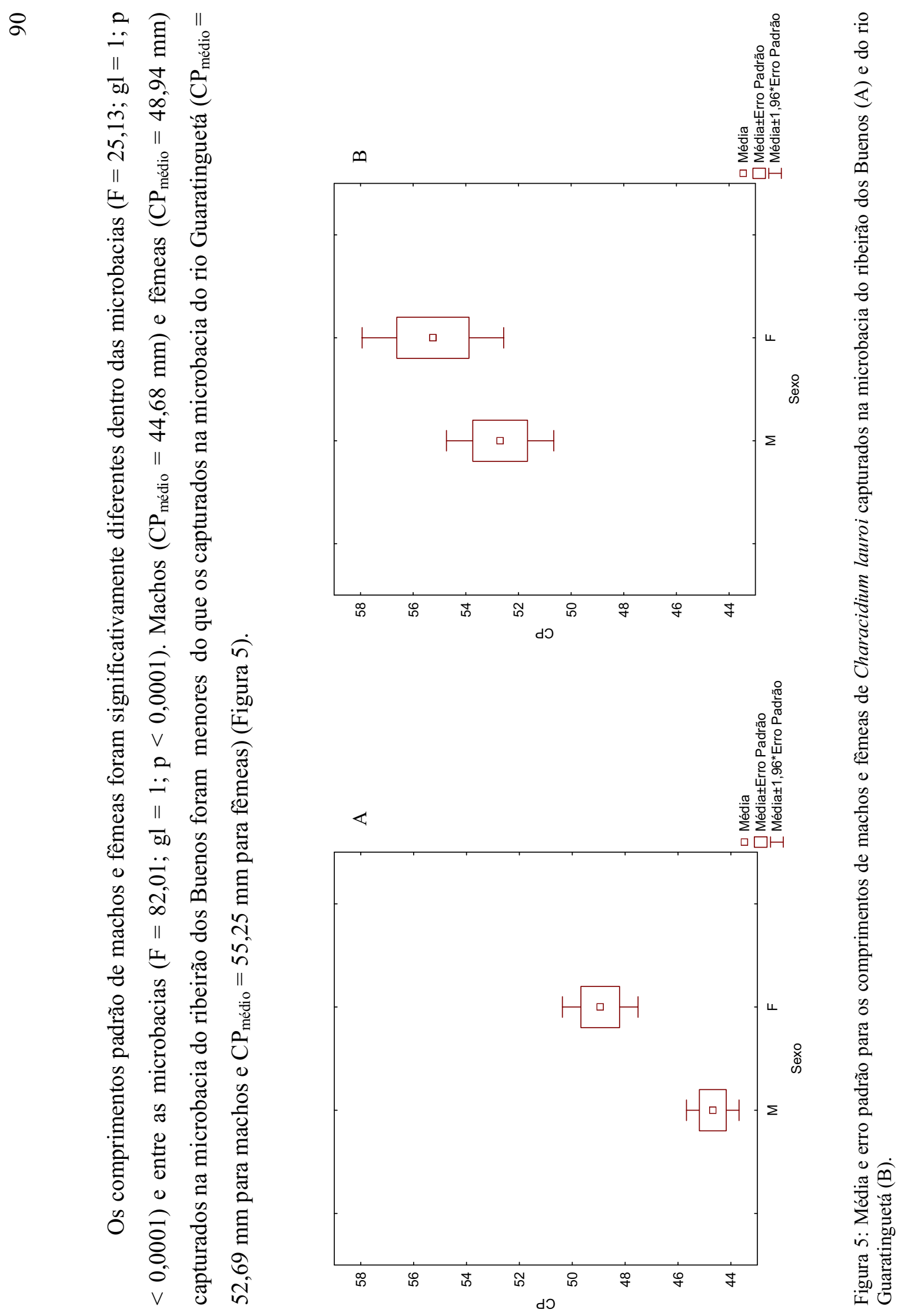


A amplitude de variação de comprimento padrão para os indivíduos de Neoplecostomus microps capturados na microbacia do ribeirão dos Buenos foi de 21 a 100 $\mathrm{mm}$ e na microbacia do rio Guaratinguetá de 22 a 103 mm (Figura 6).
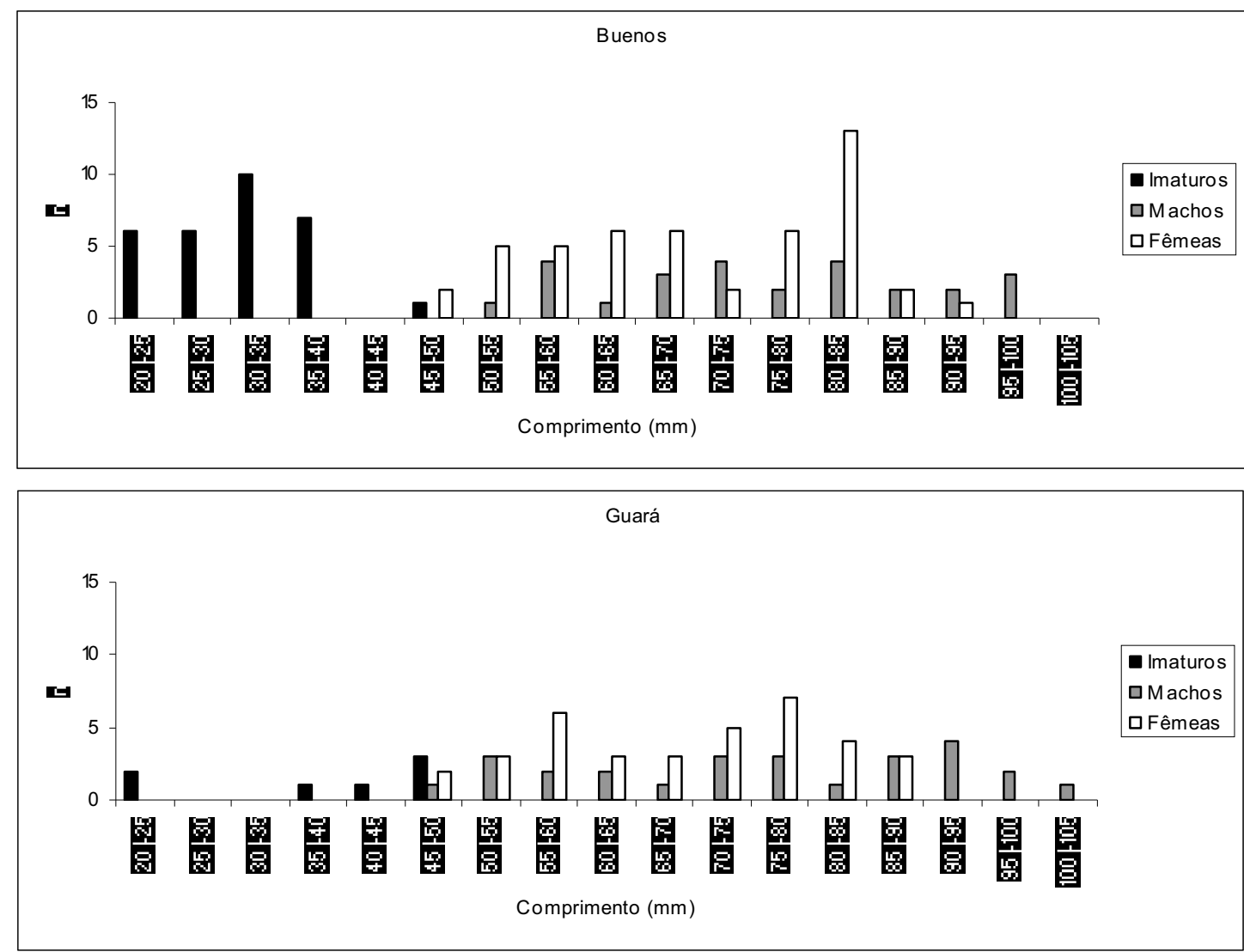

Figura 6: Freqüência numérica (n) de imaturos, machos e fêmeas de Neoplecostomus microps amostrados em cada classe de comprimento padrão $(\mathrm{mm})$ nas microbacias do ribeirão dos Buenos e do rio Guaratinguetá. 


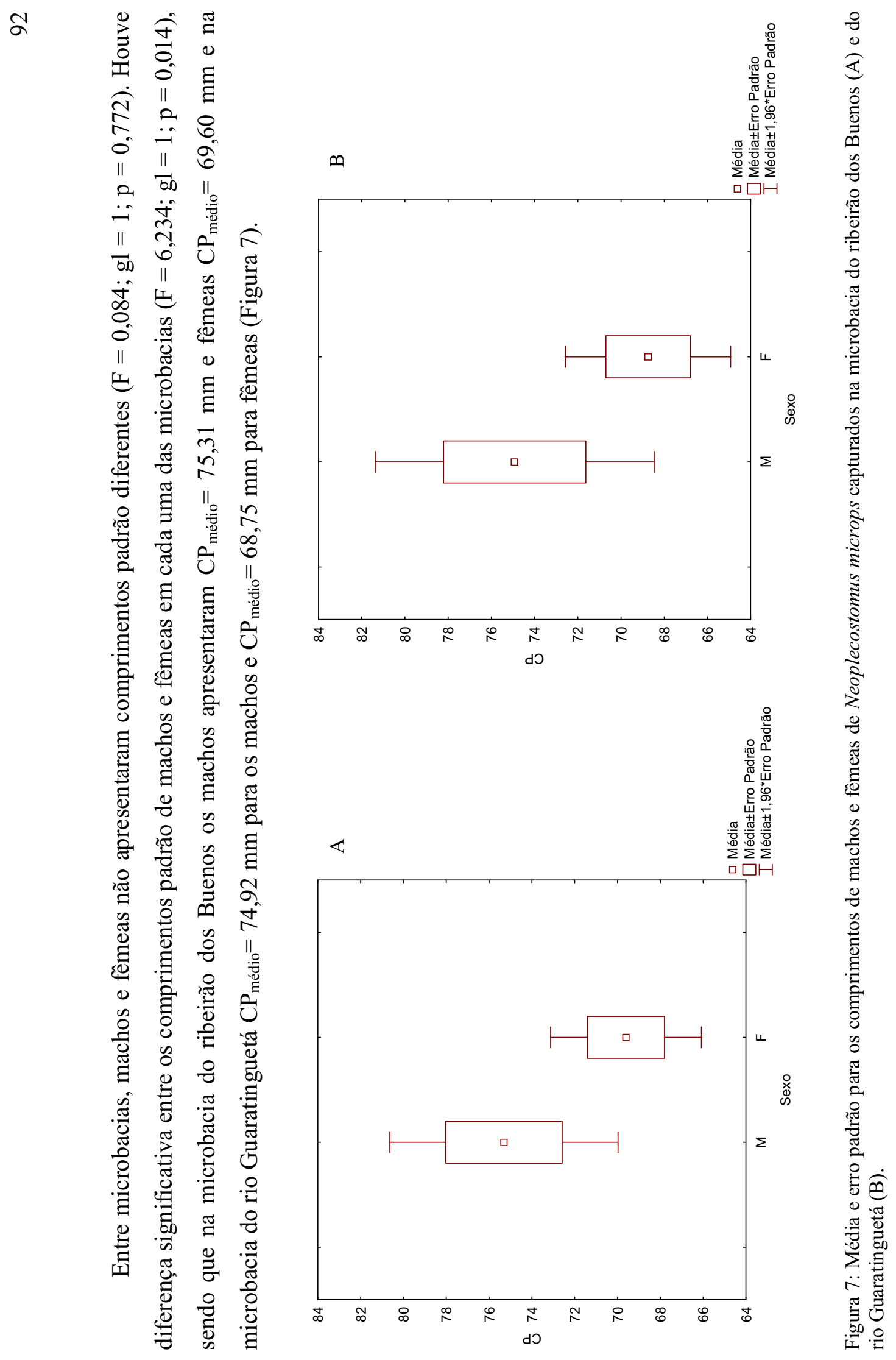


A amplitude de variação de comprimento padrão para os indivíduos de Astyanax bimaculatus capturados na microbacia do ribeirão dos Buenos foi de 23 a $98 \mathrm{~mm}$ e na microbacia do rio Guaratinguetá de 40 a 102 mm (Figura 8).
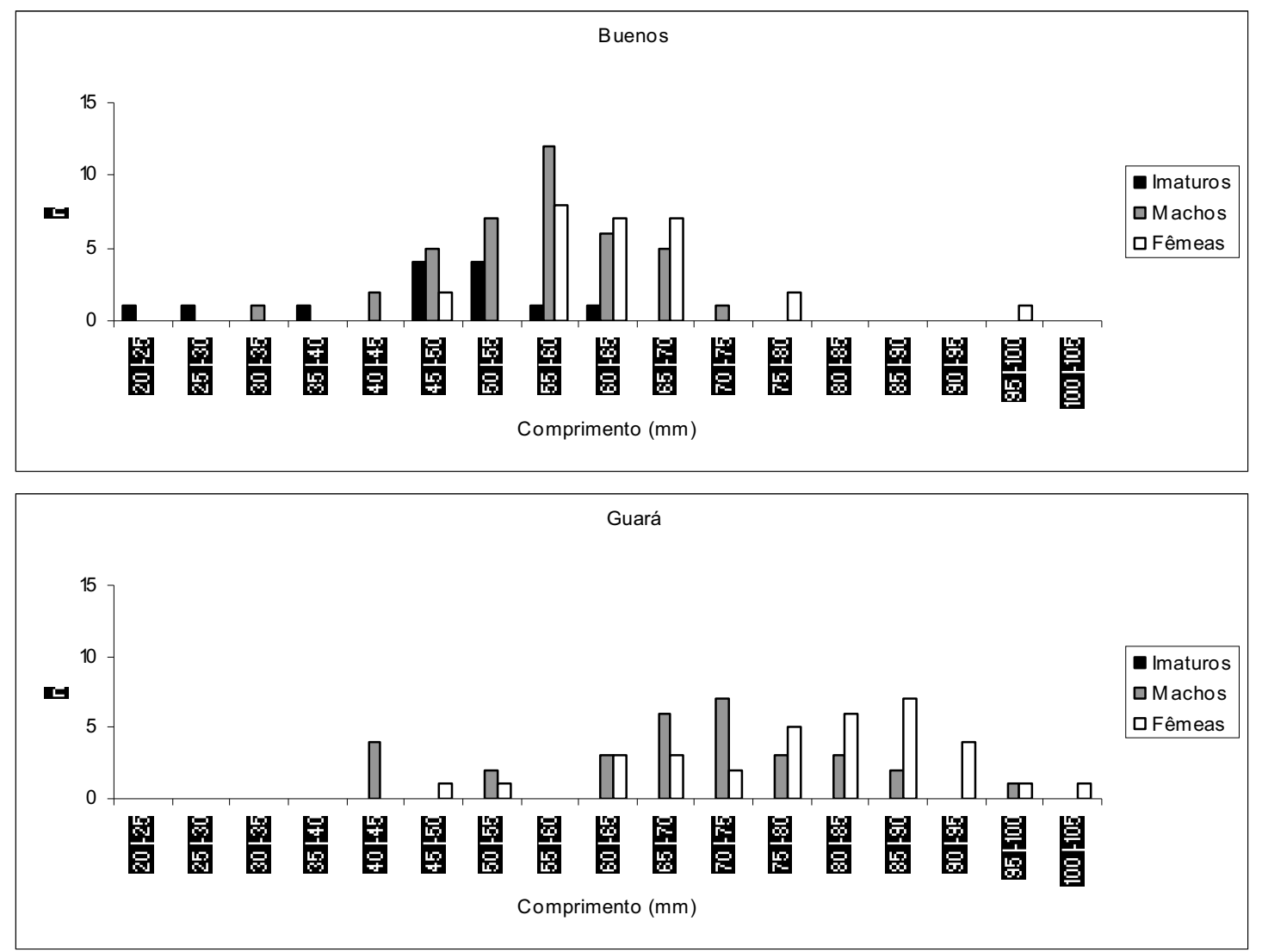

Figura 8: Freqüência numérica (n) de imaturos, machos e fềmeas de Astyanax bimaculatus amostrados em cada classe de comprimento padrão $(\mathrm{mm})$ nas microbacias do ribeirão dos Buenos e do rio Guaratinguetá. 


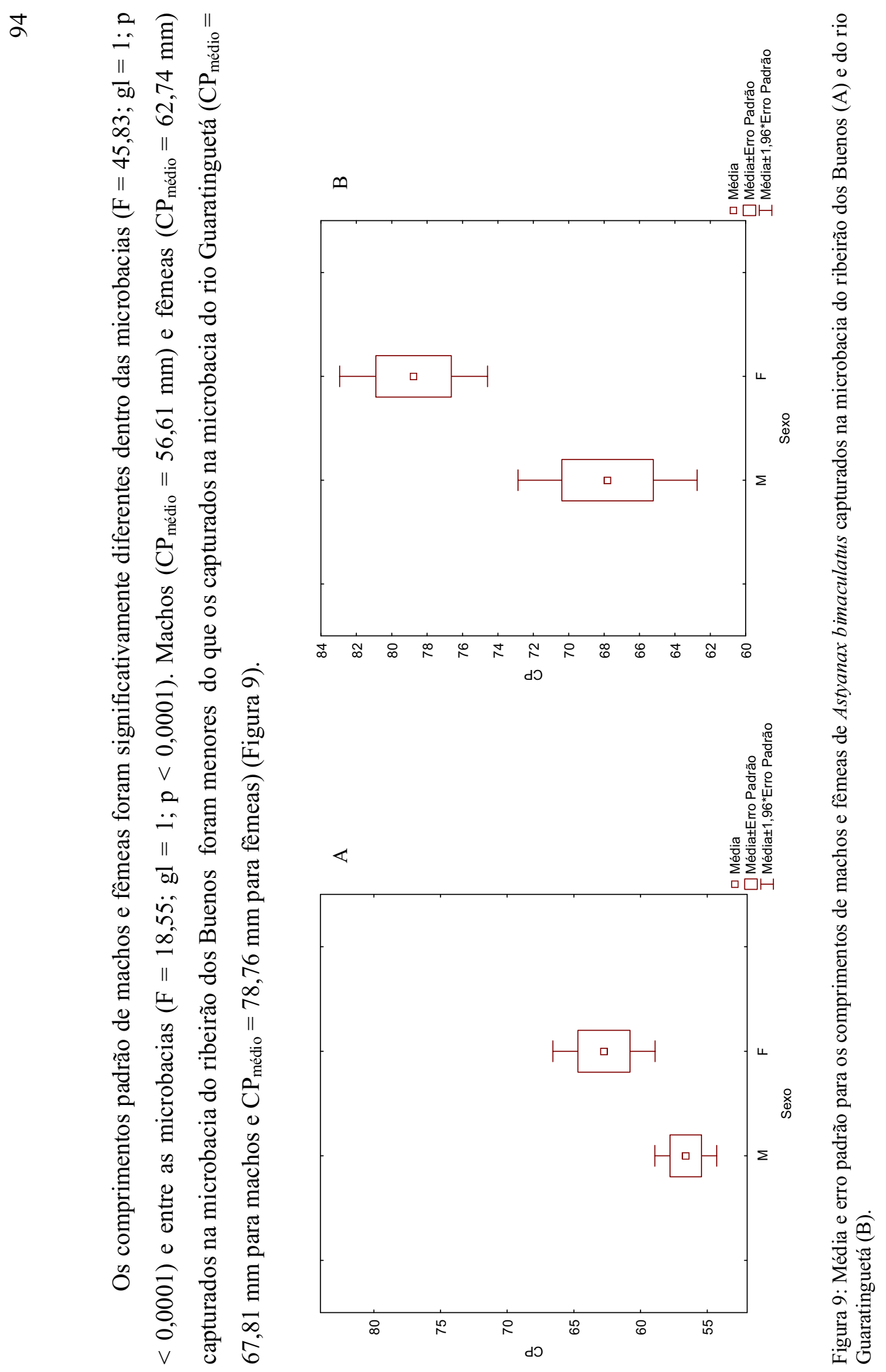


A amplitude de variação de comprimento padrão para os indivíduos de Trichomycterus iheringi capturados na microbacia do ribeirão dos Buenos foi de 23 a 94 $\mathrm{mm}$ e na microbacia do rio Guaratinguetá de 24 a $78 \mathrm{~mm}$ (Figura 10).

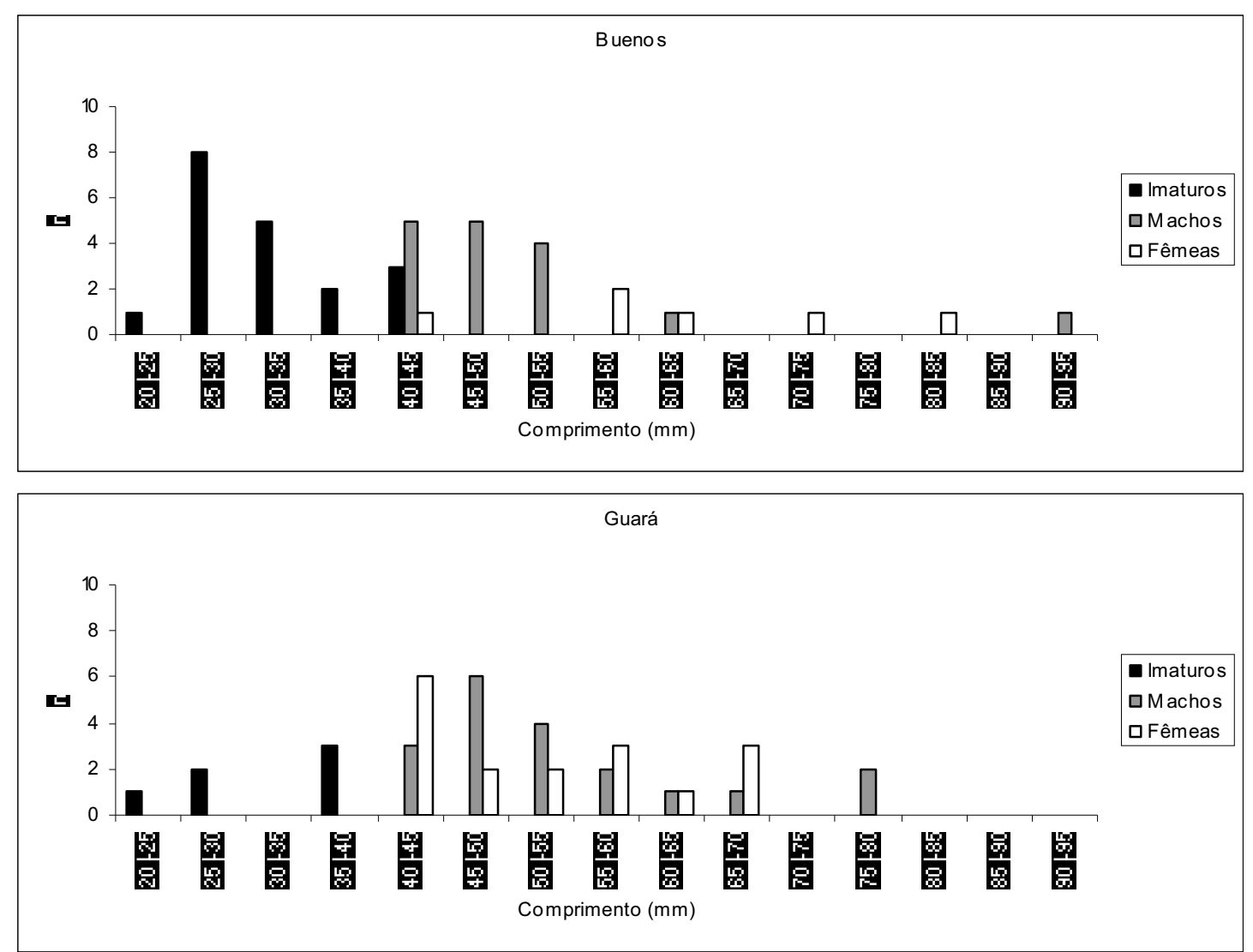

Figura 10: Freqüência numérica (n) de imaturos, machos e fềmeas de Trychomycterus iheringi amostrados em cada classe de comprimento padrão (mm) nas microbacias do ribeirão dos Buenos e do rio Guaratinguetá. 


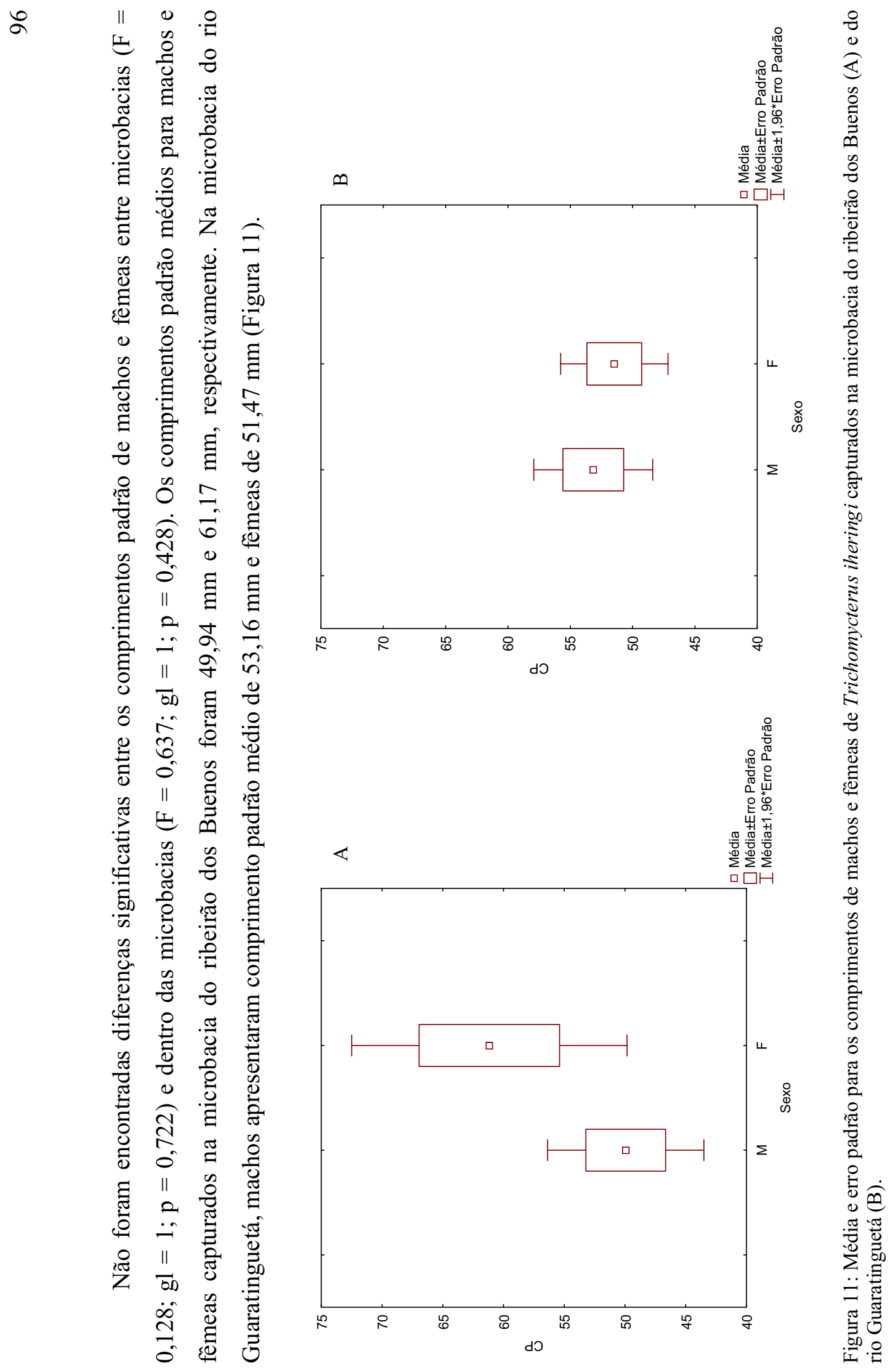


A amplitude de variação de comprimento padrão para os indivíduos de Phalloceros caudimaculatus capturados na microbacia do ribeirão dos Buenos foi de 11 a $45 \mathrm{~mm}$ (Figura 12).

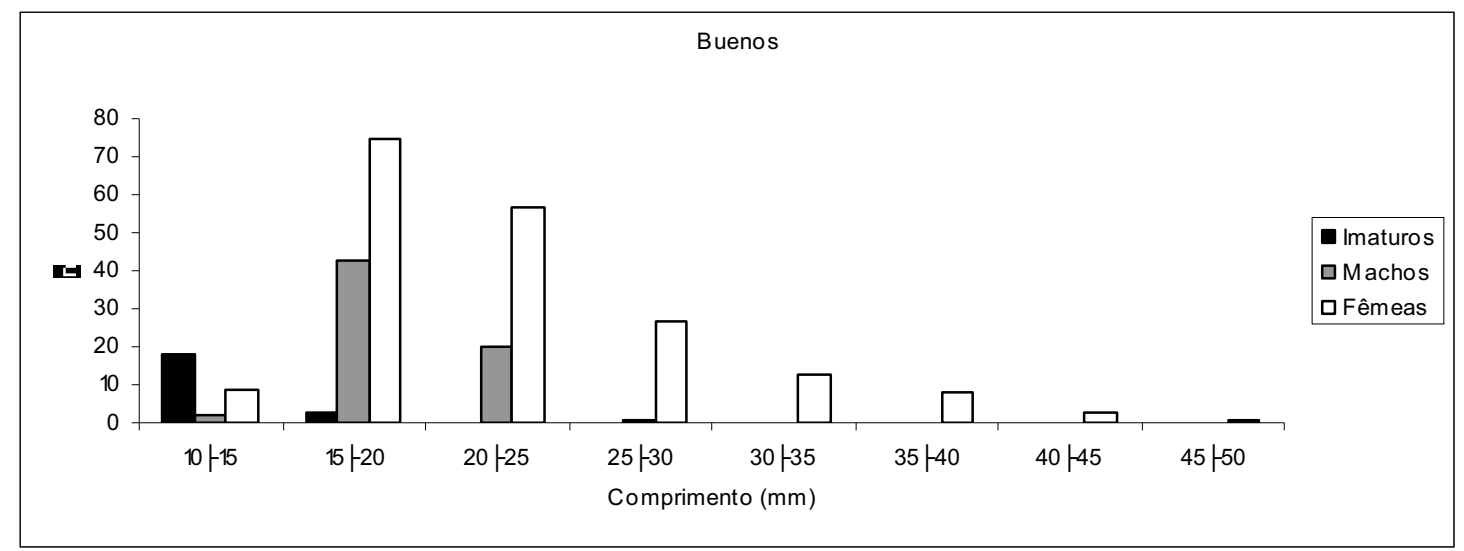

Figura 12: Freqüência numérica (n) de imaturos, machos e fêmeas de Phalloceros caudimaculatus amostrados em cada classe de comprimento padrão (mm) na microbacia do ribeirão dos Buenos.

As fêmeas foram significativamente maiores do que os machos $(\mathrm{t}=4,12 ; \mathrm{gl}=257 ; \mathrm{p}$ $<0,0001 ; \mathrm{CP}_{\text {médio }}$ para machos $=18,42 \mathrm{~mm} ; \mathrm{CP}_{\text {médio }}$ para fềmeas $\left.=21,89 \mathrm{~mm}\right)($ Figura 13$)$.

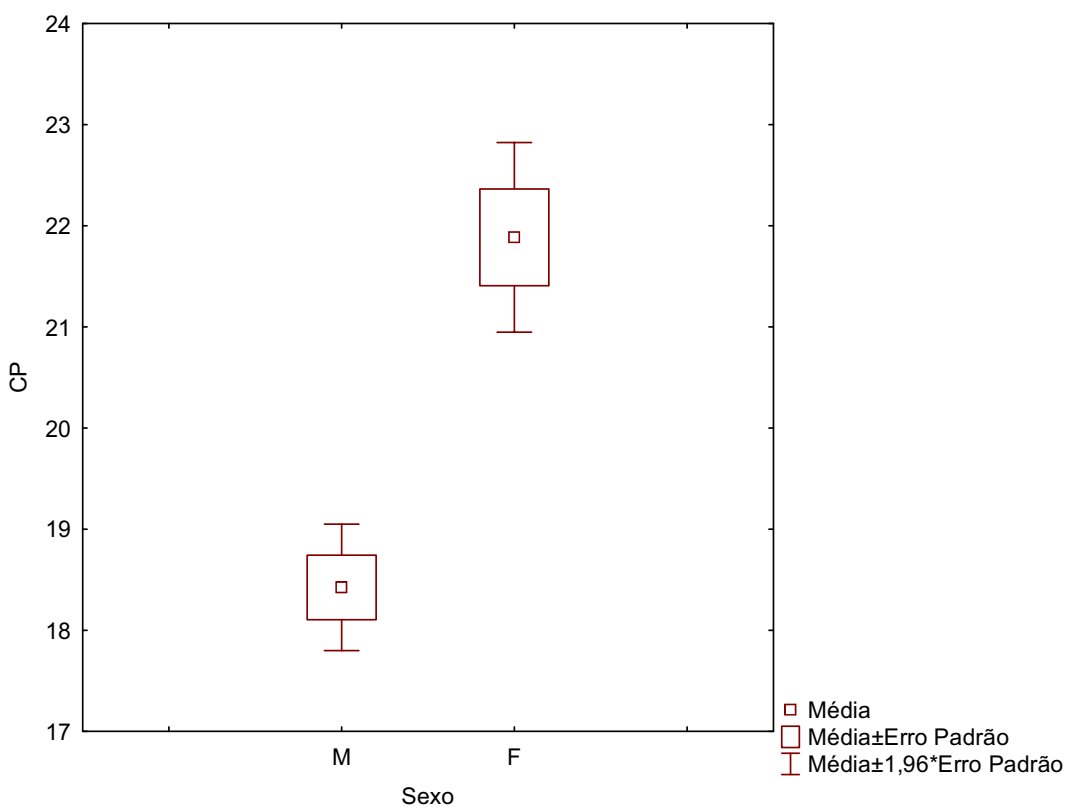

Figura 13: Média e erro padrão para os comprimentos de machos e fêmeas de Phalloceros caudimaculatus capturados na microbacia do ribeirão dos Buenos 
A amplitude de variação de comprimento padrão para os indivíduos de Characidium alipioi capturados na microbacia do ribeirão dos Buenos foi de 25 a 84 mm (Figura 14).

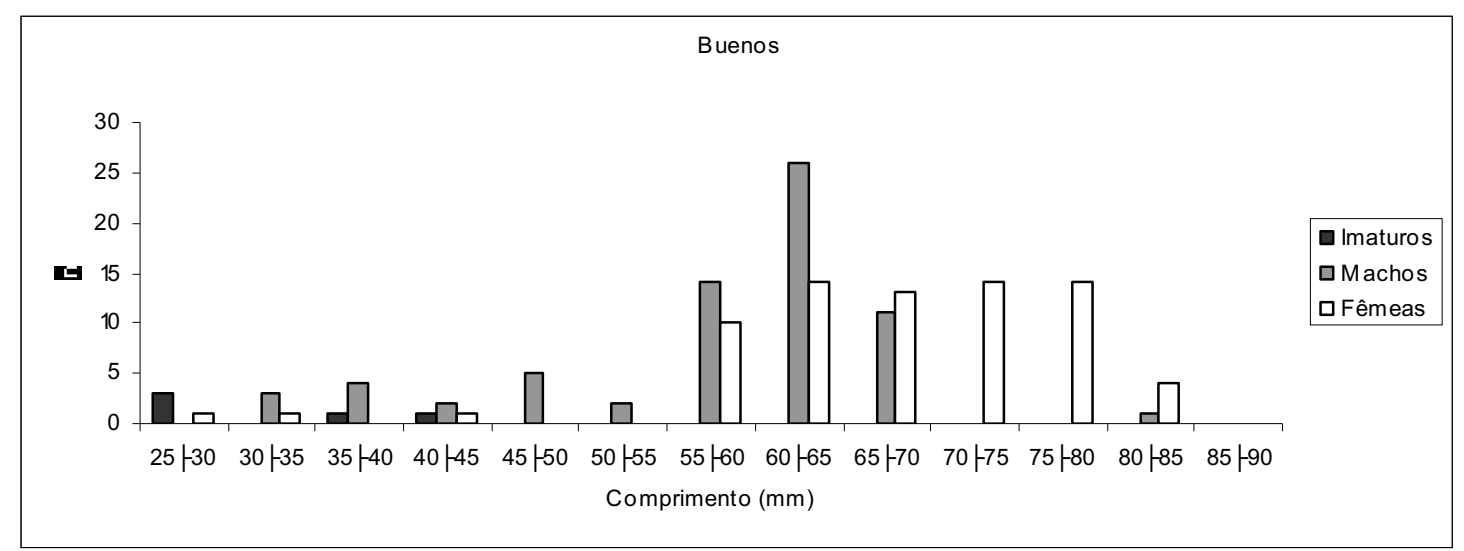

Figura 14: Freqüência numérica (n) de imaturos, machos e fềmeas de Characidium alipioi amostrados em cada classe de comprimento padrão (mm) na microbacia do ribeirão dos Buenos.

As fêmeas de C. alipioi foram significativamente maiores do que os machos $(\mathrm{t}=$ 5,$00 ; \mathrm{gl}=137 ; \mathrm{p}<0,0001 ; \mathrm{CP}_{\text {médio }}$ para machos $=56,85 \mathrm{~mm} ; \mathrm{CP}_{\text {médio }}$ para fềmeas $=66,92$ $\mathrm{mm}$ ) (Figura 15).

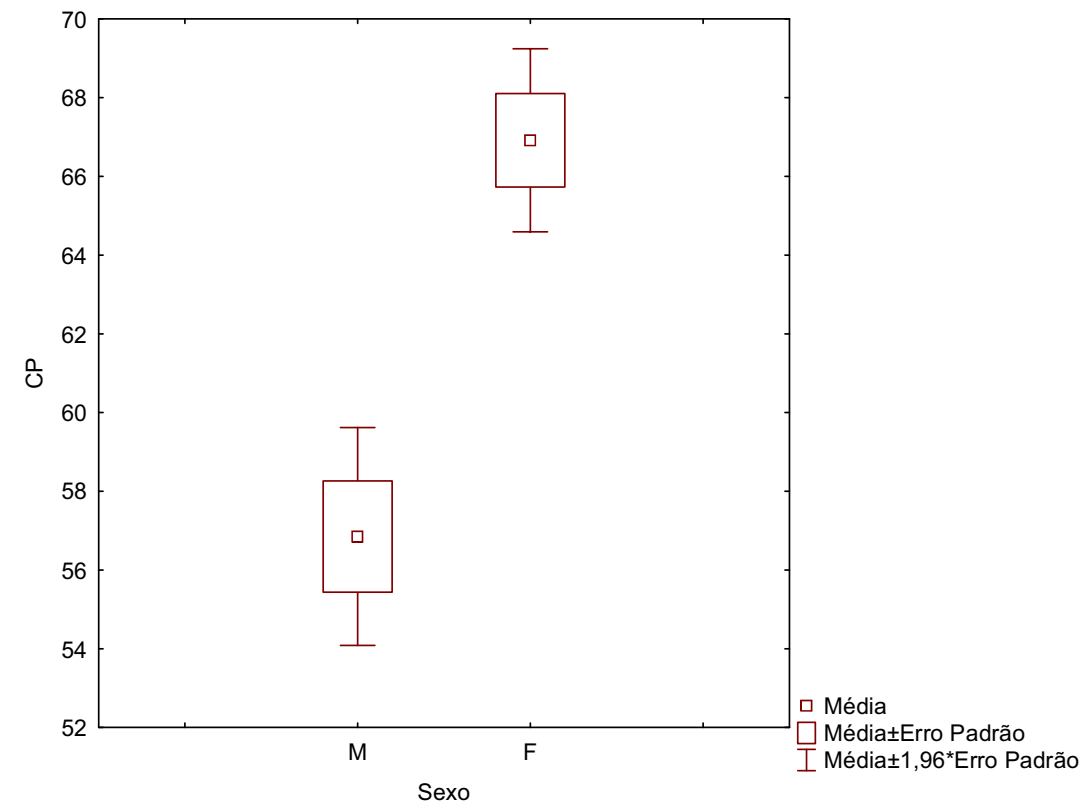

Figura 15: Média e erro padrão para os comprimentos de machos e fêmeas de Characidium alipioi capturados na microbacia do ribeirão dos Buenos 
A amplitude de variação de comprimento padrão para os indivíduos de Harttia carvalhoi capturados na microbacia do rio Guaratinguetá foi de 34 a $87 \mathrm{~mm}$ (Figura 16).

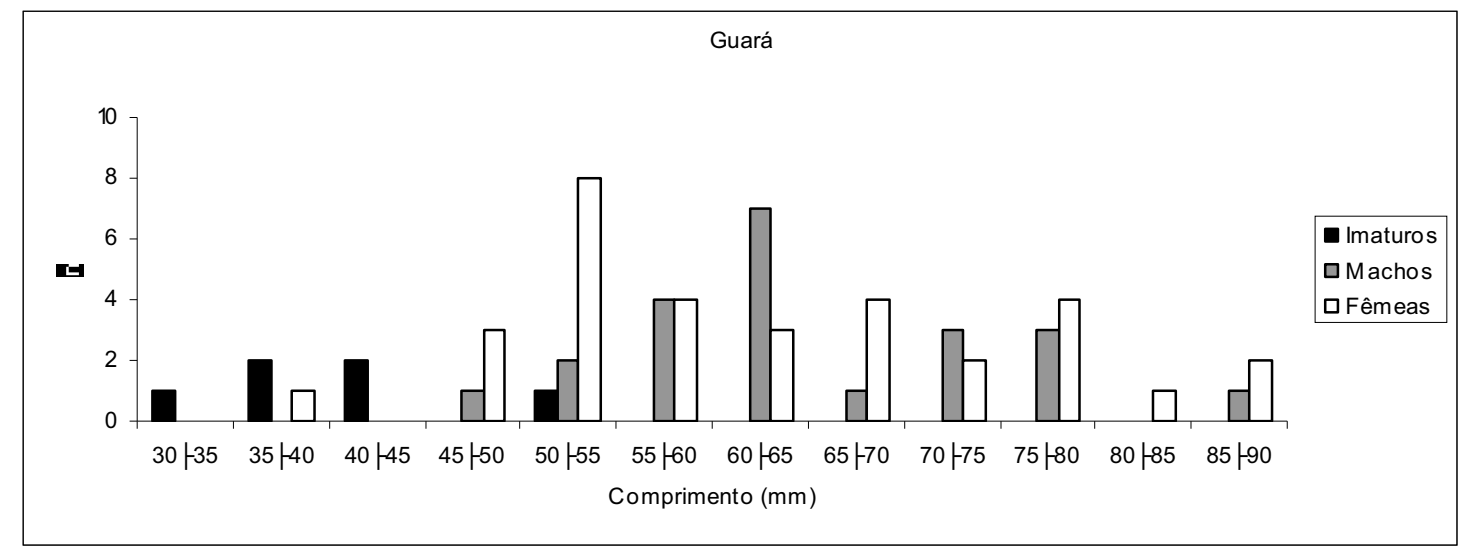

Figura 16: Freqüência numérica (n) de imaturos, machos e fềmeas de Harttia carvalhoi amostrados em cada classe de comprimento padrão $(\mathrm{mm})$ na microbacia do rio Guaratinguetá.

Machos e fêmeas de $H$. carvalhoi não apresentaram comprimento padrão diferentes $\left(\mathrm{t}=0,87 ; \mathrm{gl}=52 ; \mathrm{p}=0,39 ; \mathrm{CP}_{\text {médio }}\right.$ para machos $=64 \mathrm{~mm} ; \mathrm{CP}_{\text {médio }}$ para fềmeas $=61,38$ $\mathrm{mm}$ ) (Figura 17).

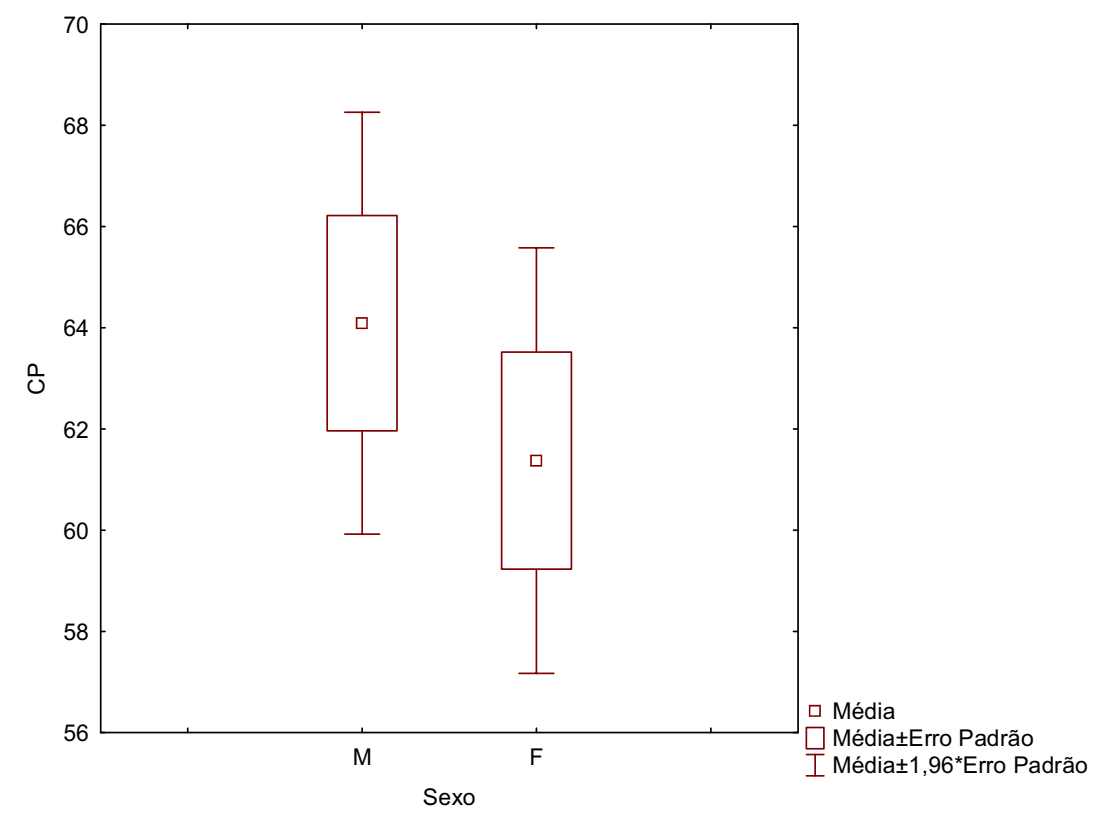

Figura 17: Média e erro padrão para os comprimentos de machos e fêmeas de Harttia carvalhoi capturados na microbacia do rio Guaratinguetá. 
A amplitude de variação de comprimento padrão para os indivíduos de Pareiohina rudolphi capturados na microbacia do rio Guaratinguetá foi de 19 a $51 \mathrm{~mm}$ (Figura 18).

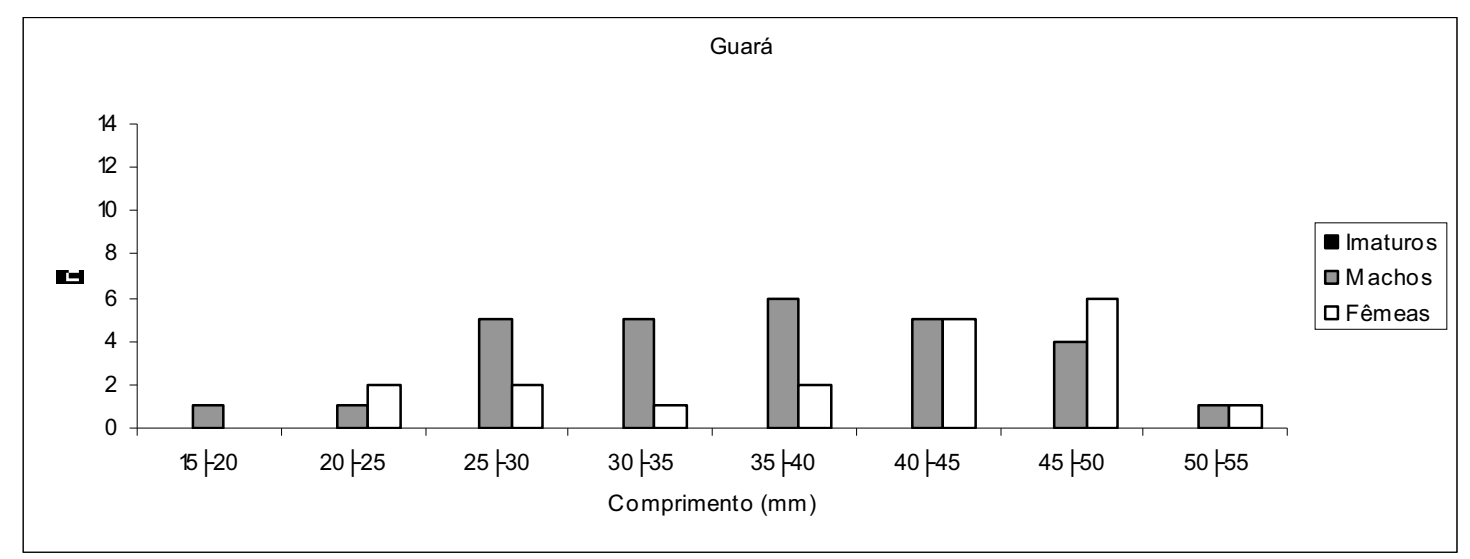

Figura 18: Freqüência numérica (n) de imaturos, machos e fềmeas de Pareiohina rudolphi amostrados em cada classe de comprimento padrão $(\mathrm{mm})$ na microbacia do rio Guaratinguetá.

Machos e fêmeas de $P$. rudolphi não apresentaram comprimento padrão diferentes $(\mathrm{t}$ $=1,90 ; \mathrm{gl}=44 ; \mathrm{p}=0,06 ; \mathrm{CP}_{\text {médio }}$ para machos $=40,5 \mathrm{~mm} ; \mathrm{CP}_{\text {médio }}$ para fềmeas $=37,79$ $\mathrm{mm}$ ) (Figura 19).

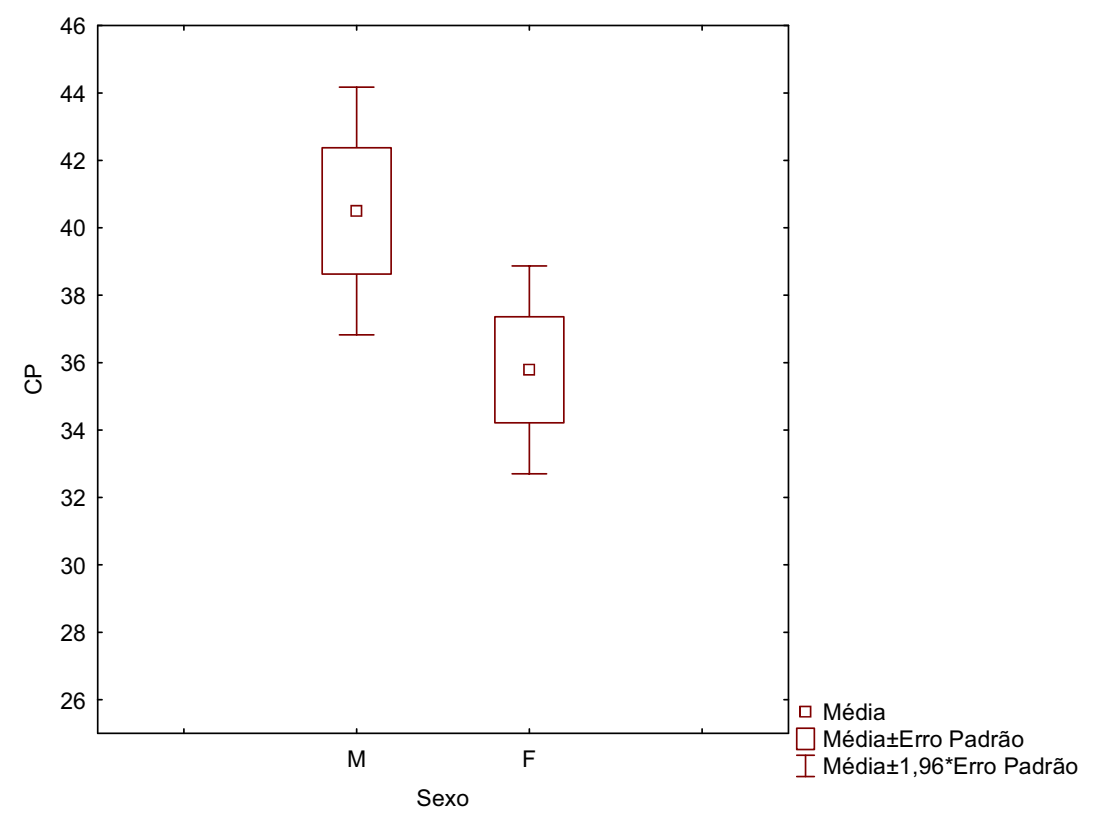

Figura 19: Média e erro padrão para os comprimentos de machos e fêmeas de Pareiohina rudolphi capturados na microbacia do rio Guaratinguetá. 
A amplitude de variação de comprimento padrão para os indivíduos de Pareiohina brachyrhyncha capturados na microbacia do rio Guaratinguetá foi de 18 a $42 \mathrm{~mm}$ (Figura 20).

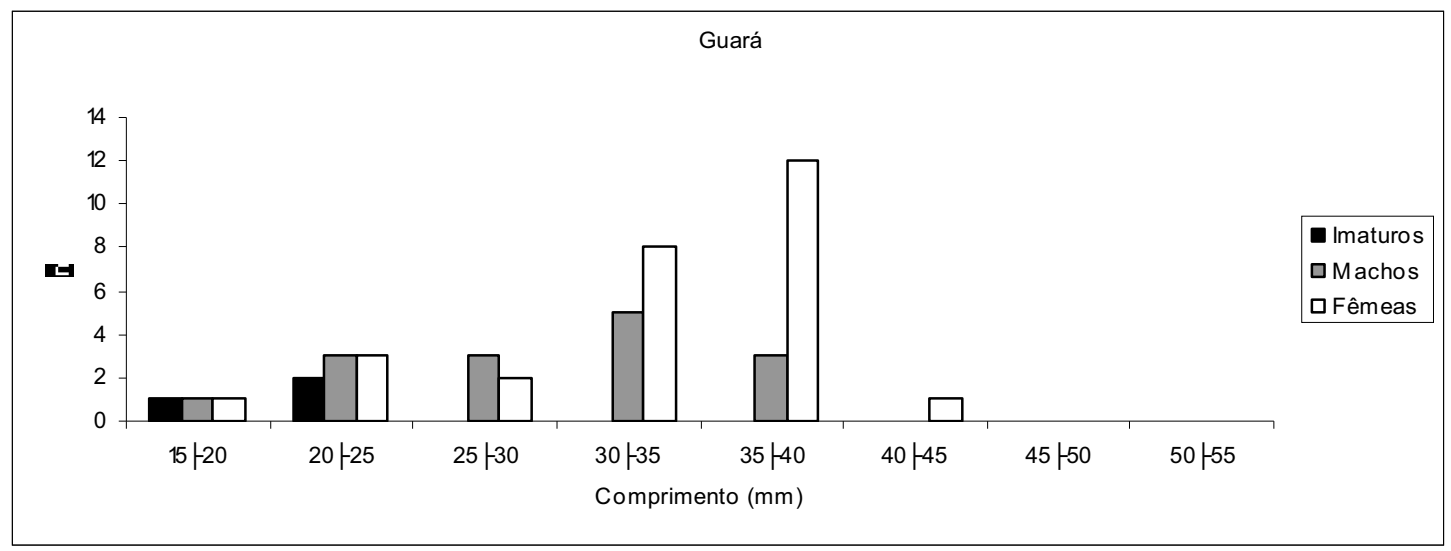

Figura 20: Freqüência numérica (n) de imaturos, machos e fêmeas de Pareiohina brachyrhyncha amostrados em cada classe de comprimento padrão $(\mathrm{mm})$ na microbacia do rio Guaratinguetá.

Machos e fềmeas de $P$. rudolphi não apresentaram comprimento padrão diferentes ( $\mathrm{t}$ $=1,63 ; \mathrm{gl}=40 ; \mathrm{p}=0,11 ; \mathrm{CP}_{\text {médio }}$ para machos $=29,27 \mathrm{~mm} ; \mathrm{CP}_{\text {médio }}$ para fêmeas $=32,56$ $\mathrm{mm}$ ) (Figura 21).

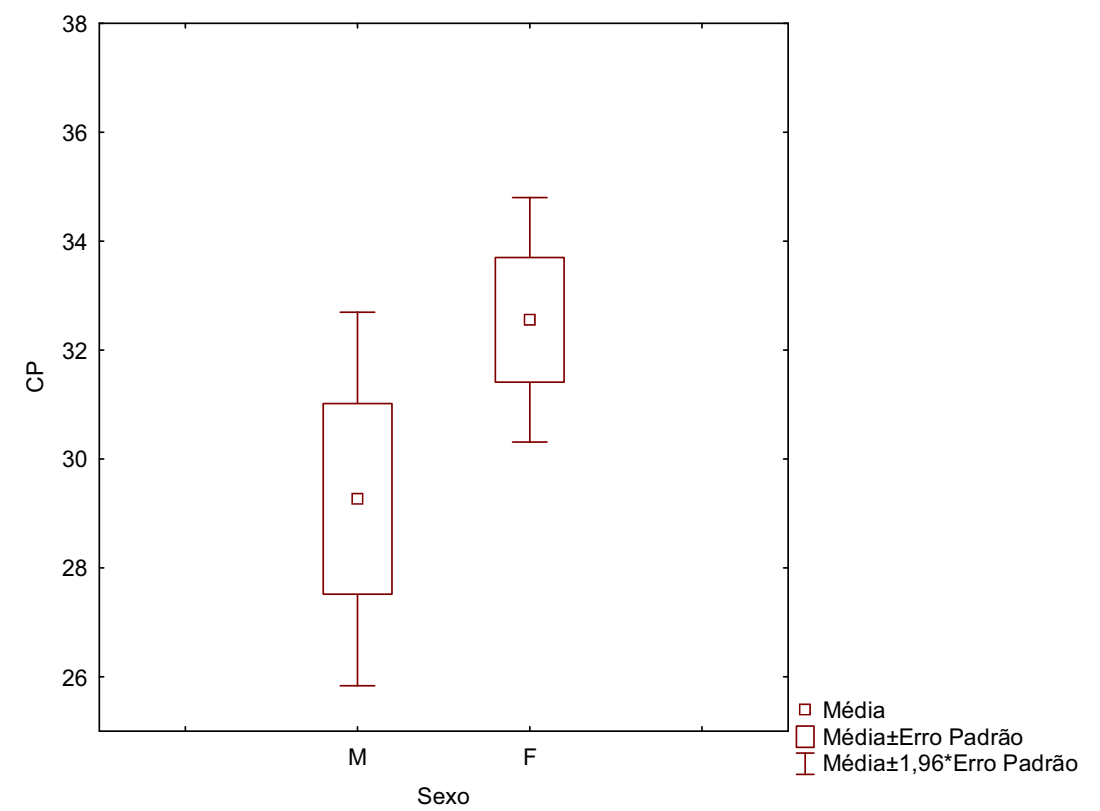

Figura 21: Média e erro padrão para os comprimentos de machos e fêmeas de Pareiohina brachyrhyncha capturados na microbacia do rio Guaratinguetá. 
A amplitude de variação de comprimento padrão para os indivíduos de Ancistrus stigmaticus capturados na microbacia do rio Guaratinguetá foi de 15 a 66 mm (Figura 22).

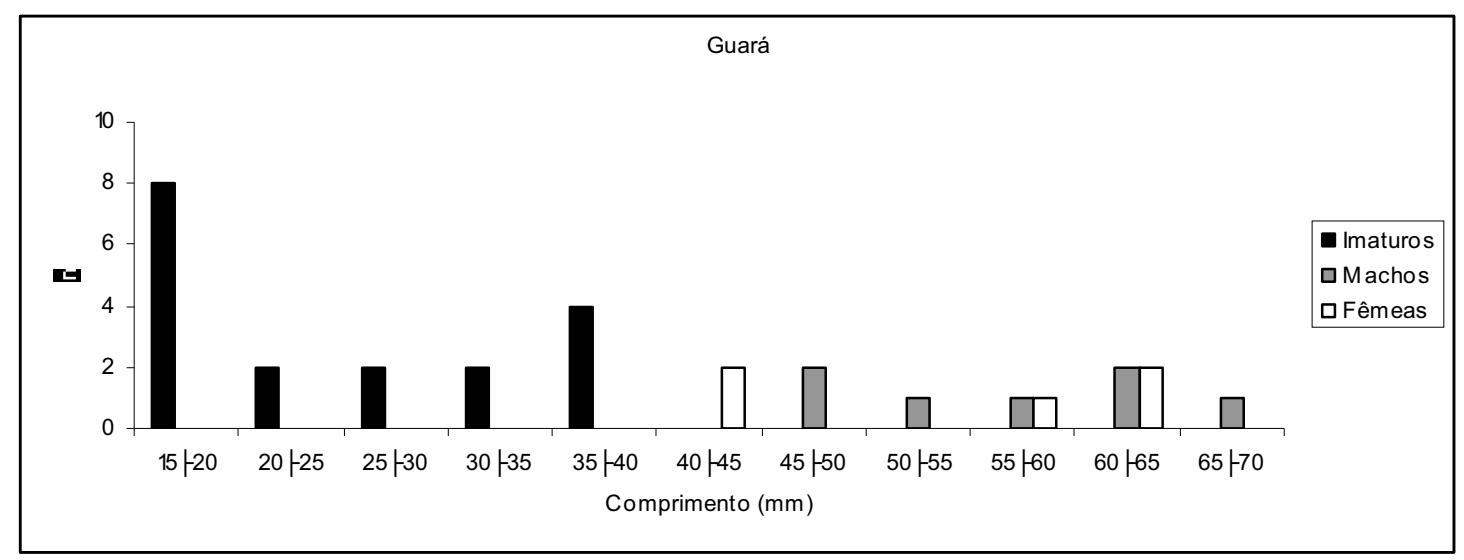

Figura 22: Freqüência numérica (n) de imaturos, machos e fêmeas de Ancistrus stigmaticus amostrados em cada classe de comprimento padrão $(\mathrm{mm})$ na microbacia do rio Guaratinguetá.

Machos e fêmeas de Ancistrus stigmaticus não apresentaram diferenças significativas em seus comprimentos padrão $\left(\mathrm{t}=0,0048 ; \mathrm{gl}=10 ; \mathrm{p}=0,99 ; \mathrm{CP}_{\text {médio }}\right.$ para machos $=55,43 \mathrm{~mm} ; \mathrm{CP}_{\text {médio }}$ para fêmeas $=55,40 \mathrm{~mm}$;) (Figura 23).

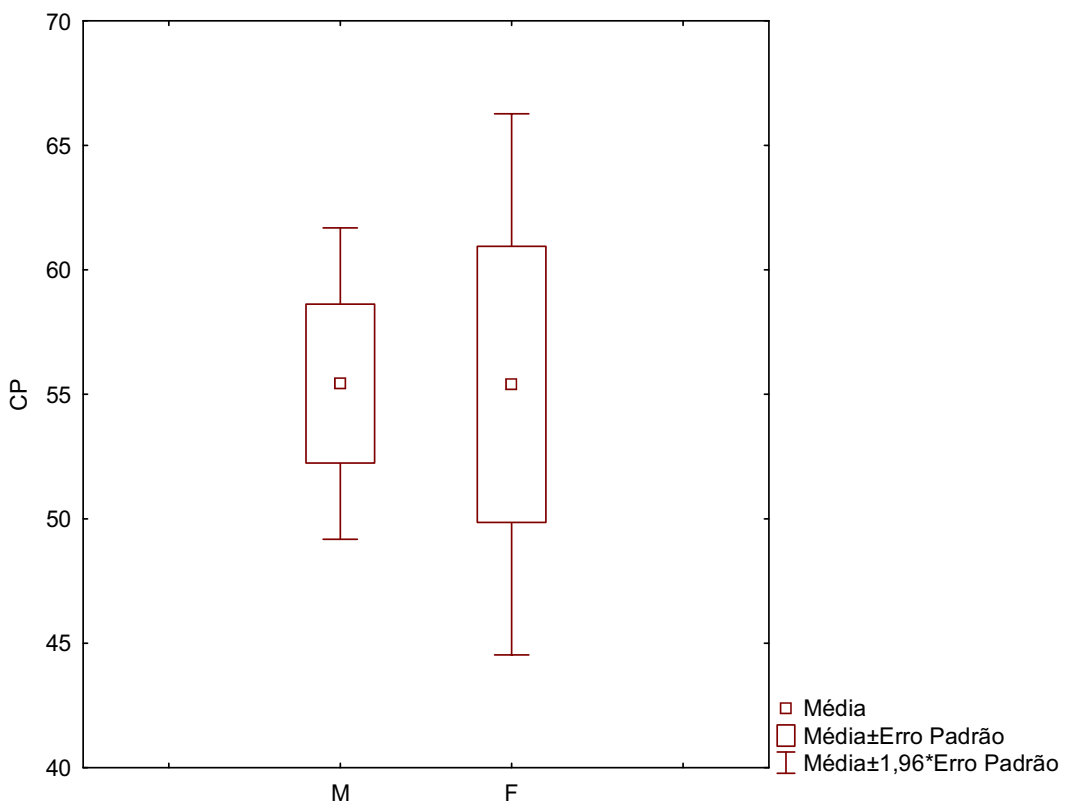

Figura 23: Média e erro padrão para os comprimentos de machos e fêmeas de Ancistrus stigmaticus capturados na microbacia do rio Guaratinguetá. 


\subsubsection{Proporção sexual}

Trichomycterus itatiayae, Neoplecostomus microps, T. iheringi e Phalloceros caudimaculatus, na microbacia do ribeirão dos Buenos, apresentaram proporção de machos e fêmeas diferente do esperado (1:1) (Tabela 2), sendo uma maior proporção de machos observada em T. itatiayae e T. iheringi e uma maior proporção de fềmeas em $N$. microps e P. caudimaculatus. Para a microbacia do rio Guaratinguetá e para as demais espécies não se observou desvio da proporção esperada de machos e fêmeas (Tabela 2).

Tabela 2: Resultados do teste de $\chi^{2}$ para cada espécie, por microbacia $(\chi 2=$ valor do teste, g1 $=$ graus de liberdade). Em negrito encontram-se os valores significativos.

\begin{tabular}{ccccc}
\hline Espécie & Microbacia & $\chi^{\mathbf{2}}$ & $\mathbf{g l}$ & $\mathbf{p}$ \\
\hline T. itatiayae & Buenos & 10,866 & 1 & $\mathbf{0 , 0 0 1}$ \\
& Guará & 0,534 & 1 & 0,465 \\
C. lauroi & Buenos & 0,781 & 1 & 0,377 \\
& Guará & 0,600 & 1 & 0,439 \\
N. microps & Buenos & 6,541 & 1 & $\mathbf{0 , 0 1 1}$ \\
& Guará & 1,613 & 1 & 0,204 \\
A. bimaculatus & Buenos & 2,182 & 1 & 0,140 \\
& Guará & 0,138 & 1 & 0,710 \\
T. iheringi & Buenos & 4,545 & 1 & $\mathbf{0 , 0 3 3}$ \\
& Guará & 0,111 & 1 & 0,739 \\
P. caudimaculatus & Buenos & 62,274 & 1 & $<\mathbf{0 , 0 0 0 1}$ \\
C. alipioi & Buenos & 0,180 & 1 & 0,671 \\
H. carvalhoi & Guará & 1,852 & 1 & 0,174 \\
P. rudolphi & Guará & 2,174 & 1 & 0,140 \\
P. brachyrhyncha & Guará & 3,429 & 1 & 0,064 \\
\hline stigmaticus & Guará & 0,333 & 1 & 0,564 \\
\hline & & &
\end{tabular}




\subsection{Dieta}

Foram analisados 403 estômagos repletos de 17 espécies (Tabela 3). Dezoito categorias de itens alimentares foram encontradas nos conteúdos estomacais analisados: larvas de Diptera (Chironomidae e Simuliidae), larvas de Trichoptera, larvas de inseto (não Diptera, principalmente Coleoptera), ninfas de Plecoptera, ninfas de Ephemeroptera, insetos aquáticos adultos (Hemiptera: Naucoridae), insetos terrestres adultos (Coleoptera, Hymenoptera, Hemiptera, Orthoptera), restos de insetos, Arachnida, Acarina, Oligochaeta, Crustacea, Mollusca, Myriapoda, restos vegetais, algas, perifiton e detrito. Os recursos de origem autóctone compuseram a maior parte das dietas das espécies analisadas, correspondendo a $56 \%$ dos itens alimentares ingeridos, em seguida vieram os recursos de origem alóctone (28\%) e de origem desconhecida (17\%).

Tabela 3: Relação do número de estômagos repletos analisados por espécie e microbacia.

\begin{tabular}{rccc} 
& Buenos & Guará & Total \\
\cline { 2 - 4 } Trichomycterus itatiayae & 38 & 114 & 152 \\
Characidium alipioi & 75 & 3 & 78 \\
Characidium lauroi & 42 & 29 & 71 \\
Astyanax bimaculatus & 19 & 16 & 35 \\
Neoplecostomus microps & 7 & 11 & 18 \\
Astyanax fasciatus & 10 & 1 & 11 \\
Trichomycterus iheringi & 2 & 7 & 9 \\
Pareiohina rudolphi & 0 & 8 & 8 \\
Hypostomus luetkeni & 0 & 5 & 5 \\
Astyanax intermedius & 0 & 5 & 5 \\
Oligosarcus hepsetus & 2 & 1 & 3 \\
Gymnotus pantherinus & 3 & 0 & 3 \\
Pimelodella sp. & 1 & 0 & 1 \\
Pareiohina brachyrhyncha & 0 & 1 & 1 \\
Gymnotus carapo & 0 & 1 & 1 \\
Taunayia bifasciata & 0 & 1 & 1 \\
Pimelodus maculatus & 0 & 1 & 1 \\
\hline Total & 199 & 204 & 403 \\
\hline
\end{tabular}

$\mathrm{Na}$ Tabela 4 encontra-se a lista dos itens alimentares consumidos pelas espécies que tiveram poucos estômagos analisados $(\mathrm{n}<5)$. 
Tabela 4: Conteúdo estomacal das espécies que tiveram poucos estômagos analisados $(\mathrm{n}<5)$.

\begin{tabular}{|c|c|}
\hline Espécie & Itens \\
\hline Trichomycterus iheringi & $\begin{array}{c}\text { Larva Diptera } \\
\text { Larva Trichoptera }\end{array}$ \\
\hline Pareiohina rudolphi & Perifíton \\
\hline Hypostomus luetkeni & $\begin{array}{c}\text { Detrito } \\
\text { Ninfa Ephemeroptera }\end{array}$ \\
\hline Astyanax intermedius & $\begin{array}{l}\text { Insetos aquáticos } \\
\text { Insetos terrestres } \\
\text { Larva Trichoptera } \\
\text { Restos vegetais }\end{array}$ \\
\hline Oligosarcus hepsetus & $\begin{array}{c}\text { Arachnida } \\
\text { Teleósteo }\end{array}$ \\
\hline Gymnotus pantherinus & $\begin{array}{l}\text { Larva Diptera } \\
\text { Larva inseto } \\
\text { Ninfa Plecoptera } \\
\text { Restos vegetais }\end{array}$ \\
\hline Pimelodella sp. & Insetos aquáticos \\
\hline Pareiohina brachyrhyncha & Perifíton \\
\hline Gymnotus carapo & Ninfa Plecoptera \\
\hline Taunayia bifasciata & Insetos terrestres \\
\hline Pimelodus maculatus & $\begin{array}{l}\text { Insetos terrestres } \\
\text { Miriápode } \\
\text { Larva inseto } \\
\text { Larva Diptera } \\
\text { Larva Trichoptera } \\
\text { Nematóides }\end{array}$ \\
\hline
\end{tabular}

Formas imaturas de insetos (larvas e ninfas) foram itens freqüentes nos conteúdos estomacais dessas espécies, estando presentes na dieta de seis dentre as onze espécies consideradas. As duas espécies de Pareiohina (P. rudolphi e P. brachyrhyncha) tiveram perifiton como o item constituinte de suas dietas. O item peixe (Teleósteo) esteve presente apenas no conteúdo estomacal de Oligosarcus hepsetus. Astyanax intermedius, Gymnotus pantherinus e Pimelodus maculatus foram espécies que ingeriram uma grande variedade de itens alimentares, sendo os insetos (formas imaturas e adultas) itens importantes. Pimelodella sp. e Taunaya bifasciata ingeriram apenas formas adultas de insetos.

$\mathrm{Na}$ Tabela 5 são apresentados os valores do GPA para as espécies Trichomycterus itatiayae, Characidium lauroi, C. alipioi, Astyanax bimaculatus, Neoplecostomus microps, A. fasciatus, T. iheringi, Pareiohina rudolphi, Hypostomus luetkeni e A. intermedius. Larvas de Diptera foi um item alimentar importante na dieta de T. itatiayae, C. alipioi e $C$. lauroi, sendo classificado como um item secundário para as duas primeiras espécies e 
preferencial para a última. Larvas de Trichoptera foi um item com altos valores do GPA nas dietas dos dois caracidíneos. Characidium lauroi ainda teve o item ninfas de Plecoptera com alto valor do GPA. O item insetos terrestres foi importante para os três lambaris, sendo preferencial em alto grau para Astyanax intermedius, preferencial para A. bimaculatus e secundário para $A$. fasciatus, que também ingeriu, de forma representativa, material vegetal. Neoplecostomus microps alimentou-se principalmente de perifiton e detrito sendo este item também consumido de forma representativa por Hypostomus luetkeni. Perifíton foi o item exclusivo e, portanto, preferencial absoluto na dieta de Pareiohina rudolphi.

Tabela 5: Valores do GPA para os itens alimentares consumidos por T. itatiayae, C. lauroi, C. alipioi, A. bimaculatus, N. microps, A. fasciatus, T. iheringi, P. rudolphi, H. luetkeni e A. intermedius. nas microbacias do ribeirão dos Buenos e do rio Guaratinguetá (os números destacados correspondem aos maiores valores do GPA).

\begin{tabular}{|c|c|c|c|c|c|c|c|c|c|c|c|c|c|c|c|c|c|}
\hline & 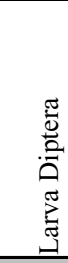 & 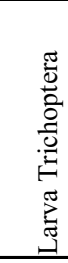 & 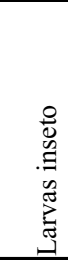 & 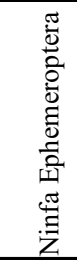 & 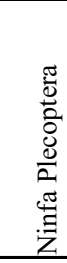 & 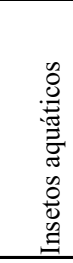 & 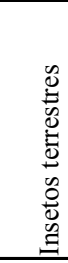 & 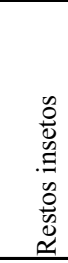 & 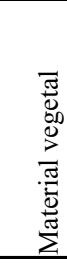 & $\frac{\mathscr{0}}{\mathbb{6}}$ & 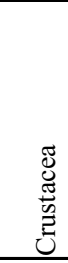 & $\begin{array}{l}\frac{\pi}{0} \\
\mathbb{J} \\
0 \\
0 \\
.000 \\
0\end{array}$ & 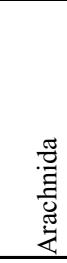 & 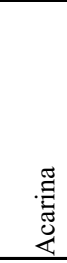 & 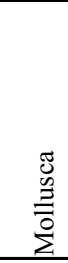 & 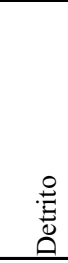 & 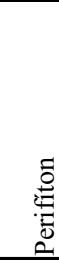 \\
\hline Trichomycterus itatiayae & 1,36 & 0,41 & 0,77 & 0,32 & 0,61 & 0,03 & 0,26 & 0,05 & 0,05 & 0,55 & 0,01 & 0,30 & - & - & 0,01 & - & - \\
\hline Characidium alipioi & 1,54 & 1,44 & 0,32 & 0,40 & 0,87 & 0,29 & 0,35 & - & - & - & - & - & - & 0,01 & - & - & - \\
\hline Characidium lauroi & 2,01 & 1,30 & 0,38 & 0,34 & 1,07 & 0,01 & 0,41 & - & 0,01 & 0,13 & - & - & 0,01 & 0,03 & - & - & - \\
\hline Astyanax bimaculatus & 0,09 & 0,09 & 0,17 & 0,03 & - & 0,11 & 2,74 & - & 0,97 & - & 0,20 & 0,09 & 0,17 & - & - & - & - \\
\hline Neoplecostomus microps & 0,39 & - & - & 0,44 & 0,17 & - & - & - & 0,44 & 0,44 & - & - & - & - & - & 1,33 & 1,00 \\
\hline Astyanax fasciatus & 0,09 & - & 0,55 & - & - & - & 1,86 & - & 1,27 & - & - & - & - & - & - & - & - \\
\hline Trichomycterus iheringi & 3,78 & 0,44 & - & - & - & - & - & - & - & - & - & - & - & - & - & - & - \\
\hline Pareiohina rudolphi & - & - & - & - & - & - & - & - & - & - & - & - & - & - & - & - & 4,00 \\
\hline Hypostomus luetkeni & - & - & - & 0,20 & - & - & - & - & - & - & - & - & - & - & - & 3,80 & - \\
\hline Astyanax intermedius & - & 0,40 & - & - & - & 0,60 & 3,00 & - & 0,60 & - & - & - & - & - & - & - & - \\
\hline
\end{tabular}

Trichomycterus itatiayae, Characidium lauroi e Astyanax bimaculatus foram as espécies que tiveram número suficiente de estômagos repletos analisados por microbacia que possibilitasse comparações. Na Tabela 6 estão apresentados os valores do GPA para cada uma dessas espécies por microbacia.

Trichomycetrus itatiayae e Characidium lauroi apresentaram dieta invertívora, alimentando-se principalmente de formas imaturas de insetos. Na microbacia do ribeirão dos Buenos, T. itatiayae teve os itens larvas de Diptera e larvas de inseto com os maiores valores do GPA e classificados como itens secundários na dieta da espécie. Na microbacia do rio Guaratinguetá, T. itatiayae consumiu maior variedade de itens alimentares, sendo 
larvas de Diptera o item com o maior valor do GPA, classificado como item secundário. Characidium lauroi teve o item larvas de Diptera como preferencial na microbacia do ribeirão dos Buenos e como secundário na microbacia do rio Guaratinguetá. Ainda na microbacia do ribeirão dos Buenos, larvas de Trichoptera e ninfas de Plecoptera foram importantes, sendo classificados como secundários na dieta dessa espécie.

Astyanax bimaculatus teve como item preferencial, nas duas microbacias, insetos terrestres. Material vegetal também foi um item importante na microbacia do ribeirão dos Buenos, sendo classificado como secundário. Os demais itens ingeridos foram todos ocasionais.

Tabela 6: Valores do GPA para os itens alimentares consumidos por T. itatiayae, C. lauroi e A. bimaculatus nas microbacias do ribeirão dos Buenos e do rio Guaratinguetá (os números destacados correspondem aos maiores valores do GPA).

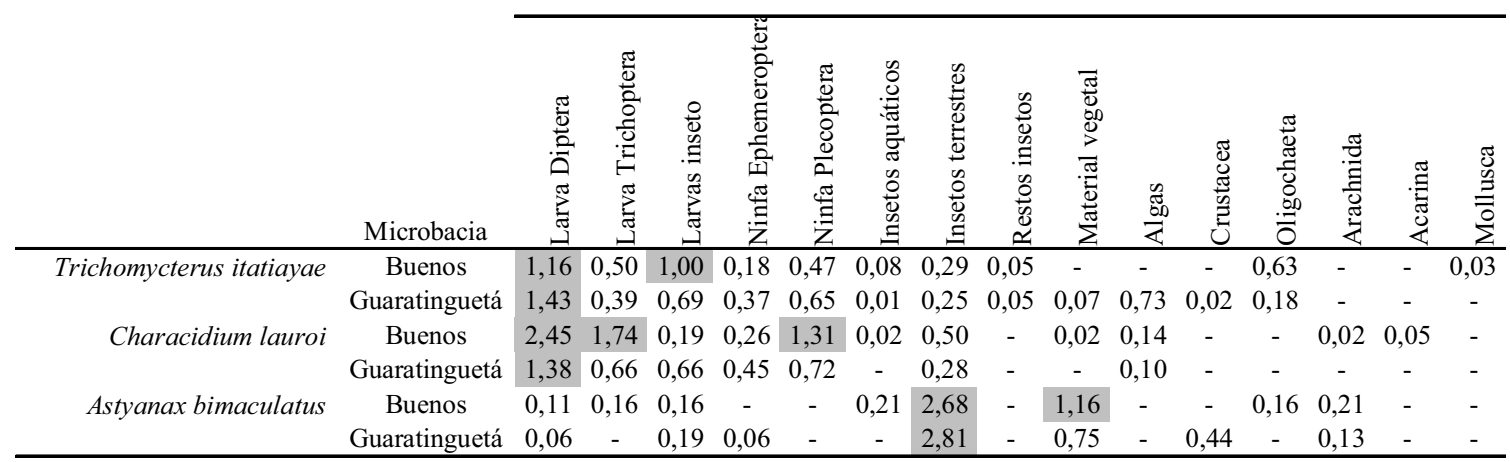

Houve correlação entre as dietas de T. itatiayae, C. lauroi e A. bimaculatus nas microbacias, o que indicou que não houve variação significativa entre os itens alimentares ingeridos por essas espécies por microbacia (Tabela 7).

Tabela 7: Resultado do teste de correlação de Spearman aplicado aos valores do GPA das espécies $T$. itatiayae, $C$. lauroi e A. bimaculatus por microbacia $(\mathrm{R}=$ coeficiente de correlação; $\mathrm{N}=$ número de estômagos).

\begin{tabular}{cccc}
\cline { 2 - 4 } & $\mathrm{R}$ & $\mathrm{N}$ & $\mathrm{P}$ \\
\hline Trichomycterus itatiayae & 0,78 & 13 & $<0,05$ \\
Characidium lauroi & 0,76 & 11 & $<0,05$ \\
Astyanax bimaculatus & 0,9 & 10 & $<0,05$ \\
\hline
\end{tabular}


Na Tabela 8 são apresentados os valores do GPA para os diferentes itens alimentares por época de amostragem. Larvas de Diptera, larvas de Trichoptera e ninfas de Plecoptera foram os itens com maiores valores do GPA na época de seca, sendo classificados como itens de preferência secundária. Durante a cheia, todos os itens alimentares foram ocasionais, indicando um espectro alimentar amplo, em que as espécies alimentaram-se de vários itens. O teste de correlação indicou que não houve diferença significativa $(\mathrm{R}=0,66 ; \mathrm{p}<0,01)$ entre os itens alimentares ingeridos durante as épocas de seca e cheia.

Tabela 8: Valores do GPA encontrados para os diferentes itens alimentares e suas respectivas classificações por época de amostragem (os números destacados correspondem aos maiores valores do GPA).

\begin{tabular}{ccccc}
\cline { 2 - 5 } & \multicolumn{2}{c}{ Seca } & \multicolumn{2}{c}{ Cheia } \\
\hline Itens alimetares & GPA & Classificação & GPA & Classificação \\
\hline larva Diptera & 1,64 & Secundário & 0,87 & Ocasional \\
larva Trichoptera & 1,08 & Secundário & 0,51 & Ocasional \\
larva inseto & 0,30 & Ocasional & 0,80 & Ocasional \\
ninfa Ephemeroptera & 0,20 & Ocasional & 0,44 & Ocasional \\
ninfa Plecoptera & 1,15 & Secundário & 0,26 & Ocasional \\
inseto aquático & 0,09 & Ocasional & 0,16 & Ocasional \\
inseto terrestre & 0,57 & Ocasional & 0,78 & Ocasional \\
restos insetos & - & - & 0,05 & Ocasional \\
Arachnida & 0,05 & Ocasional & 0,05 & Ocasional \\
Acarina & 0,04 & Ocasional & 0,01 & Ocasional \\
Oligochaeta & 0,18 & Ocasional & 0,24 & Ocasional \\
Crustacea & 0,33 & Ocasional & - & - \\
Mollusca & - & - & 0,01 & Ocasional \\
Myriapoda & - & - & 0,02 & Ocasional \\
material vegetal & 0,78 & Ocasional & 0,21 & Ocasional \\
alga & 0,17 & Ocasional & 0,10 & Ocasional \\
perifiton & - & - & 0,18 & Ocasional \\
detrito & - & - & 0,12 & Ocasional \\
\hline
\end{tabular}

Ao considerar os itens alimentares consumidos pelas espécies nos ambientes de encosta, pediplano e vale, verificou-se um gradiente decrescente de importância de itens autóctones da encosta em direção ao vale. Em relação aos itens alóctones, esse gradiente mostrou-se de modo inverso: maior consumo de itens alóctones na região do vale (Tabela 9). 
Tabela 9: Ocorrência percentual de itens autóctones e alóctones nos ambientes de encosta, pediplano e vale.

\begin{tabular}{ccc} 
& Itens Autóctones & Itens Alóctones \\
\hline Encosta & 90,9 & 9,1 \\
Pediplano & 85,7 & 14,3 \\
Vale & 31,3 & 68,7 \\
\hline
\end{tabular}

\subsection{Reprodução}

\subsubsection{Gordura acumulada na cavidade visceral}

Trichomycterus itatiayae e T. iheringi não acumularam gordura em suas cavidades viscerais. Characidium lauroi apresentou variação nos graus de gordura acumulada entre as épocas de seca e cheia na microbacia do ribeirão dos Buenos $\left(\chi^{2}=30,568 ; \mathrm{gl}=2 ; \mathrm{p}<\right.$ $0,0001)$ e na do rio Guaratinguetá $\left(\chi^{2}=49,47 ; \mathrm{gl}=2 ; \mathrm{p}<0,0001\right)$. Neoplecostomus microps apresentou variação nos graus de gordura acumulada apenas na microbacia do rio Guaratinguetá $\left(\chi^{2}=8,572 ; \mathrm{gl}=2 ; \mathrm{p}=0,014\right)$, sendo que a variação não foi significativa para a microbacia do ribeirão dos Buenos $\left(\chi^{2}=2,379 ; \mathrm{gl}=2 ; \mathrm{p}=0,306\right)$. Para Astyanax bimaculatus a variação foi significativa para as duas microbacias (Buenos: $\chi^{2}=29,83$; $\mathrm{gl}=$ 2; $\mathrm{p}<0,0001$; Guaratinguetá: $\left.\chi^{2}=15,34 ; \mathrm{gl}=2 ; \mathrm{p}<0,0001\right)$. Characidium alipioi apresentou diferença significativa na variação nos graus de gordura para microbacia do ribeirão dos Buenos $\left(\chi^{2}=104,29 ; \mathrm{gl}=2 ; \mathrm{p}<0,0001\right)$. Harttia carvalhoi não apresentou variação nos graus de gordura para a microbacia do rio Guaratinguetá $\left(\chi^{2}=570,8 ; \mathrm{gl}=2 ; \mathrm{p}\right.$ $=0,685)$. As espécies de Pareiohina capturadas na microbacia do rio Guaratinguetá, apresentaram variação nos graus de gordura $\left(\chi^{2}=7,18 ; \mathrm{gl}=2 ; \mathrm{p}=0,028\right)$ no caso de $P$. rudolphi e não apresentaram variação $\left(\chi^{2}=0,432 ; \mathrm{gl}=2 ; \mathrm{p}=0,806\right)$ no caso de $P$. brachyrhyncha.

\subsubsection{Estádios de maturidade gonadal e relação gonadossomática}

As distribuições dos diferentes estádios de maturidade gonadal, da variação no grau máximo de gordura acumulada na cavidade visceral e dos valores da relação gonadossomática por amostra para as espécies mais abundantes em cada uma das microbacias estudadas encontram-se nas Figuras de 24 a 37. 


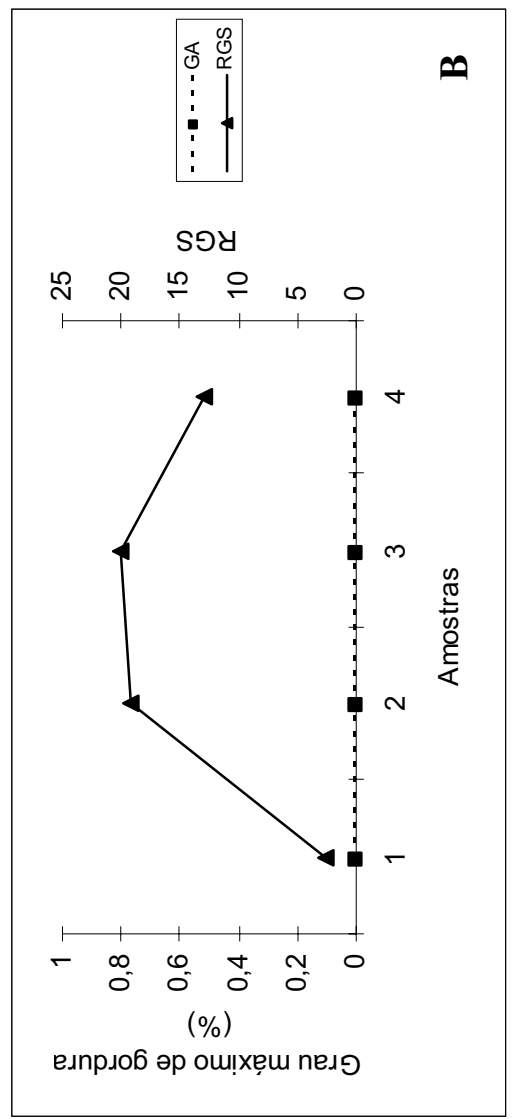

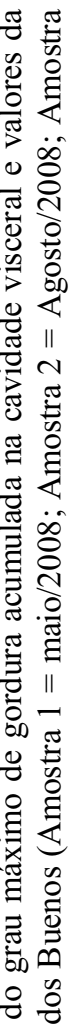

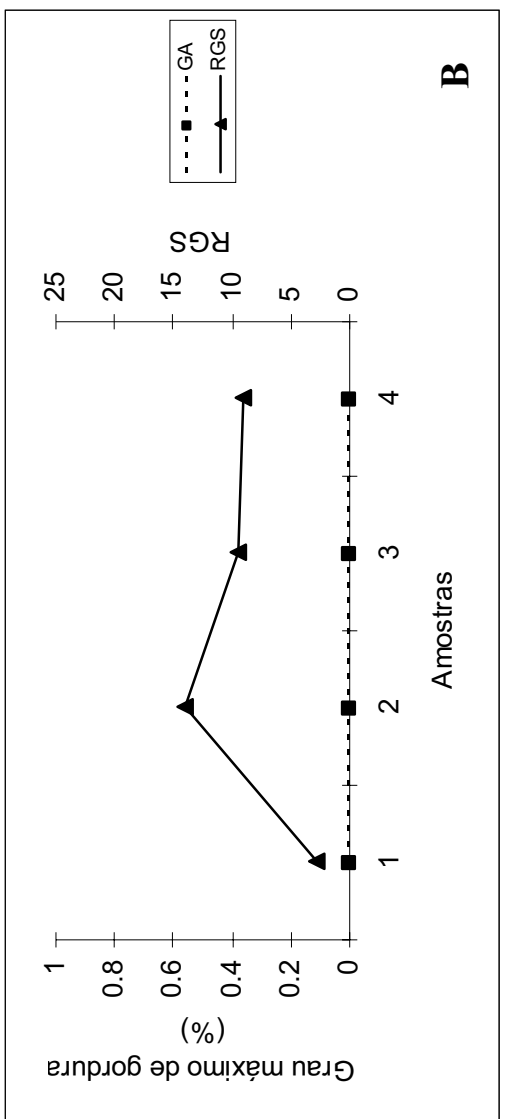

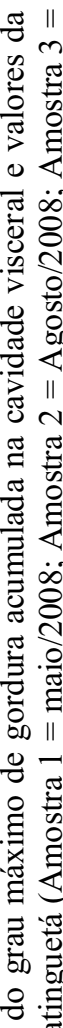

శ్ జి

exprob әр ourxem neג

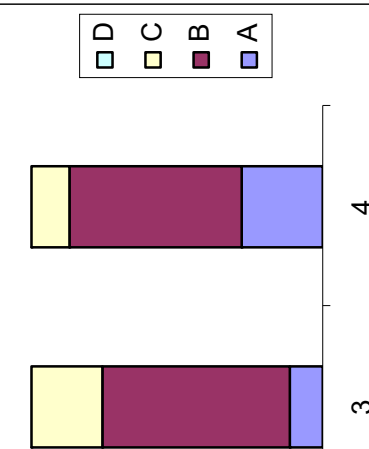

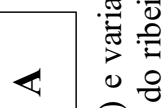

ङ.

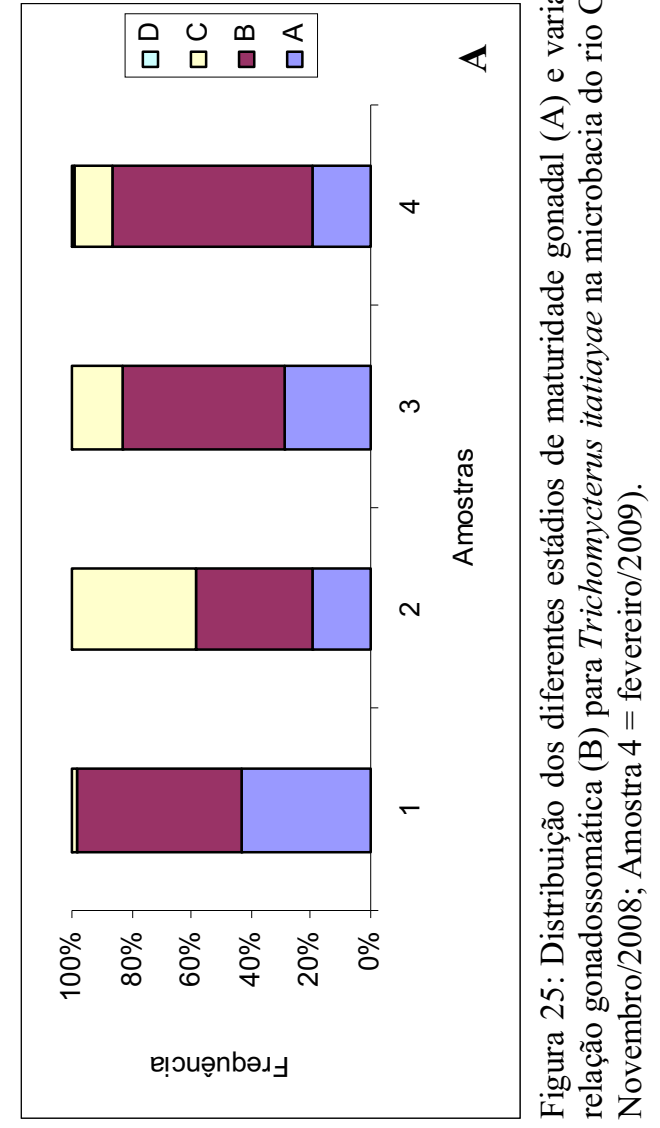

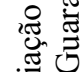




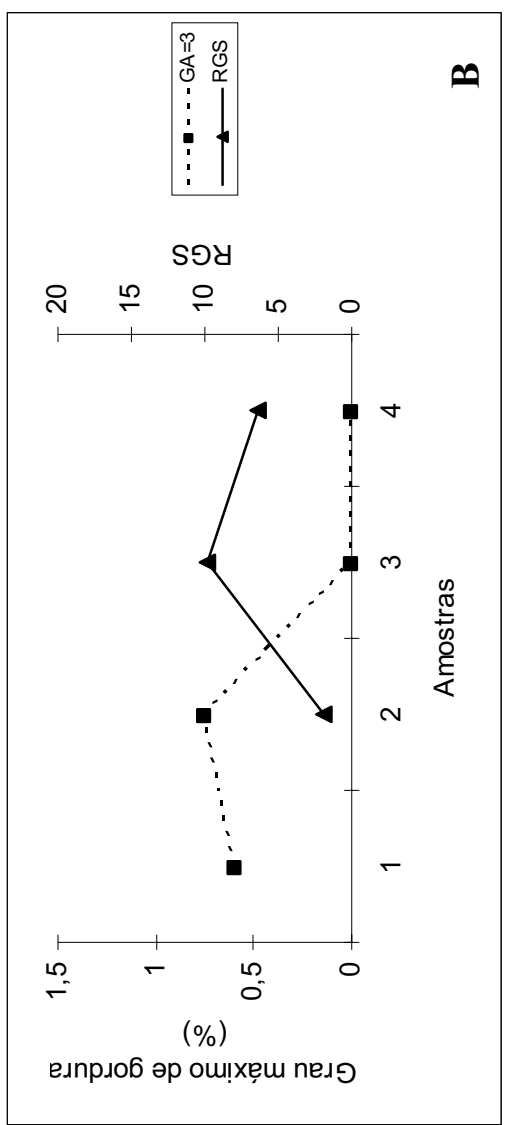

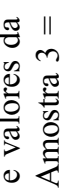

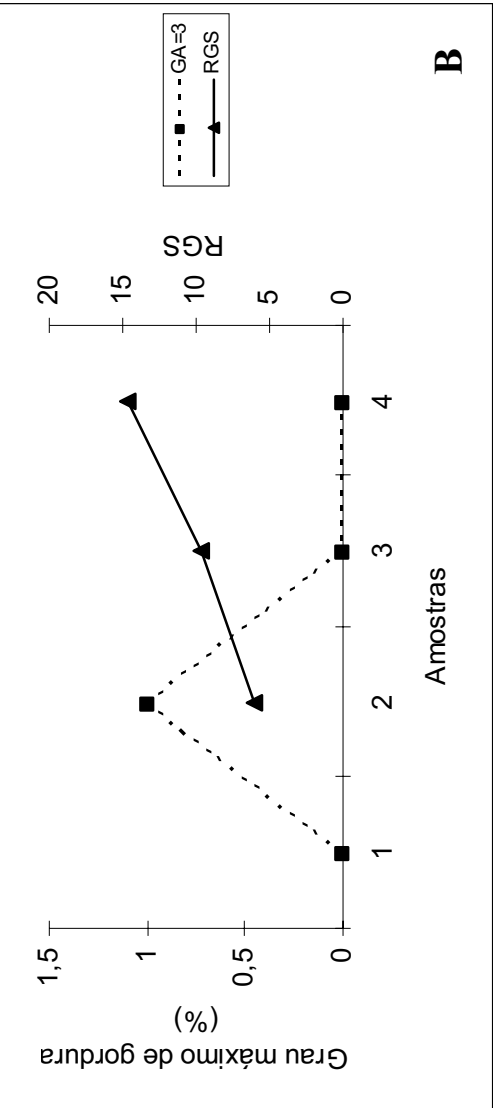

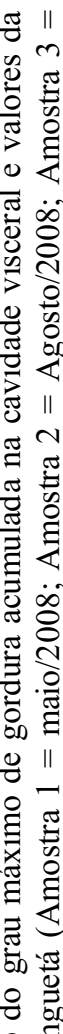

if

요
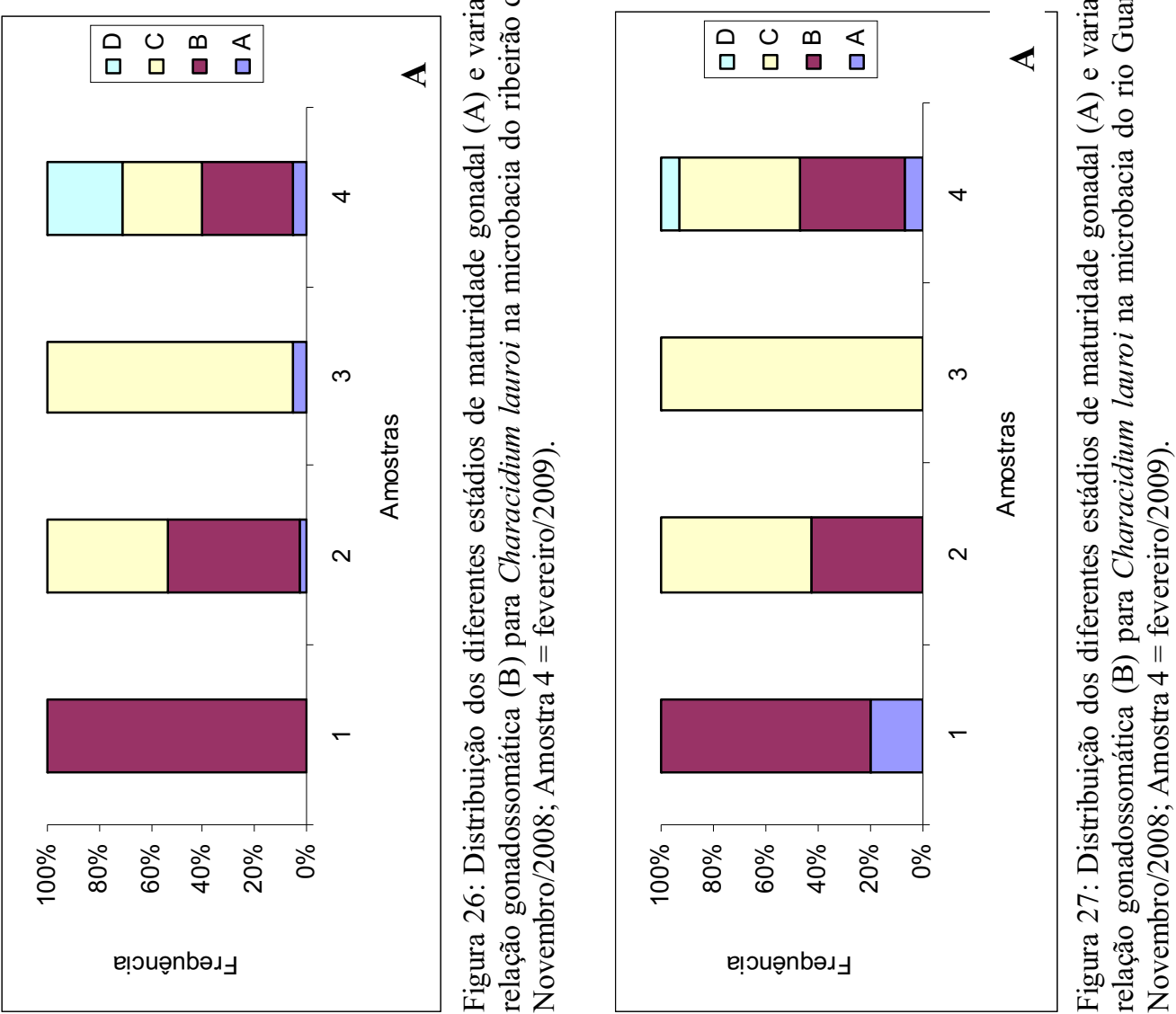


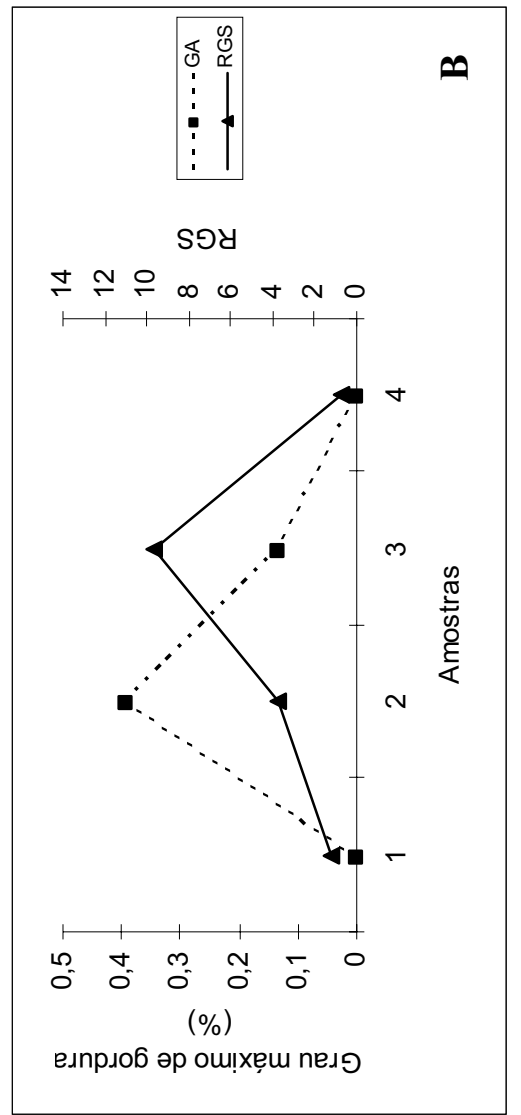

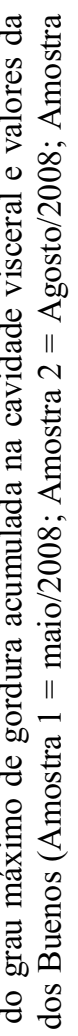

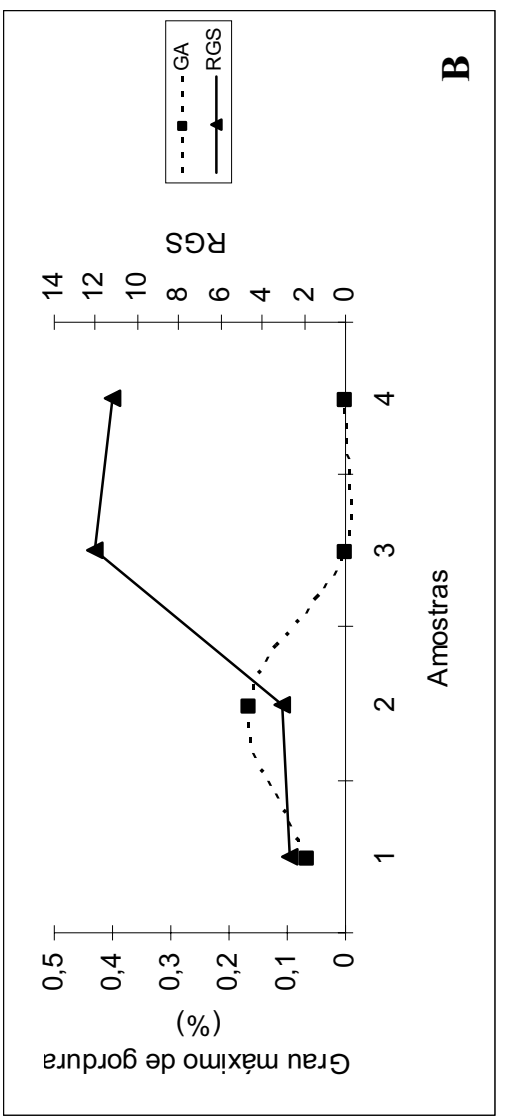

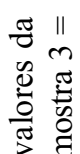
0 \&

퓰

盟

曾

है

可

월

芩

تु

흠

웅

웛 쥴
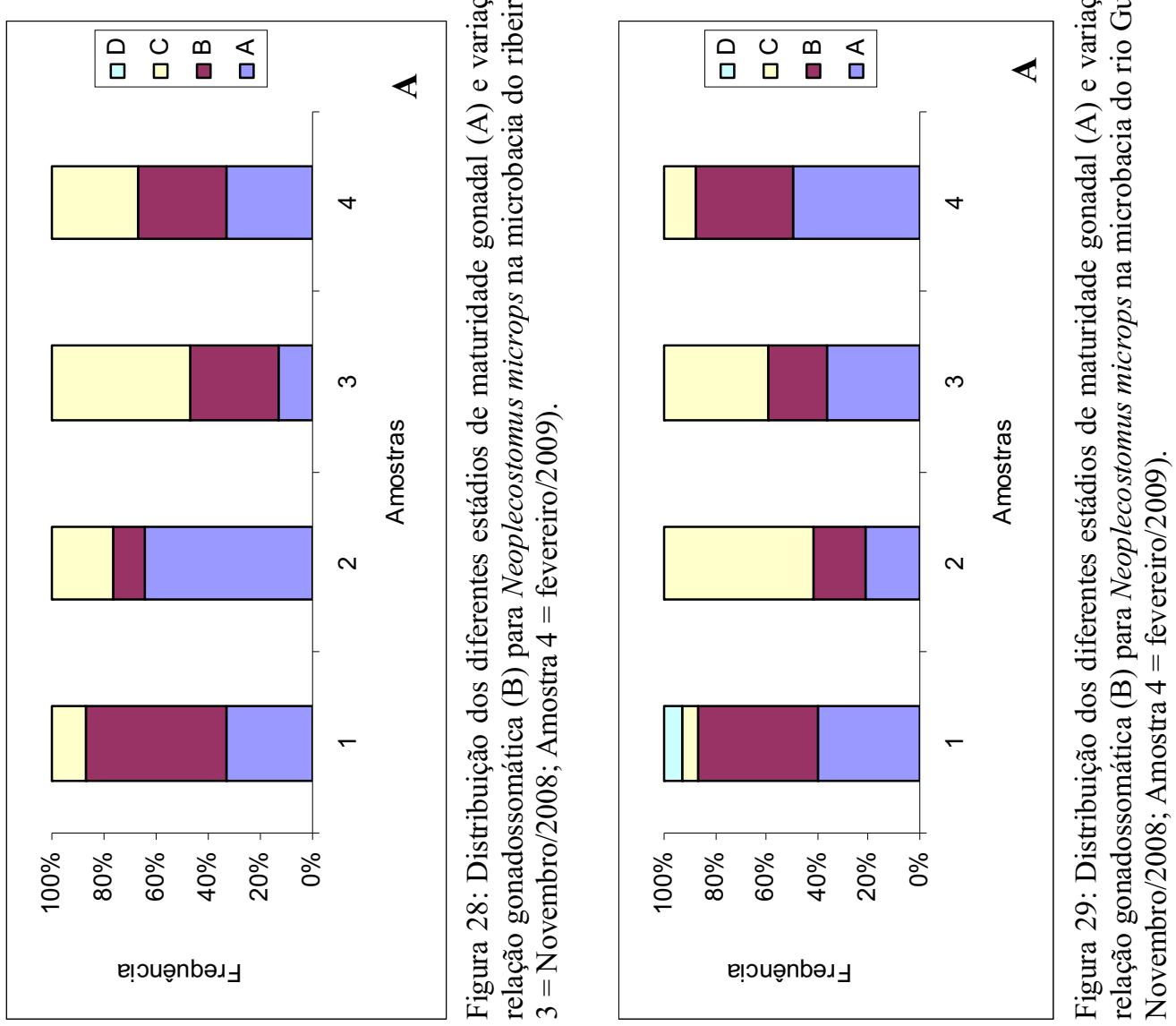


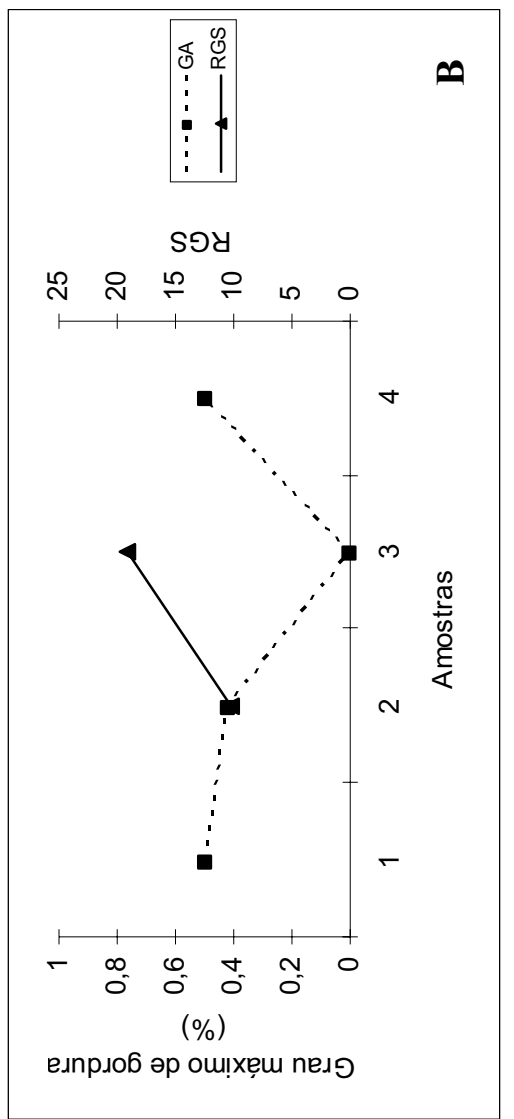

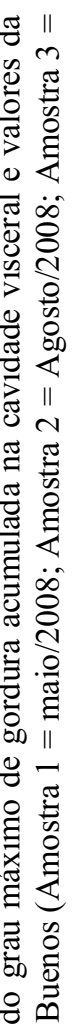

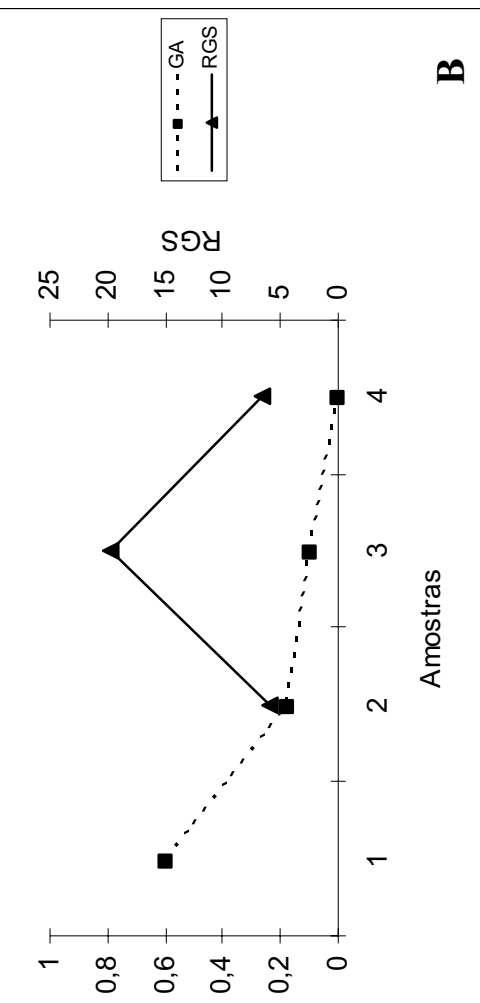

(\%)

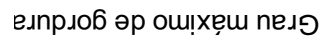

\&્.
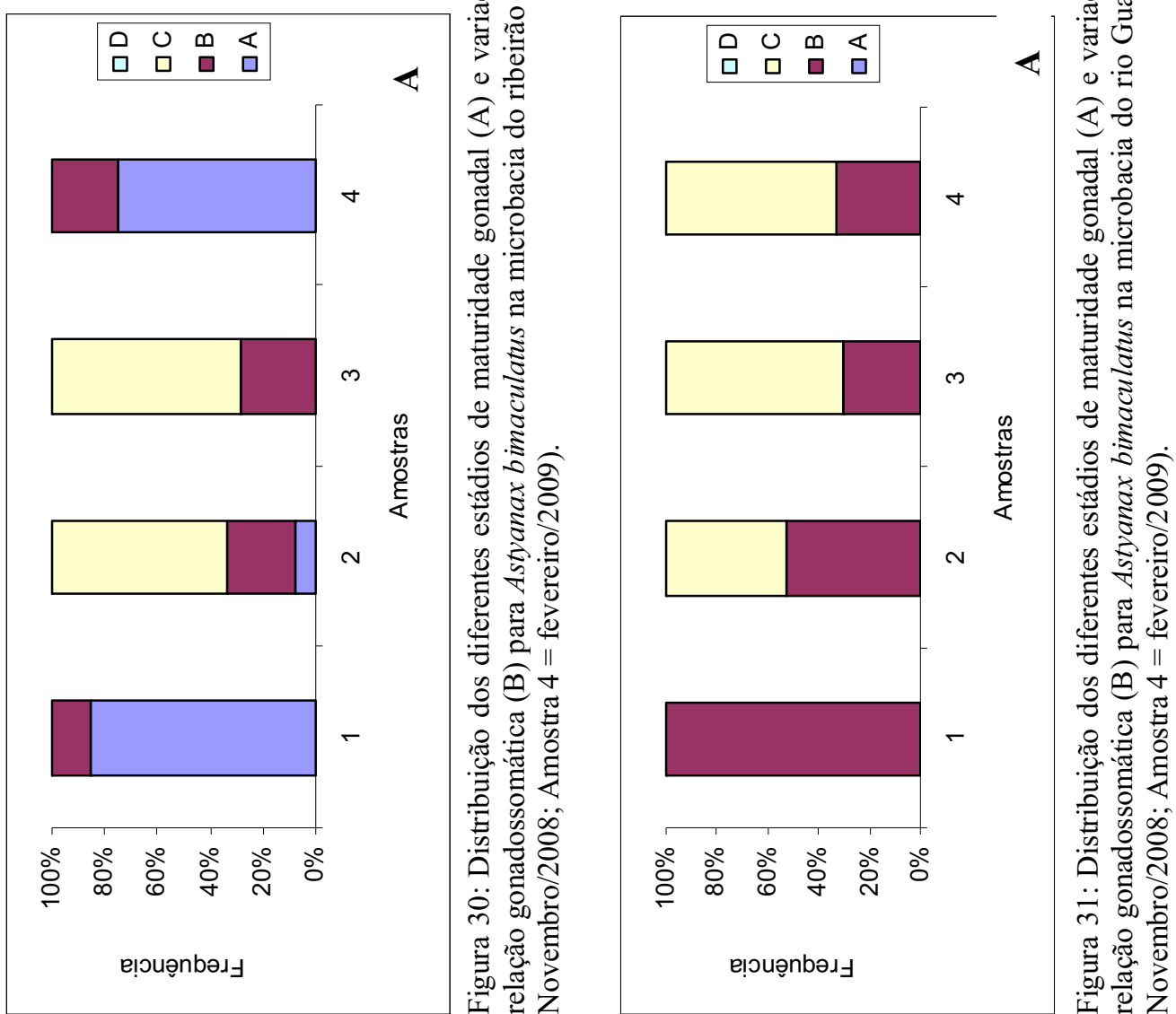


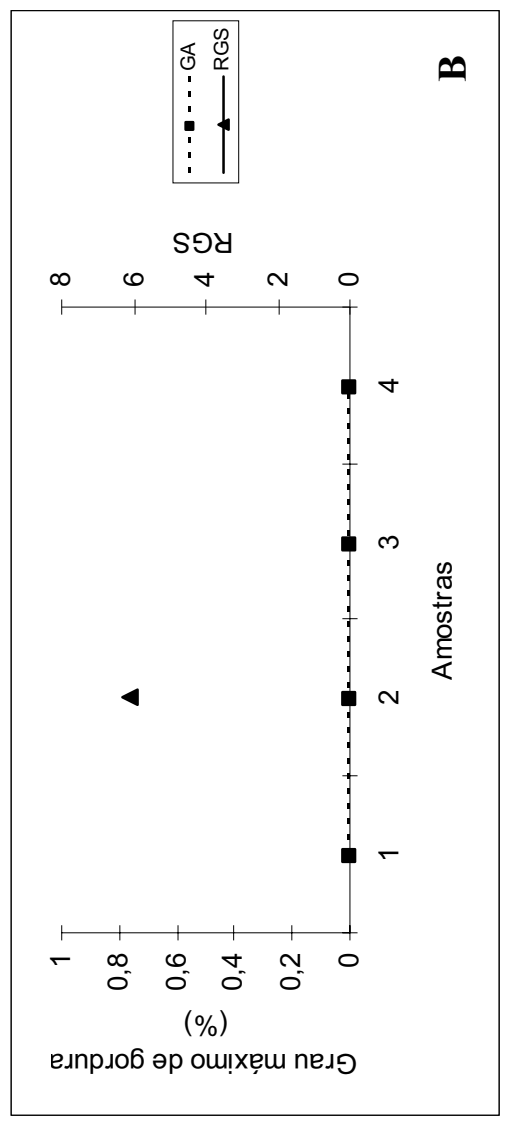

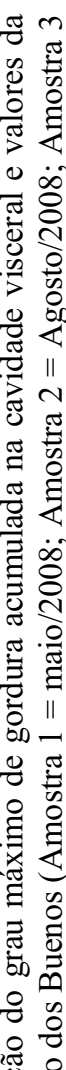

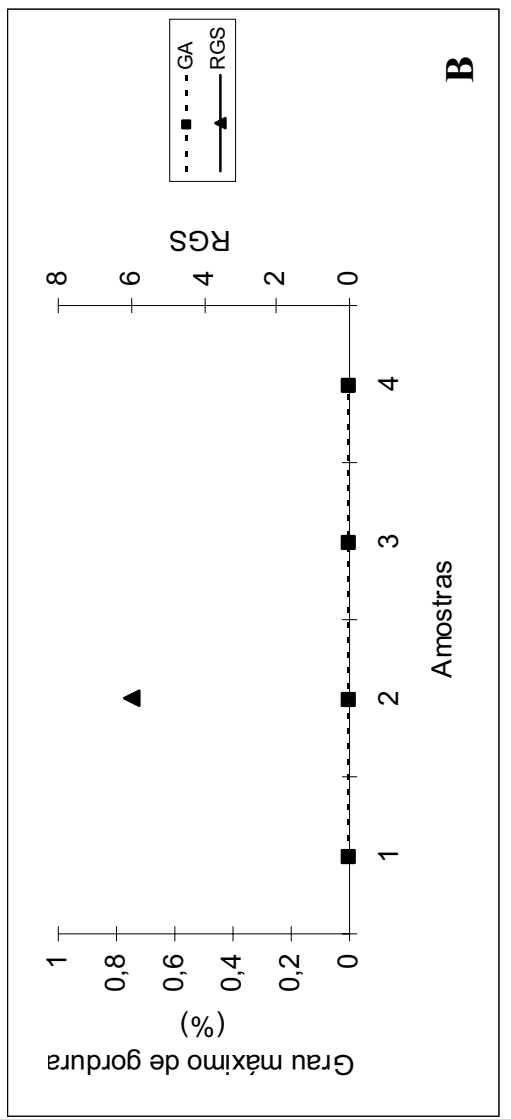

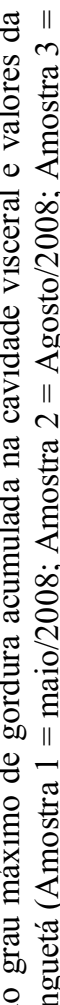

요
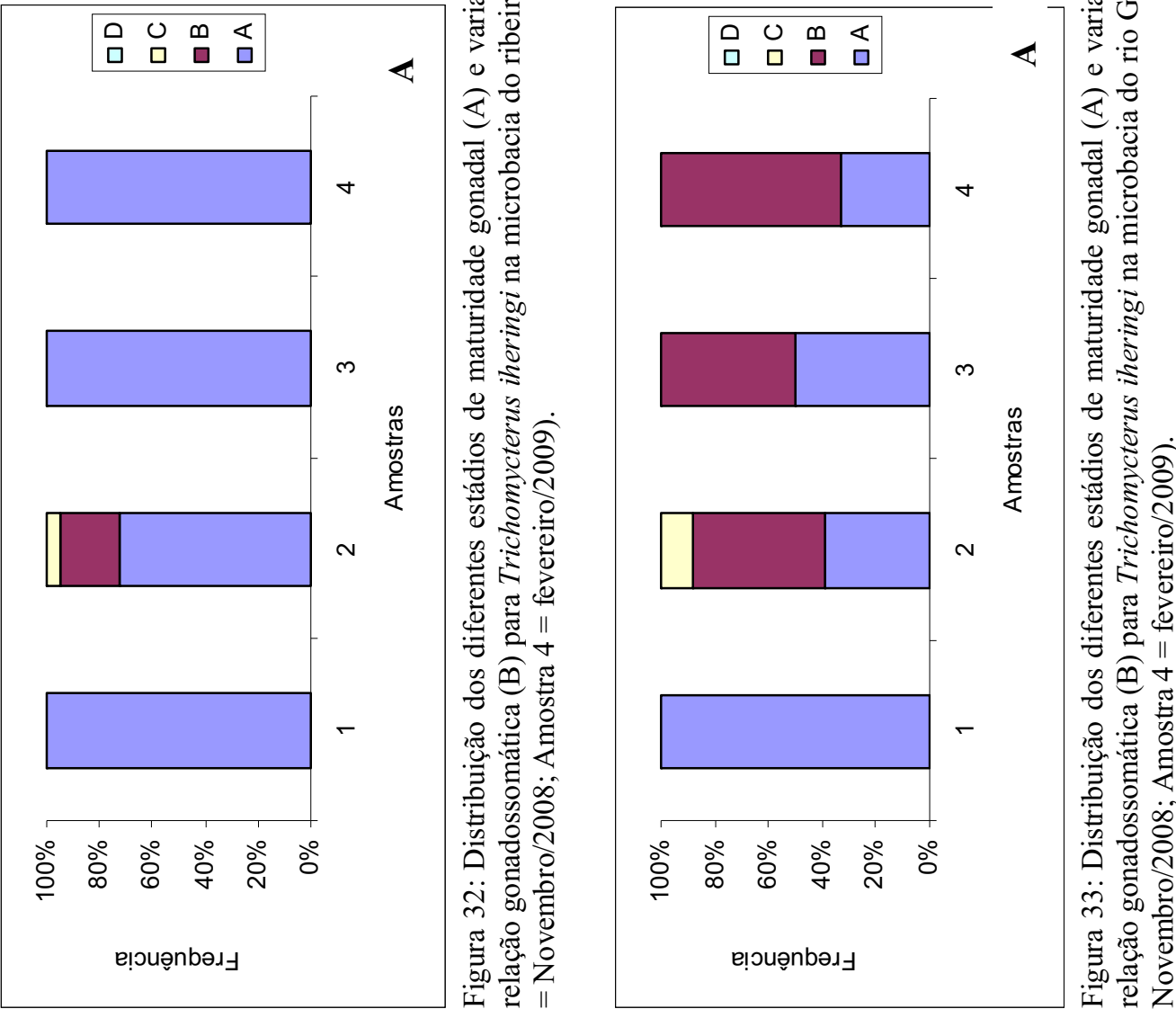


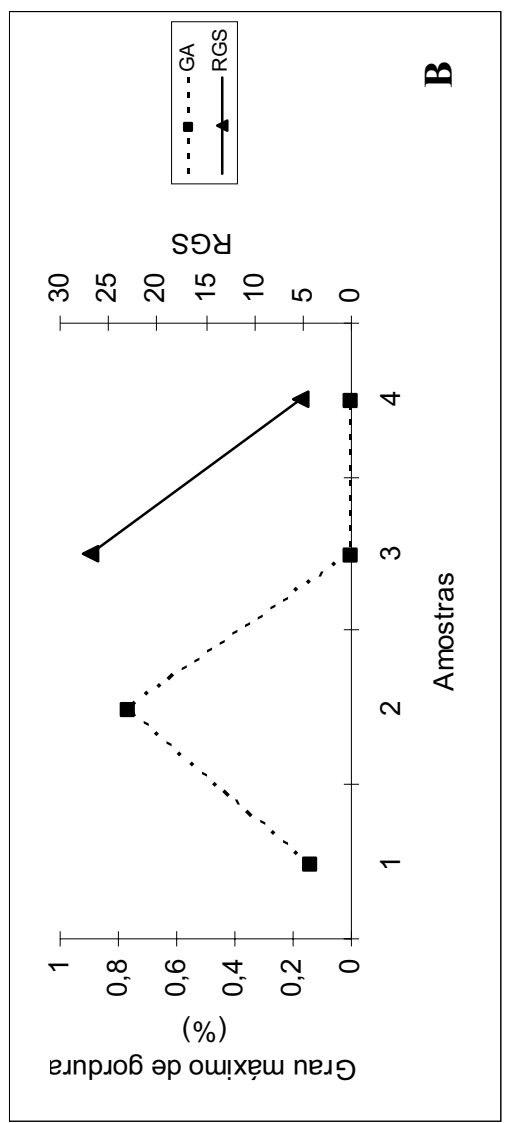

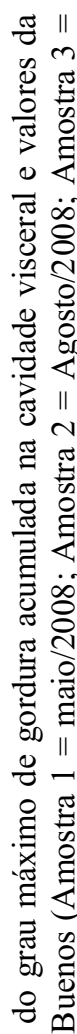

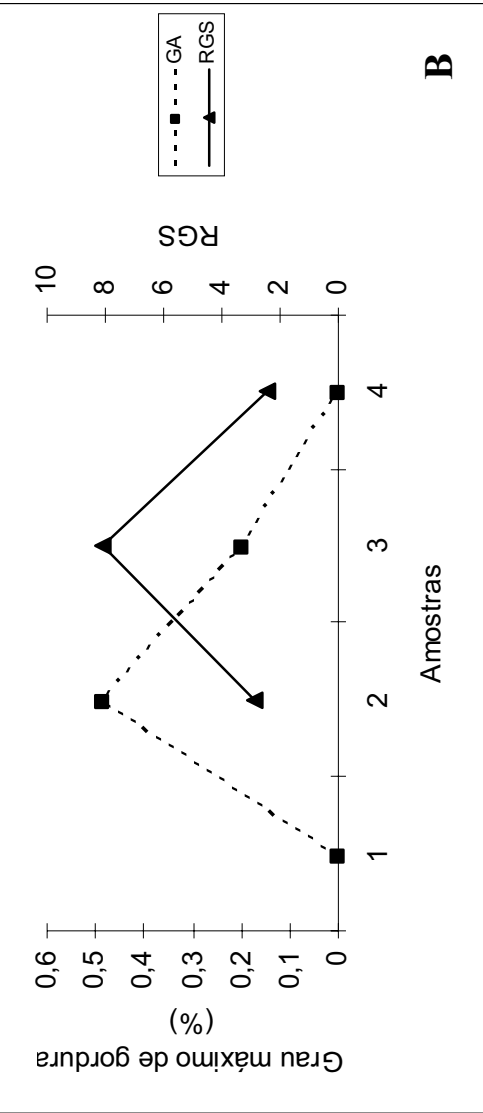

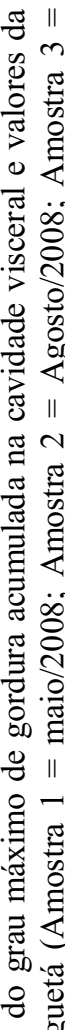

串

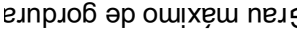
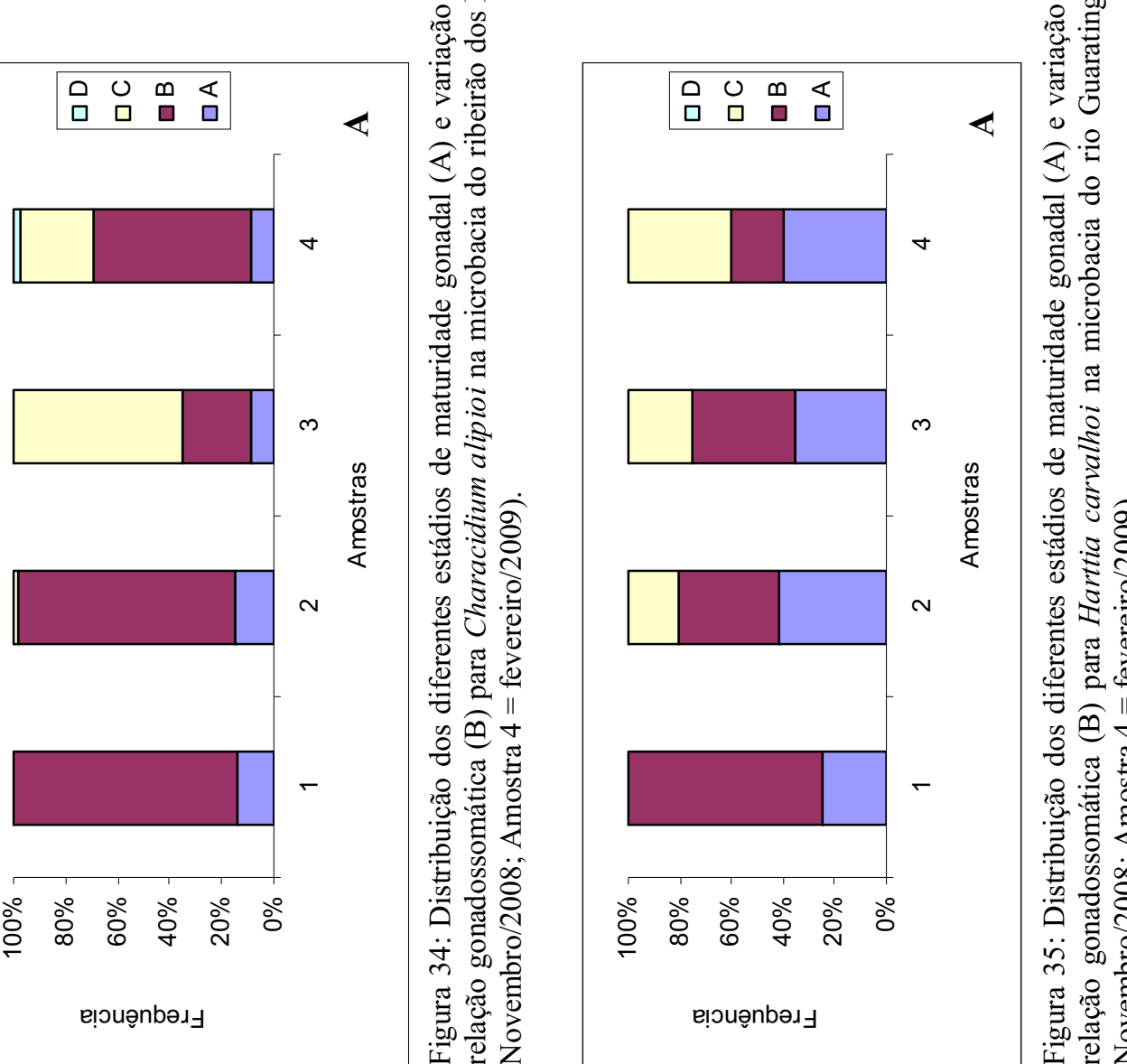


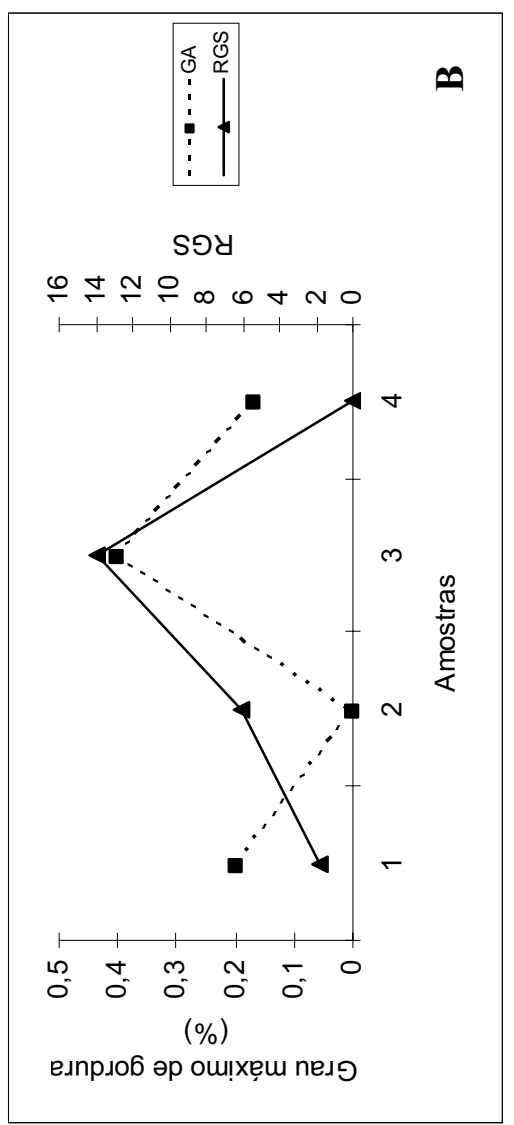

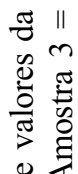

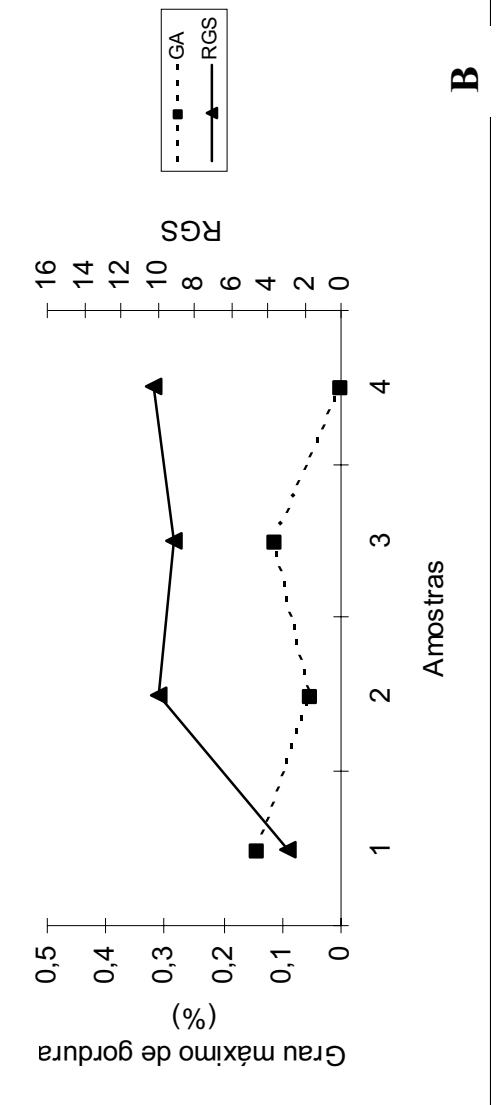

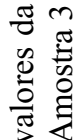

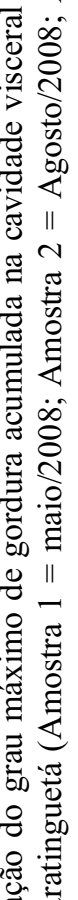

둥

요

年

完

牙

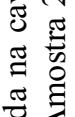

票定

$\ddot{8}$

종

总

\%
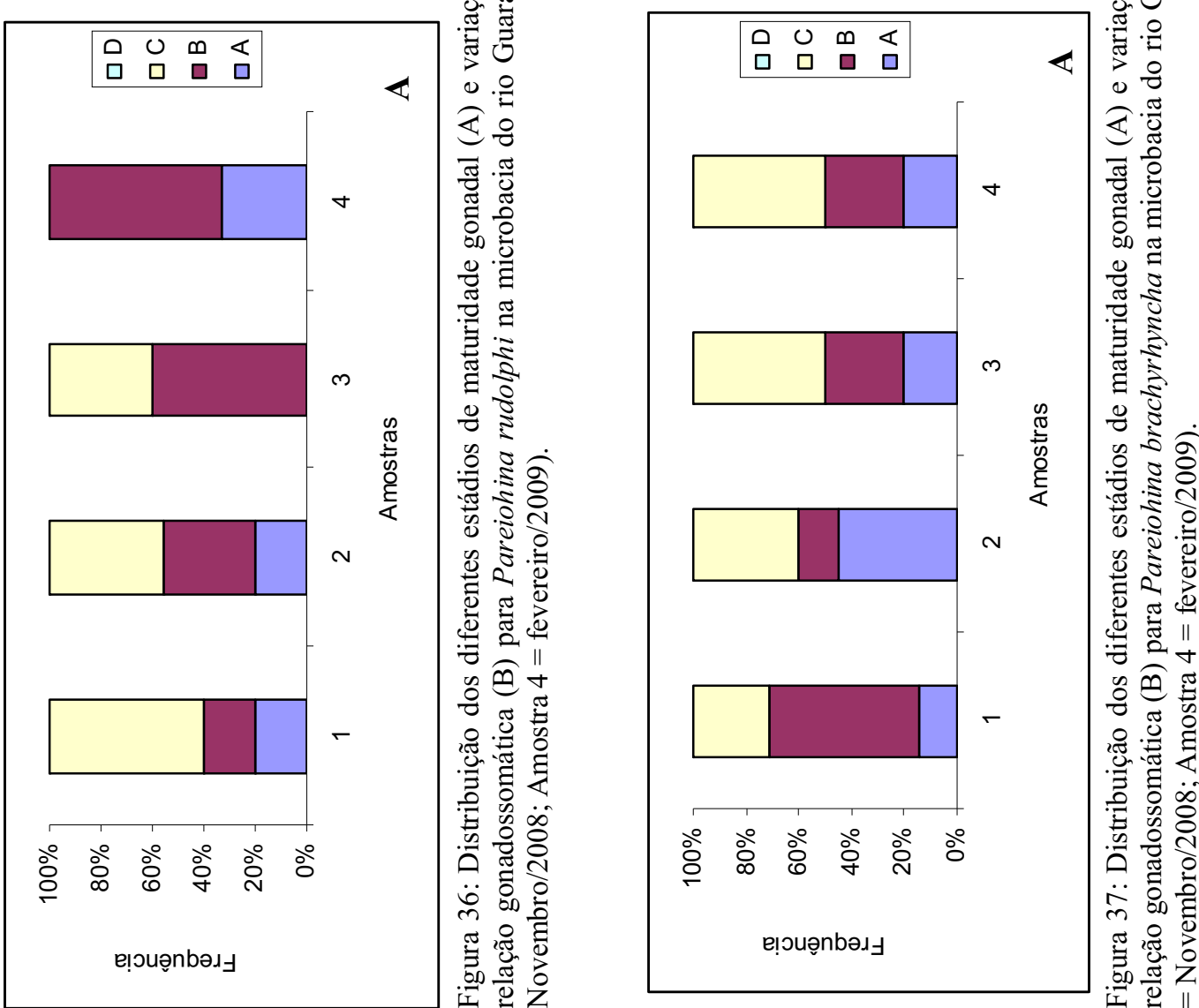
Com exceção dos tricomicterídeos (que não acumularam gordura na cavidade visceral), para as demais espécies as freqüências do grau máximo de gordura $(\mathrm{GA}=3)$ foram inversas aos valores da relação gonadossomática: quando a freqüência de gordura foi elevada, o valor da relação gonadossomática permaneceu baixo e vice-versa (Figuras 24 a 37).

Trichomycterus itatiayae apresentou maior freqüência de indivíduos maduros na amostra 2 para ambas as microbacias. Os maiores valores da relação gonadossomática coincidiram com as coletas em que a freqüência de indivíduos maduros foi elevada. $\mathrm{O}$ período reprodutivo dessa espécie estendeu-se do final da estação seca (amostra 2) até o fim da estação chuvosa (amostra 4). O pico da estação reprodutiva se deu na amostra 2, onde ocorreu a maior freqüência de indivíduos maduros e o maior valor da RGS.

Tanto na microbacia do ribeirão dos Buenos como na do rio Guaratinguetá, Characidium lauroi apresentou indivíduos maduros nas amostras 2, 3 e 4, sendo as maiores freqüências na amostra 3. Indivíduos esgotados estiveram presentes, nas duas microbacias, na amostra 4. Os maiores valores da RGS aconteceram na amostra 3 para o ribeirão dos Buenos, e na amostra 4 para o rio Guaratinguetá. Pode-se dizer que o período reprodutivo dessa espécie estende-se do final da estação de seca até o final da estação chuvosa. O pico reprodutivo se deu entre as amostra 3 e 4 .

Neoplecostomus microps apresentou indivíduos maduros ao longo de todo o período. As maiores freqüências ocorreram na amostra 3 , no caso da microbacia do ribeirão dos Buenos, e na amostra 2, na microbacia do rio Guaratinguetá. Os maiores valores da RGS para as duas microbacias aconteceram na amostra 3. A espécie apresenta período reprodutivo extenso, com maior intensidade de reprodução na amostra 3.

Astyanax bimaculatus apresentou maiores freqüências de indivíduos maduros e dos valores da RGS na amostra 3 para ambas as microbacias. Pode-se dizer que o período reprodutivo dessa espécie estende-se do final da estação de seca até o final da estação de cheia.

Trichomycetrus iheringi apresentou indivíduos maduros apenas na amostra 2. Por conta dos poucos exemplares maduros capturados, não foi possível estabelecer o período reprodutivo para essa espécie. 
Characidium alipioi apresentou maior freqüência de indivíduos maduros na amostra 3, assim como os maiores valores da RGS. Indivíduos esgotados estiveram presentes na amostra 4. O período reprodutivo dessa espécie concentra-se na estação de cheia.

Harttia carvalhoi apresentou maior freqüência de indivíduos maduros na amostra 4 e os maiores valores da RGS na amostra 3. Assim, essa espécie reproduz-se do final da estação seca e durante toda a estação de cheia.

Pareiohina rudolphi apresentou indivíduos maduros nas amostras 1, 2 e 3, sendo o maior valor de RGS na amostra 3. O período reprodutivo de P. rudolphi parece ocorrer durante todo o período de seca e início do período de cheia. Pareiohina brachyrhyncha apresentou indivíduos maduros em todo o período, e os maiores valores de RGS nas amostras 2, 3 e 4. A espécie apresenta período reprodutivo prolongado.

\subsection{Condição corporal}

Os valores do intercepto, coeficiente angular e coeficiente de correlação nas relações peso e comprimento de Trichomycterus itatiayae, Neoplecostomus microps, Astyanax bimaculatus e Characidium lauroi para cada sexo, por microbacia e por época encontram-se na Tabela 10. Houve uma nítida tendência dos valores do coeficiente angular serem menores do que 3,0 entre sexos e períodos, indicando, com isso, um crescimento alométrico negativo, onde os indivíduos crescem mais em comprimento do que em ganho de peso. 
Tabela 10: Valores estimados de a (intercepto), b (coeficiente angular) e r (coeficiente de correlação) nas relações peso e comprimento para as espécies mais abundantes nos períodos de seca e cheia.

\begin{tabular}{|c|c|c|c|c|c|c|c|c|}
\hline \multirow[b]{2}{*}{ Espécie } & \multirow[b]{2}{*}{ Microbacia } & \multirow[b]{2}{*}{ Sexo } & \multicolumn{3}{|c|}{ Seca } & \multicolumn{3}{|c|}{ Cheia } \\
\hline & & & $\mathbf{a}$ & b & $\mathbf{R}$ & $\mathbf{a}$ & b & $\mathbf{R}$ \\
\hline \multirow{4}{*}{ T. itatiayae } & \multirow{2}{*}{ Buenos } & Machos & 0,00005 & 2.6501 & 0.98 & 0,00005 & 2.6783 & 0.98 \\
\hline & & Fêmeas & 0,00003 & 2.8157 & 0.98 & 0.00006 & 2.6015 & 0.98 \\
\hline & \multirow{2}{*}{ Guará } & Machos & 0.00003 & 2.7702 & 0.98 & 0.00003 & 2.7791 & 0.98 \\
\hline & & Fêmeas & 0.00003 & 2.8078 & 0.98 & 0.00006 & 2.5684 & 0.96 \\
\hline \multirow{4}{*}{ N. microps } & \multirow{2}{*}{ Buenos } & Machos & 0.00002 & 3.0241 & 0.99 & 0.00002 & 2.9865 & 0.99 \\
\hline & & Fêmeas & 0.00001 & 3.1624 & 0.99 & 0.00001 & 3.1282 & 0.99 \\
\hline & \multirow{2}{*}{ Guará } & Machos & 0.00002 & 2.9476 & 0.99 & 0.00002 & 2.9893 & 0.99 \\
\hline & & Fêmeas & 0.00008 & 2.6457 & 0.98 & 0.00001 & 3.0757 & 0.98 \\
\hline \multirow{4}{*}{ A. bimaculatus } & \multirow{2}{*}{ Buenos } & Machos & 0.00005 & 2.8338 & 0.97 & 0.00004 & 2.9502 & 0.97 \\
\hline & & Fêmeas & 0.00003 & 2.9560 & 0.98 & - & - & - \\
\hline & \multirow{2}{*}{ Guará } & Machos & 0.00002 & 3.0529 & 0.99 & 0.00002 & 3.0469 & 0.98 \\
\hline & & Fêmeas & 0.00004 & 2.9309 & 0.98 & 0.00002 & 3.1450 & 0.97 \\
\hline \multirow{4}{*}{ C. lauroi } & \multirow{2}{*}{ Buenos } & Machos & 0.0002 & 2.3639 & 0.91 & 0.0001 & 2.4530 & 0.95 \\
\hline & & Fêmeas & 0.0003 & 2.2773 & 0.94 & 0.0002 & 2.4234 & 0.97 \\
\hline & \multirow{2}{*}{ Guará } & Machos & 0.0001 & 2.5050 & 0.95 & 0.00001 & 3.0421 & 0.96 \\
\hline & & Fêmeas & 0.0003 & 2.2748 & 0.97 & 0.0005 & 2.1559 & 0.90 \\
\hline
\end{tabular}

A relação alométrica entre peso e comprimento não foi diferente para machos e fềmeas de Trichomycterus itatiayae (Tabela 11). A interação significativa entre o comprimento e época sugere que, para cada época (seca e cheia) a relação peso e comprimento é diferente (Tabela 12). Assim, o modelo da ANCOVA foi simplificado: em cada época avaliou-se o efeito da microbacia na condição corporal de $T$. itatiayae. Não houve variação significativa na condição corporal de $T$. itatiayae com relação à microbacia (Tabelas 13 e 14).

Tabela 11: Resultados da análise de covariância para o logaritmo natural do peso (PT) (variável dependente) e do comprimento padrão (CP) (covariável) para machos e fêmeas de Trichomycterus itatiayae. $(\mathrm{FV}=$ fonte de variação; $\mathrm{SQ}=$ soma de quadrados; $\mathrm{GL}=$ graus de liberdade; $\mathrm{QM}=$ quadrado médio; $\mathrm{F}=$ teste $\mathrm{F}$ ).

\begin{tabular}{rrrrrr}
\hline FV & SQ & gl & QM & F & P \\
\hline CP & 427,730 & 1 & 427,730 & 27071,797 & $<0,0001$ \\
Sexo & 0,000 & 1 & 0,000 & 0,019 & 0,891 \\
Sexo*CP & 0,001 & 1 & 0,001 & 0,077 & 0,781 \\
Resíduo & 20,271 & 1283 & 0,016 & & \\
\hline
\end{tabular}


Tabela 12: Resultados da análise de covariância para o logaritmo natural do peso (PT) (variável dependente) e do comprimento padrão (CP) (covariável) de Trichomycterus itatiayae nas microbacias do ribeirão dos Buenos e do rio Guaratinguetá (fatores) e nas épocas de seca e cheia (fatores). (FV = fonte de variação; $S Q=$ soma de quadrados; GL = graus de liberdade; $\mathrm{QM}=$ quadrado médio; $\mathrm{F}=$ teste $\mathrm{F}$ ).

\begin{tabular}{rrrrrr}
\hline FV & SQ & gl & QM & $\mathbf{F}$ & $\mathbf{P}$ \\
\hline CP & 282,898 & 1 & 282,898 & 18885,063 & $<0,0001$ \\
Bacia & 0,036 & 1 & 0,036 & 2,428 & 0,119 \\
Época & 0,106 & 1 & 0,106 & 7,048 & 0,008 \\
Bacia*CP & 0,023 & 1 & 0,023 & 1,556 & 0,212 \\
Época*CP & 0,094 & 1 & 0,094 & 6,286 & $\mathbf{0 , 0 1 2}$ \\
Bacia*Época & 0,009 & 1 & 0,009 & 0,628 & 0,428 \\
Resíduo & 19,174 & 1280 & 0,015 & & \\
\hline
\end{tabular}

Tabela 13: Resultados da análise de covariância para o logaritmo natural do peso (PT) (variável dependente) e do comprimento padrão (CP) (covariável) de Trichomycterus itatiayae na época de seca (fator). (FV = fonte de variação; $\mathrm{SQ}=$ soma de quadrados; $\mathrm{GL}=$ graus de liberdade; $\mathrm{QM}=$ quadrado médio; $\mathrm{F}=$ teste $\mathrm{F}$ ).

\begin{tabular}{rrrrrr}
\hline FV & SQ & gl & QM & F & P \\
\hline CP & 158,965 & 1 & 158,965 & 10204,777 & $<0,0001$ \\
Bacia & 0,022 & 1 & 0,022 & 1,429 & 0,232 \\
Bacia*CP & 0,014 & 1 & 0,014 & 0,900 & 0,343 \\
Resíduo & 10,110 & 649 & 0,016 & & \\
\hline
\end{tabular}

Tabela 14: Resultados da análise de covariância para o logaritmo natural do peso (PT) (variável dependente) e do comprimento padrão (CP) (covariável) de Trichomycterus itatiayae na época de cheia (fator). (FV = fonte de variação; $\mathrm{SQ}=$ soma de quadrados; $\mathrm{GL}=$ graus de liberdade; $\mathrm{QM}=$ quadrado médio; $\mathrm{F}=$ teste $\mathrm{F}$ ).

\begin{tabular}{rrrrrr}
\hline FV & SQ & gl & QM & F & P \\
\hline CP & 126,539 & 1 & 126,539 & 8794,678 & $<0,0001$ \\
Bacia & 0,014 & 1 & 0,014 & 1,000 & 0,318 \\
Bacia*CP & 0,009 & 1 & 0,009 & 0,651 & 0,420 \\
Resíduo & 9,064 & 630 & 0,014 & & \\
\hline
\end{tabular}

A interação significativa entre o peso e o comprimento para machos e fêmeas de Neoplecostomus microps indica que relação alométrica é diferente entre os sexos (Tabela 15). Assim, separou-se os sexos para identificar diferenças na relação entre o peso e o comprimento dentro de cada sexo associadas às microbacias e épocas. Machos e fêmeas de Neoplecostomus microps não apresentaram diferenças na condição corporal entre microbacias e épocas (Tabelas 16 e 17). 
Tabela 15: Resultados da análise de covariância para o logaritmo natural do peso (PT) (variável dependente) e do comprimento padrão (CP) (covariável) para machos e fềmeas de Neoplecostomus microps. (FV = fonte de variação; $\mathrm{SQ}$ = soma de quadrados; $\mathrm{GL}$ = graus de liberdade; $\mathrm{QM}=$ quadrado médio; $\mathrm{F}=$ teste $\mathrm{F}$ ).

\begin{tabular}{rrrrrr}
\hline FV & SQ & gl & QM & F & P \\
\hline CP & 2085,078 & 1 & 2085,078 & 1805,017 & $<0,0001$ \\
Sexo & 18,534 & 1 & 18,534 & 16,044 & $<0,0001$ \\
Sexo*CP & 27,211 & 1 & 27,211 & 23,556 & $<\mathbf{0 , 0 0 0 1}$ \\
Resíduo & 53,636 & 133 & 1,155 & & \\
\hline
\end{tabular}

Tabela 16: Resultados da análise de covariância para o logaritmo natural do peso (PT) (variável dependente) e do comprimento padrão $(\mathrm{CP})$ (covariável) de fêmeas de Neoplecostomus microps nas microbacias do ribeirão dos Buenos e do rio Guaratinguetá, nas épocas de seca e cheia. ( $F V=$ fonte de variação; $S Q=$ soma de quadrados; $\mathrm{GL}=$ graus de liberdade; $\mathrm{QM}=$ quadrado médio; $\mathrm{F}=$ teste $\mathrm{F}$ ).

\begin{tabular}{rrrrrr}
\hline FV & SQ & gl & QM & F & P \\
CP & 665,423 & 1 & 665,423 & 1153,470 & $<0,0001$ \\
Bacia & 1,904 & 1 & 1,904 & 3,300 & 0,073 \\
Época & 0,017 & 1 & 0,017 & 0,030 & 0,863 \\
Bacia*CP $^{*}$ Época*CP & 1,524 & 1 & 1,524 & 2,642 & 0,108 \\
Bacia*Época & 0,073 & 1 & 0,073 & 0,126 & 0,724 \\
Bacia*Época*CP & 0,835 & 1 & 0,835 & 1,447 & 0,233 \\
Resíduo & 43,844 & 1 & 1,152 & 1,997 & 0,162 \\
\hline
\end{tabular}

Tabela 17: Resultados da análise de covariância para o logaritmo natural do peso (PT) (variável dependente) e do comprimento padrão (CP) (covariável) de machos de Neoplecostomus microps nas microbacias do ribeirão dos Buenos e do rio Guaratinguetá, nas épocas de seca e cheia. ( $F V=$ fonte de variação; $S Q=$ soma de quadrados; $\mathrm{GL}=$ graus de liberdade; $\mathrm{QM}=$ quadrado médio; $\mathrm{F}=$ teste $\mathrm{F}$ ).

\begin{tabular}{rrrrrr}
\hline FV & SQ & gl & QM & $\mathbf{F}$ & $\mathbf{P}$ \\
\hline CP & 1134,572 & 1 & 1134,572 & 602,625 & $<0,0001$ \\
Bacia & 0,868 & 1 & 0,868 & 0,461 & 0,501 \\
Época & 0,933 & 1 & 0,933 & 0,496 & 0,485 \\
Bacia*CP & 2,098 & 1 & 2,098 & 1,114 & 0,297 \\
Época*CP & 1,411 & 1 & 1,411 & 0,749 & 0,391 \\
Bacia*Época & 1,660 & 1 & 1,660 & 0,881 & 0,353 \\
Bacia*Época*CP & 0,842 & 1 & 0,842 & 0,447 & 0,507 \\
Resíduo & 84,722 & 45 & 1,883 & & \\
\hline
\end{tabular}


A interação significativa entre o comprimento e o sexo de Astyanax bimaculatus indica que a relação alométrica é diferente para machos e fêmeas (Tabela 18). Assim, como realizado para $N$. microps, os sexos foram separados para identificar diferenças na relação entre o peso e o comprimento dentro de cada sexo associadas às microbacias e épocas. As interações significativas observadas sugeriram que, para cada microbacia e para cada época, a relação peso e comprimento tanto de machos como de fềmeas foi diferente (Tabelas 19 e 20).

Tabela 18: Resultados da análise de covariância para o logaritmo natural do peso (PT) (variável dependente) e do comprimento padrão (CP) (covariável) para machos e fêmeas de Astyanax bimaculatus. (FV = fonte de variação; $\mathrm{SQ}=$ soma de quadrados; $\mathrm{GL}$ = graus de liberdade; $\mathrm{QM}=$ quadrado médio; $\mathrm{F}=$ teste $\mathrm{F}$ ).

\begin{tabular}{rrrrrr}
\hline FV & SQ & gl & QM & F & P \\
\hline CP & 3983,226 & 1 & 3983,226 & 495,805 & $<0,0001$ \\
Sexo & 36,668 & 1 & 36,668 & 4,564 & 0,035 \\
Sexo*CP & 45,423 & 1 & 45,423 & 5,654 & $\mathbf{0 , 0 1 9}$ \\
Resíduo & 1020,299 & 127 & 8,034 & & \\
\hline
\end{tabular}

Tabela 19: Resultados da análise de covariância para o logaritmo natural do peso (PT) (variável dependente) e do comprimento padrão (CP) (covariável) de fêmeas de Astyanax bimacuatus nas microbacias do ribeirão dos Buenos e do rio Guaratinguetá, nas épocas de seca e cheia. (FV = fonte de variação; $S Q=$ soma de quadrados; $\mathrm{GL}=$ graus de liberdade; $\mathrm{QM}=$ quadrado médio; $\mathrm{F}=$ teste $\mathrm{F}$ ).

\begin{tabular}{rrrrrr}
\hline FV & SQ & gl & $\mathbf{Q M}$ & $\mathbf{F}$ & $\mathbf{P}$ \\
\hline CP & 732,853 & 1 & 732,853 & 221,901 & $<0,0001$ \\
Bacia & 240,616 & 1 & 240,616 & 72,856 & $<0,0001$ \\
Época & 18,526 & 1 & 18,526 & 5,609 & 0,022 \\
Bacia*CP & 332,831 & 1 & 332,831 & 100,778 & $<\mathbf{0 , 0 0 0 1}$ \\
Época*CP & 31,702 & 1 & 31,702 & 9,599 & $\mathbf{0 , 0 0 3}$ \\
Bacia*Época & 114,545 & 1 & 114,545 & 34,683 & $<\mathbf{0 , 0 0 0 1}$ \\
Bacia*Época*CP & 151,662 & 1 & 151,662 & 45,922 & $<\mathbf{0 , 0 0 0 1}$ \\
Resíduo & 175,038 & 53 & 3,303 & & \\
\hline
\end{tabular}


Tabela 20: Resultados da análise de covariância para o logaritmo natural do peso (PT) (variável dependente) e do comprimento padrão (CP) (covariável) de machos de Astyanax bimacuatus nas microbacias do ribeirão dos Buenos e do rio Guaratinguetá, nas épocas de seca e cheia. (FV = fonte de variação; $\mathrm{SQ}=$ soma de quadrados; $\mathrm{GL}=$ graus de liberdade; $\mathrm{QM}=$ quadrado médio; $\mathrm{F}=$ teste $\mathrm{F}$ ).

\begin{tabular}{rrrrrr}
\hline FV & SQ & gl & QM & F & P \\
CP & 474.670 & 1 & 474,670 & 340,984 & $<0,0001$ \\
Bacia & 21,571 & 1 & 21,571 & 15,495 & $<0,0001$ \\
Época & 16,932 & 1 & 16,932 & 12,163 & 0,001 \\
Bacia*CP & 23,531 & 1 & 23,531 & 16,903 & $<\mathbf{0 , 0 0 0 1}$ \\
Época*CP & 16,509 & 1 & 16,509 & 11,859 & $\mathbf{0 , 0 0 1}$ \\
Bacia*Época & 4,377 & 1 & 4,377 & 3,144 & 0,081 \\
Bacia*Época*CP & 2,711 & 1 & 2,711 & 1,947 & 0,168 \\
Resíduo & 86,308 & 62 & 1,392 & & \\
\hline
\end{tabular}

A relação alométrica entre peso e comprimento não foi diferente para machos e fềmeas de Characidium lauroi (Tabela 21). A interação significativa indica que a condição corporal de $C$ lauroi é diferente entre as microbacias (Tabela 22). Assim, o modelo da ANCOVA foi simplificado: em cada microbacia avaliou-se o efeito da época na condição corporal de C. lauroi. Não houve alteração na condição corporal de $C$. lauroi entre as épocas de seca e cheia nas microbacias do ribeirão dos Buenos e do rio Guaratinguetá (Tabelas 23 e 24).

Tabela 21: Resultados da análise de covariância para o logaritmo natural do peso (PT) (variável dependente) e do comprimento padrão (CP) (covariável) para machos e fêmeas de Characidium lauroi. (FV = fonte de variação; $\mathrm{SQ}=$ soma de quadrados; $\mathrm{GL}=$ graus de liberdade; $\mathrm{QM}=$ quadrado médio; $\mathrm{F}=$ teste $\mathrm{F}$ ).

\begin{tabular}{rrrrrr}
\hline FV & SQ & gl & QM & $\mathbf{F}$ & $\mathbf{P}$ \\
\hline CP & 101,487 & 1 & 101,487 & 1103,840 & $<0,0001$ \\
Sexo & 0,171 & 1 & 0,171 & 1,863 & 0,174 \\
Sexo*CP & 0,216 & 1 & 0,216 & 2,354 & 0,126 \\
Resíduo & 19,399 & 211 & 0,092 & & \\
\hline
\end{tabular}


Tabela 22: Resultados da análise de covariância para o logaritmo natural do peso (PT) (variável dependente) e do comprimento padrão (CP) (covariável) de Characidium lauroi nas microbacias do ribeirão dos Buenos e do rio Guaratinguetá (fatores) e nas épocas de seca e cheia (fatores). (FV = fonte de variação; $S Q=$ soma de quadrados; $\mathrm{GL}=$ graus de liberdade; $\mathrm{QM}=$ quadrado médio; $\mathrm{F}=$ teste $\mathrm{F}$ ).

\begin{tabular}{rrrrrr}
\hline FV & SQ & gl & QM & F & P \\
\hline CP & 56,831 & 1 & 56,831 & 714,949 & $<0,0001$ \\
Bacia & 0,367 & 1 & 0,367 & 4,616 & 0,033 \\
Época & 0,043 & 1 & 0,043 & 0,536 & 0,465 \\
Bacia*CP & 0,582 & 1 & 0,582 & 7,323 & $\mathbf{0 , 0 0 7}$ \\
Época*CP & 0,061 & 1 & 0,061 & 0,765 & 0,383 \\
Bacia*Época & 0,000 & 1 & 0,000 & 0,004 & 0,950 \\
Bacia*Época*CP & 0,008 & 1 & 0,008 & 0,096 & 0,757 \\
Resíduo & 16,454 & 207 & 0,079 & & \\
\hline
\end{tabular}

Tabela 23: Resultados da análise de covariância para o logaritmo natural do peso (PT) (variável dependente) e do comprimento padrão (CP) (covariável) de Characidium lauroi na microbacia do ribeirão dos Buenos nas épocas de seca e cheia (fatores). (FV = fonte de variação; $\mathrm{SQ}=$ soma de quadrados; $\mathrm{GL}=$ graus de liberdade; $\mathrm{QM}=$ quadrado médio; $\mathrm{F}=$ teste $\mathrm{F}$ ).

\begin{tabular}{rrrrrr}
\hline FV & SQ & gl & QM & $\mathbf{F}$ & $\mathbf{P}$ \\
\hline CP & 31,757 & 1 & 31,757 & 428,179 & $<0,0001$ \\
Época & 0,029 & 1 & 0,029 & 0,397 & 0,529 \\
Época*CP & 0,077 & 1 & 0,077 & 1,040 & 0,309 \\
Resíduo & 11,199 & 151 & 0,074 & & \\
\hline
\end{tabular}

Tabela 24: Resultados da análise de covariância para o logaritmo natural do peso (PT) (variável dependente) e do comprimento padrão (CP) (covariável) de Characidium lauroi na microbacia do rio Guaratinguetá nas épocas de seca e cheia (fatores). (FV = fonte de variação; $\mathrm{SQ}=$ soma de quadrados; GL = graus de liberdade; $\mathrm{QM}=$ quadrado médio; $\mathrm{F}=$ teste $\mathrm{F}$ ).

\begin{tabular}{rrrrrr}
\hline FV & SQ & gl & QM & F & P \\
CP & 26,980 & 1 & 26,980 & 287,507 & $<0,0001$ \\
Época & 0,018 & 1 & 0,018 & 0,192 & 0,663 \\
Época*CP & 0,010 & 1 & 0,010 & 0,106 & 0,746 \\
Resíduo & 5,255 & 56 & 0,094 & & \\
\hline
\end{tabular}




\section{Discussão}

\section{Estrutura das populações}

O tamanho de um organismo é um atributo muito importante, porque dele depende a natureza das interações com outros organismos e com o ambiente (GOMIERO \& BRAGA, 2005). A maioria dos peixes de riachos apresenta tamanhos reduzidos, o que permite a ocupação de micro-hábitats específicos encontrados nesses ambientes (CASTRO, 1999), o que corrobora com a estrutura em comprimento das espécies analisadas nas microbacias do ribeirão dos Buenos e do rio Guaratinguetá, que apresentaram comprimento padrão inferior a $15 \mathrm{~cm}$.

A variação no tamanho corpóreo é um dimorfismo sexual de ocorrência generalizada entre os peixes, havendo um predomínio de fềmeas nas maiores classes de tamanho (NIKOLSKII, 1963). As fềmeas foram maiores do que os machos em Characidium lauroi, C. alipioi, Astyanax bimaculatus e Phalloceros caudimaculatus. Machos maiores do que fềmeas foram constatados apenas em Neoplecostomus microps. Para as demais espécies analisadas, não foram encontradas diferenças significativas nos comprimentos médios de machos e fềmeas. Resultados semelhantes foram obtidos por Mazzoni et al. (2002), Braga et al. (2007) e Becker et al. (2008) em Characidium spp., Braga et al. (2008) em N. microps e Braga et al. (2009) em Pareiohina rudolphi. O maior tamanho alcançado pelas fềmeas foi relacionado por Nikolskii (1963) e Lowe-McConnell (1999) à seleção para o aumento da fecundidade. Assumindo-se que a fecundidade é diretamente proporcional ao potencial reprodutivo da população, e conhecendo-se a correlação positiva entre a fecundidade e o tamanho da fêmea, explica-se a tendência das fềmeas apresentarem maiores tamanhos que os machos (SHINE, 1990). Por outro lado, o macho tende a ser maior em espécies que defendem a prole no ninho contra outros peixes e predadores (NIKOLSKII, 1963), sendo o tamanho do macho diretamente afetado pela seleção natural, com machos maiores apresentando vantagens reprodutivas (SHINE, 1990).

Para as espécies que ocorreram nas duas microbacias, Characidium lauroi e Astyanax bimaculatus capturados na microbacia do ribeirão dos Buenos apresentaram tamanhos inferiores daqueles da microbacia do rio Guaratinguetá, os exemplares de 
Trichomycterus itatiayae da microbacia do ribeirão dos Buenos foram maiores do que os da microbacia do rio Guaratinguetá e, no caso de Neoplecostumus microps e Trichomycterus iheringi, os exemplares das duas microbacias apresentaram comprimentos semelhantes. De acordo com Nikolskii (1969), dentro dos limites de cada espécie, a estrutura em comprimento é uma característica flexível, podendo refletir um ajuste às alterações do meio de modo a garantir a sobrevivência.

A análise da estrutura populacional em relação ao sexo fornece subsídios importantes para o conhecimento da relação entre os indivíduos e o meio ambiente (NIKOLSKII, 1969), sendo que a proporção entre os sexos pode variar consideravelmente de espécie para espécie, podendo também variar na mesma população de um ano para o outro (NIKOLSKII, 1963). Na microbacia do ribeirão dos Buenos, Trichomycterus itatiayae e T. iheringi apresentaram maior proporção de machos, assim como o encontrado por Trajano (1997), Manriquez et al. (1988) e Rondineli et al. (2009) para outras espécies de Trichomycterus. Na mesma microbacia, fêmeas ocorreram em maior proporção em Neoplecostomus microps, como o encontrado na microbacia contígua à do ribeirão dos Buenos por Braga et al. (2008). Em Phalloceros caudimaculatus uma maior proporção de fêmeas também foi encontrada, sendo que Hein (1916) apud Aranha et al. (1999) apontou como geral o predomínio de fêmeas em coleções de Poecilidae. De acordo com Nikolskii (1969), o suprimento alimentar da população pode ser considerado como fator importante na proporção sexual, sendo que as fêmeas predominam quando o alimento disponível é abundante.

Ao longo do ciclo de vida, diversos fatores podem atuar na determinação da proporção sexual de peixes. A mortalidade, o crescimento e o comportamento são exemplos de fatores que, atuando de forma diferenciada sobre os sexos, podem alterar a proporção sexual em diversas fases de desenvolvimento (VAZZOLER, 1996). Em grande parte dos estudos de peixes observa-se uma proporção sexual de 1:1 para a população como um todo e em análises mais detalhadas podem ser constatadas alterações na proporção, indicando, por exemplo, o predomínio de machos ou fềmeas em diferentes classes de comprimento ou em épocas distintas do estudo (VAZZOLER, 1996). Braga (2006) chama a atenção da importância em se conhecer a real segregação das populações estudadas, pois algumas 
podem distribuir-se melhor no ambiente em que vivem, o que pode interferir na proporção encontrada.

\section{Dieta}

Os peixes de água doce apresentam uma série de especializações alimentares, sendo que a maioria possui uma considerável plasticidade alimentar (GERKING, 1994), que acaba favorecendo a utilização de recursos sazonalmente abundantes, principalmente em ambientes com grande instabilidade ambiental. Esta sazonalidade é induzida principalmente por mudanças no nível d'água que afetam o hábitat e conseqüentemente a disponibilidade de alimento (WINEMILLER \& JEPSEN, 1998; ARANHA et al., 2000). A partilha de recursos nestes ambientes é um importante fator ecológico para redução da competição entre as espécies, permitindo sua coexistência (ARANHA et al., 1998), assim como a estratégia alimentar utilizada pelas populações que por si só já é um fator que diferencia as espécies ecologicamente (COSTELLO, 1990; AMUNDSEN et al., 1996). Em riachos de cabeceira, a vegetação ripária desempenha importante papel sobre a ecologia alimentar de peixes, pois como a incidência de luz é menor, há uma redução na produtividade primária (VANNOTE et al., 1980; HENRY et al., 1994; REZENDE \& MAZZONI, 2003). O conhecimento da dieta, estratégia alimentar e relações tróficas entre as espécies de peixe são fundamentais para a compreensão da estrutura e dinâmica dessas comunidades.

Casatti \& Castro (1998) observaram que as atividades de forrageio de Characidium spp. foram predominantemente diurnas, bentônicas e larvofágicas, utilizando a tática alimentar de espreita. A insetivoria parece predominar em Characidium spp. (SILVA, 1993; ARANHA et al., 1998; CASTRO \& CASATTI, 1998; SABINO \& CASTRO, 1990; UIEDA et al., 1997; ARANHA et al., 2000; ESTEVES \& LOBÓN-CERVIÁ, 2001; MOTTA \& UIEDA, 2004; BRAGA, 2005a; BARRETO \& ARANHA, 2006; LUZAGOSTINHO et al. 2006; ROMÁN-VALENCIA et al.,2007; ROLLA et al., 2009). Characidium lauroi e C. alipioi, nos riachos da microbacia do Ribeirão Grande, alimentaram-se principalmente de formas imaturas de insetos (larvas de Diptera e Trichoptera e ninfas de Ephemeroptera) (BRAGA, 2005a), indo de encontro com o encontrado no presente estudo. Os Crenuchidae vivem próximos ao fundo em locais de 
fluxo rápido, apresentando, para tanto, características morfológicas adequadas para viverem nesses ambientes, tais como ausência de bexiga natatória e nadadeiras peitorais alargadas (BRAGA, 2004). A existência de uma relação entre o alimento consumido e o microhábitat no qual a espécie vive foi observado no estudo de Silva (1993), refletindo que a dieta dos peixes representa uma interação entre a preferência pelo alimento, a disponibilidade e acessibilidade a esse alimento (ANGERMEIER \& KARR, 1984).

A dieta dos lambaris pode ser considerada onívora, com grande importância de insetos alóctones. Para Astyanax intermedius, Souza (2009) registrou 41 itens na dieta da espécie, classificada como onívora, com tendência a insetivoria, sendo os principais itens fragmentos de insetos, Formicidae, ninfas de Ephemeroptera e larvas de Diptera. A autora também verificou mudanças ontogenéticas na dieta, com peixes menores consumindo principalmente itens autóctones e os peixes maiores itens alóctones. Uma dieta onívora para A. bimaculatus foi relatada em diversos trabalhos (NOMURA, 1975; ARCIFA et al., 1991; COSTA \& BRAGA, 1993; ESTEVES \& GALETTI-JR, 1995; MESCHIATTI, 1995; ESTEVES, 1996; HARTZ et al., 1996; LUIZ et al., 1998; LOBÓN-CERVIÁ \& BENNEMANN, 2000; ANDRIAN et al., 2001; LUZ et al., 2001; VILLELA et al. 2002; ANDRADE, 2004; BENNEMANN et al., 2005; GURGEL et al., 2005), assim como em $A$. fasciatus (NOMURA, 1975; ARCIFA et al., 1991; ESTEVES \& GALETTI-JR, 1995; ESTEVES, 1996; VILLELA et al., 2002; CASTRO et al., 2004; BENNEMANN et al., 2005; GURGEL et al., 2005; GOMIERO \& BRAGA, 2008). Em geral, a sobreposição alimentar dessas espécies é elevada, no entanto, as espécies coexistem, utilizando de forma semelhante os recursos alimentares existentes, quer seja pela relativa abundância desses recursos ou pela certa segregação espacial apresentada (ARCIFA et al., 1991; VILELLA et al., 2002; GURGEL et al., 2005). A flexibilidade na dieta e na seleção alimentar exibida pelos onívoros pode apresentar conseqüências complexas e intrigantes para a dinâmica populacional de consumidores e suas presas, visto a habilidade dos onívoros de trocar de um tipo de alimento para outro, quando o primeiro está em baixa densidade (DIEHL, 1993 apud ATTAYDE et al., 2006).

A dieta de Oligosarcus hepsetus foi investigada por Araújo et al. (2005) no reservatório de Lajes (RJ) e Botelho et al. (2007) no Núcleo Santa Virgínia (SP). Em ambos os trabalhos constatou-se diferenciação ontogenética, sendo os indivíduos menores 
principalmente insetívoros e os maiores restritamente piscívoros. Os dados aqui apresentados sobre a dieta de $O$. hepsetus parecem estar de acordo com esses autores, visto que os itens alimentares consumidos pela espécie foram Arachnida e Teleostei e, dentre os exemplares capturados, encontravam-se jovens e adultos. Mudanças na captura de presas entre classes de tamanho sugerem diminuição da competição intra-específica, sendo a plasticidade alimentar uma estratégia usada por essa espécie, que acaba consumindo os recursos alimentares disponíveis no ambiente (BRAGA \& BRAGA, 1987).

Trichomycterus são espécies predominantemente noturnas, bentônicas e larvofágicas, que praticam a especulação do substrato (CASATTI \& CASTRO, 1998; CASATTI, 2002). Apenas dois itens alimentares foram registrados nos conteúdos estomacais de T. iheringi, ocorrendo uma maior variedade de itens em T. itatiayae. Braga \& Gomiero (2009) verificaram um espectro alimentar bem mais amplo para T. iheringi (Ostracoda, Decapoda, Oligochaeta, ninfas de Plecoptera, insetos terrestres e vegetal superior, além de larvas de inseto) e um bem semelhante para $T$. itatiayae na microbacia do Ribeirão Grande. A preferência por larvas de Diptera tem sido verificada para outras espécies de Trichomycterus em um riacho de águas claras na Mata Atlântica (ESTEVES \& LOBÓN-CERVIÁ, 2001), no Parque Estadual do Morro do Diabo (CASATTI, 2002, 2003), em riachos no Chile (HABIT et al., 2005) e na Colômbia (CHARÁ et al., 2006) e no rio Passa Cinco/SP (RONDINELI et al., 2009).

Os Loricariidae se alimentam de detrito, algas, perifiton e invertebrados sugados ou raspados no substrato, sendo a morfologia do corpo e da boca, responsáveis pela diferenciação na alimentação (DELARIVA \& AGOSTINHO, 2001). Casatti (2002) incluiu os cascudos do Córrego São Carlos na guilda dos pastadores perifitívoros, com dieta composta principalmente por diatomáceas, clorofíceas e matéria orgânica. No caso específico dessa guilda, um padrão de exploração espacial diferencial parece diluir o impacto da predação sobre a comunidade de algas, apesar deste ser um recurso relativamente abundante em riachos (Uieda et al., 1997). A espécie Hypostomus ancistroides, embora tenha sido considerada herbívora em alguns estudos (e.g. CASTRO \& CASATTI, 1997; ESTEVES \& LOBÓN-CERVIÁ, 2001), em trechos do ribeirão Cambé e em riachos da serra do Japi se comportou essencialmente como detritívora (OLIVEIRA \& BENEMMANN, 2005; ROLLA et al., 2009), assim como H. strigaticeps na bacia do rio 
Corumbataí (CARDONE et al., 2006; GOMIERO \& BRAGA, 2008) e o relato de Terra et al. (2008) para Hypostomus luetkeni. Pareiohina rudolphi e P. brachyrhyncha alimentaram-se exclusivamente de perifiton e, de acordo com Braga et al. (2009), os dentes filiformes conspícuos e os lábios em forma de abas presentes nessas espécies, permitem vasculhar o substrato raspando o perifiton. Neoplecostomus microps é um peixe de hábito bentônico e desprovido de bexiga natatória, tendo facilidade de nadar próximo ao fundo e vasculhar o substrato com o lábio e papilas em busca de presas e sugá-las (BRAGA, 2004). A dieta encontrada para Neoplecostomus microps constituiu-se principalmente de detrito e perifiton. Rolla et al. (2009), em riachos da serra do Japi, encontraram algas, formas imaturas de insetos, matéria orgânica e detrito no conteúdo estomacal de $N$. paranensis. Na microbacia do Ribeirão Grande, Braga et al. (2008) verificaram para N. microps uma dieta baseada, principalmente, em larvas e ninfas aquáticas, prevalecendo as de Diptera. Os autores chamam a atenção pela maneira pela qual essa espécie obtém o alimento principal (larvas de Diptera: Simulium e Chironomus) relacionando sua estrutura bucal e o modo de vida de suas presas.

No único estômago analisado de Taunaya bifasciata, amostrada no pediplano da microbacia do rio Guaratinguetá, insetos terrestres estiveram presentes no conteúdo estomacal. De acordo com as informações contidas em Machado et al. (2008), a espécie em questão, alimenta-se principalmente de insetos autóctones e de tecidos animais, possivelmente vertebrados, sugerindo necrofagia ou ataque a outros peixes vivos. Braga \& Gomiero (2009) encontraram para T. bifasciata uma dieta composta por formas imaturas de insetos (larvas e ninfas), oligoqueta e vegetal superior, sendo todos os itens considerados ocasionais. Com isso, um novo item alimentar pode ser incluído na dieta de T. bifasciata.

Pimelodus maculatus ingeriu grande variedade de itens alimentares, assim como o encontrado por Lobón-Cerviá \& Bennemann (2000). Luz-Agostinho et al. (2006) classificaram a espécie como piscívora-insetívora. Lima-Júnior \& Goiten (2003) encontraram diferenciação ontogenética na dieta dessa espécie: juvenis alimentaram-se principalmente de insetos bentônicos, ao passo que exemplares de maior porte, tiveram uma dieta piscívora. Lolis \& Andrian (1996) atribuem o amplo espectro alimentar dessa espécie às estruturas morfológicas presentes, tais como rastros branquiais, dentes faringeanos, morfologia do estômago e intestino. 
As espécies de Gymnotus alimentaram-se basicamente de formas imaturas de insetos. Meschiatti (1995), Luiz et al. (1998), Meschiatti \& Arcifa (2002) e Rocha et al. (2009) verificaram em G. carapo uma dieta basicamente composta por insetos, como constatado por Esteves \& Lobón-Cerviá (2001) para G. pantherinus e Braga \& Gomiero (2009), que verificaram também a ingestão significativa de material vegetal por essa espécie.

Espécies simpátricas com poucas diferenças anatômicas podem apresentar forte potencial competitivo (WOOTTON, 1990), no entanto, quando os recursos alimentares são suficientes para manter duas ou mais populações, como parece ser o caso dos riachos amostrados, pode haver sobreposição, geralmente parcial, do nicho (PIANKA, 1973). Uma maior diversidade e abundância de recursos alimentares podem induzir ao uso oportuno dos mesmos, resultando num espectro alimentar mais generalista, por outro lado tendências à especialização podem ser explicadas pela escolha de itens energeticamente mais importantes, dentre os diversos oferecidos (CENEVIVA-BASTOS \& CASATTI, 2007). No geral, não ocorreu um único item alimentar dominante nas dietas das espécies estudadas, que foi consumido em grande quantidade pela maioria da população, o que pode reforçar a idéia da existência de um generalismo alimentar (BRASIL-SOUZA et al., 2009). A grande plasticidade na utilização dos recursos alimentares pelas espécies estudadas parece permitir a partilha dos recursos disponíveis. Isso pode ser verificado na análise do conteúdo estomacal pelo método do GPA (BRAGA, 1999), que demonstrou dietas bastante diversificadas com pouca ocorrência de itens preferenciais (Tabela 5).

Segundo Lowe-McConell (1999), os peixes dos riachos tropicais são afetados por mudanças sazonais devido à expansão e retração de seus hábitats que, por sua vez, alteram a disponibilidade dos recursos alimentares (GROSSMAN et al., 1990). No entanto, de acordo com Esteves \& Aranha (1999), dependendo do regime das chuvas e das características locais, pode-se ou não detectar variações sazonais na dieta das espécies. Como não foram encontradas diferenças no consumo de itens alimentares pelas espécies analisadas nas microbacias consideradas entre as estações de seca e cheia, acredita-se que os recursos alimentares permaneceram disponíveis ao longo de todo o ano e em quantidades suficientes para resultar na ausência de variações sazonais nas dietas das espécies. Esteves \& Lobón-Cerviá (2001) encontraram resultados semelhantes em um 
riacho da Mata Atlântica do sudeste do Brasil, assim como Rondineli (2007) para o rio Passa Cinco (SP). Braga (2006) afirma que a fonte alimentar, embora limitada em riachos torrentosos, mantém-se constante o ano todo, pois o sistema mantém-se em equilíbrio com o entorno.

Winemiller (1990) aponta que a importância relativa de itens autóctones e alóctones como fonte de alimento pode variar de modo espacial. Foi evidente o maior consumo de itens autóctones na encosta e no pediplano, ao passo que no vale os itens alóctones prevaleceram. Tais variações podem estar relacionadas com a estrutura das comunidades de peixes nesses ambientes: os pontos localizados na encosta e no pediplano apresentaram uma composição de espécies bastante similares quando comparados aos pontos localizados no vale. Além disso, os hábitos alimentares dessas espécies e uma maior ou menor disponibilidade dos itens alimentares nesses ambientes também podem favorecer tal diferenciação.

Um maior consumo de itens autóctones pelas comunidades de peixes de riacho tem sido reportado em diversos estudos (ARGERMEIER \& KARR, 1984; SABINO \& CASTRO, 1990; ESTEVES \& LOBÓN-CERVIÁ, 2001; CASATTI, 2002; BRAGA, 2005a). No entanto, a participação desses itens na dieta dos peixes deve ser vista com cautela, pois uma variação pode ser encontrada quando se verifica o consumo de itens autóctones e alóctones em termos da abundância relativa de cada espécie (CENEVIVABASTOS \& CASATTI, 2007). Esteves \& Lobón-Cerviá (2001) encontraram maior consumo de itens autóctones na dieta de peixes quando consideraram o número de espécies, visto que, dentre as 14 espécies amostradas apenas 5 consumiram itens alóctones; porém, considerando que as espécies que se alimentam de itens alóctones (incluindo os detritívoros) representaram $87,2 \%$ da abundância total, a importância dos recursos alóctones aumentou, já que a maioria da biomassa de peixes deriva desta fonte. Das 11 espécies mais abundantes em riachos da microbacia do Ribeirão Grande, Braga \& Gomiero (2009) encontraram uma predominância de itens autóctones na dieta dos peixes, sendo que, quando ocorriam itens alóctones, esses eram basicamente ocasionais, como insetos terrestres, frutos e vegetal superior.

Existe um consenso no sentido de que a produção de recursos autóctones depende da entrada de recursos de origem alóctone, que servem de base para a cadeia alimentar de 
diversos invertebrados aquáticos (ESTEVES \& ARANHA, 1999; RUSSO et al., 2002), assim, as populações de peixes dependem direta ou indiretamente dos recursos alimentares que derivam da mata ribeirinha. A fauna bentônica apresenta um papel funcional importante nos ecossistemas aquáticos por participar do processo de transformação da matéria orgânica particulada e servir de alimento para níveis tróficos adjacentes e superiores (CALLISTO \& ESTEVES, 1995). Segundo Cummins \& Lauff (1969) apud Amorim et al. (2007), a distribuição espacial dos insetos aquáticos parece obedecer a quatro categorias de maior influência ambiental: a velocidade da corrente, parâmetros físico-químicos, tamanho da partícula de substrato e a disponibilidade de alimento, estando as duas primeiras influenciando a macrodistribuição desses organismos e as duas últimas, a microdistribuição. Bispo et al. (2006) atribuem as alterações na abundância de insetos aquáticos às chuvas e características estruturais dos corpos d'água.

De acordo com Winnemiller \& Jepsen (1998), os peixes funcionam como condutores de matéria e energia nos ecossistemas aquáticos: como predadores que potencialmente afetam a dinâmica populacional de suas presas, e como presas que potencialmente influenciam o sucesso de forrageamento e adequação dos seus predadores. Portanto, a maneira em que peixes se deslocam sobre as paisagens influenciam fortemente a estrutura e função das teias alimentares aquáticas.

\section{Reprodução}

A maioria das espécies de peixes neotropicais apresenta um período reprodutivo cíclico (VAZZOLER, 1996), sendo as alterações no nível da água, a sequência de estações úmidas e secas (LOWE-McCONNELL, 1999) e as alterações qualitativas e quantitativas na disponibilidade de alimentos (BYE, 1984) os principais eventos reguladores. Cada espécie apresenta, dentro do período reprodutivo, exigências particulares relativas à qualidade de água, disponibilidade de alimento adequado e refúgios que garantam a sobrevivência dos indivíduos nas fases iniciais do desenvolvimento (VAZZOLER, 1996). Uma periodicidade no processo reprodutivo da maioria dos peixes pode ser constatada, com o início do desenvolvimento gonadal ocorrendo em uma época anterior àquela de reprodução, e completando a maturação gonadal no momento em que as condições ambientais são 
adequadas à fecundação e ao desenvolvimento da prole (NIKOLSKII, 1969; VAZZOLER, 1996). A mata ciliar regula a incidência solar no ecossistema aquático, sendo que sua ausência pode ter efeitos negativos para o sucesso da reprodução, relacionados à falta de sincronia entre o aumento da temperatura da água e o regime de chuvas, efeitos no reconhecimento de parceiros, aumento da taxa de mortalidade de ovos e larvas, fuga de predadores, alterações na estrutura do hábitat e dinâmica trófica, além de efeitos diretos nas taxas metabólicas e de resistência a doenças (PUSEY \& ARTHINGTON, 2003).

Nos peixes de água doce, a capacidade de acumular gordura permite que a época de desova seja independente da época de maior oferta alimentar (KRAMER, 1978). Uma alimentação intensa durante períodos não reprodutivos pode representar uma estratégia de alocação de energia para a reprodução, quando essas reservas serão utilizadas na vitelogênese (NIKOLSKII, 1969). Os recursos alimentares presentes em riachos, embora limitados, mantêm-se constantes durante o ano todo, fazendo com que as espécies residentes mantenham a atividade alimentar contínua ao longo do ano, inclusive no período reprodutivo, o que leva a um bom aporte de nutrientes para a maturação das gônadas, principalmente no período reprodutivo (BRAGA, 2006). O acúmulo sazonal de reservas além de ser um pré-requisito para a maturidade gonadal pode influenciar também a fecundidade (GUILLEMOT et al., 1985). Bunnel et al. (2007) conduziram um experimento para quantificar os efeitos da alimentação (em um período anterior à desova) no investimento gonadal de fêmeas e machos de um Perciformes (Pomoxis annularis). Os autores verificaram que as fêmeas aumentaram o investimento gonadal com o aumento da disponibilidade dos recursos alimentares, sendo que as fềmeas mais "bem alimentadas" produziram ovócitos maiores do que aquelas com alimentação limitada. Doria \& Andrian (1997) verificaram variações significativas no conteúdo energético de componentes reprodutivos relacionadas ao processo de vitelogênese, que ocorreram em virtude da diminuição da atividade alimentar nos indivíduos adultos e sem a diminuição das reservas somáticas e da taxa de crescimento, sugerindo que, nesta fase do processo reprodutivo, a gordura visceral atue como fonte de reserva acessória, garantindo o desenvolvimento gonadal e a manutenção dos outros componentes. De acordo com Goulding (1980), o tamanho do animal é importante porque ele determina a quantidade de gordura que pode ser armazenada, assim, peixes pequenos, com pouco potencial de armazenamento de gordura, 
seriam forçados a se especializar em períodos de baixa abundância de alimentos a fim de garantir sua sobrevivência (ESTEVES \& GALETTI-JR, 1995).

Assim, um equilíbrio na alocação da energia assimilada para o metabolismo ou crescimento somático e reprodutivo é esperado de modo a garantir a sobrevivência e sucesso reprodutivo do peixe (WOOTTON, 1990). A energia para o desenvolvimento gonadal em Trichomycterus, provavelmente, seja derivada da ingestão alimentar atual e não a partir de material previamente armazenado na forma de gordura, como o proposto por Guillemot et al. (1985), visto que ambas as espécies não acumularam gordura em um período anterior ao amadurecimento das gônadas. Para as demais espécies, a quantidade máxima de gordura acumulada na cavidade visceral coincidiu com as maiores freqüências de gônadas em processo de maturação. Embora para algumas espécies a variação de gordura não tenha sido significativa entre as épocas de seca e cheia, o acúmulo de gordura por si só demonstra que recursos previamente armazenados na forma de gordura foram posteriormente investidos em reprodução (BRAGA, 2005b; BRAGA et al., 2008; BALLESTEROS et al., 2009).

Durante a maturação gonadal, a relação gonadossomática (RGS) vem a ser alta, já que acontece o consumo de reservas para a maturação ovariana, síntese vitelogênica e transferência aos ovócitos. Ribeiro et al. (2007) atribuem variações na RGS não somente à maturação gonadal, mas também à fisiologia e capacidade adaptativa de cada espécies. De acordo com June (1953), o pico de uma atividade reprodutiva pode ser indicado pela relação gonadossomática, enquanto que a análise dos estádios gonadais indica o período reprodutivo. Marcucci et al. (2005) encontraram grande amplitude do desvio padrão das médias da RGS em cada amostragem, indicando que indivíduos em diferentes fases de maturação ocorrem em um mesmo período e que alguns deles podem se reproduzir fora do período reprodutivo da maior parte da população. A assincronia da reprodução entre os exemplares adultos de uma mesma espécie parece ser uma estratégia comum voltada para maximizar o sucesso reprodutivo em determinados ambientes, sendo uma das explicações a maior probabilidade de sucesso da reprodução frente a eventos aleatórios, como as chuvas torrenciais que determinam, por deriva, a perda de ovos e larvas recém-eclodidas (MAZZONI \& SILVA, 2006). 
Grande parte dos peixes neotropicais se reproduz na estação chuvosa (KRAMER, 1978; LOWE-McCONNELL, 1999), entre a primavera e o verão (VAZZOLER \& MENEZES, 1992). Uma prolongada época reprodutiva tem sido tratada como uma resposta adaptativa às restrições ambientais que prevalecem nos riachos (GARUTTI, 1988), que são ambientes sujeitos à flutuações sazonais, principalmente na época chuvosa. Apenas Characidium alipioi apresentou período reprodutivo concentrado na estação chuvosa, as demais espécies analisadas apresentaram períodos reprodutivos que se estenderam desde o final da estação seca até o final da estação chuvosa. Fêmeas com gônadas esgotadas ocorrerem em C. alipioi e C. lauroi na última amostra, pertencente à estação chuvosa, o que é um bom indicativo de desova no ambiente (GOMIERO \& BARAGA, 2007). No caso das duas espécies de Pareiohina, indivíduos maduros estiveram presentes em todas as amostras, sugerindo uma reprodução contínua. O pico reprodutivo das espécies, baseado nos maiores valores da RGS, se deu durante a estação chuvosa, com exceção de $T$. itatiayae, cujo pico aconteceu durante a estação de seca.

Longos períodos reprodutivos também têm sido encontrados para outras espécies congêneres àquelas aqui apresentadas. Para Trichomycterus spp., Rondineli et al. (2009), no rio Passa Cinco, verificaram indivíduos maduros desde o final da estação seca e em toda a estação chuvosa e Casatti (2003), em um riacho no Morro do Diabo, encontrou indivíduos maduros ao longo de todo o ano. Em riachos da Argentina, Marraro et al. (2005) delimitaram a estação reprodutiva de $T$. corduvense de outubro a fevereiro (outono e verão) e Habit et al. (2005), em riachos do Chile, verificaram que T. areolatus se reproduz na primavera e verão. Para espécies de Characidium, Braga (2006), na microbacia do Ribeirão Grande, e Becker et al. (2008), no rio Maquiné, encontram indivíduos maduros em outubro e fevereiro, já Mazzoni et al. (2002) e Rondineli \& Braga (no prelo) encontraram indivíduos maduros ao longo de todo o ano. Um período reprodutivo prolongado para Astyanax bimaculatus também foi documentado nos trabalhos de Barbieri et al. (1982), Godinho \& Castro (1985), Agostinho et al. (1984), Rodrigues et al. (1989), Barbieri \& Marins (1995) e Braga (2001), assim como para A. fasciatus (BARBIERI et al., 1982; GOMIERO \& BRAGA, 2007), A. janeiroensis (MAZZONI et al., 2005) e A. intermedius (SOUZA, 2009). Para Neoplecostomus microps, Braga et al. (2008) encontraram um período reprodutivo de outubro a fevereiro, onde ocorreram os maiores valores da RGS. 
Para Pareiohina rudolphi, Braga et al. (2009) também encontraram indivíduos maduros ao longo de todo o ano. No trecho inferior do rio Paraíba do Sul, Menezes et al. (1998) verificaram em Harttia loricariformes um período reprodutivo longo, indo de setembro a fevereiro.

Como o ciclo reprodutivo em peixes é um processo dinâmico, as espécies, por meio das táticas reprodutivas, que envolvem adaptações morfológicas, fisiológicas e comportamentais (VAZZOLER, 1996), procuram se adequar ao meio em que vivem. Estudos desenvolvidos com espécies da microbacia do Ribeirão Grande, um sistema muito semelhante ao encontrado nas microbacias do ribeirão dos Buenos e do rio Guaratinguetá, tem demonstrado essas adaptações. Characidium lauroi, que habita trechos mais altos, estreitos e torrentosos apresenta uma desova parcelada, com ovócitos grandes e em número reduzido, que ao eclodirem nas sucessivas desovas, melhor utilizam os recursos oferecidos pelo ambiente; por outro lado, C. alipioi que habita trechos mais largos, apresenta uma desova total, com ovócitos menores e em maior número, que, ao eclodirem, encontrarão mais espaço e maior área para a alimentação (BRAGA et al., 2007). Neoplecostomus microps apresentou fecundidade absoluta entre 44 e 54 ovócitos, com diâmetro médio de $1836 \mu \mathrm{m}$ (BRAGA et al., 2008). Pareiohina rudolphi também apresentou fecundidade baixa, com o número médio total de ovócitos igual a 58, sendo eliminados, em média, 7 ovócitos por lote (BRAGA et al., 2009). Além do período reprodutivo extenso, essas características biológicas (que ainda necessitam serem confirmadas para as espécies do presente estudo) parecem direcionar as espécies encontradas nesses ambientes para uma maior eficiência em explorar o meio em que vivem, proporcionando a manutenção das populações.

\section{Condição corporal}

O parâmetro $b$ da relação peso e comprimento geralmente é constante, assumindo valores próximos a 3,0 (KING, 1995), o que reflete um incremento do tipo isométrico (RICKER, 1975). Dulcic \& Kraljevis (1996) apud Benedito-Cecílio \& Agostinho (1997) apontam que vários são os fatores que podem ser responsáveis pelas diferenças nos parâmetros da relação peso e comprimento entre estações do ano, tais como temperatura, 
alimento disponível, sexo e estádio de maturidade. Ricker (1979) admite que quando $b$ é maior do que 3,0 o peixe está aumentando em peso numa taxa maior do que a necessária para manter constante as proporções corpóreas.

Em um estudo conduzido por Cinco (1982) sobre a relação peso e comprimento de peixes marinhos, o coeficiente angular situou-se entre 2,29 e 3,43, com média em 3,0 e distribuição normal nos valores. Nomura (1962) encontrou para 22 espécies de peixes marinhos do sul do Brasil valores do coeficiente angular que variaram de 2,39 a 3,30, também com valor médio de 3,0. Como o valor do coeficiente angular igual a 3,0 é considerado isométrico na relação peso e comprimento (RICKER, 1975), significa que nesse momento o peixe está crescendo de maneira semelhante em peso e em comprimento (KING, 1995). Mas essa situação não é constante durante toda a vida do peixe, pois como a constante $b$ da relação peso e comprimento $\left(P=a C^{b}\right)$ relaciona-se com a constante $a$ (fator de condição), e a condição do peixe não é constante durante o seu ciclo de vida, a constante $b$ pode variar e, de fato, varia de maneira inversa à da constante $a$ (BRAGA, 1997). Em 4 espécies estudadas nas microbacias do ribeirão dos Buenos e do rio Guaratinguetá, considerando-se machos e fềmeas, o valor do coeficiente angular variou de 2,15 a 3,14, com média em 2,80 (Tabela 10). Isso indica que para essas espécies nessas microbacias, o crescimento em comprimento em relação ao peso é alométrico negativo, sugerindo que as espécies crescem mais e pesam menos. Dessas 4 espécies analisadas, excluindo-se $A$. bimaculatus que é uma espécie mais amplamente distribuída e cujo valor do coeficiente angular foi ao redor de 3,0, as outras espécies (T. itatiayae, $N$. microps e C. lauroi) estão bem adaptadas ao ambiente encontrado em riachos torrentosos (BRAGA, 2004; BRAGA, 2005a, b; BRAGA \& ANDRADE, 2005; BRAGA, 2006; BRAGA et al., 2007; BRAGA et al., 2008; BRAGA \& GOMIERO, 2009), desenvolvendo várias estratégias adaptativas para adequarem-se ao ambiente. O menor peso em relação ao comprimento e a menor deposição de gordura visceral ou mesmo a ausência, pode estar associado a uma menor densidade corpórea para manterem-se nesses corpos de água torrentosos.

Como o peso e o comprimento são duas variáveis fortemente correlacionadas, é necessário remover o efeito do comprimento para se verificar outras influências sobre o peso (CETRA, 2005). Nesse contexto, a análise de covariância permite verificar se um peixe apresenta melhor condição corporal que outro, para um dado comprimento médio, 
caso apresente maior peso. Alterações na condição corporal estão associadas às mudanças fisiológicas que ocorrem em função do ciclo reprodutivo das espécies, sendo que a atividade alimentar, o desenvolvimento de gordura e a reprodução dos peixes são dependentes do ciclo hidrológico (BENNEMANN et al., 1996).

As relações peso e comprimento não diferiram entre sexos em Trichomycterus itatiayae e Characidium lauroi, ao passo que para Neoplecostomus microps e Astyanax bimaculatus essas relações foram distintas. A maior inclinação das retas da relação peso e comprimento para fêmeas foi relacionada por Agostinho et al. (1990) ao maior peso das gônadas em relação aos testículos. Na época chuvosa, onde ocorreram os valores mais altos da RGS e, portanto, ocorreram os picos reprodutivos de $N$. microps e A. bimaculatus, as relações peso e comprimento das fêmeas foram mais inclinadas do que os machos, o que ressalta a maior colaboração em peso dos ovários quando comparados aos testículos dado um mesmo comprimento.

A condição corporal diferente entre épocas encontrada para $T$. itatiayae e $A$. bimaculatus parece estar relacionada com o período reprodutivo dessas espécies. O pico reprodutivo de $T$. itatiayae se deu na época de seca e, em $A$. bimaculatus na época chuvosa, assim o maior volume das gônadas (e conseqüentemente seu peso) encontrado nas épocas de pico reprodutivo, contribui e muito para um aumento do peso em uma dado comprimento médio. Diferenças na condição corporal entre microbacias encontradas em $A$. bimaculatus e $C$. lauroi podem estar relacionadas às exigências particulares das espécies durante o período reprodutivo e que um ou outro ambiente pode dispor de melhor forma, fazendo com que em um dado comprimento, a espécie apresente maior peso. 


\section{Referências}

AGOSTINHO, A. A.; BARBIERI, G.; VERANI, J. R. \& HAHN, N. S. Variação do fator de condição e do índice hepatossomático e suas relações com o ciclo reprodutivo em Rhinelepis áspera (Agassiz, 1829) (Osteichthyes, Loricariidae) no rio Paranapanema, Porecatu, PR. Ciência e Cultura, v. 42, n. 9, p. 711-714, 1990.

AgOstinho, C. A.; MOLinARI, S. L.; AgOstinho, A. A. \& VERANI, J. R. Ciclo reprodutivo e primeira maturação sexual de fêmeas do lambari Astyanax bimaculatus (L.) (Osteichthyes - Characidae) do rio Ivaí, estado do Paraná. Revista Brasileira de Biologia, v. 44, n. 1, p. 31-36, 1984.

AMORIM, R. M.; HENRIQUES-LIVEIRA, A. L. \& NESSIMIAN, J. L. Distribuição espacial e temporal das larvas de Chironomidae (Insecta: Diptera) na seção ritral do rio Cascatinha, Nova Friburgo, Rio de Janeiro, Brasil. Lundiana, v. 5, n. 2, p. 119-127, 2004.

AMUNDSEN, P.A., GABLER, H.M. \& STALDVIK, F.J. A new approach to graphical analysis of feeding strategy from stomach contents data: modification of the Costello (1990) method. J. Fish Biol., v. 48, p. 607-614, 1996.

ANDRADE, P. M. Distribuição, dieta e ecomorfologia das espécies de peixes no sistema do ribeirão Grande, no município de Pindamonhangaba, SP. 2004. Tese (Doutorado em Zoologia) - Universidade Estadual Paulista, Rio Claro, 2004.

ANDRIAN, I. F.; SILVA, H. B. R. \& PERETTI, D. Dieta de Astyanax bimaculatus Linnaeus, 1758 (Characiformes, Characidae), da área de influência do reservatório de Corumbá, Estado de Goiás, Brasil. Acta Scientiarum, v. 23, n. 2, p. 435-440, 2001.

ANGERMEIER, P. L. \& KARR, J. R. Relationships between woody debris and fish habitat in a small warmwater stream. Trans. Am. Fish. Soc., v. 113, p. 716-726, 1984.

ARANHA, J. M. R. \& CARAMASCHI, E. P. Estrutura populacional, aspectos da reprodução e alimentação dos Cyprinodontiformes (Oeteichthyes) de um riacho do sudeste do Brasil. Rev. Bras. Zool., n. 16, n. 1, p. 637-651, 1999. 
ARANHA, J. M.; GOMES, J. H. \& FOGAÇA, F. N. O. Feeding of two sympatric species of Characidium, C. lanei and C. pterostictum (Characidiinae) in a coastal stream of Atlantic Forest (Southern Brazil). Brazilian Archives of Biology and Technology, v.43, n.5, p.527-531, 2000 .

ARANHA, J. M.; TAKEUTI, D. F. \& YOSHIMURA, T. M. Habitat use and food partitioning of the fishes in a coastal stream of Atlantic Forest, Brazil. Rev. Biol. Trop., v.46 n.4, p.951-959, 1998.

ARAÚJO, F. G.; ANDRADE, C. C.; SANTOS, R. N.; SANTOS, A. F. G. N. \& SANTOS, L. N. Spatial and seasonal changes in the diet of Oligosarcus hepsetus (Characiformes, Characidae) in a brazilian reservoir. Braz. J. Biol., v. 65, n. 1, p. 1-8, 2005.

ARCIFA, M. S.; NORTHCOTE, T. G.; FROEHLICH, O. Interactive ecology of two cohabiting characin fishes (Astyanax fasciatus and Astyanax bimaculatus) in an eutrophic Brazilian reservoir. Journal of Tropical Ecology, v. 7, p. 257-268, 1991.

ARCIFA, M. S.; NORTHCOTE, T. G. \& FROEHLICH, O. Interactive ecology of two cohabiting characin fishes (Astyanax fasciatus and Astyanax bimaculatus) in a eutrophic Brazilian Resevoir. J. Trop. Ecol., v.7, n.2, p.257-268, 1991.

ATTAYDE, J. L.; ISKIN, M. \& CARNEIRO, L. O papel da onivoria na dinâmica das cadeia alimentares. Oecol. Bras., v. 10, n. 1, p. 69-77, 2006.

BALlESTEROS, T. M.; TORRES-MEJIA, M. \& RAMÍREZ-PINILLA, M. P. How does diet influence the reproductive seasonality of tropical freshwater fish? A case study of a characin in a tropical mountain river. Neotropical Ichthyology, v. 7, n. 4, p. 693-700, 2009.

BARBIERI, G. \& BARBIERI, M. C. Curva de maturação, tamanho de primeira maturação gonadal e fecundidade de Astyanax bimaculatus e Astyanax fasciatus, na represa do Lobo, Estado de São Paulo (Osteichthyes, Characidae). Revista Ceres, v. 35, n. 197, p. 64-77, 1988. 
BARBIERI, G. \& MARINS, M. A. Estudo da dinâmica da reprodução de fêmeas de Astyanax bimaculatus (Linnaeus, 1758) da represa do Lobo, Estado de São Paulo (Osteichthyes, Characidae). Arq. Biol. Tecnol., v. 38, n. 4, p. 1191 - 1197, 1995.

BARBIERI, G.; SANTOS, M. V. R. \& SANTOS, J. M. Época de reprodução e relação peso/comprimento de duas espécies de Astyanax (Pisces, Characidae). Pesq. agropec. bras., v. 17, n. 7, p. 1057-1065, 1982.

BARRETO, A. P. \& ARANHA, J. M. R. Alimentação de quatro espécies de Characiformes de um riacho da Floresta Atlântica, Guaraqueçaba, Paraná, Brasil. Revista Brasileira de Zoologia, v. 23, n. 3, p. 779-788, 2006.

BECKER, F.G., CARVALHO, S. \& HARTZ, S.M. Life-history of the South American darter, Characidium pterostictum (Crenuchidae): evidence for small scale spatial variation in a piedmont stream. Neotrop. Ichthyol., v. 6, n. 4, p. 591-598, 2008.

BENEDITO-CEÍCILIO, E. \& AGOSTINHO, A.A. Estrutura das populações de peixes do reservatório de Segredo. In: A. A. Agostinho e L. C. Gomes (eds.). Reservatório de Segredo: bases ecológicas para o manejo. Editora da Universidade Estadual de Maringá, 1997.

BENNEMANN, S. T.; GEALH, A. M.; ORSI, M. L. \& SOUZA, L. M. Ocorrência e ecologia trófica de quatro espécies de Astyanax (Characidae) em diferentes rios da bacia do rio Tibagi, Paraná, Brasil. Iheringia, Sér. Zool., v. 95, n. 3, p. 247-254, 2005.

BENNEMANN, S. T.; ORSI, M. L. \& SHIBATA, O. A. Atividade alimentar de espécies de peixe do rio Tibagi, relacionada com o desenvolvimento de gordura e gônadas. Rev. Bras. Zool., v.13, n. 2, p. 501-512, 1996.

BISPO, P. C.; OLIVEIRA, L. G.; BINI, L. M. \& SOUSA, K. G. Ephemeroptera, Plecoptera and Trichoptera assemblages from riffles in mountain streams of Central Brazil: environmental factors influencing the distribution and abundance of immatures. Brazilian Journal of Biology, v. 66, n. 2B, p. 611-622, 2006. 
BOTELHO, M. L. L. A.; GOMIERO, L. M. \& BRAGA, F. M. S. Feeding of Oligosarcus hepsetus (Cuvier, 1829) (Characiformes) in the Serra do Mar State Park - Santa Virgínia Unit, São Paulo, Brazil. Braz. J. Biol., v. 67, n. 4, p. 741-748, 2007.

BRAGA, F. M. S. Aspectos da reprodução e alimentação de peixes comuns em um trecho do rio Tocantins entre Imperatriz e Estreito, Estado do Maranhão e Tocantins, Brasil. Rev. Brasil. Biol., v. 50, n. 3, p. 547-558, 1990.

BRAGA, F. M. S. Análise da equação alométrica na relação peso e comprimento e o fator de condição em Plagioscion squamosissimus (Teleostei - Sciaenidae). Rev. Brasil. Biol., v. 57, n. 3, p. 417-425, 1997.

BRAGA, F. M. S. O grau de preferência alimentar: um método qualitativo e quantitativo para o estudo do conteúdo estomacal de peixes. Acta Scientiarum,v. 21, n. 2, p. 291-295, 1999.

BRAGA, F. M. S. Hábitat, distribuição e aspectos adaptativos de peixes da microbacia do ribeirão Grande, Estado de São Paulo, Brasil. Acta Sci. Biol. Sci., v. 26, n. 1, p. 31-36, 2004.

BRAGA, F. M. S. Feeding and condition factor of characidiin fish in Ribeirão Gtande system, Southeastern Brazil. Acta Scientiarum, v. 27, n. 3, p. 271-276, 2005a.

BRAGA, F. M. S. Spatial distribution of characidiin fishes (Teleostei, Crenuchidae) in the Ribeirão Grande system, a tributary of Paraíba do Sul river basin, Brazil. Acta Scientiarum, v. 27, n. 3, p. 259-263, 2005b.

BRAGA, F. M. S. Aspectos da reprodução no gênero Characidium Reinhardt, 1867 (Crenuchidae, Characidiinae) na microbacia do Ribeirão Grande, serra da Mantiqueira oriental, sudeste do Brasil. Acta Scientiarum, v. 28, n. 4, p. 365-371, 2006.

BRAGA, F. M. S. Reprodução de peixes (Osteichthyes) em afluentes do reservatório de Volta Grande, rio Grande, sudeste do Brasil. Iheringia, Sér. Zool., v. 91, p. 67-74, 2001. 
BRAGA, F. M. S. \& BRAGA, M. A. A. S. Estudo do hábito alimentar de Prionotus punctatus (Block, 1797) (Teleostei, Triglidae), na região da ilha Anchieta, Estado de São Paulo, Brasil. Rev. Brasil. Biol., v. 47, p. 31-36, 1987.

BRAGA, F. M. S.; GOMIERO, L. M. \& SOUZA, U. P. Aspectos da reprodução e alimentação de Neoplecostomus microps (loricariidae, Neoplecostominae) na microbacia do Ribeirão Grande, serra da Mantiqueira oriental (estado de São Paulo). Acta Scientiarum, v. 30, n. 4, p. 455-463, 2008.

BRAGA, F. M. S.; GOMIERO, L. M. \& SOUZA, U. P. Biologia populacional de Pareiohina rudolphi (Loricariidae, Hypostominae) na microbacia do Ribeirão Grande, estado de São Paulo. Acta Scientiarum, v. 31, n, 1, p. 79-88, 2009.

BRAGA, F. M. S. \& GOMIERO, L. M. Alimentação de peixes na microbacia do Ribeirão Grande, Serra da Mantiqueira oriental, SP. Biota Neotropica, v. 9, n. 3, p. 1-6, 2009.

BRAGA, F. M. S., SOUZA, U. P. \& CARMASSI, A. L. Dinâmica populacional de Characidium lauroi e C. alipioi (Teleostei, Crenuchidae) na microbacia do Ribeirão Grande, serra da Mantiqueira Oriental, Estado de São Paulo. Acta Scientiarum, v. 29, n. 3, p. 281-287, 2007.

BRASIL-SOUZA, C.; MARQUES, R. M. \& ALBRECHT, M. P. Segregação alimentar entre duas espécies de Heptapteridae no Rio Macaé, RJ. Biota Neotropica, v. 9, n. 3, p. 1$7,2009$.

BUNNELL, D. B.; THOMAS, S. E. \& STEIN, R. A. Prey resources before spawing influence gonadal investment of female, but not male, white crappie. Journal of Fish Biology, v. 70, p. 1838-1854, 2007.

BYE, V. J. The role of environmental factors in the timing of reproductive cycles. In: WOOTTON, R. J. Fish reproduction strategies and tactics. New York: Chapman \& Hall, p. 188-205, 1984.

CALISTO, M. \& ETEVES, F. A. Biomonitoramento da macrofauna bentônica de Chironomidae (Diptera) em dois iguarapés amazônicos sob influência das atividades de 
uma mineração de bauxita, p. 299-309. In: J. L. Nessimian \& A. L. Carvalho (eds.). Ecologia de insetos aquáticos. Rio de Janeiro, PPGE-UFRJ, Oecologia Brasiliensis, 1998.

CARDONE, I. B.; LIMA-JÚNIOR, S. E. \& GOITEN, R. Diet and capture of Hypostomus strigaticeps (Siluriformes, Loricariidae) in a small brazilian stream: relationship with limnological aspects. Brazilian Journal of Biology, v. 66, n. 1A, p. 25-33, 2006.

CASATTI, L. Alimentação dos peixes em um riacho do Parque Estadual Morro do Diabo, Bacia do Alto Rio Paraná, sudeste do Brasil. Biota Neotrop., v. 2, n. 2, p. 1-14, 2002.

CASATTI, L. Biology of Cattfish, Trichomycterus sp. (Pisces, Siluriformes), in a Pristine Stream in the Morro do Diabo State Park, Southeastern Brazil. Studies on Neotropical Fauna and Environmental, v. 38, n. 2, p. 105-110, 2003.

CASATTI, L. \& CASTRO, R. M. C. A fish community of the São Francisco Rivers headwaters riffles, southeastern Brazil. Ichthyol. Explor. Freshwaters, v. 9, n. 3, p. 229$242,1998$.

CASTRO, R. M. C. Evolução da ictiofauna de riachos sul-americanos: padrões gerais e possíveis processos causais. In: Oecologia Brasiliensis: Ecologia de Peixes de Riachos. (E.P. Caramaschi; R. Mazzoni; P.R. Peres-Neto. eds.). Programa de Pós-Graduação em Ecologia, UFRJ. Rio de Janeiro. p. 139-155, 1999.

CAStRO, R. M. C.; CASATti, L.; SANTOS, H. F.; MElO, A. L. A.; MARTINS, L. S. F.; FERREIRA, K. M.; GIBRAN, F. Z.; BENINE, R. C.; CARVALHO, M. RIBEIRO, A. C.; ABREU, T. X; BOCKMANN, F. A.; PEliÇÃO, G. Z.; STOPliGiA, R. \& LANGEANI, F. Estrutura e composição da ictiofauna de riachos da bacia do Rio Grande no estado de São Paulo, sudeste do Brasil. Biota Neotropica, v. 4, n. 1, p. 1-39, 2004.

CASTRO, R.M.C. \& CASATTI, L. The fish fauna from small forest stream of the upper Paraná River basin, southeastern Brazil. Ichthyol.Explor. Freshwaters., v. 7, n. 4, p. 337 $352,1997$. 
CENEVIVA-BASTOS, M. \& CASATTI, L. Oportunismo alimentar de Knodus moenkhausia (Teleostei, Characidae): uma espécie abundante em riachos do noroeste do Estado de São Paulo, Brasil. Iheringia, v. 97, p. 7-15, 2007.

CETRA, M. Avaliação do bem estar em peixes: ANCOVA uma alternative para estudos da relação pesocomprimento. Boletim da Sociedade Brasileira de Ictiologia, n. 81, p. 3-5, 2005.

CHARÁ, JD., BAIRDS, DJ., TELFER, TC. \& RUBIO, EA. Feeding ecology and habitat preferences of the catfish genus Trichomycterus in low-order streams of the colombian Andes. Journal Fish Biol., v. 68, n. 4, p. 1026-1040, 2006.

CINCO, E. Length-weight relationships of fishes. In: Pauly, D. \& Mines, A. N. (Eds.). Small-scale fisheries of San Miguel bay, Philippines: biology and stock assessment. ICLARM Techinical Reports, 124p., 1982.

COSTA, F. E. S. \& BRAGA, F. M. S. Estudo da alimentação natural de Astyanax bimaculatus, Astyanax schubarti e Moenkhausia intermedia (Characidae, Tetragonopterinae) na represa de Barra Bonita, Rio Piracicaba (SP). Revista UNIMAR, v. 15, n. 2, p. 117-134, 1993.

COSTELLO, M.J. Predator feeding strategy and prey importance: a new graphical analysis. J. Fish Biol., v, 36, p. 261-263, 1990.

DELARIVA, R. L. \& AGOSTINHO, A.A. Relationship between morphology and diets of six neotropical loricariids. Journal of Fish Biology, v. 58, p. 832-847, 2001.

DORIA, C. R. C. \& ANDRIAN, I. F. Variation in energy content of somatic and reproductive, tissues related to the reproductive cycle and feeding of female Pimelodus maculatus Lacépède, 1803 (Siliuriformes, Pimelodidae) and Schizodon borelli Boulenger, 1895 (Characiformes, Anostomidae). Revista UNIMAR, v. 19, n. 2, p. 421-437, 1997.

ESTEVES, K. E. \& ARANHA, J. M. Ecologia trófica de peixes de riachos. Pp. 157-182. In: Caramaschi, E. P.; Mazzoni, R. \& Peres-Neto, P. R. (eds.). Ecologia de peixes de riachos. Série Oecologia Brasiliensis, vol 6. PPGE-UFRJ. Rio de Janeiro, Brasil, 1999. 
ESTEVES, K. E. Feeding ecology of three Astyanax species (Characidae, Tetragonopterinae) from a foodplain lake of Mogi-Guaçú River, Paraná River basin, Brazil. Environmental Biology of Fishes, v. 46, p. 83-101, 1996.

ESTEVES, K. E. \& GALETTI JR, P. M. Food partitioning among some characids of a small Brazilian foodplain lake from the Paraná River basin. Environmental Biology of Fishes, v. 42, p. 375-389, 1995.

ESTEVES, K. E. \& LOBÓN-CERVIÁ, J. Composition and trophic structure of a fish community of a clear water Atlantic rainforest stream in southeastern Brazil. Environmental Biology of Fishes, v. 62, p. 429-440, 2001.

GARUTTI, V. Distribuição longitudinal da ictiofauna em um córrego da região noroeste do estado de São Paulo, Bacia do rio Paraná. Rev. Brasil. Biol., v. 48, n. 4, p. 747-759, 1988.

GERKING, S. D. Feeding ecology of fish. Academic Press, 416p., 1994.

GODINHO, H. P. \& CASTRO, E. F. T. Ciclo reprodutivo anual de lambaris (Astyanax bimaculatus Linnaeus, 1756) em viveiros. Arq. Bras. Méd. Vet. Zoot., v. 37, n. 5, p. 435 447, 1985.

GOMIERO, L. M. \& BRAGA, F. M. S. Reproduction of a fish assemblage in the state of São Paulo, southeastern Brazil. Braz. J. Biol., v.6 7, n. 2, p. 283-292, 2007.

GOMIERO, L. M. \& BRAGA, F. M. S. Feeding habits of the ichthyofauna in a protected area in the state of São Paulo, southeastern Brazil. Biota Neotropica, v. 8, n. 1, p. 1-7, 2008.

GOMIERO, L. M. \& BRAGA, F. M. S. Length structure of fishes from a protected área in the State of São Paulo, Southeastern Brazil. Acta. Sci. Biol. Sci., v. 27, n. 4, p. 339-346, 2005.

GOMIERO, L.M.; MANZATTO, A.G. \& BRAGA, FMS. The role of riverine forests for food supply for the omnivorous fish Brycon opalinus Cuvier, 1819 (Characidae) in the 
Serra do Mar, southeast Brazil. Brazilian Journal of Biology, v. 68, n. 2, p. 321-328, 2008.

GOULDING, M. The fishes and the forest: explorations in amazonian natural history. Berkeley: University of California Press, 1980.

GROSSMAN, G. D.; DOWD, J. F. \& CRAWFORD, M. Assemblage stability in streams fishes: a review. Environmental Management, v. 14, n. 5, p. 661-671, 1990.

GUILLEMOT, P. J.; LARSON, R. J. \& LENARZ, W. H. Seasonal cycles of fat and gonad volume in five species of northern california rockfish (Scorpaenidae: Sebastes). Fishery Bulletin, v. 83, n. 3, p. 299-311, 1985.

GURGEL, H. C. B.; SILVA, N. B.; LUCAS, F. D. \& SOUZA, L. L. Alimentação da comunidade de peixes de um trecho do rio Ceará Mirim, em Umari, Taipu, Estado do Rio Grande do Norte, Brasil. Acta Sci.Anim. Sci., v. 27, n. 2, p. 229-233, 2005.

HABIT, E., VICTORIANO , P. \& CAMPOS, H. Ecología trófica y aspectos reproductivos de Trichomycterus areolatus (Pisces, Trichomycteridae) en ambientes lóticos artificiales. Rev. Biol. Trop., v. 53, n.1-2, p. 195-210, 2005.

HARTZ, S. M.; SILVEIRA, C. M. \& BARBIERI, G. Alimentação das espécies de Astyanax Baird \& Girard, 1854 ocorrentes na lagoa Caconde, RS, Brasil (Teleostei, Characidae). Rev. Unimar, v. 18, n. 2, p. 269-281, 1996.

HENRY, R.; UIEDA, V. S.; AFONSO, A. A. O. \& KIKUCHI, R. M. Input of allochthonous and structure of fauna in a Brazilian headstream. Verh. Internat. Verein Limnol., v. 25, p. 1866-1870, 1994.

JUNE, F.C. Spawning of yellowfin tuna in Hawaiian waters. Fish. Bull., v. 54, p. 47-64, 1953.

KING, M. Fisheries biology, assement and management. Oxford: Fishing News Books. 341 p., 1995. 
KRAMER, D. L. Reproductive seasonality in the fishes of a tropical stream. Ecology, v. 59, n. 5, p. 976-985, 1978.

LE CREN, E. D. The lenght-weight relationship and seasonal cycle in gonad weigth and condition in the perch (Perca fluviatilis). J. Animal Ecology, v. 20, n. 2, p. 201-219, 1951.

LIMA JR., S.E.; GOITEN, R. Ontogenetic diet shifts of a Neotropical catfish, Pimelodus maculatus (Siluriformes: Pimelodidae): an ecomorphological approach. Environ. Biol. Fishes., Norwell, n. 68, p. 73-79, 2003.

LOBÓN-CERVIÁ, J.; BENNEMANN, S. Temporal trophic shifts and feeding diversity in two sympatric, neotropical omnivorous fishes: Astyanax bimaculatus and Pimelodus maculatus in rio Tibagi (Paraná, Southern Brazil). Arch. Hydrobiol., v. 149, n. 2, p. 285 $306,2000$.

LOLIS, A. A. \& ANDRIAN, I. F. Alimentação de Pimelodus maculatus Lacépède, 1803 (siluriformes, Pemilodidae), na planície de inundação do Alto rio Paraná, Brasil. Boletim do Instituto de Pesaca, v. 23, p. 187-202, 1996.

LOWE-MCCONNELL, R.H. Estudos ecológicos em comunidades de peixes tropicais (A.E.A.M. Vazzoler, A.A. Agostinho \& P.T.M.Cunnhingham, trads.). EDUSP, São Paulo, 1999.

LUIZ, E. A.; AGOSTINHO, A. A.; GOMES, L. C. \& HAHN, N. S. Ecologia trófica de peixes em dois riachos da Bacia do Rio Paraná. Rev. Bras. Biol., v. 58, n. 2, p. 273-285, 1998.

LUZ, K. D. G.; ABUJAnRA, F.; AGOSTINHO, A. A. \& LUIZ, C. G. Caracterização trófica da ictiofauna de três lagoas da planície aluvial do alto rio Paraná, Brasil. Acta Scientiarum, v. 23, n. 2, p. 401-407, 2001.

LUZ-AGOSTINHO, K. D. G.; BINI, L. M.; FUGI, R.; AGOSTINHO, A. A. \& JÚLIO-JR, H. F. Food spectrum and trophic structure of the ichthyofauna of Corumbá reservoir, Paraná river Basin, Brazil. Neotropical Ichthyology, v. 4, n. 1, p. 61-68, 2006. 
MACHADO, A. B. M.; DRUMMOND, G. M. \& PAGLIA, A. P. Livro vermelho da fauna brasileira ameaçada de extinção. Belo Horizonte: Fundação Biodiversitas, 2008.

MANRIQUEZ, A., HUAQUIN, L., ARELANO, M. \& ARRATIA, G. Aspectos reproductivos de Trichomycterus areolatus Valenciennes, 1846 (Pisces: Teleostei: Siluriformes) en Rio Angostura, Chile. Stud. Neotrop. Fauna E., v. 23, p. 89-102, 1988.

MARCUCCI, K. M. I.; ORSI, M. L. \& SHIBATTA, O. A. Abundância e aspectos reprodutivos de Loricariichthys platymetopon (Siluriformes, Loricariidae) em quatro trechos da represa Capivara, médio rio Paranapanema. Iheringia, Ser. Zoologia, v. 95, n. 2, p. 197-203, 2005.

MARRARO, F., BISTONI, MA. \& CARRANZA, M. Spawing season, ovarian development and fecundity of female Trichomycterus corduvense (Osteichthyes, Siluriformes). Hydrobiologia, v. 534, p. 223-230, 2005.

MAZZONI, R., CARAMASCHI, E.P. \& FENERICH-VERANI, N. Reproductive biology of Characidiinae (Psteichthyes, Characidae) from the Ubatiba river, Maricá - RJ. Braz. J. Biol., v. 62, n. 3, p. 487-494, 2002.

MAZZONI, R.; MENDONÇA, R. S. \& CARAMASCHI, E. P. Reproductive biology of Astyanax janeiroensis (Osteichthyes, Characidae) from the Ubatiba river, Maricá, RJ, Brazil. Braz. J. Biol., v. 65, n. 4, p. 643-649, 2005.

MAZZONI, R. \& SILVA, A. P. F. Aspectos da história de vida de Bryconamericus microcephalus (Miranda Ribeiro) (Characiformes, Characidae) de um riacho costeiro de Mata Atlântica, Ilha Grande, Rio de Janeiro, Brasil. Revista Brasileira de Zoologia, v. 23, n. 1, p. 228-233, 2006.

MENEZES, M. S.; ARANHA, J. M. R. \& CARAMASCHI, E. P. Ocorrência e aspectos da biologia reprodutiva de Harttia loricariformes (Loricariinae) no trecho inferior do rio Paraíba do Sul (RJ, Brasil). Acta Biol. Par., v. 27, n. 1-2-3-4, p. 15-26, 1998.

MESCHIATTI, A. J. Alimentação da comunidade de peixes de uma lagoa marginal do rio Mogi Guaçu, SP. Acta Limnologica Brasiliensia, v. 7, p. 115-137. 1995. 
MESCHIATTI, A. J. \& ARCIFA, M. S. Early life stages of fish and the relationships with zooplankton in a tropical brazilian reservoir: lake Monte Alegre. Brazilian Journal of Biology, v. 62, n. 1, p. 41-50, 2002.

MOTTA, R. L. \& UIEDA, V. S. Dieta de duas espécies de peixes do Ribeirão do Atalho, Itatinga, SP. Rev. Bras. Zoociências, v. 6, n. 2, p. 191-205, 2004.

NIKOLSKII, G. V. Theory of Fish Population Dynamics: as the Biological Background for Rational Exploitation and Management of Fishery Resources. Edinburgh: Oliver and Boyd Ltd, 321 p.,1969.

NIKOLSKY, G.V. The ecology of fishes. London: Academic Press, 1963.

NOMURA, H. Alimentação de três espécies de peixes do gênero Astyanax Baird \& Girard, 1854 (Osteichthyes, Characidae) do rio Mogi Guaçu, SP. Rev. Brasil. Biol., v. 35, n. 4, p. $595-614,1975$.

NOMURA, H. Length-weight tables of some fishes speices from southern Brazil. Boletim do Instituto Oceanográfico, USP, n. 164, 1962.

OLIVEIRA, D. C. \& BENNEMANN, S. T. Ictiofauna, recursos alimentares e relações com as interferências antrópicas em um riacho urbano no sul do Brasil. Biota Neotropica, v. 5, n. 1, p. 95-107, 2005.

PAULY, D. 1993. Editorial Fishbyte Section. Naga. The ICLARM Q. v. 16, n. 2-3, p. 26. PIANKA, E. R. On r and k selection. The American Naturalist, v. 104, n. 940, p. 592, 1970.

PIANKA, E.R. The structure of lizard communities. Annual Review of Ecology and Systematics, n. 4, p. 53-74, 1973.

PUSEY, B. J. \& ARTHINGTON, A. H. Importance of the riparian zone to the conservation and management of freshwater fish: a review. Marine and Freshwater Research, v. 54, p. 1-16, 2003. 
REZENDE, C. F. \& MAZZONI, R. Aspectos da alimentação de Bryconamericus microcephalus (Characiformes, Tetragonopterinae) no córrego Andorinha, Ilha Grande RJ. Biota Neotropica, v. 3, n. 1, p. 1-6, 2003.

RIBEIRO, V. M. A.; SANTOS, G. B. \& BAZZOLI, N. Reproductive biology of Steindachnerina insculpita (Fernadez-Yépez) (Teleostei, Curimatidae) in Furnas reservoir, Minas Gerais, Brazil. Revista Brasileira de Zoologia, v. 24, n. 1, p. 71-76, 2007.

RICKER, W. E. Growth rates and models. In: Fish physiology, bioenergetics and growth. (W.S. Hoar; D.J. Randall; J.R. Brett. eds.). New York: Academic Press, p. 677-743, 1979.

ROCHA, F. C.; CASATTI, L. \& PEREIRA, D. C. Structural and feeding of a stream fish assemblage in Southeastern Brazil: evidence of low seasonal influences. Acta Limnol. Bras., v. 21, n. 1, p. 123-134, 2009.

RODRIGUES, A. M.; RODRIGUES, J. D.; CAMPOS, E. C. \& FERREIRA, A. E. Aspectos da estrutura populacional e época de reprodução do tambiú Astyanax bimaculatus (Characiformes, Characidae) na represa de Bariri, rio Tietê, Estado de São Paulo, Brasil. B. Inst. Pesca, v. 16, n. 1, p. 97-110, 1989.

ROLLA, A. P. P. R.; ESTEVES, K. E. \& ÁVILA-DA-SILVA, A. O. Feeding ecology of a stream fish assemblage in an Atlantic Forest remnant (Serra do Japi, SP, Brazil). Neotropical Ichthyology, v. 7, n. 1, p. 65-76, 2009.

ROMÁN-VALENCIA, C.; Hernández, J. H. \& Samudio, H. F. Sobre a ecologia de Characidium caucanum (Pisces: Crenuchidae) no Alto rio Cauca, Colômbia. Dahlia (Rev. Asoc. Colomb. Ictiol.), v. 9, p. 33-42, 2007.

RONDINELI, G R. \& BRAGA, F. M. S. Reproduction of the fish community of Passa Cinco stream, Corumbataí river sub-basin, São Paulo state, Southeastern Brazil. Brazilian Journal of Biology, v. 70, n. 1, p. 631-637, 2010.

RONDINELI, G. R. Biologia alimentar e reprodutiva na comunidade de peixes do rio Passa Cinco (SP). 2007. Dissertação (Mestrado em Zoologia) - Universidade Estadual Paulista, Rio Claro, 2007. 
RONDINELI, G.R., CARMASSI, A.L. \& BRAGA, F.M.S. Population biology of Trichomycterus sp. (Siluriformes, Trichomycteridae) in Passa Cinco stream, Corumbataí River sub-basin, São Paulo State, southeastern Brazil. Braz. J. Biol., v. 69, n. 3, p. $925-$ 934, 2009.

RUSSO, M. R.; FERREIRA, A. \& DIAS, R. M. Disponibilidade de invertebrados aquáticos para peixes bentófagos de dois riachos da bacia do rio Iguaçu, estado do Paraná, Brasil, Acta Scientiarum, v. 24, n. 2, p. 411-417, 2002.

SABINO, J. \& CASTRO, R. M. C. Alimentação, período de atividade e distribuição espacial dos peixes de um riacho da Floresta Atlântica (Sudeste do Brasil). Revista Brasileira de Biologia, v. 50, n. 1, p. 23-36, 1990.

SANTOS, A. T. B. Estudo da comunidade de peixes no Ribeirão Claro, Rio Claro SP. 2005. Dissertação (Mestrado em em Zoologia) - Universidade Estadual Paulista, Rio Claro, 2005.

SHINE, R. Proximate determinants of sexual differences in body size. American Naturalist, v. 135, p. 278-283, 1990.

SIEGEL, S. Estatística não-paramétrica para as ciências do comportamento. Rio de Janeiro: McGraw-Hill do Brasil, 350p., 1975.

SILVA, C. P. D. Alimentação e distribuição espacial de algumas espécies de peixes do igarapé do Candiru, Amazonas, Brasil. Acta Amazônica, v. 23, n. 2-3, p. 271-285, 1993.

SOUZA, U. P. Biologia e ciclo de vida de Astyanax cf. scabripinnis paranae Eigenmann, 1914 (Characidae, Tetragonopterinae), no Ribeirão Grande, Parque Estadual da Serra do Mar, Núcleo Santa Virgínia, SP. 2009. Tese (Doutorado em Zoologia) - Universidade Estadual Paulista, Rio Claro, 2009.

TEIXEIRA, T. P.; PINTO, B. C. T.; TERRA, B. F.; ESTILIANO, E. O.; GRACIA, D. \& ARAÚJO, F. G. Diversidade das assembléias de peixes nas quatro unidades geográficas do rio Paraíba do Sul. Iheringia Ser. Zoologia, vol. 95, no. 4, p. 347-357, 2005. 
TERRA, B. F.; ARAÚJO, F. G.; CALZA, C. F.; LOPES, R. T. \& TEIXEIRA, T. P. Heavy Metal in Tissues of Three Fish Species from Different Trophic Levels in a Tropical Brazilian River. Water Air Soil Pollut, v. 187, p. 275-284, 2008.

TRAJANO, E. Population ecology of Trichomycterus itacarambiensis, a cave catfish from eastern Brazil (Siluriformes, Trichomycteridae). Environ. Biol. Fishes., v. 50, p. 357-369, 1997.

UIEDA, V. S.; BUZZATO, P. \& KIKUCHI, R. M. Partilha de recursos alimentares em peixes em um riacho de serra do Sudeste do Brasil. An. Acad. Bras. Ci., v. 69, n. 2, p. 244-252, 1997.

VANNOTE, R. L.; MINSHALL, G. W.; CUMMINS, K. W.; SEDELL, J. R. \& CUSHING, C. E. The river continuum concept. Can. J. Fish. Aquat. Sci., v. 37, p. 130-137, 1980.

VAZZOLER, A. E. A. M. Biologia da reprodução de peixes teleósteos: Teoria e Prática. Maringá: EDUEM, SBI, São Paulo, 169p.,1996.

VAZZOLER, A. E. A. M.; MENEZES, N. Síntese de conhecimentos sobre o comportamento reprodutivo dos Characiformes da América do Sul (Teleostei, Ostariophysi). Rev. Brasil. Biol., v. 52, n. 4, p. 627-640, 1992.

VAZZOLER, A. E. A. M.; SUZUKI, H. I.; MARQUES, E. E. \& LIZAMA, M. L. A. P. Primeira maturação gonadal, períodos e áreas de reprodução. In: A planície de inundação do alto rio Paraná: aspectos físicos, biológicos e socioeconômicos. (A.E.A.M., Vazzoler; A.A., Agostinho; N.S., Hahn. eds.). Maringá: Editora da UEM. p. 249-265. 1997.

VIEIRA, S. Bioestatística: tópicos avançados. 2 ed. Rio de Janeiro: Elsevier, 216 p., 2004.

VILELLA, F. S.; BECKER, F. G.; HARTZ, S. M. Diet of Astyanax species (Teleostei, Characidae) in Atlantic Forest River in Southern Brazil. Brazilian Archives Biology and Technology, v. 45, n. 2, p. 223-232, 2002. 
WINEMILLER, K. O. Spatial and temporal variation in tropical fish trophic networks. Ecological Monographs, v. 60, p. 331-367, 1990.

WINEMILLER, K. O.; JEPSEN, D. B. Effects of seasonality and fish movement on tropical river food webs. Journal of Fish Biology, v. 3, supplement A, p. 267-296, 1998.

WINEMILLER, K.O. \& K.A. ROSE. Patterns of life-history diversification in North American fishes: implications for population regulation. Canadian Journal of Fisheries and Aquatic Sciences, v. 49, p. 2196-2218, 1992.

WINEMILLER, KO. Patterns of variation in life history among South American fishes in seasonal environments. Oecologia, Rio de Janeiro, vol. 81, p. 225-241, 1989.

WOOTTON, R. J. Introduction: Strategies and tactics in fish reproduction. In: G.W. Potts and R.J. Wootton (eds). Fish Reproduction strategies and tactics. Orlando: Academic Press, p. 1-12,1984.

WOOTTON, R.J. Ecology of teleost fishes. Chapman \& Hall, New York, 1990.

ZAVALA-CAMIN, L. A. Introdução aos estudos sobre alimentação natural em peixes. Maringá: EDUEM/Nupelia, 129p., 1996. 


\section{CONSIDERAÇÕES FINAIS}

A serra da Mantiqueira oriental é a porção mais íngrime e escarpada da serra da Mantiqueira (PONÇANO et al., 1981), que é um divisor de águas natural que separa as bacias do rio Grande e do Paraíba do Sul, percorrendo o Vale do Paraíba nos estados de São Paulo e Rio de Janeiro. Na face fortemente inclinada e festonada, descem inúmeros riachos que vão tributar o rio Paraíba do Sul. Esses riachos de encosta formam microbacias separadas umas das outras por cristas de relevo (BRAGA, 2004), cujas nascentes encontram-se na cimeira da serra, sendo em alguns casos separadas por poucos metros (MODENESI-GAUTTIERI et al., 2002).

Esses ambientes são caracterizados por vales aluviais limitados por colinas de inclinações suaves (MODENESI-GAUTTIERI et al., 2002), cuja vegetação predominante são touceiras da Poacea Cortaderia modesta e extensos bancos da Bryophyta Sphagnum sp. Os bancos de Sphagnum quando morrem não apodrecem em suas partes inferiores, armazenando água por capilaridade e formando um extenso tapete higrófilo, impedindo, com isso, que a água seque na estação de seca. Desta forma, a área forma um imenso manacial aqüífero que mantém constante o fluxo de água dos riachos que lá nascem e descem as encostas.

Nas vertentes voltadas para o Vale do Paraíba, pode-se encontrar ainda trechos preservados de Mata Atlântica interiorana (desde a cota de 2.000 metros até a de 500 metros) recobertos pelas formações vegetais constituídas por campos de altitude, mata pluvial superior (mata de neblina), mata pluvial (floresta ombrófila densa) e mata semi-seca do Vale do Paraíba, atualmente presente apenas em algumas áreas restritas (HUECK, 1972). Em grande parte da área da encosta, a vegetação natural foi derrubada em virtude do plantio do café no século XIX (DEAN, 1996) e, recentemente, pela ocupação urbana (LOURENÇO, 2009).

Este quadro apresentado tem grande influência na distribuição de peixes dos riachos que integram as microbacias da serra da Mantiqueira oriental, principalmente quando a eles são acrescidos eventos recentes que aconteceram no Pleistoceno terminal (15 mil anos atrás) e no Holoceno (de 8 a 5 mil anos atrás). Durante o Pleistoceno (cerca de 25 mil anos atrás), as partes baixas das encostas e o vale eram tomados por vegetação xeromórfica, em 
decorrência de um clima mais seco e árido, ficando a vegetação mais úmida limitada às partes mais altas da encosta (AB'SABER, 1969). Com o término do Pleistoceno, o clima tornou-se mais úmido e as florestas avançaram para as partes mais baixas, indo em direção ao vale. Evidências paleoclimáticas estão marcadas pelas linhas de pedra situadas em cotas baixas nas microbacias do ribeirão dos Buenos e do rio Guaratinguetá (Figura 2). Braga (2005) discutiu a distribuição das espécies Characidium lauroi e C. alipioi na microbacia do Ribeirão Grande em decorrência desses eventos.

Num período recente da história geológica desta região, entre 8 e 5 mil anos atrás, a ocorrência de falhas separaram blocos de rochas, formando cicatrizes na encosta e ativando antigos falhamentos, modelando a cimeira e a encosta (MODENESI-GAUTTIERI et al., 2002; FAPESP, 2002). A paisagem assim remodelada veio orientar os riachos que desciam as encostas da serra da Mantiqueira oriental em unidade distintas, as microbacias (BRAGA, 2004).

Embora contíguas, as microbacias do ribeirão dos Buenos e do rio Guaratinguetá apresentaram composições ictiofaunísticas diferentes. Na microbacia do ribeirão dos Buenos foram capturadas 27 espécies, sendo 4 exclusivas de seus riachos e na microbacia do rio Guaratinguetá ocorreram 30 espécies, sendo 8 também exclusivas de seus riachos. Trichomycterus itatiayae foi a espécie mais freqüente nas duas microbacias e, juntamente com Astyanax bimaculatus, compôs o grupo de espécies mais importantes: que ocorreram em um grande número de pontos, tiveram muitos indivíduos capturados e contribuições significantes em peso. Um conjunto de espécies raras (que foram pouco freqüentes, tiveram poucos indivíduos coletados e baixa contribuição em biomassa) também pode ser encontrado para cada microbacia. Pareiohina brachyrhyncha, Hoplerythrinus unitaeniatus, Geophagus brasiliensis, Astyanax fasciatus, Pseudotocinclus parahybae, Trichomycterus sp. e Pareiohina rudolphi para a microbacia do ribeirão dos Buenos; e Synbranchus marmoratus, Crenicichla lacustris, Hoplosternum littorale, Hoplerythrinus unitaeniatus, Hypostomus luetkeni, Hypostomus sp.2 e Hypostomus sp.3 para a microbacia do rio Guaratiguetá.

Um padrão de adição de espécies indo da encosta em direção ao pediplano pode ser observado nas microbacias estudadas, ao passo que do pediplano ao vale foi verificado um padrão de substituição de espécies. Um gradiente crescente da diversidade, riqueza e 
equitabilidade foi observado da encosta em direção ao vale. Interações significativas entre ambientes e microbacias para os índices de diversidade e riqueza indicaram que pelo menos um ambiente em uma microbacia diferiu quanto à diversidade e riqueza de espécies. $\mathrm{Na}$ dimensão temporal, nenhuma variação significativa nos índices de diversidade, riqueza e equitabilidade foi detectada. Assim, parece que as características espaciais tenham maior importância do que as temporais sobre a organização das comunidades de peixes nas microbacias estudadas. Dentre as variáveis estruturais e físicas e químicas da água, o tipo de substrato presente no canal e o pH foram importantes na distribuição das espécies nos pontos amostrais das microbacias estudadas.

As curvas de abundância e biomassa encontradas para as microbacias do ribeirão dos Buenos e do rio Guaratinguetá indicaram que essas comunidades encontram-se sob condições intermediárias de estresse, havendo, portanto, um equilíbrio entre as estratégias de vida adotadas pelas espécies. Os exemplares de Trichomycterus itatiayae capturados na microbacia do ribeirão dos Buenos foram significativamente maiores do que os capturados na microbacia do rio Guaratinguetá. O oposto ocorreu com os exemplares de Characidium lauroi e Astyanax bimaculatus. Com exceção de A. bimaculatus, que é uma espécie amplamente distribuída nas microbacias, $T$. itatiayae e $C$. lauroi são espécies que ocorrem preferencialmente na encosta e também no pediplano, desenvolvendo, para tanto, diversas estratégias adaptativas para adequarem-se ao ambiente. Assim, dentro dos limites de cada espécie, a estrutura em comprimento parece refletir um ajuste às alterações do meio de modo a garantir a sobrevivência.

No geral, não ocorreu um único item alimentar dominante nas dietas das espécies estudadas, que foi consumido em grande quantidade pela maioria da população. A dieta foi bastante diversificada com pouca ocorrência de itens preferenciais, o que pode reforçar a idéia da existência de um generalismo alimentar. Não foram encontradas diferenças significativas no consumo de itens alimentares pelas espécies analisadas entre as estações de seca e cheia e, com isso, acredita-se que os recursos alimentares permanecem disponíveis ao longo de todo o ano e em quantidades suficientes para resultar na ausência de variações sazonais nas dietas das espécies. Foi evidente o maior consumo de itens autóctones na encosta e no pediplano, ao passo que no vale os itens alóctones prevaleceram. Tais variações podem estar relacionadas com a estrutura das comunidades de peixes nesses 
ambientes: os pontos localizados na encosta e no pediplano apresentaram uma composição de espécies bastante similares quando comparados aos pontos localizados no vale. Além disso, os hábitos alimentares dessas espécies e uma maior ou menor disponibilidade dos itens alimentares nesses ambientes também podem favorecer tal diferenciação.

Com exceção dos tricomicterídeos, que não acumulam gordura na cavidade visceral, nas demais espécies, a quantidade máxima de gordura acumulada coincidiu com as maiores freqüências de gônadas em processo de maturação. No geral, as espécies analisadas apresentaram períodos reprodutivos que se estenderam desde o final da estação seca até o final da estação chuvosa. O período reprodutivo extenso parece direcionar as espécies encontradas nesses ambientes para uma maior eficiência em explorar o meio em que vivem.

O menor peso em relação ao comprimento e a menor deposição de gordura visceral ou mesmo a ausência, pode estar associado a uma maior densidade corpórea encontrada em espécies de riachos, característica necessária para manterem-se nesses corpos de água torrentosos. A condição corporal diferente entre épocas encontrada para algumas espécies parece estar relacionada com o período reprodutivo: o maior volume das gônadas (e conseqüentemente seu peso) encontrado nas épocas de pico reprodutivo, contribui e muito para um aumento do peso em um dado comprimento médio. Diferenças encontradas na condição corporal de algumas espécies entre microbacias podem estar relacionadas às exigências particulares das espécies durante o período reprodutivo e que um ou outro ambiente pode dispor de melhor forma, fazendo com que em um dado comprimento, a espécie apresente maior peso.

Portanto, parece que os papéis desempenhados pelas espécies de peixes das microbacias do ribeirão dos Buenos e do rio Guaratinguetá diferem, visto que a ocorrência, distribuição, abundância relativa e a biomassa dessas espécies são particulares para cada microbacia. Provavelmente isso seja resultante do equilíbrio mantido entre elas e o ambiente, que é particular dentro de cada microbacia, no sentido de explorá-lo de uma maneira mais eficiente, proporcionando a manutenção dessas populações. 


\section{Literatura citada}

AB'SABER, A. N. Ocorrência de "linhas de pedra" na região de São Paulo. Geomorfologia, v. 10, p. 9-10, 1969.

BRAGA, F. M. S. Hábitat, distribuição e aspectos adaptativos de peixes da microbacia do ribeirão Grande, Estado de São Paulo, Brasil. Acta Sci. Biol. Sci., v. 26, n. 1, p. 31-36, 2004.

BRAGA, F. M. S. Spatial distribution of characidiin fishes (Teleostei, Crenuchidae) in the Ribeirão Grande system, a tributary of Paraíba do Sul river basin, Brazil. Acta Scientiarum, v. 27, n. 3, p. 259-263, 2005.

DEAN, W. A ferro e fogo: a história da devastação da Mata Atlântica brasileira. São Paulo, Companhia das Letras, 484p., 1996.

HUECK, H. As florestas da América do Sul: Ecologia, composição e importância econômica. Tradução de R. Hans. Brasília/São Paulo: Ed. Univ. de Brasília / Ed. Polígono, $1972,465 \mathrm{p}$.

LOURENÇO, M. R. M. F. Caracterização geográfica e análise da distribuição horizontal da ictiofauna da microbacia do ribeirão dos Buenos ou Moreiras (serra da Mantiqueira oriental). 2009. Dissertação (Mestrado em Geografia) - Unesp, Rio Claro, SP., 2009.

MODENESI-GAUTTIERI, M. C.; HIRUMA, S. T. \& RICCOMINI, C. Morphotectonics of a high plateu on the northwestern flank of the Continental Rift of southeastern Brazil. Geomorphlogy, v. 43, p. 257-271, 2002.

PONÇANO, W. L.; CARNEIRO, C. D. R.; BISTRICHI, C. A.; ALMEIDA, F. F. \& PRANDINI, F. L. Mapa geomorfológico do Estado de São Paulo. São Paulo, Instituto de Pesquisas Tecnológicas, v. 1, p. 38-41 (Monografias 5), 1981.

FAPESP. Escultores de paisagem. Pesquisa FAPESP, v. 77, p. 54-57, 2002. 


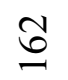
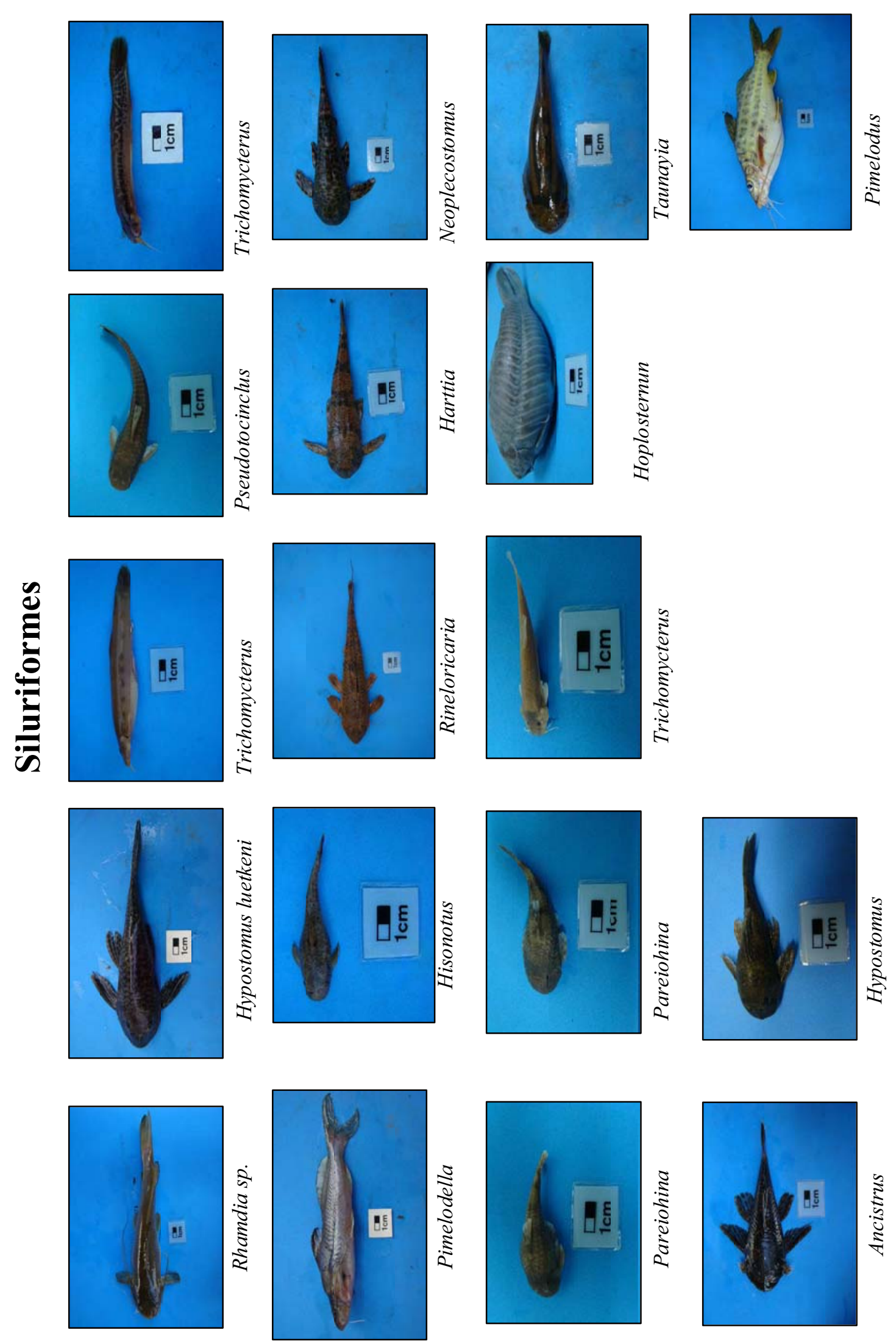


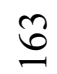
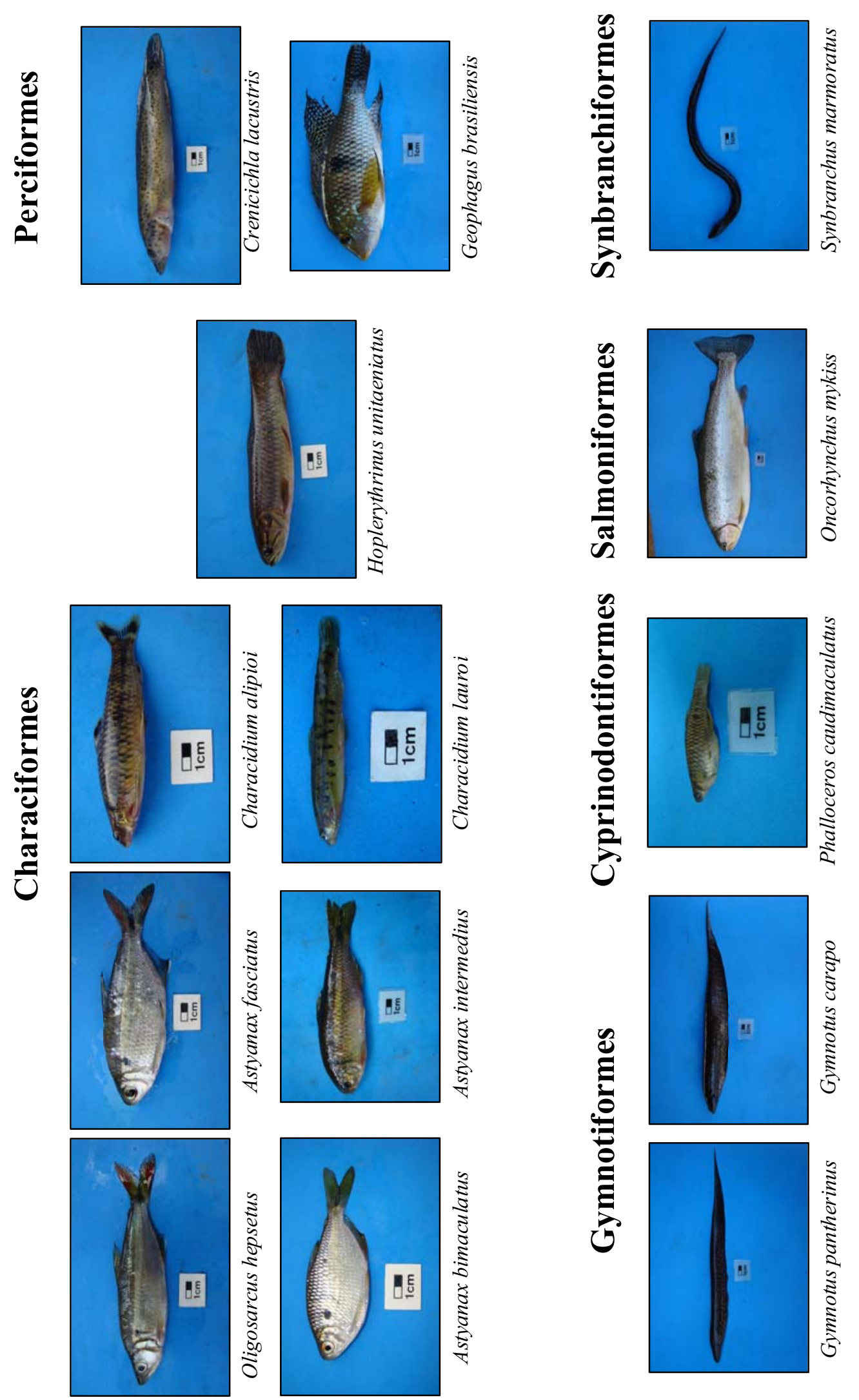